US Army Corps

of Engineers ${ }_{\circledast}$

Engineer Research and

Development Center
INNOVATIVE SOLUTIONS for a safer, better world

\title{
Full-Scale Accelerated Pavement Testing of Warm-Mix Asphalt (WMA) for Airfield \\ Pavements
}

Mariely Mejías-Santiago, Jesse D. Doyle, and John F. Rushing

January 2014 
The US Army Engineer Research and Development Center (ERDC) solves the nation's toughest engineering and environmental challenges. ERDC develops innovative solutions in civil and military engineering, geospatial sciences, water resources, and environmental sciences for the Army, the Department of Defense, civilian agencies, and our nation's public good. Find out more at www.erdc.usace.army.mil.

To search for other technical reports published by ERDC, visit the ERDC online library at http://acwc.sdp.sirsi.net/client/default. 


\title{
Full-Scale Accelerated Pavement Testing of Warm-Mix Asphalt (WMA) for Airfield Pavements
}

\author{
Mariely Mejías-Santiago, Jesse D. Doyle, and John F. Rushing \\ Geotechnical and Structures Laboratory \\ US Army Engineer Research and Development Center \\ 3909 Halls Ferry Road \\ Vicksburg, MS 39180-6199
}

Final report

Approved for public release; distribution is unlimited.
Prepared for US Air Force Civil Engineer Center 139 Barnes Drive, Suite 1
Tyndall AFB, FL 32403-5319




\section{Abstract}

This report presents results from full-scale accelerated pavement testing of warm-mix asphalt (WMA) mixtures designed for airfield pavements. Three WMA mixtures were evaluated and compared to a control hot-mix asphalt (HMA) mixture. Data are presented from instrumented pavement test sections of WMA and HMA trafficked using a heavy-vehicle simulator (HVS-A) configured with an F-15E military jet aircraft wheel with a high load, high tire pressure and at high pavement temperatures. Surface permanent deformation is presented as a function of number of traffic cycles for the different pavement sections. Pavement instrumentation data are presented to show that rutting performance was not influenced by any differences in the structural capacity of the supporting layers. Additional testing was conducted on areas of the test sections not trafficked by the HVS-A to assess any potential problems associated with grooving the surface of WMA airfield pavements and to compare the performance of grooved WMA to that of grooved HMA. The results from this research demonstrated that WMA is a viable alternative to HMA for use on heavily trafficked airfield pavements.

DISCLAIMER: The contents of this report are not to be used for advertising, publication, or promotional purposes. Citation of trade names does not constitute an official endorsement or approval of the use of such commercial products. All product names and trademarks cited are the property of their respective owners. The findings of this report are not to be construed as an official Department of the Army position unless so designated by other authorized documents. 


\section{Contents}

Abstract...................................................................................................................................... if

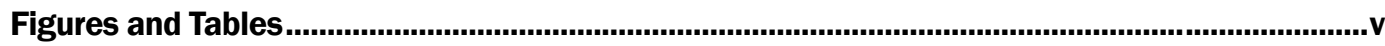

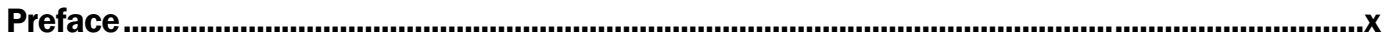

Unit Conversion Factors........................................................................................................xi

1 Introduction......................................................................................................................... 1

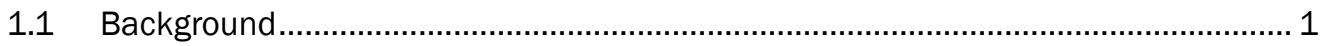

1.2 Previous Work ................................................................................................ 1

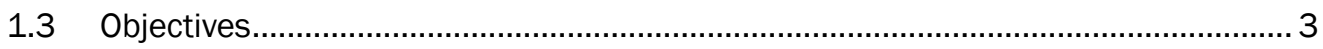

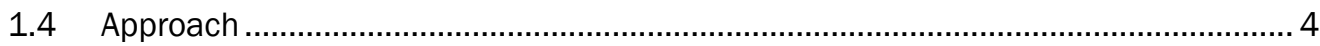

2 Full-Scale Evaluation Plan .................................................................................................... 5

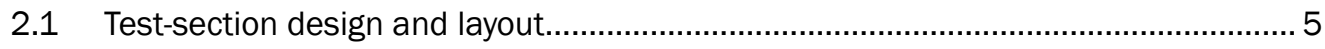

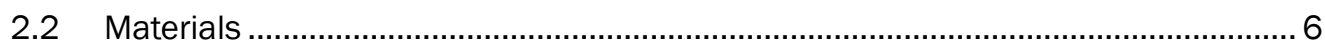

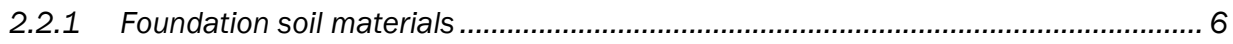

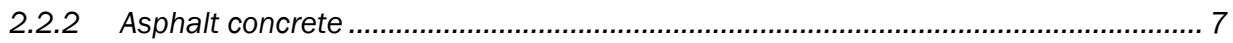

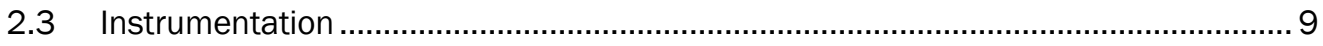

2.4 Test conditions .............................................................................................. 13

3 Full-Scale Simulated Traffic and Evaluation Procedures.....................................................15

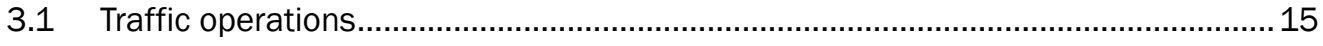

3.2 Data collection ................................................................................................ 18

3.2.1 Temperature monitoring ................................................................................. 19

3.2.2 Centerline and cross-section profiles...................................................................... 19

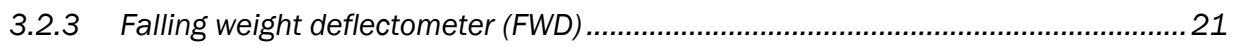

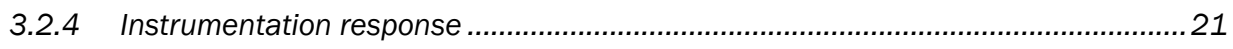

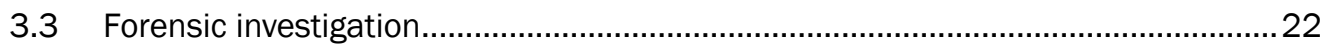

4 Pavement Performance Results.............................................................................................24

4.1 Temperature measurements ....................................................................... 24

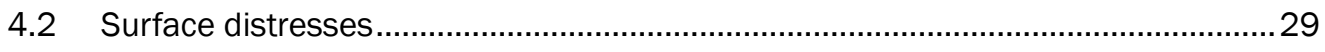

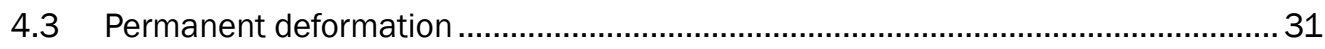

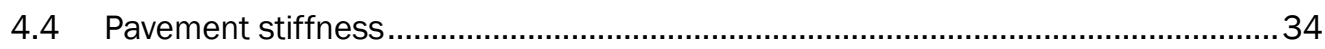

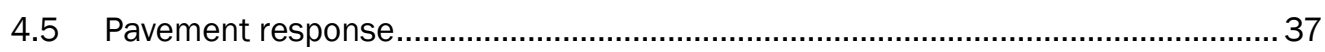

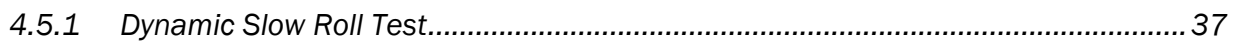

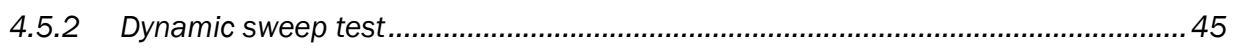

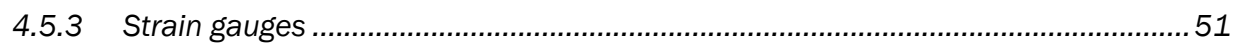

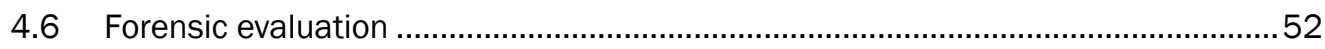

$5 \quad$ Analysis and Discussion of Results.............................................................................65 


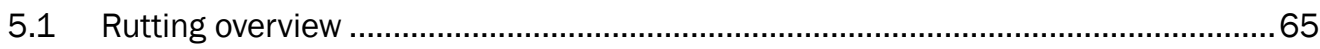

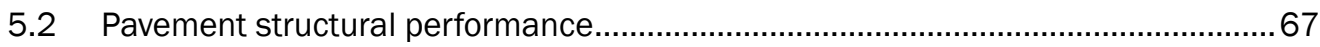

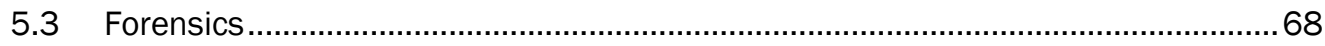

6 Grooving of WMA Surfaced Airfield Pavements .................................................................69

6.1 Evaluation procedure ............................................................................................. 70

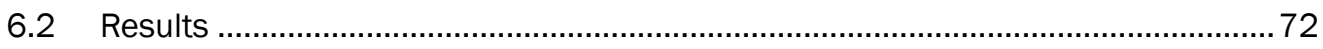

7 Conclusions and Recommendations ................................................................................... 76

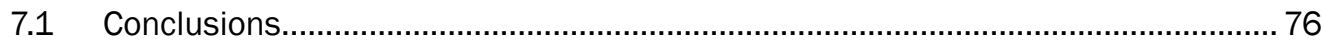

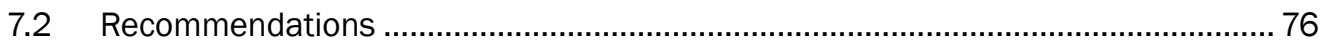

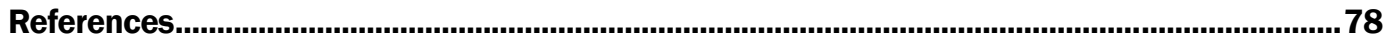

Appendix A: Raw temperature data...................................................................................79

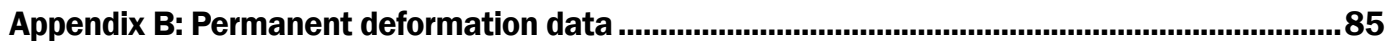

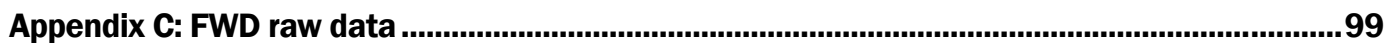

Appendix D: Pavement Response Data............................................................................... 111

Report Documentation Page 


\section{Figures and Tables}

\section{Figures}

Figure 1. WMA research flow chart. ………………………...................................................... 2

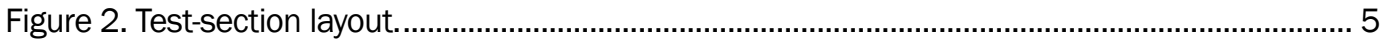

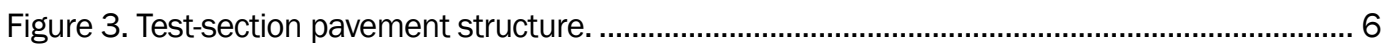

Figure 4. Gradation of aggregate for asphalt mixtures................................................................. 8

Figure 5. Instrumentation layout........................................................................................... 10

Figure 6. Typical installation of ASGs at the base surface........................................................... 11

Figure 7. Typical installation of SSGs............................................................................................. 11

Figure 8. Applying protective coating to SSGs and lead wires....................................................... 12

Figure 9. I-button used to record temperature readings (www.maturitycentral.com) ............................. 12

Figure 10. Typical I-button installation layout. ........................................................................... 13

Figure 11. Overview and inside view of the HVS-A ....................................................................... 15

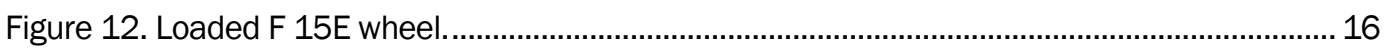

Figure 13. HVS-A traffic pattern used for the single wheel F-15E. ............................................... 17

Figure 14. Data collection layout for each test item. ............................................................... 18

Figure 15. Cross-section readings with robotic total station............................................................. 20

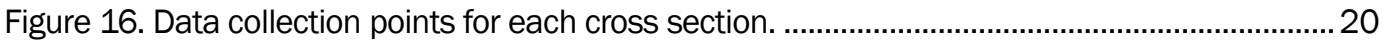

Figure 17. FWD testing on Item 4 ......................................................................................... 22

Figure 18. Trenching Layout.............................................................................................................. 23

Figure 19. Average pavement temperatures as measured at the top, middle, and bottom

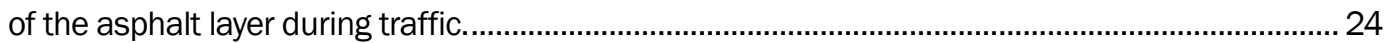

Figure 20. Average pavement temperatures during traffic in three regions on each test item...........25

Figure 21. I-button layout in reference to the HVS heating system layout....................................... 26

Figure 22. Typical surface temperatures as measured with infrared camera during testing........... 27

Figure 23. Average pavement test temperatures of each test item.................................................28

Figure 24. Average inside and outside air temperatures during traffic on each test item............28

Figure 25. HMA rutting after 3,326 passes.............................................................................. 29

Figure 26. Foamed Asphalt upheaval west side of the rut (@ STA 0+15) after 5,906 passes..............30

Figure 27. Evotherm ${ }^{\mathrm{TM}} 3 \mathrm{G}$ rutting at STA $0+30$ due to localized base failure after 741 passes. ..............30

Figure 28. Typical cracks in asphalt surface at STA 0+30........................................................... 31

Figure 29. Typical cracks in asphalt surface at strain gauge location. ............................................. 31

Figure 30. HMA centerline profiles and average pavement temperature. .....................................32

Figure 31. Foamed Asphalt centerline profiles and average pavement temperature.......................33

Figure 32. Sasobit $₫$ centerline profiles and average pavement temperature. …............................33

Figure 33. Evotherm ${ }^{\text {TM }} 3 G$ centerline profiles and average pavement temperature.........................34

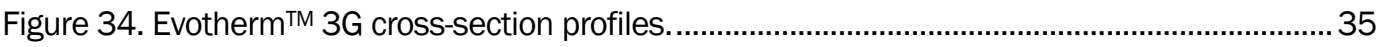


Figure 35. ISM values for all four test items.

Figure 36. HMA maximum pressure measured at the base, subbase and subgrade during slow roll test at each pass level.

Figure 37. Foamed Asphalt maximum pressure measured at the base, subbase and subgrade during slow roll test at each pass level.

Figure 38. Sasobit ${ }^{\circledR}$ maximum pressure measured at the base, subbase and subgrade during slow roll test at each pass level.

Figure 39. Evotherm ${ }^{\mathrm{TM}} 3 \mathrm{G}$ maximum pressure measured at the base, subbase and subgrade during slow roll test at each pass level.

Figure 40. Pressure difference between EP5 and EP6 at the top of the base in Sasobit ${ }^{\circledR} . . . . . . . . . . . .41$

Figure 41. Maximum pressure distribution from dynamic slow roll test data.

Figure 42. HMA maximum deflection measured at the base, subbase and subgrade during dynamic slow roll test at each pass level.

Figure 43. Foamed Asphalt maximum deflection measured at the base, subbase and subgrade during dynamic slow roll test at each pass level.

Figure 44. Sasobit $\circledast$ maximum deflection measured at the base, subbase and subgrade during dynamic slow roll test at each pass level.

Figure 45. Evotherm ${ }^{\mathrm{TM}} 3 \mathrm{G}$ maximum deflection measured at the base, subbase and subgrade during dynamic slow roll test at each pass level.

Figure 46. HMA maximum pressure measured the base, subbase and subgrade during the first 23 passes of each data collection interval.

Figure 47. Foamed Asphalt maximum pressure measured at the base, subbase and subgrade during the first 23 passes of each data collection interval......

Figure 48. Sasobit ${ }^{\circledR}$ maximum pressure measured at the base, subbase and subgrade during the first 23 passes of each data collection interval.

Figure 49. Evotherm ${ }^{\mathrm{TM}} 3 \mathrm{G}$ maximum pressure measured at the base, subbase and subgrade during the first 23 passes of each data collection interval.....

Figure 50. Pressure difference between EP5 and EP6 at the top of the base in Sasobit ${ }^{\circledR} . . . . . . . . . . .48$

Figure 51. Maximum pressure distribution from dynamic sweep test data......

Figure 52. HMA maximum deflection measured the base, subbase and subgrade during dynamic sweep test at each pass level.

Figure 53. Foamed Asphalt maximum deflection measured at the base, subbase and subgrade during dynamic sweep test at each pass level.

Figure 54. Sasobit $\circledast$ maximum deflection measured at the base, subbase and subgrade during dynamic sweep test at each pass level. 50

Figure 55. Evotherm ${ }^{\mathrm{TM}} 3 \mathrm{G}$ maximum deflection measured at the base, subbase and subgrade during dynamic sweep test at each pass level.................................................................. 51

Figure 56. Changes in soil properties after traffic. ........................................................................ 55

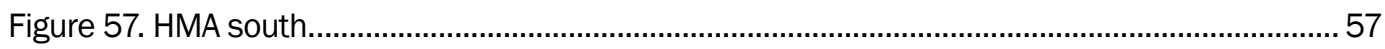

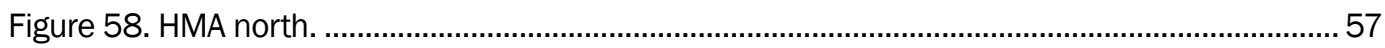

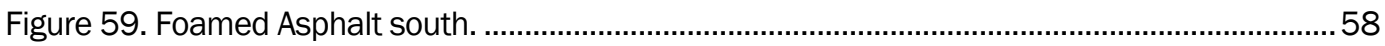

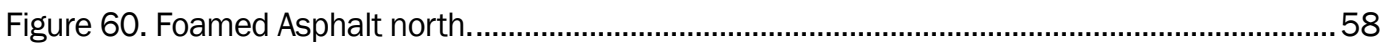

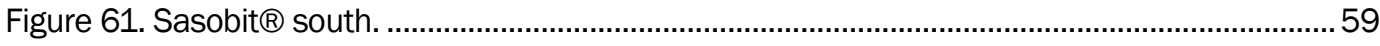

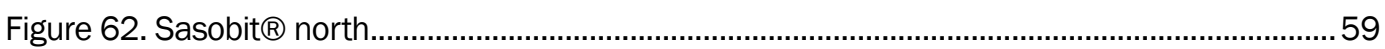




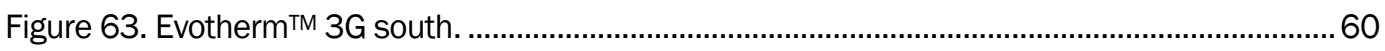

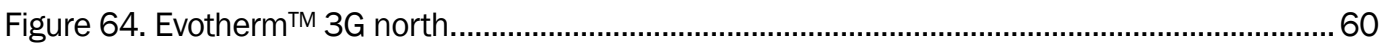

Figure 65. HMA South Trench (STA 0+16).......................................................................... 61

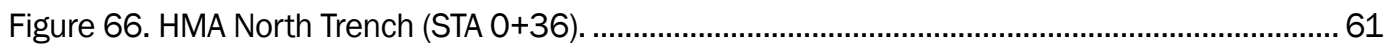

Figure 67. Foamed Asphalt South Trench (STA 0+16)............................................................... 62

Figure 68. Foamed Asphalt North Trench (STA 0+36)................................................................ 62

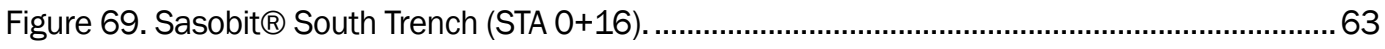

Figure 70. Sasobit ${ }^{\circledR}$ North Trench (STA 0+36). ......................................................................... 63

Figure 71. Evotherm ${ }^{\mathrm{TM}} 3 \mathrm{G}$ South Trench (STA 0+16)…........................................................... 64

Figure 72. Evotherm ${ }^{\text {TM }} 3 G$ North Trench (STA 0+36). ……....................................................... 64

Figure 73. Actual average permanent deformation overview........................................................ 65

Figure 74. Average maximum pressures measured at each pavement unbound layer.....................67

Figure 75. Groove diagram and suggested failure mechanism (not to scale)................................. 70

Figure 76. Layout of WMA grooving evaluation experimental design (not to scale). ........................ 71

Figure 77. F-15 load cart. .......................................................................................................... 72

Figure 78. Typical grooves before traffic. ................................................................................... 73

Figure 79. Typical partial groove closure and full groove closure................................................... 73

Figure 80. Groove closure at each pass level............................................................................74

Figure 81. Pavement surface temperature at each pass level........................................................74

Figure A1. HMA pavement temperature range - south end. …………….................................... 79

Figure A2. HMA pavement temperature range - center of the item............................................... 79

Figure A3. HMA pavement temperature range - north end ......................................................... 80

Figure A4. Foamed Asphalt pavement temperature range - south end........................................... 80

Figure A5. Foamed Asphalt pavement temperature range - center of the item............................. 81

Figure A6. Foamed Asphalt pavement temperature range - north end.......................................... 81

Figure A7. Sasobit $\AA$ pavement temperature range - south end...................................................... 82

Figure A8. Sasobit ${ }^{\circledR}$ pavement temperature range - center of the item......................................... 82

Figure A9. Sasobit $\AA^{\circ}$ pavement temperature range - north end. ....................................................... 83

Figure A10. Evotherm ${ }^{\mathrm{TM}} 3 \mathrm{G}$ pavement temperature range - south end. ......................................... 83

Figure A11. Evotherm ${ }^{\text {TM }} 3 G$ pavement temperature range - center of the item...............................8 84

Figure A12. Evotherm ${ }^{\mathrm{TM}} 3 \mathrm{G}$ pavement temperature range - north end. ........................................ 84

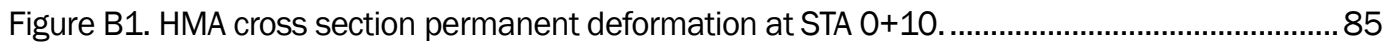

Figure B2. HMA cross section permanent deformation at STA 0+15............................................ 85

Figure B3. HMA cross section permanent deformation at STA 0+20 .......................................... 86

Figure B4. HMA cross section permanent deformation at STA 0+25........................................... 86

Figure B5. HMA cross section permanent deformation at STA 0+30......................................... 87

Figure B6. HMA cross section permanent deformation at STA 0+35 ........................................... 87

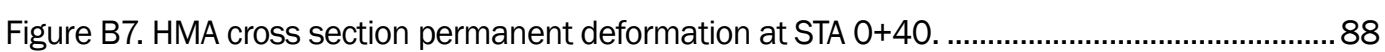

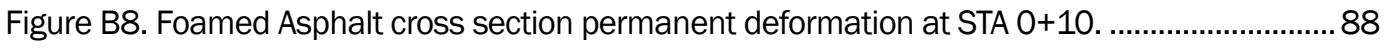

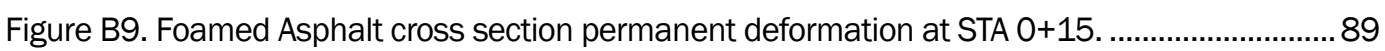


Figure B10. Foamed Asphalt cross section permanent deformation at STA 0+20 89

Figure B11. Foamed Asphalt cross section permanent deformation at STA 0+25........................90

Figure B12. Foamed Asphalt cross section permanent deformation at STA $0+30 \ldots \ldots \ldots \ldots \ldots . . . . . . . . . . . . .90$

Figure B13. Foamed Asphalt cross section permanent deformation at STA $0+35 \ldots \ldots \ldots \ldots . . . . . . . . . . . . . .91$

Figure B14. Foamed Asphalt cross section permanent deformation at STA 0+40.......................... 91

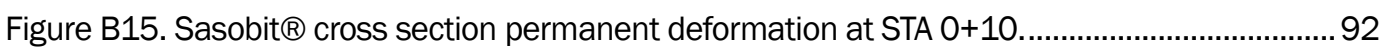

Figure B16. Sasobit $\AA$ cross section permanent deformation at STA 0+15 ......................................92

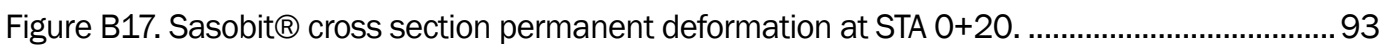

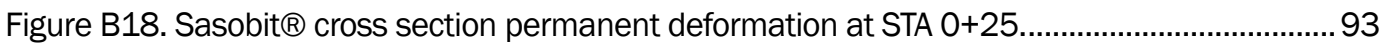

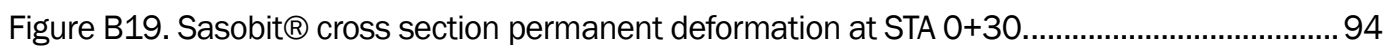

Figure B20. Sasobit $\AA$ cross section permanent deformation at STA 0+35 ..................................... 94

Figure B21. Sasobit $\AA$ cross section permanent deformation at STA 0+40..................................... 95

Figure B22. Evotherm ${ }^{\mathrm{TM}} 3 \mathrm{G}$ cross section permanent deformation at STA $0+10 \ldots \ldots \ldots \ldots \ldots \ldots \ldots \ldots . . . . . . .95$

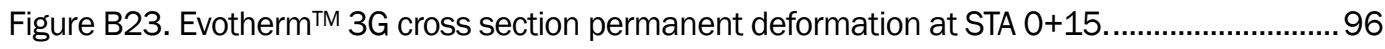

Figure B24. Evotherm ${ }^{\mathrm{TM}} 3 \mathrm{G}$ cross section permanent deformation at STA $0+20 \ldots \ldots \ldots \ldots \ldots \ldots \ldots \ldots \ldots . . . . .96$

Figure B25. Evotherm ${ }^{\text {TM }} 3 \mathrm{G}$ cross section permanent deformation at STA 0+25........................... 97

Figure B26. Evotherm ${ }^{\text {TM }} 3 G$ cross section permanent deformation at STA $0+30 \ldots \ldots \ldots \ldots \ldots \ldots \ldots \ldots . . . . . . .97$

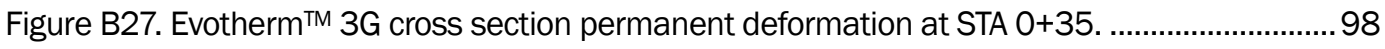

Figure B28. Evotherm ${ }^{\mathrm{TM}} 3 \mathrm{G}$ cross section permanent deformation at STA $0+40 \ldots \ldots \ldots \ldots . . . . . . . . . . . . . . . .98$

Figure C1. FWD test raw data for HMA (pre-traffic at ambient temperature)...................................99

Figure C2. FWD test raw data for HMA (pre-traffic at high temperature)......................................100

Figure C3. FWD test raw data for HMA (post-traffic at high temperature)...................................... 101

Figure C4. FWD test raw data for Foamed Asphalt (pre-traffic at ambient temperature)...............102

Figure C5. FWD test raw data for Foamed Asphalt (pre-traffic at high temperature)......................103

Figure C6. FWD test raw data for Foamed Asphalt (post-traffic at high temperature). ...................104

Figure C7. FWD test raw data for Sasobit $₫$ (pre-traffic at ambient temperature). .........................105

Figure C8. FWD test raw data for Sasobit $\AA$ (pre-traffic at high temperature).................................106

Figure C9. FWD test raw data for Sasobit $\AA$ (post-traffic at high temperature)................................ 107

Figure C10. FWD test raw data for Evotherm ${ }^{\mathrm{TM}}$ 3G (pre-traffic at ambient temperature)................108

Figure C11. FWD test raw data for Evotherm ${ }^{\text {TM }}$ 3G (pre-traffic at high temperature)......................109

Figure C12. FWD test raw data for Evotherm ${ }^{\mathrm{TM}} 3 \mathrm{G}$ (post-traffic at high temperature)....................110

Figure D1. Typical of EPC raw data from dynamic slow roll test. ....................................................111

Figure D2. Typical of SSD raw data from dynamic slow roll test..................................................111

Figure D3. Typical of SSG raw data from dynamic slow roll test....................................................112

Figure D4. Typical of ASG raw data from dynamic slow roll test. ...................................................112

Figure D5. Typical of EPC raw data from dynamic sweep test. .......................................................113

Figure D6. Typical of SSD raw data from dynamic sweep test......................................................113

Figure D7. Typical of SSG raw data from dynamic sweep test. ....................................................114

Figure D8. Typical of ASG raw data from dynamic sweep test.........................................................114 


\section{Tables}

Table 1. Foundation layer soil properties as constructed............................................................... 7

Table 2. WMA products description............................................................................................ 7

Table 3. Volumetric properties of asphalt cores................................................................................ 9

Table 4. Traffic operations sequence. ............................................................................................ 17

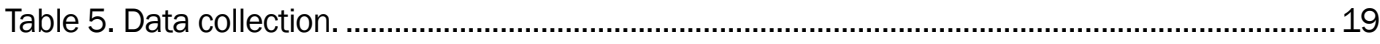

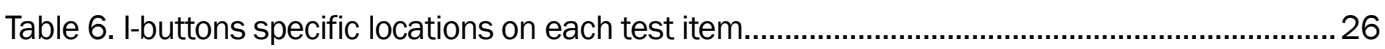

Table 7. Maximum soil pressures during dynamic slow roll test....................................................38

Table 8. Maximum deflections measured with the SDDs during dynamic slow roll tests................. 42

Table 9. Maximum soil pressures during dynamic sweep test. ..................................................... 45

Table 10. Maximum deflections measured with the SDDs during dynamic sweep tests.................49

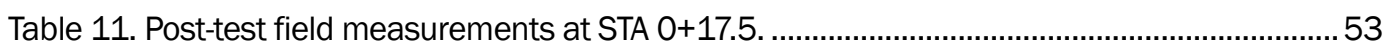

Table 12. Post-test field measurements at STA 0+37.5 ….........................................................5

Table 13. Comparison of before and after traffic layer thicknesses. ................................................56

Table 14. Actual failure data. ................................................................................................... 66

Table 15. Factor/level combinations for WMA grooving evaluation. ................................................ 71 


\section{Preface}

This study was conducted for the US Air Force, Air Combat Command, as part of the Warm-Mix Asphalt Evaluation Project. The Technical Monitor was Dr. David A. Horner.

The work was performed by the Airfields and Pavements Branch (GM-A) and the Concrete Materials Branch (GM-C), US Army Engineer Research and Development Center, Geotechnical and Structures Laboratory (ERDCGSL). At the time of publication, Dr. Gary L. Anderton was Chief, CEERDGM-A, and Christopher M. Moore was Chief, CEERD-GM-C; Dr. Larry N. Lynch was Chief, CEERD-GM; and Dr. David A. Horner, CEERD-GV-T, was the Technical Director for Force Projection and Maneuver Support. The Deputy Director of ERDC-GSL was Dr. William P. Grogan, and the Director was Dr. David W. Pittman.

COL Jeffrey R. Eckstein was the Commander of ERDC, and Dr. Jeffery P. Holland was the Director. 


\section{Unit Conversion Factors}

\begin{tabular}{|l|c|l|}
\hline Multiply & By & To Obtain \\
\hline degrees Fahrenheit & $($ F-32)/1.8 & degrees Celsius \\
\hline feet & 0.3048 & meters \\
\hline inches & 0.0254 & meters \\
\hline kips (force) per square inch & 6.894757 & megapascals \\
\hline pounds (force) per square inch & 6.894757 & kilopascals \\
\hline pounds (mass) & 0.45359237 & kilograms \\
\hline
\end{tabular}




\section{Introduction}

\subsection{Background}

The hot-mix asphalt (HMA) industry seeks emerging technologies that reduce environmental impact during production of bituminous paving materials. In recent years, warm-mix asphalt (WMA) has replaced HMA for many paving projects. WMA is a general description for asphalt concrete that is produced at lower temperatures than conventional HMA. Many techniques have been developed to produce WMA, including chemical additives, organic wax additives, and foaming. Many state departments of transportation (DOTs) are quickly adopting WMA for roadway paving, and many are using it in place of conventional HMA. As the states' departments of transportation gain experience with WMA, conventional HMA may become less available for paving. Empirical evidence to date indicates that WMA performs well on highways and has the potential to be adopted for airfield pavements.

\subsection{Previous Work}

The study presented in this report is part of a larger research effort that has been conducted by the US Army Corps of Engineers to evaluate WMA technologies and provide guidance on their use for airfield pavements. A general description of the WMA research is summarized in the following paragraphs and presented in the flow chart in Figure 1.

In FY10, the ERDC was tasked with evaluating the laboratory performance of different WMA technologies in order to certify their use for airfield pavements. The performance of mixtures produced in the laboratory using different WMA technologies was compared to the performance of the same mixtures produced at HMA temperatures. Properties assessed included susceptibility to permanent deformation, moisture damage and lowtemperature cracking, durability, and workability. The use of high recycled asphalt pavement (RAP) contents was also evaluated. Results indicated that WMA was a viable product for airfield pavement surface mixtures. Guidance for the use of WMA on airfields was developed and published in a Unified Facilities Guide Specification (UFGS 3212 15.16) and an Engineering Technical Letter (ETL 11-3). Specific details on the WMA laboratory evaluation conducted in FY10 are presented in Mejías-Santiago et al. (2012). 
Figure 1. WMA research flow chart.

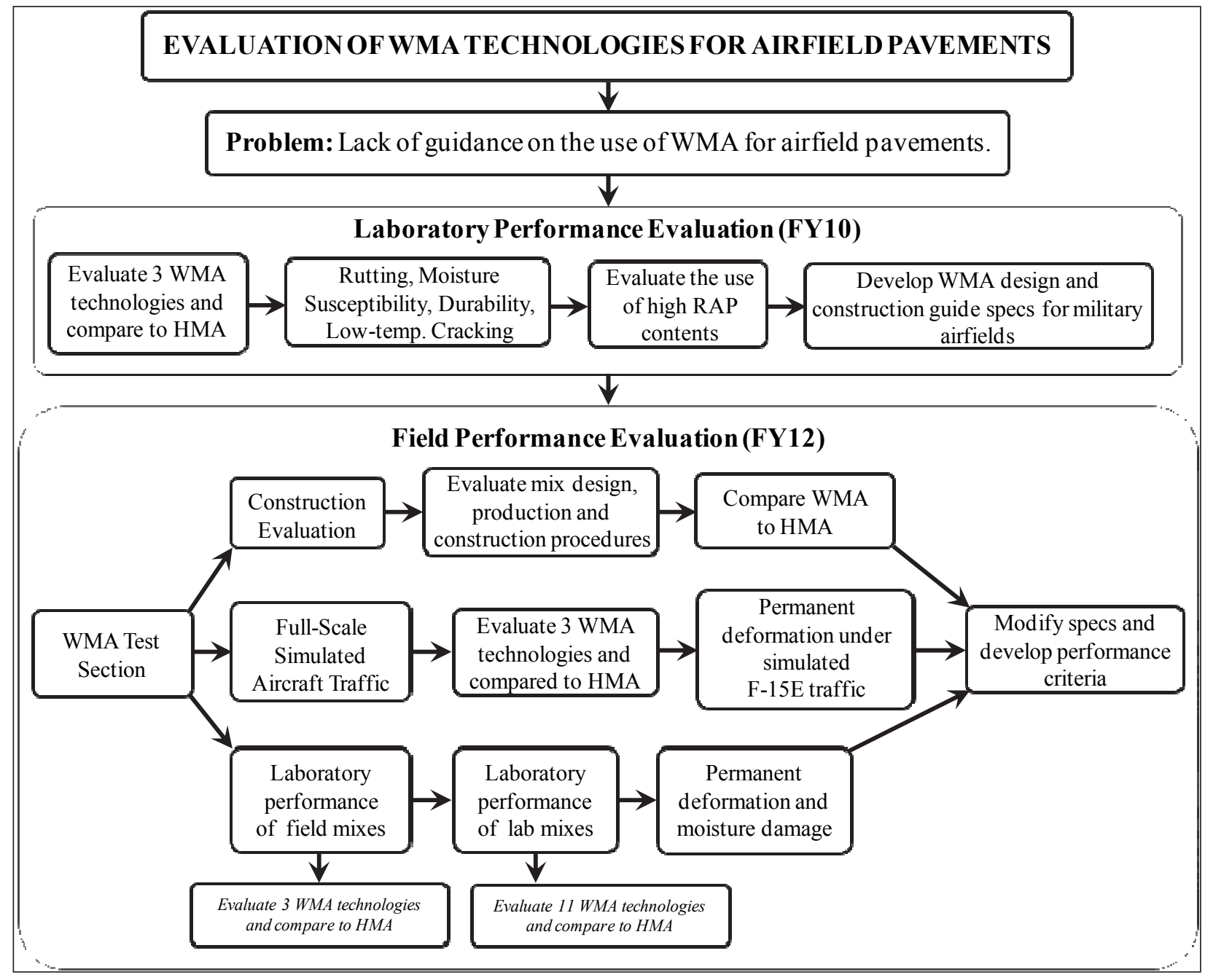

In FY12, the team conducted additional research to validate the results from the FY10 laboratory performance evaluation using results from fullscale testing and laboratory testing on plant-produced WMA mixtures. For this purpose, a full-scale test section consisting of four test items was designed and constructed at ERDC's pavement testing facility (Hangar 4) to evaluate the performance of a mixture produced using three different WMA technologies and to compare the performance of the same mixture produced at HMA temperature. This second study consisted of three main parts: 1) laboratory performance evaluation of field mixtures, 2) evaluation of design, production, and construction procedures, and 3) full-scale simulated aircraft traffic evaluation.

For the first part of the study, a laboratory evaluation was conducted using mixture samples collected at the asphalt plant and from the test section 
constructed. A suite of laboratory tests was conducted to evaluate the performance of the plant-produced WMA mixtures and to compare it to the plant-produced HMA mixture. In addition, the performance of 11 different laboratory-produced WMA mixtures was studied. Properties evaluated included susceptibility to moisture damage, permanent deformation, and binder performance grade. Results showed that WMA's potential for permanent deformation was somewhat greater than HMA for both laboratory and field mixtures. WMA also exhibited poorer performance than HMA in moisture damage tests on laboratory-produced specimens. However, the plant-produced WMA mixture indicated very little difference compared to HMA. Also, there were some differences in performance among WMA mixtures, but these were not attributed to a specific WMA technology category. Specific details on the first portion of the study are presented in Doyle et al. (2013).

In the second part of the study, WMA mix design, plant production, and placement were evaluated and compared to those of HMA. The research team did not find anything critical that would preclude the use of WMA for airfield pavements and recommended the use of specifications included in UFGS 32-12-15.16 to govern constructing airfield pavements with a WMA surface. A more detailed description of the second portion of the study is presented in Rushing et al. (2013).

Finally, the test section was evaluated under simulated F-15E aircraft traffic in the third part of the study, and the results are presented in this report. The main focus of this report consists of comparing field performance of WMA to HMA for recommending its use in airfield pavements.

\subsection{Objectives}

The objectives of this report include:

- presenting the results from the full-scale simulated aircraft traffic evaluation of WMA compared to conventional HMA, and

- presenting results from the evaluation of surface grooving on WMA compared to conventional HMA. 


\subsection{Approach}

The approach of this field evaluation consisted of trafficking four test items (three WMAs and one HMA) using HVS-A simulated F-15E traffic. Testing was conducted at high pavement temperature, high tire pressure, and heavy load. The failure criterion was established at $1 \mathrm{in}$. of permanent surface deformation. Data collected included temperature, permanent deformation, asphalt strains, pavement stiffness, and soil stresses and deflections. 


\section{Full-Scale Evaluation Plan}

This chapter presents a general description of the test-section design and layout, materials, instrumentation, and traffic conditions. A more detailed description of most of these aspects of the study can be found in Rushing et al. (2013).

\subsection{Test-section design and layout}

The test section was constructed in an open-ended aircraft hangar test facility (Hangar 4) at ERDC. The test section was designed within the limits of the DOD's minimum thickness criteria for flexible pavements in medium-load Air Force airfields detailed in UFC 3-260-02. It consisted of four test items as shown in Figure 2. The only difference between the test items was the WMA additive used in the asphalt mix. Three different types of WMA technologies were used: chemical additive, organic additive, and foaming process. A dense-graded HMA mix was used in the control test item. The same asphalt mix design was used for the four mixes.

Figure 2. Test-section layout.

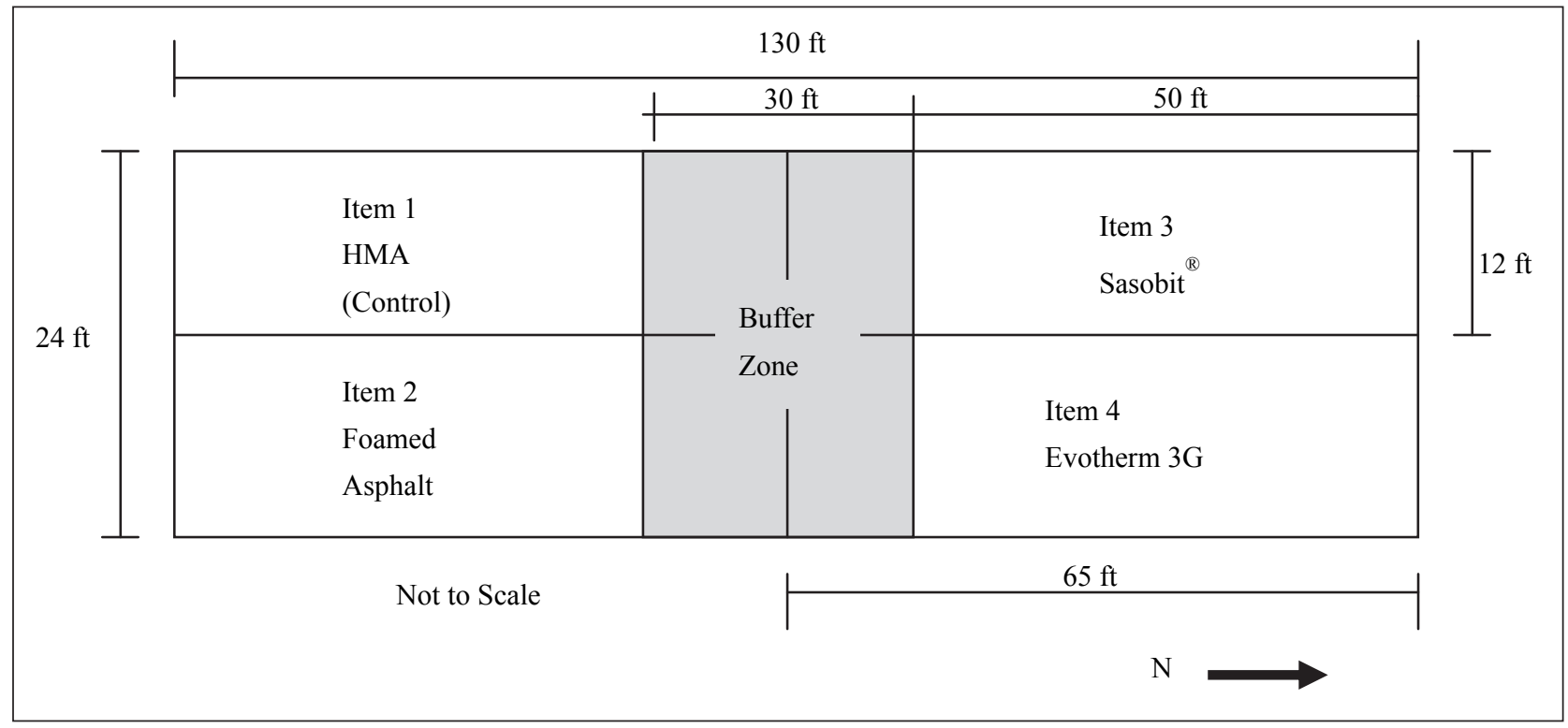

The pavement structure was designed to minimize deformation in the unbound layers so that failure would occur predominantly in the surface layer. Pavement Transportation Computer Aided Structural Evaluation (PCASE) software and Pavement Engineering Utility (PSEVEN) were used 
to determine the optimum pavement structural design in accordance with DOD airfield design criteria (UFC 3-260-02). Locally available materials that would withstand over 100,000 passes of an F-15E aircraft fully loaded to approximately 35,000-lb load and 325-psi tire pressure without failure were used. Failure for this analysis was defined as $1 \mathrm{in}$. of rutting mainly attributed to the subgrade or subbase layers. The resulting pavement structure consisted of $4 \mathrm{in}$. of asphalt concrete over $10 \mathrm{in}$. of base course with a California bearing ratio (CBR) of 100, over a 10-in.-thick subbase course with a CBR of 30 . The subgrade had an assumed CBR of 15. Each test item was designed using the same pavement structure (Figure 3). The asphalt concrete layer was varied to include three WMAs and one HMA surface.

Figure 3. Test-section pavement structure.

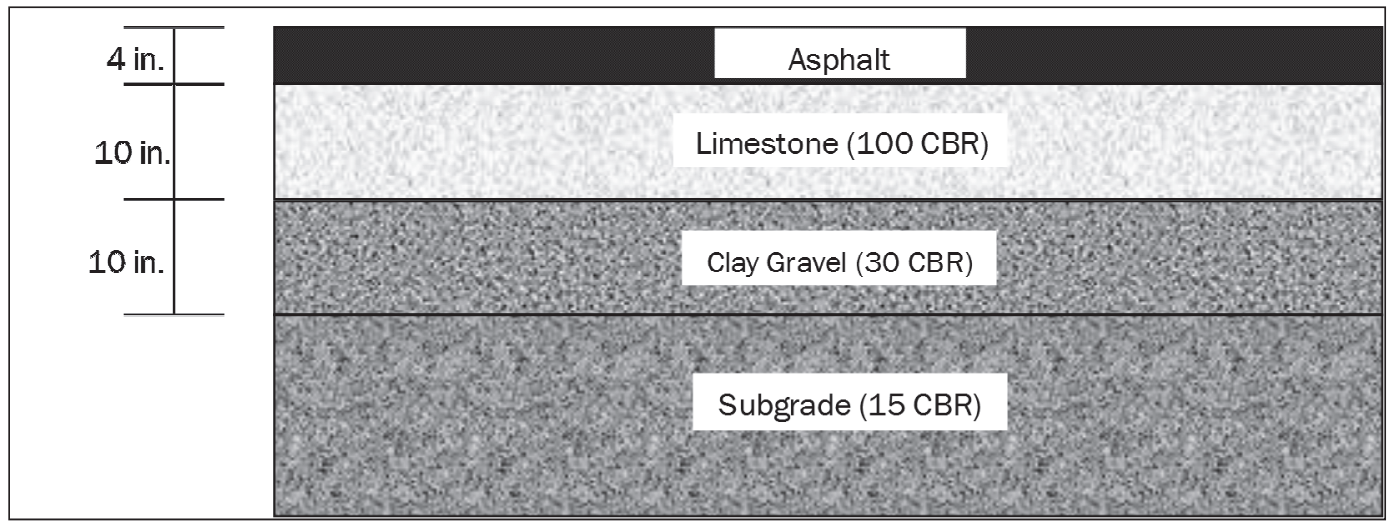

\subsection{Materials}

\subsubsection{Foundation soil materials}

The subgrade consisted of a clay material classified as high-plasticity clay (CH) by the Unified Soil Classification System (USCS) as described in ASTM D 2487. This material was procured from a local source in Vicksburg, Mississippi, and was selected for its ability to retain its moisture condition and strength characteristics over long periods of time. The subbase material was a clay-gravel mixture also procured from a local source in Vicksburg, and its USCS classification was clayey sand (SC) with gravel. The base course was a limestone material classified as gravel with silt and sand (GP-GM). This material was stockpiled at a local facility, but it was previously transported by barge to Vicksburg from its source in western Kentucky. A summary of the as-constructed soil properties from the foundation layers is given in Table 1. 
Table 1. Foundation layer soil properties as constructed.

\begin{tabular}{|c|c|c|c|c|c|c|c|c|c|}
\hline \multirow[b]{3}{*}{$\begin{array}{l}\text { Test } \\
\text { Item }\end{array}$} & \multicolumn{3}{|c|}{ Subgrade } & \multicolumn{3}{|c|}{ Subbase } & \multicolumn{3}{|c|}{ Base } \\
\hline & \multirow[b]{2}{*}{$\begin{array}{l}\text { Avg. } \\
\text { CBR } \\
\text { (\%) }\end{array}$} & \multicolumn{2}{|c|}{ Drive Cylinder } & \multirow[b]{2}{*}{$\begin{array}{l}\text { Avg. } \\
\text { CBR } \\
\text { (\%) }\end{array}$} & \multicolumn{2}{|c|}{ Sand Cone } & \multirow[b]{2}{*}{$\begin{array}{l}\text { Avg. } \\
\text { CBR } \\
(\%)\end{array}$} & \multicolumn{2}{|c|}{ Sand Cone } \\
\hline & & \begin{tabular}{|l} 
Dry \\
Density \\
(pcf)
\end{tabular} & $\begin{array}{l}\text { Moisture } \\
\text { Content } \\
(\%)\end{array}$ & & $\begin{array}{l}\text { Dry } \\
\text { Density } \\
\text { (pcf) }\end{array}$ & $\begin{array}{l}\text { Moisture } \\
\text { Content } \\
(\%)\end{array}$ & & $\begin{array}{l}\text { Dry } \\
\text { Density } \\
\text { (pcf) }\end{array}$ & $\begin{array}{l}\text { Moisture } \\
\text { Content } \\
(\%)\end{array}$ \\
\hline 1 & 13.8 & 97.1 & 22.8 & 26.7 & 127.7 & 8.4 & 100.0 & 144.3 & 2.7 \\
\hline 2 & 15.1 & 96.2 & 21.8 & 34.6 & 130.8 & 7.5 & 106.1 & 139.7 & 2.5 \\
\hline 3 & 14.9 & 96.1 & 22.2 & 35.1 & 131.6 & 7.1 & 103.6 & 133.5 & 2.2 \\
\hline 4 & 14.9 & 99.9 & 20.5 & 33.3 & 129.4 & 6.9 & 103.1 & 138.7 & 2.5 \\
\hline Average & 14.7 & 97.3 & 21.8 & 32.4 & 129.9 & 7.4 & 103.2 & 139.1 & 2.5 \\
\hline Target & 15.0 & 103.0 & 22.0 & 30.0 & 130.0 & 8.0 & 100.0 & $141.0-145.0$ & $3.0-5.0$ \\
\hline
\end{tabular}

\subsubsection{Asphalt concrete}

\subsubsection{Binder and WMA additives:}

The base binder used for this project was an unmodified PG 67-22. A neat asphalt binder was used instead of a polymer-modified binder to avoid any interaction between WMA technologies and other binder modifiers. The Evotherm ${ }^{\mathrm{TM}} 3 \mathrm{G}$ additive was pre-blended with the base binder prior to use. The Sasobit $\AA$ additive was fed into the asphalt drum mixer near the same location as the binder. The Foamed Asphalt used water injection near the binder feed line. WMA product descriptions and dosage rates are provided in Table 2.

Table 2. WMA products description.

\begin{tabular}{|l|l|l|}
\hline Product Name & WMA Category & Dosage Rate $(\%)$ \\
\hline Sasobit ${ }^{\circledR}$ & organic wax & 1.5 \\
\hline Evotherm ${ }^{\text {TM }} 3 \mathrm{G}$ & chemical additive & 0.5 \\
\hline Foamed Asphalt (water) & foam process & 2.0 \\
\hline
\end{tabular}

a Dosage rate by percentage of binder weight.

\subsubsection{Aggregate}

An aggregate blend was designed to meet job mix formula (JMF) gradation requirements for a $0.5 \mathrm{in}$. $(12.5 \mathrm{~mm})$ nominal maximum aggregate size mixture according to UFGS 32- 12- 15.16. The blend consisted of $45 \%$ crushed gravel, 40\% limestone, and 15\% natural sand (maximum allowed by specification). The aggregate sources and blend were selected based on materials available for plant production. The fine aggregate angularity 
(FAA) value for this blend of $42.6 \%$ was below the specified minimum requirement of $45.0 \%$ and could indicate increased propensity for rutting. Gradation and aggregate properties for the JMF aggregate blend are provided in Figure 4.

Figure 4. Gradation of aggregate for asphalt mixtures.

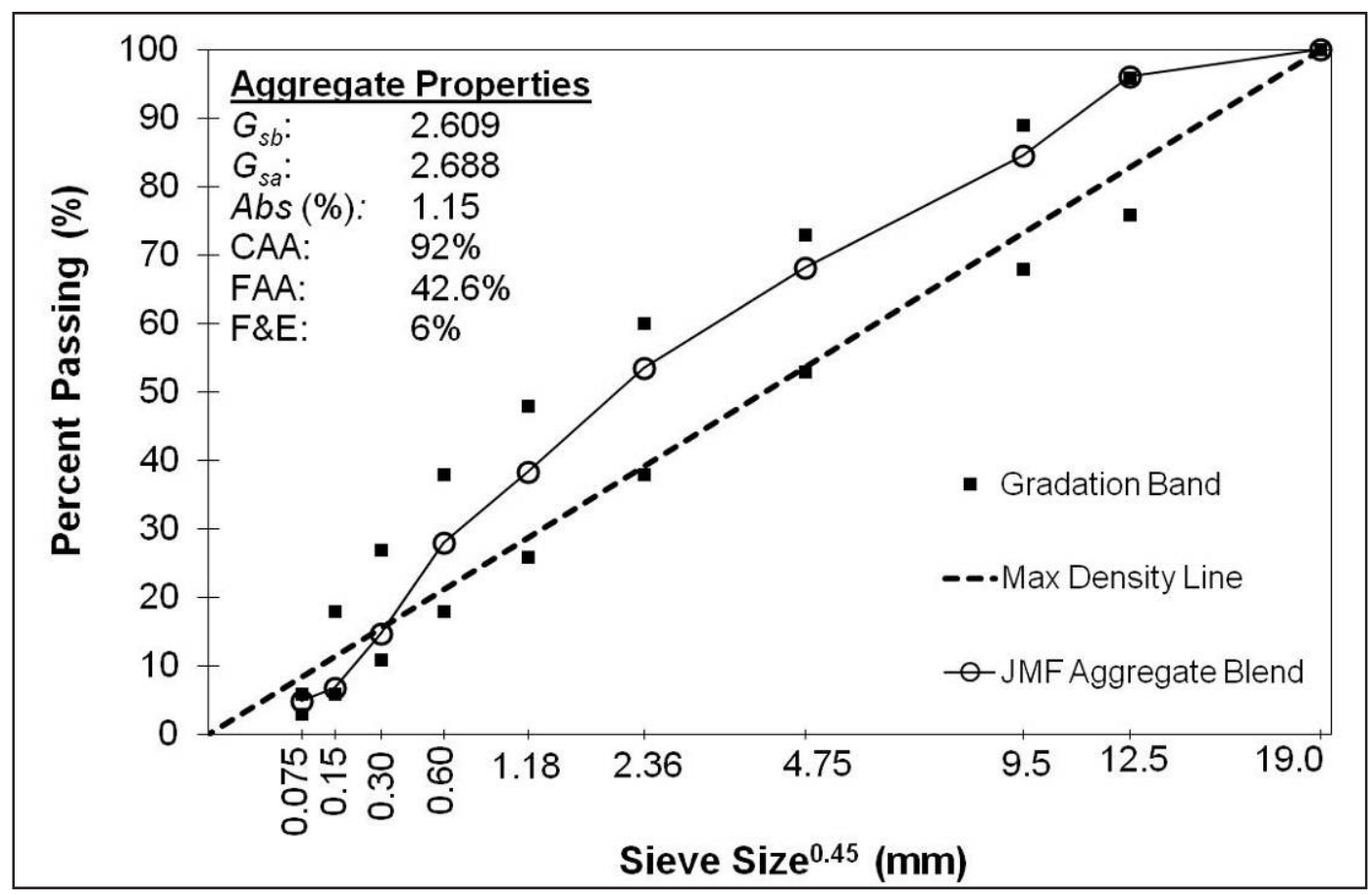

\subsubsection{Mix design}

Asphalt mixtures were designed to 75 gyrations in the Superpave gyratory compactor (SGC) according to UFGS 32-12-15.16 requirements.

\subsubsection{In-situ volumetric properties}

Cores were extracted from the asphalt concrete pavement sections to determine the in-situ volumetric properties. Table 3 provides average values for 10 cores taken from each test item. The theoretical maximum specific gravity, $G_{m m}$, and percent binder, $P_{b}$, values were determined from quality assurance (QA) laboratory testing. The $G_{m b}$ was measured according to AASHTO T166.

The compacted air voids percentage was close to the target of 4.0 for the HMA, Sasobit ${ }^{\circledR}$, and Evotherm ${ }^{\mathrm{TM}} 3 \mathrm{G}$ test items. The Foamed Asphalt item had the highest air void content. This item was also compacted at the lowest temperature. During construction, it did not achieve density as quickly as the other items, which resulted in higher air voids. The higher 
voids in mineral aggregate (VMA) and lower voids filled with asphalt (VFA) values result from lower density. Overall, the total thickness of the items was close to the target value of 4.0 in.

Table 3. Volumetric properties of asphalt cores.

\begin{tabular}{|c|c|c|c|c|c|c|c|}
\hline Mix ID & $\mathrm{G}_{m m}$ & $G_{m b}$ & $P_{b}$ & $V_{a}$ & VMA & VFA & Thickness (in.) \\
\hline Target & -- & -- & -- & 4.0 & $\geq 14.0$ & $65-78$ & 4.0 \\
\hline HMA & 2.454 & 2.360 & 5.3 & 3.8 & 14.3 & 73 & $4.2 \pm 0.16$ \\
\hline Foamed Asphalt & 2.471 & 2.322 & 4.8 & 6.0 & 15.3 & 61 & $4.1 \pm 0.31$ \\
\hline Sasobit $\AA$ & 2.460 & 2.351 & 4.9 & 4.4 & 14.3 & 69 & $4.2 \pm 0.23$ \\
\hline Evotherm ${ }^{\mathrm{TM}} 3 \mathrm{G}$ & 2.463 & 2.345 & 4.9 & 4.8 & 14.5 & 67 & $4.2 \pm 0.26$ \\
\hline
\end{tabular}

\subsection{Instrumentation}

During construction, each test item was instrumented with earth pressure cells (EPCs), single-depth deflectometers (SDDs), asphalt strain gauges (ASGs), and surface strain gauges (SSGs) to measure the pavement response to simulated aircraft loading. Moisture sensors were also installed in the subgrade of all four test items to monitor moisture changes throughout the test period. Figure 5 shows the instrumentation layout.

The EPCs and SDDs were installed in the subgrade, subbase and base layers to measure the soil stresses and deformations, respectively, generated in the different sub-layers underneath the asphalt surface during traffic. EPCs were installed 2 in. into each sub-layer, and the SDDs were installed 4 in. into each sub-layer. The ASGs were installed on top of the limestone base to measure deformations at the bottom of the asphalt layer. Two ASGs were installed at each location: one oriented in the longitudinal (traffic) direction and the second one oriented transverse to the traffic direction. The ASGs were installed 6 in. apart (center-to-center spacing), as shown in Figure 7, using the manufacturer's installation instructions. To protect each gauge during paving, asphalt mix was screened over a \#4 sieve, and the fine portion was used to create a thin, compacted dome over the gauge. The SSGs were installed at the asphalt surface at the same locations where the ASGs were installed in each test item. Two SSGs were installed 6 in. apart (center-to-center spacing) at each location: one oriented in the longitudinal (traffic) direction and the second one oriented transverse to the traffic direction (Figure 7). The SSGs were adhered to the pavement using a rapidcuring general purpose adhesive (epoxy) following the manufacturer's installation instructions. Protective coating was applied to the SSGs and the lead wires to protect them from traffic abrasion (Figure 8). 
Figure 5. Instrumentation layout.

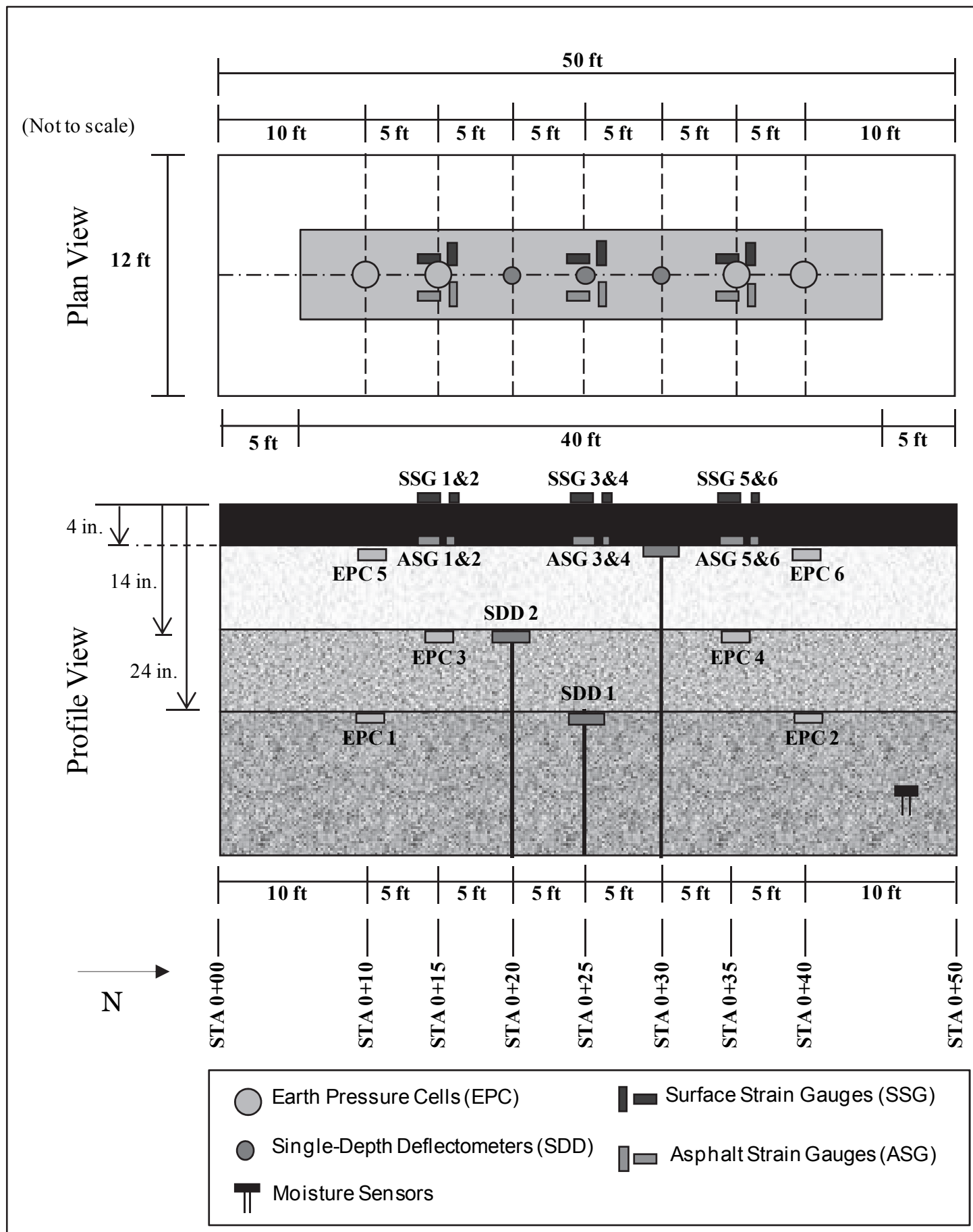


Figure 6. Typical installation of ASGs at the base surface.

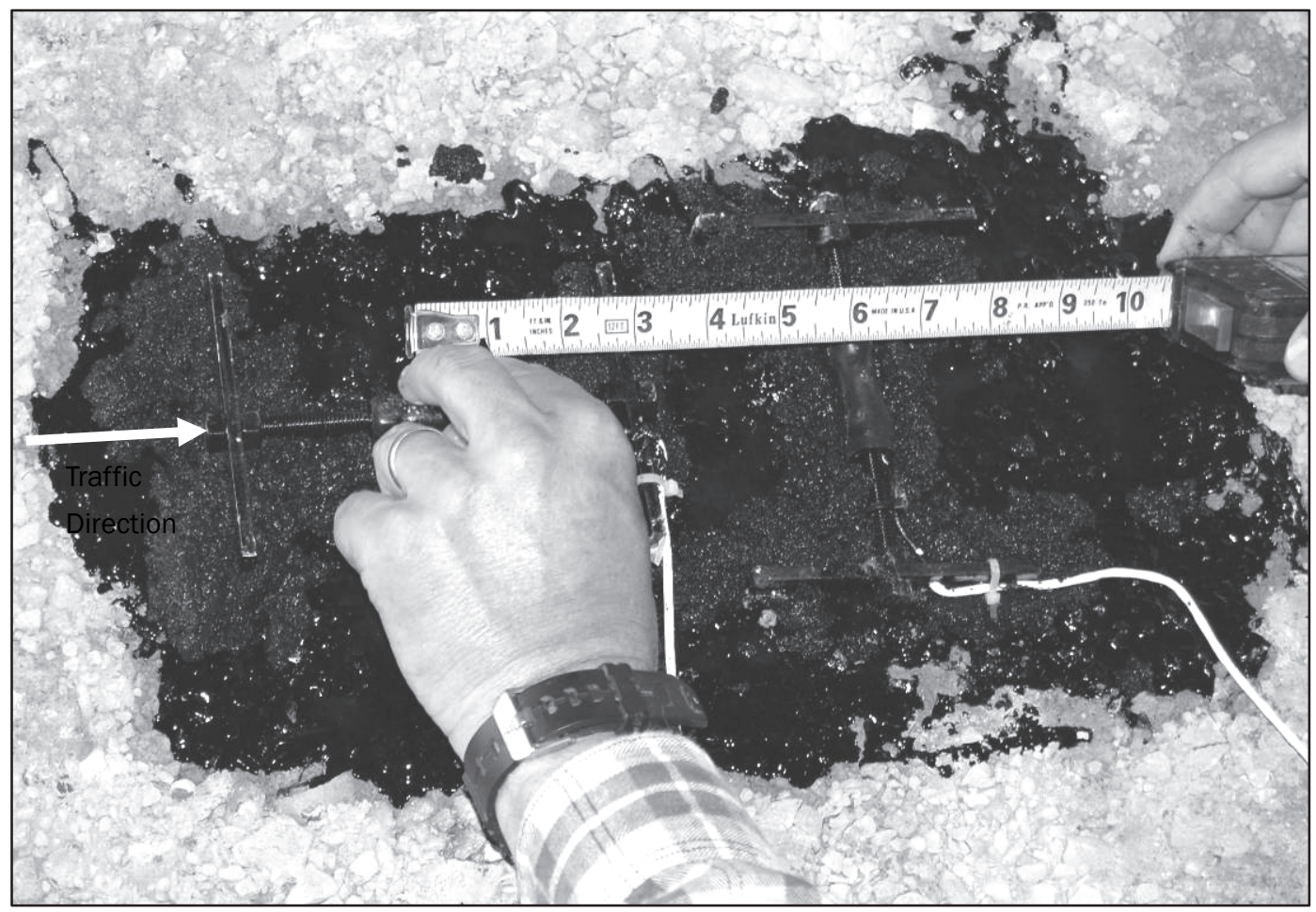

Figure 7. Typical installation of SSGs.

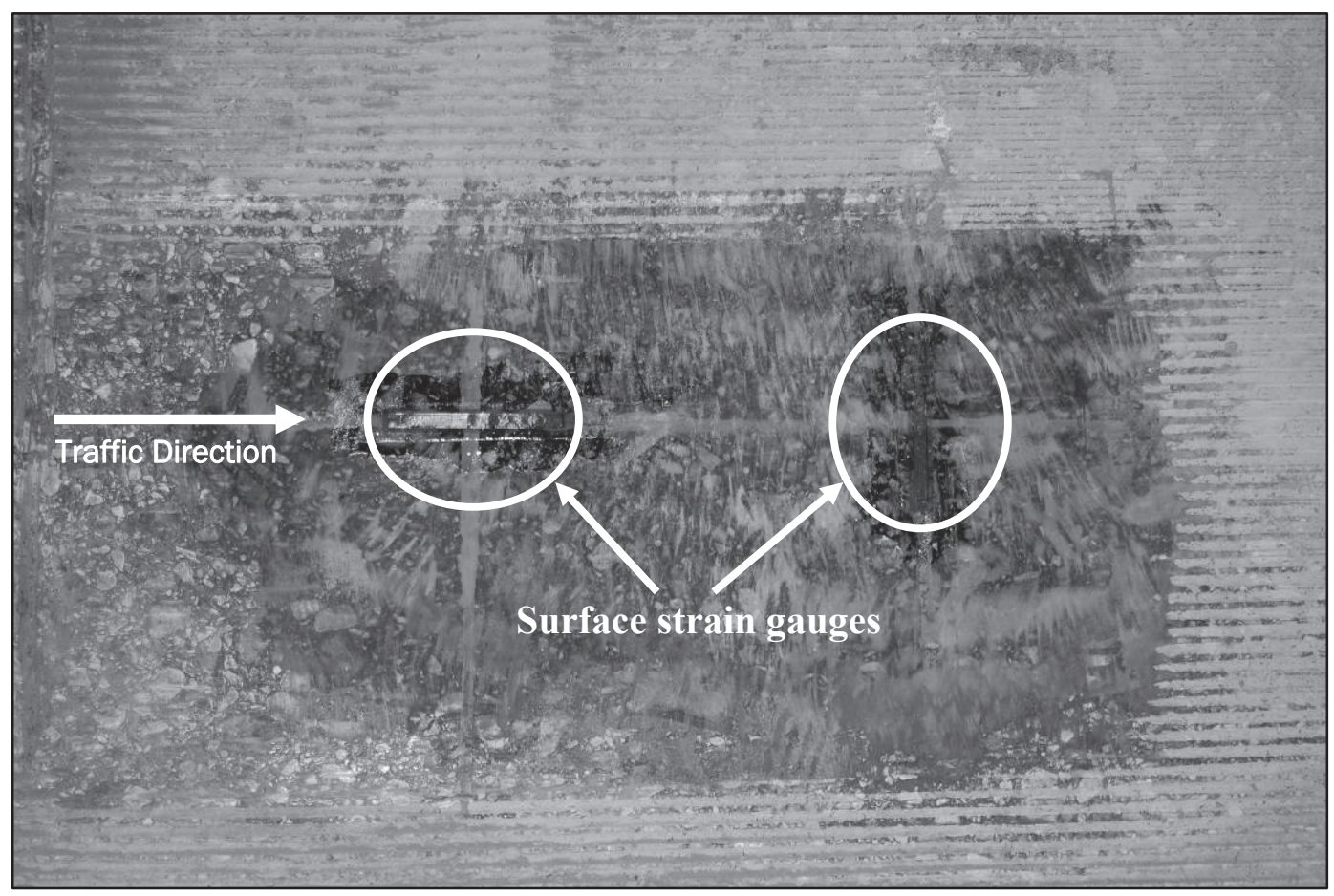


Figure 8. Applying protective coating to SSGs and lead wires.

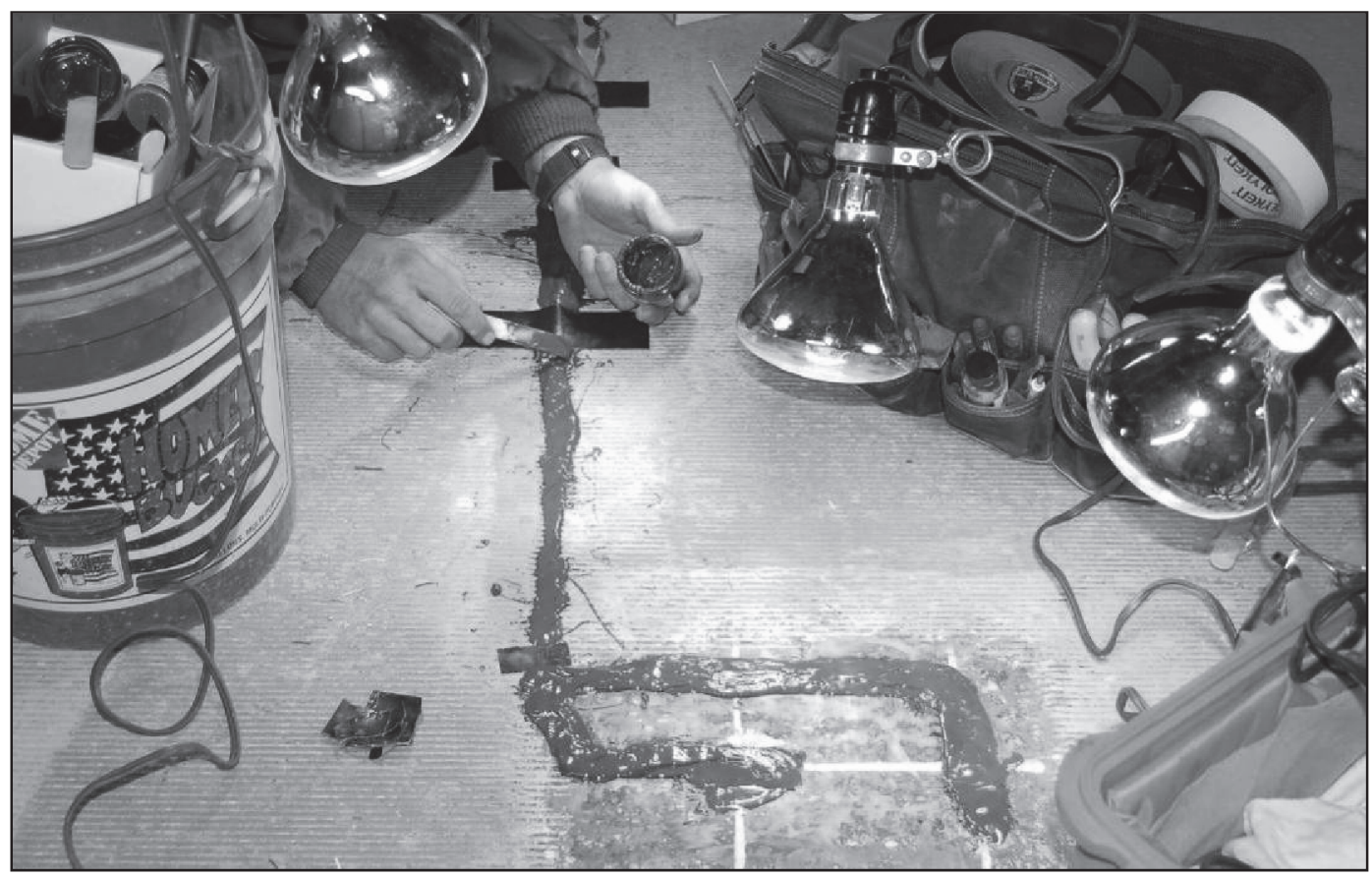

I-buttons (Figure 9) were installed outside the traffic zone on both the surface of and within the asphalt layer to continuously measure pavement internal temperature. They were installed at three locations (north, center, and south), and at three different depths within the asphalt layer (near the surface or top, mid-depth, and at the bottom). I-buttons were also used to monitor the air temperature inside the HVS chamber (one on the north end and one on the south end), and the outside temperature. Figure 10 shows a typical I-button installation layout.

Figure 9. I-button used to record temperature readings (www.maturitycentral.com).

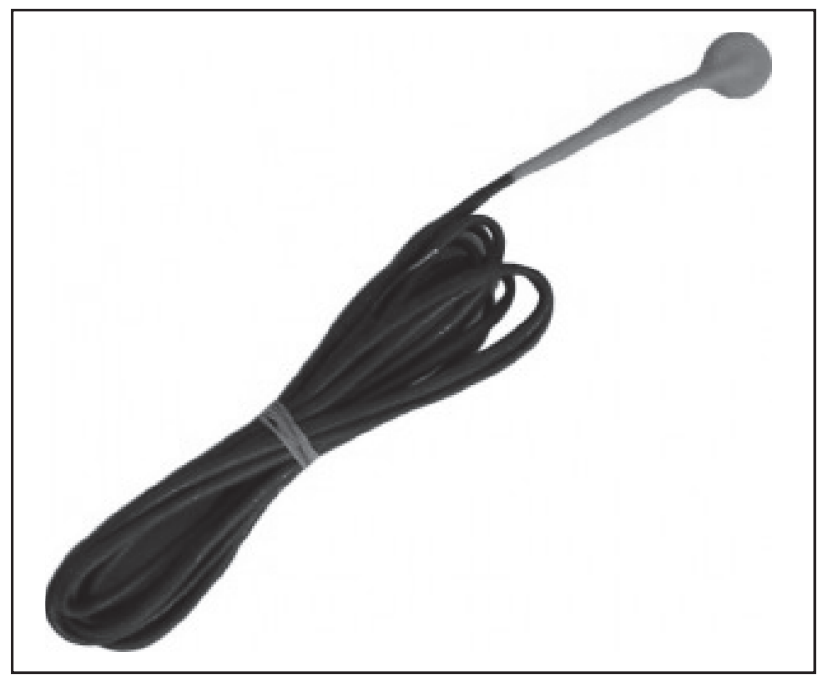


Figure 10. Typical I-button installation layout.

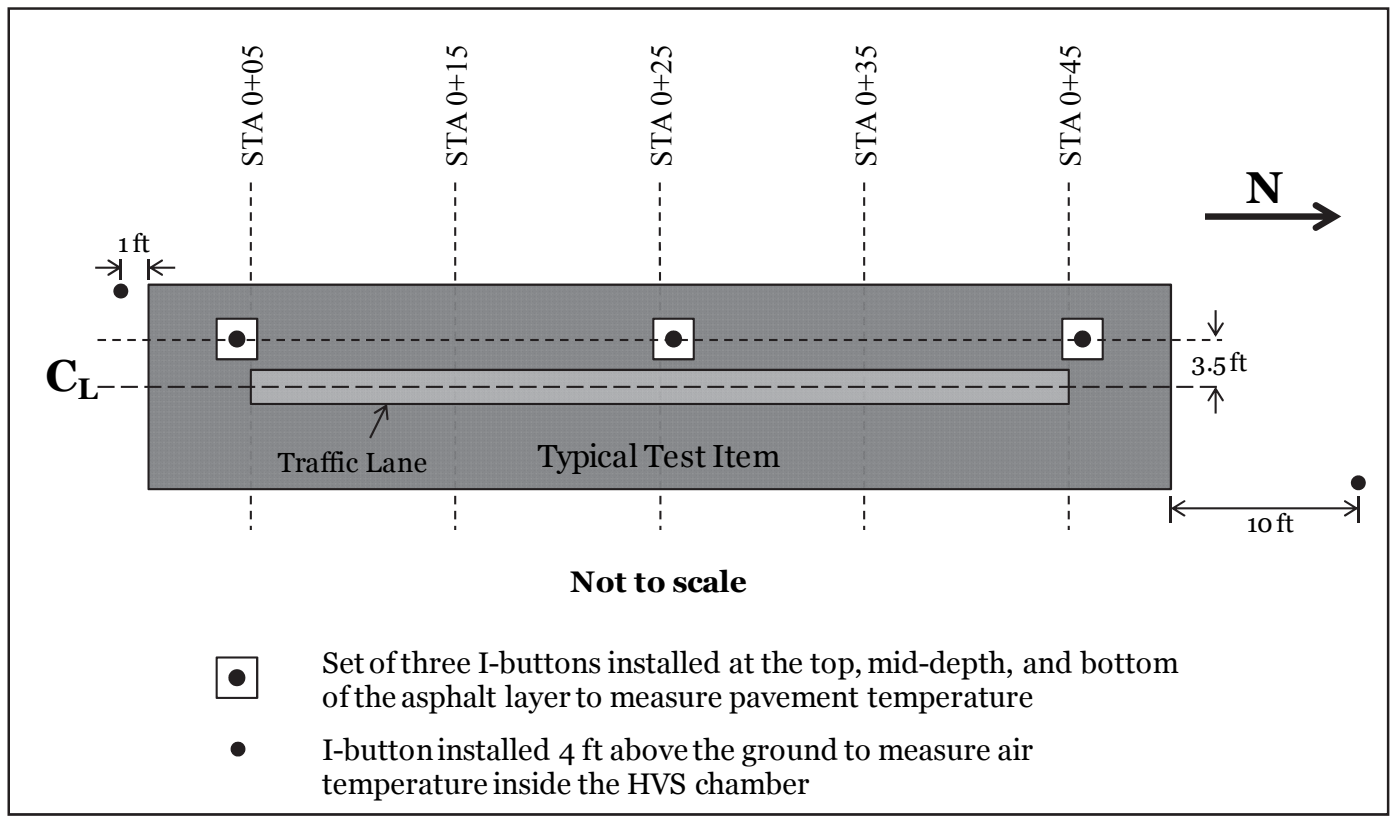

\subsection{Test conditions}

The main focus of this study was to evaluate failure of the asphalt layer to compare the field rutting performance of three different WMA technologies to conventional HMA. Therefore, a combination of worst-case loading conditions and high pavement temperature was applied to the flexible pavement under study to induce the failure in the asphalt layer.

Generally speaking, moderately loaded aircraft with high tire pressures and relatively small footprints (e.g., fighter aircraft) produce higher stresses near the top of a pavement structure, while heavily loaded aircraft with moderate tire pressures and relatively larger footprints (e.g., cargo aircraft) produce higher stresses in the lower layers of the structure. Hence, a high-tire-pressure aircraft is more likely to cause more damage as a result of shear stress in materials near the pavement surface. The F-15E military fighter jet aircraft was selected for accelerated traffic simulation in this study. This aircraft is considered the most damaging aircraft in the USAF inventory to pavement surfaces because of its small footprint and high tire pressure of 325-psi. This type of loading results in very high stresses near the pavement surface, producing an aggressively damaging effect on the asphalt layer.

For a given properly proportioned asphalt mixture and properly constructed pavement, temperature is arguably the most important factor contributing 
to rutting performance. The higher the temperature a flexible pavement is exposed to, the higher its propensity for rutting. Where testing temperature control is practical, using a single test temperature is efficient, as it greatly reduces testing time as well as the analytical efforts in the mixture evaluation process. The presence of a single test temperature at which asphalt mixtures can be evaluated has been termed effective temperature by Witczak (1992). Effective temperature has been defined as a single test temperature at which an amount of a given type of distress, within a given pavement system, would be equivalent to that which would occur from the seasonal temperature fluctuation throughout the annual temperature cycle (NCHRP 704, 2011). For this study, a test temperature of $109^{\circ} \mathrm{F}$ was selected as it is the Witczak effective test temperature for Jackson, Mississippi. 


\section{Full-Scale Simulated Traffic and Evaluation Procedures}

\subsection{Traffic operations}

Each test item was trafficked in a bi-directional, normally distributed traffic pattern using a heavy vehicle simulator (HVS-A model). The HVS-A is a fully automated machine that simulates accelerated aircraft traffic on pavement test sections while allowing control of the pavement temperature with an integrated climate control system (Figure 11).

Figure 11. Overview and inside view of the HVS-A.

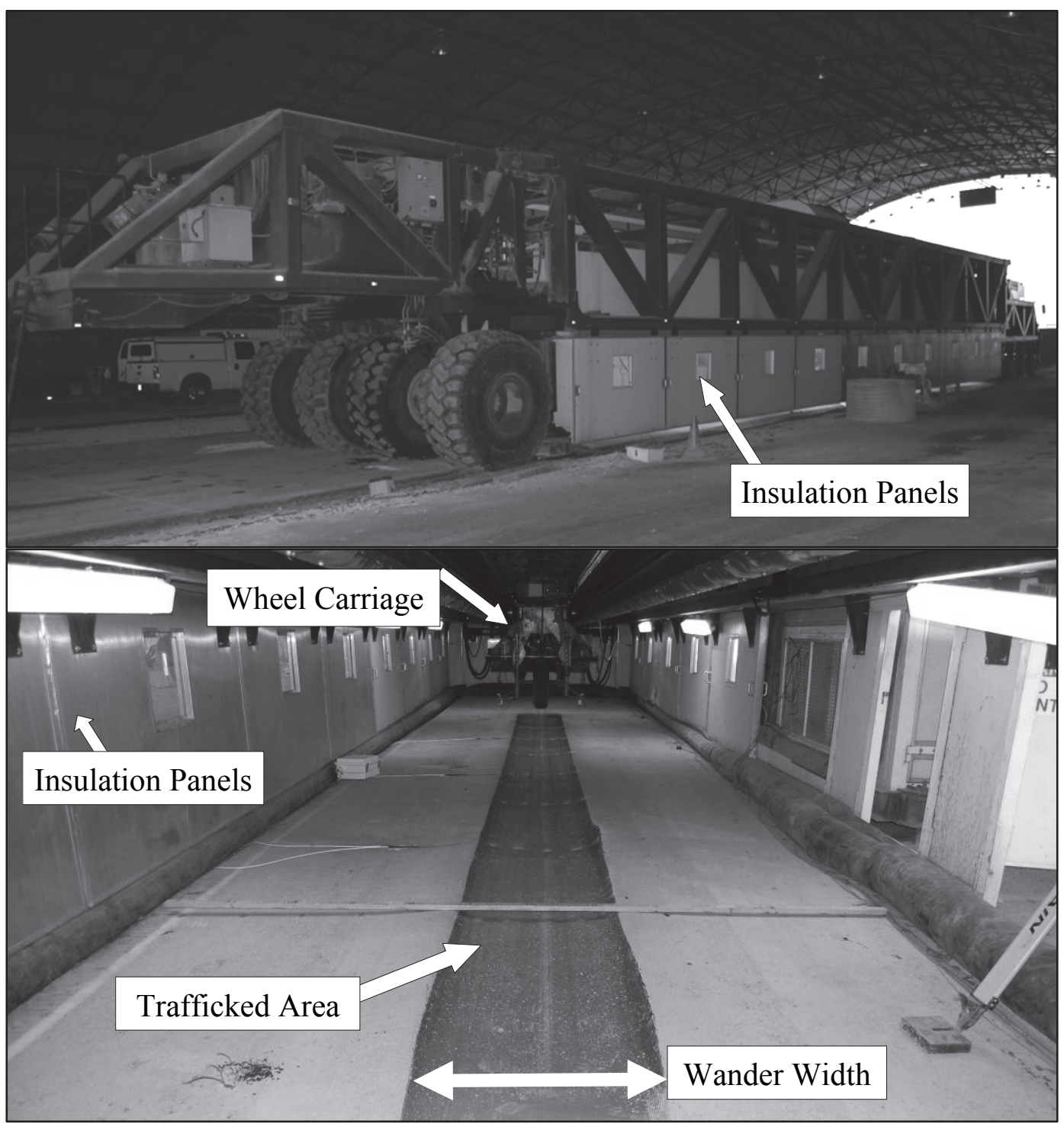


The wheel carriage travels forward and backward at a speed of approximately $5 \mathrm{mph}$ over a longitudinal distance of $40 \mathrm{ft}$. The HVS-A, one of only eight in the world, is the largest of its kind with the ability to traffic airfield pavements with high aircraft loads. All test items were trafficked with a single F-15E wheel loaded to approximately $35,500 \mathrm{lb}$ with 325 -psi tire pressure, which is within the normal range of loads that are expected in Air Force medium-load airfields. The wheel load for an F-15E at maximum take-off weight is $35,235 \mathrm{lb}$. Prior to testing, an externally calibrated aircraft scale was used to calibrate the hydraulically actuated wheel loading system of the HVS-A. During testing, the wheel load was monitored by the HVS-A's onboard control system. Prior to each day's testing, the tire inflation pressure was checked using a tire pressure gauge and adjusted if necessary. Figure 12 shows the loaded F-15E wheel.

Figure 12. Loaded F 15E wheel.

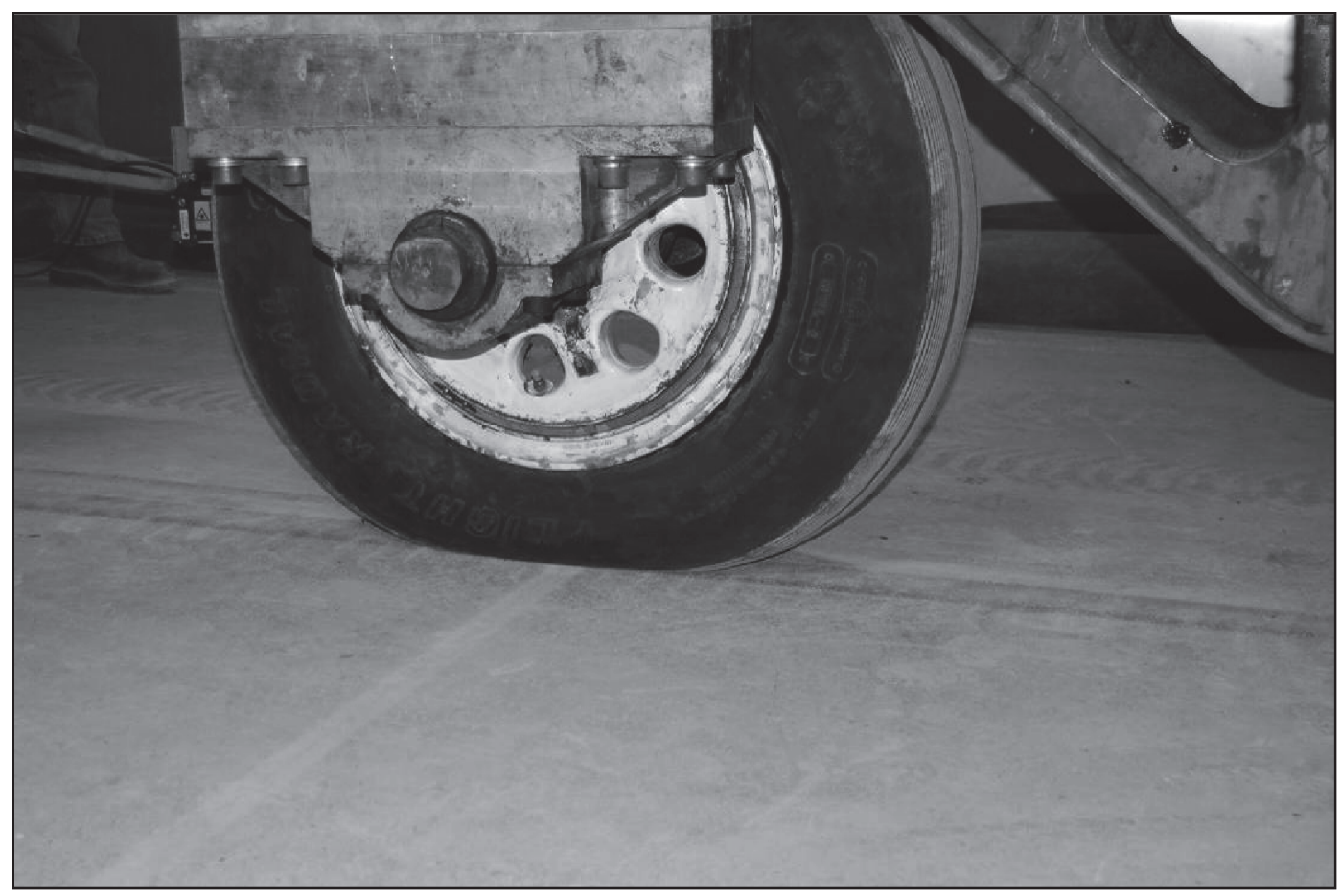

A pass is defined in this study as one movement of the aircraft wheel down the length of the test section, and a coverage is defined as one application of the aircraft wheel over every single point in the central portion of the traffic lane. A normally distributed traffic wander pattern was used for this testing by programming a defined pass pattern into the HVS-A control system. The lateral wander width for this traffic pattern was 32 in., as seen in Figure 11. Each complete traffic pattern consisted of 46 passes at which point the wheel carriage had returned to its original position. The 
minimum pass to coverage ratio for the $\mathrm{F}-15 \mathrm{E}$ traffic pattern used in this study was 2.6. Figure 13 shows the distribution of wheel loads used on the test section. The offset index represents 1 in. distance between the loaded wheel for each pass. Each bar represents the total number of passes applied over each offset distance after one full pattern was completed.

Figure 13. HVS-A traffic pattern used for the single wheel F-15E.

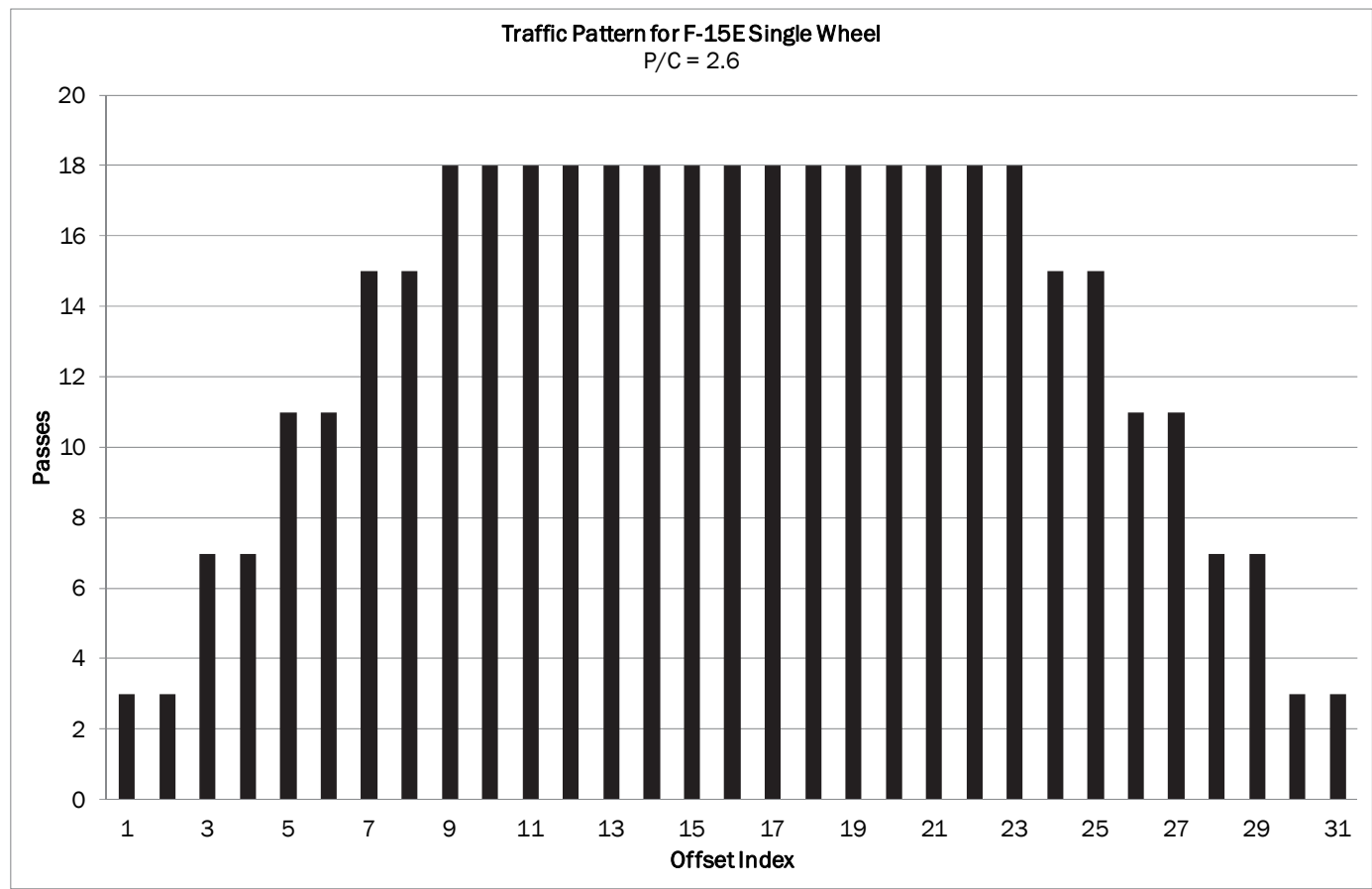

The configuration of the HVS-A only allowed for traffic over one test item at a time. Traffic operations started on November 15, 2012, and concluded on February 12, 2013. The test items were trafficked in the order listed in Table 4.

Table 4. Traffic operations sequence.

\begin{tabular}{|l|l|l|l|}
\hline Test Period & Test Item & $\begin{array}{l}\text { Traffic Application } \\
\text { Period (days) }\end{array}$ & $\begin{array}{l}\text { Total Passes } \\
\text { Applied }\end{array}$ \\
\hline $11 / 15 / 12-11 / 29 / 12$ & Item 4: Evotherm ${ }^{\text {TM }} 3 G$ & 9 & 2221 \\
\hline $12 / 10 / 12-12 / 27 / 12$ & Item 3: Sasobit ${ }^{\circledR}$ & 6 & 2590 \\
\hline $01 / 14 / 13-01 / 22 / 13$ & Item 2: Foamed Asphalt & 7 & 7012 \\
\hline $02 / 05 / 13-02 / 12 / 13$ & Item 1: HMA (control) & 6 & 3326 \\
\hline
\end{tabular}

For this study, permanent deformation was defined as change in elevation of the pavement surface relative to its initial position. Depth of the rut valley was considered, but uplift on the edges of the rutted areas was not. 
Uplift was measured as part of the survey process, but was not considered as part of the failure criterion for the purposes of this study. The DOD failure criterion for flexible pavements is typically based upon $1 \mathrm{in}$. of rutting. For this study the failure criterion was 1 in. of permanent deformation; however, to ensure that the failure criterion was exceeded, all four test items were trafficked until the average permanent deformation was approximately $1.2 \mathrm{in}$.

Testing was conducted under controlled temperatures to keep consistency in the evaluation and allow for reasonable comparisons. In some cases however, outside weather conditions changes affected the performance of the HVS-A heating system so that it was not able to maintain the desired temperature throughout the testing period. In winter, the inside temperature decreased as the outside temperature decreased. In addition, there was an internal temperature difference from one end to the other.

\subsection{Data collection}

The data collected at different traffic intervals included surface permanent deformation measurements at the centerline and cross sections using a robotic total station; surface profile measurements using the HVS laser profiler; rut depth measurements; pavement and air temperature measurements; pavement deflection measurements from falling weight deflectometer (FWD) tests; and instrumentation response measurements. All data were collected at the stations shown in Figure 14 for each data collection traffic interval.

Figure 14. Data collection layout for each test item.

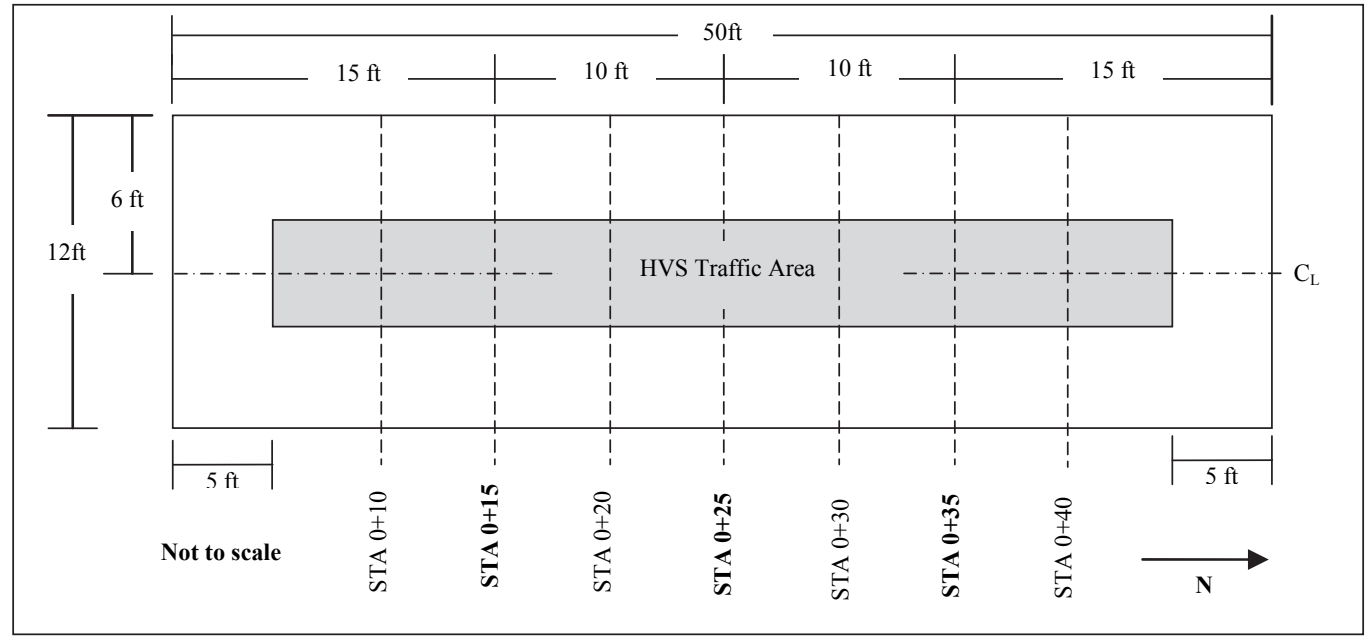


Instrumentation readings were collected to measure the pavement response under static and dynamic loading. Baseline total station data, laser profile data, and rut depths were collected prior to trafficking at ambient temperature (pre-heat). Baseline instrumentation response and FWD data were collected at room temperature and also after the pavement was heated to the desired test temperature (post-heat) for comparison. The pavement and air temperature were monitored continuously throughout the tests. Table 5 lists all the measurements collected.

Table 5. Data collection.

\begin{tabular}{|c|c|c|c|c|c|c|c|}
\hline \multirow[b]{2}{*}{ Traffic Interval } & \multirow[b]{2}{*}{$\begin{array}{l}\text { Total } \\
\text { Station }\end{array}$} & \multirow[b]{2}{*}{$\begin{array}{l}\text { Rut } \\
\text { Depth }\end{array}$} & \multirow[b]{2}{*}{$\begin{array}{l}\text { HVS } \\
\text { Profiler }\end{array}$} & \multirow[b]{2}{*}{ FWD } & \multicolumn{3}{|c|}{ Pavement Response (Instrumentation) } \\
\hline & & & & & $\begin{array}{l}\text { Static } \\
\text { Testa }\end{array}$ & $\begin{array}{l}\text { Dynamic } \\
\text { Slow Roll Testb }\end{array}$ & $\begin{array}{l}\text { Dynamic } \\
\text { Sweep Testc }\end{array}$ \\
\hline Pre-heat & $x$ & $x$ & $x$ & $x$ & $x$ & $x$ & \\
\hline Post-heat & & & & $x$ & $x$ & $x$ & \\
\hline During traffic & $x$ & $x$ & $x$ & & & $x$ & $x$ \\
\hline Post-traffic & $x$ & $x$ & $x$ & $x$ & $x$ & $x$ & \\
\hline
\end{tabular}

a Loaded wheel was dropped at the instruments locations and held for a few seconds.

b Loaded wheel was rolled twice over the centerline at $5 \mathrm{mph}$ at each traffic interval.

$\mathrm{b}$ Instrumentation data were recorded during the first 23 passes (1 sweep) of each traffic interval.

\subsubsection{Temperature monitoring}

I-buttons were set up to start collecting data before heat was to be applied to the pavement. Temperatures were recorded continuously to measure the full temperature range to which the pavement was subjected during the testing period. Data were downloaded periodically from all three Ibuttons at each location to monitor the temperatures until the heat was ceased and testing was completed. Prior to the application of traffic, data were downloaded to ensure the high temperature condition was consistent throughout the asphalt pavement layer before the application of any traffic. During traffic, data were downloaded to monitor any changes in the pavement temperature. After traffic, the full set of data was downloaded for further analysis.

\subsubsection{Centerline and cross-section profiles}

Centerline and cross-section profiles were collected with a robotic total station (Figure 15) to aid in the measurement of the surface elevation changes after selected passes of the single wheel F-15E load cart. Measurements on the centerline were collected at $1-\mathrm{ft}$ intervals, while the crosssection profile measurements were collected at the intervals shown in Figure 16. 
Figure 15. Cross-section readings with robotic total station.

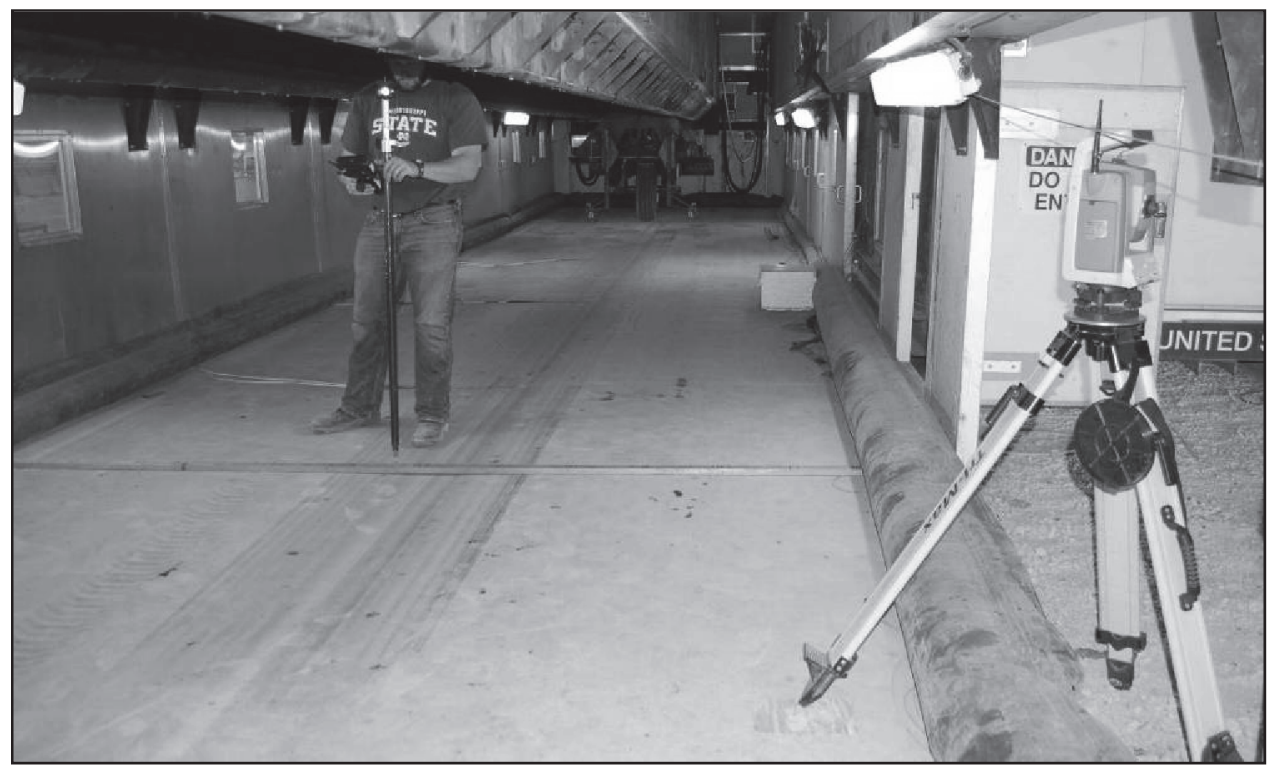

Figure 16. Data collection points for each cross section.

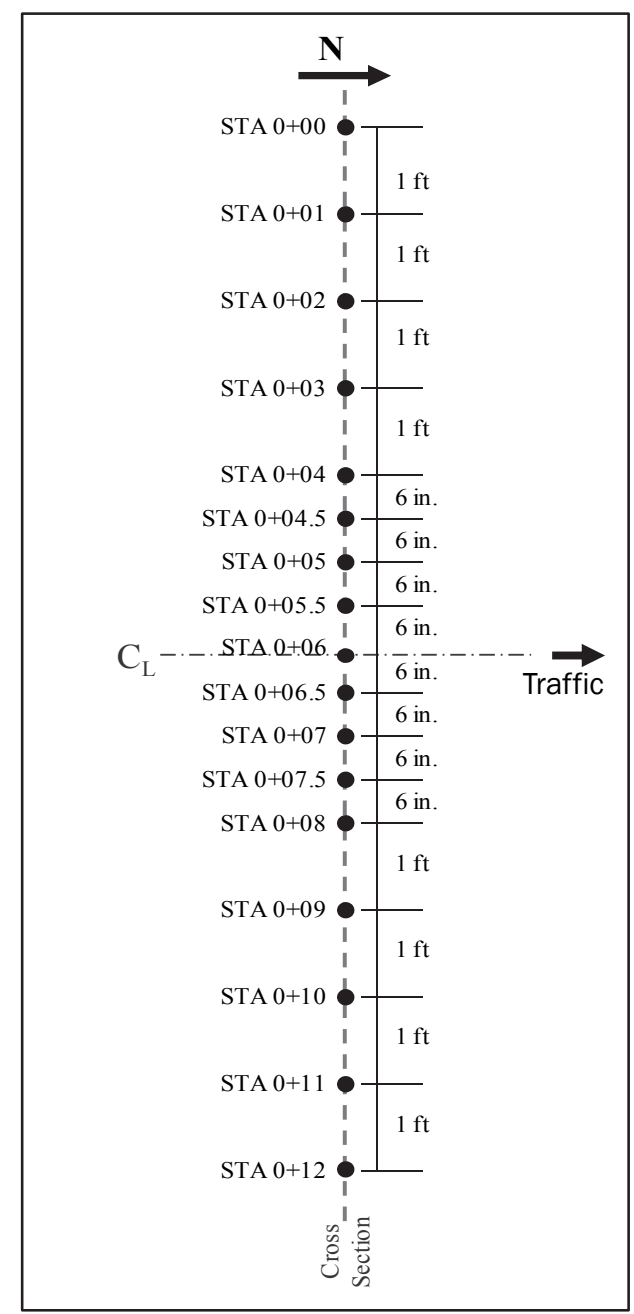


The resulting surface profiles were used to establish the permanent surface deformation of the centerline and across all stations (10, 15, 20, 25, 30, 35, and 40) as trafficking progressed. Rut depth measurements were also collected across all stations $(10,15,20,25,30,35$, and 40) at the center point, $1 \mathrm{ft}$ west of the center point, and $1 \mathrm{ft}$ east of the center point as a quick measure of the rutting performance at each pass level. Surface scans were also performed using the total station to map the entire test area surface of each test item before and after trafficking. These data were collected as a backup and are not presented in this report.

\subsubsection{Falling weight deflectometer (FWD)}

The FWD is a nondestructive, impact load device that applies a singleimpulse transient load of approximately 25- to 30-msec duration. With this trailer-mounted device, a dynamic force is applied to the pavement surface by dropping a weight onto a set of rubber cushions. This results in an impulse loading on an underlying 11.8-in.-diameter circular plate in contact with the pavement. The applied force and the pavement deflections are measured with load cells and velocity transducers, respectively. The drop height of the weights can be varied from 0 to $15.7 \mathrm{in}$. to produce a force from 1,500 to $27,000 \mathrm{lb}$. The system is controlled with a laptop computer that also records the output data. Deflections were recorded at the center of the load plate (D1) and at offset distances of 12, 24, 36, 48, 60, and 72 in. (D2 through D7) from the center of the load plate. Pavement deflection measurements were recorded at force levels of approximately 25,000 lb.

The FWD is normally trailer-mounted on a vehicle; however, for this project, the FWD was manually moved under the HVS-A and the pavement was tested at Stations 10, 15, 20, 25, 30, 35, and 40 before trafficking at both ambient and at high temperature conditions, and later after trafficking at the high temperature condition. Figure 17 shows FWD testing on Item 4.

\subsubsection{Instrumentation response}

The instrumentation data were collected under dynamic loading over the center of each gauge or stack of gauges. The loaded F-15E wheel was slowly rolled down and back over the centerline, which is where all the instrumentation gauges were located at each station. This test was called the dynamic slow roll test. At the start of all traffic intervals, the instrumentation data were recorded for 23 passes (1 sweep pattern) to show the response as the wheel moved toward and away from each gauge. This test was called the dynamic sweep test. 
Figure 17. FWD testing on Item 4.

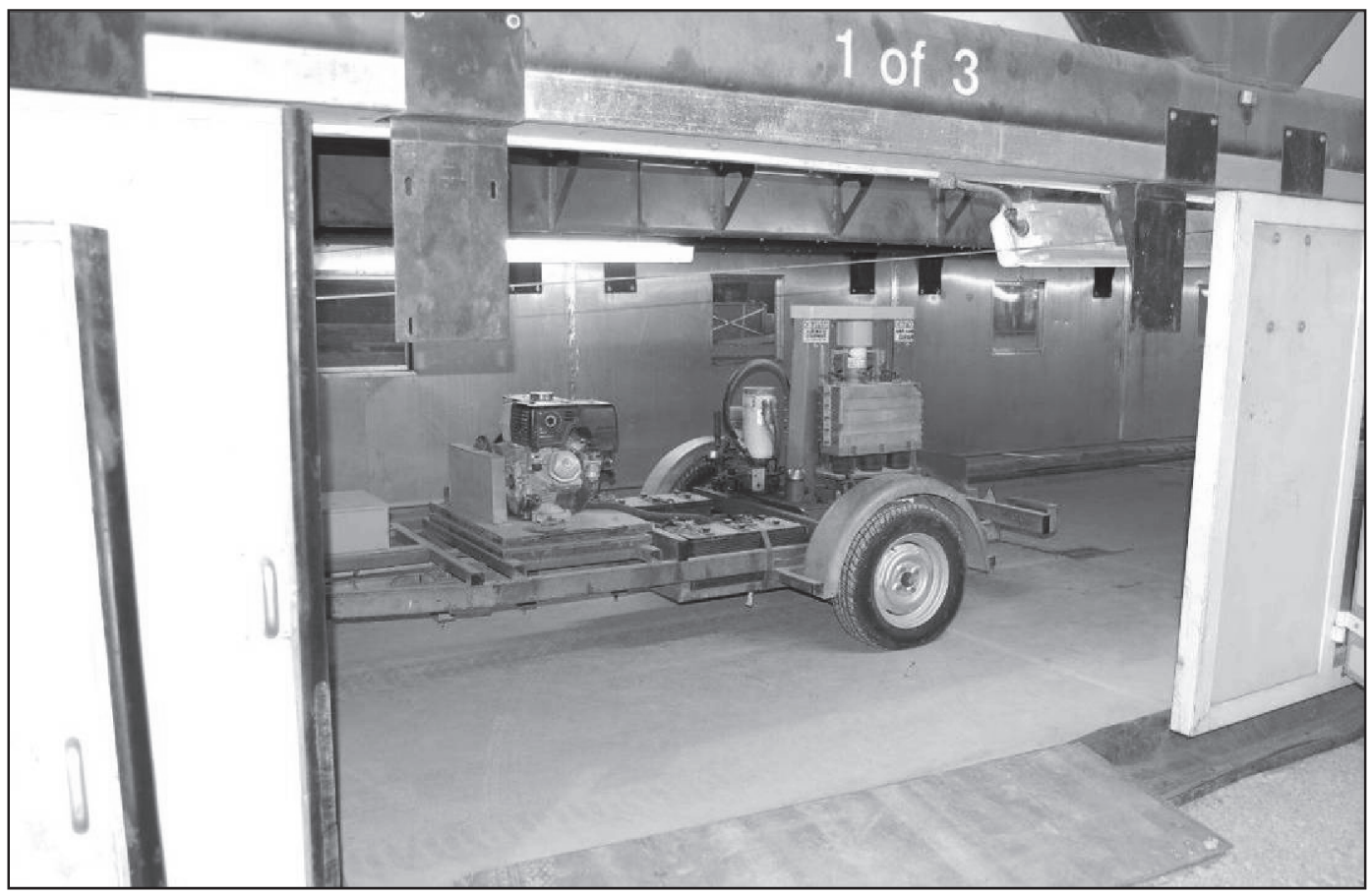

\subsection{Forensic investigation}

After trafficking of the test section was complete, 3 -ft-wide by approximately 3 -ft-deep trenches were excavated on each test item as indicated in Figure 18. These locations were selected to avoid trenching over the instrumentation and to get a good assessment of the pavement failure. The trenches on the north end of the test items were used to assess the areas with the least rutting measured, and the trenches on the south end were used to assess the areas with the deepest rutting measured.

All four test items were trenched 6 months after trafficking was completed. Each layer of the pavement structure was removed individually and assessed at the center of the rut and outside the traffic lane. CBR tests, nuclear density and moisture measurements, and oven moisture tests were completed at each location on each foundation layer. Furthermore, visual inspection and manual profile measurements were performed to aid in determining where failure occurred. 
Figure 18. Trenching Layout.

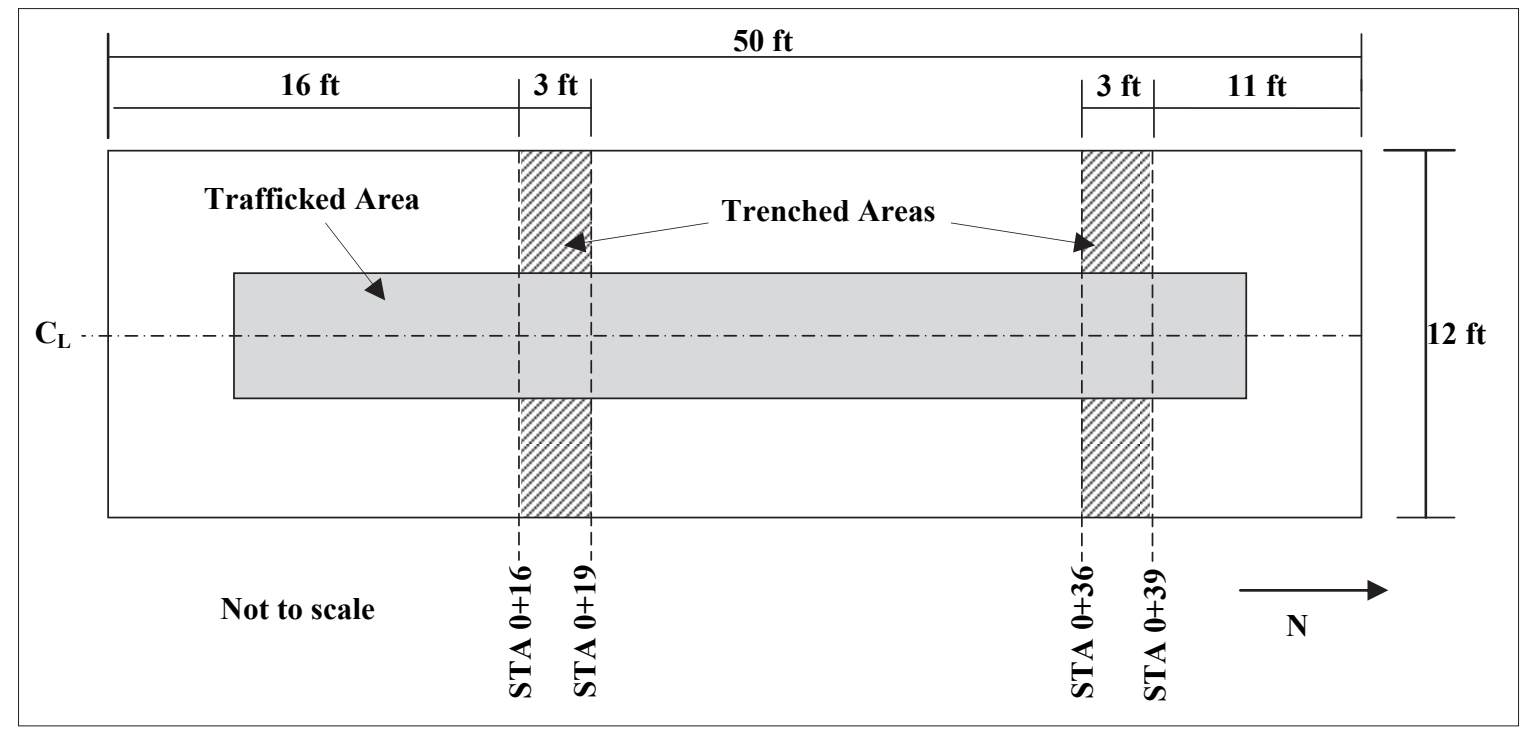




\section{Pavement Performance Results}

\subsection{Temperature measurements}

The raw temperature data collected during the traffic tests on each test item are available in Appendix A. Average pavement temperatures were determined for the three locations where the I-buttons were installed: south (STA $\mathrm{O}+05$ ), center (STA O+25), and north (STA O+45). These average temperatures were calculated using only the data that were collected when traffic was applied to the pavement. Figure 19 presents the average temperatures at the three locations as measured at the top, mid-depth, and bottom of the asphalt layer on each test item. Average air temperatures measured at the north and south ends of the test items are also included in the figures for comparison.

Figure 19. Average pavement temperatures as measured at the top, middle, and bottom of the asphalt layer during traffic.
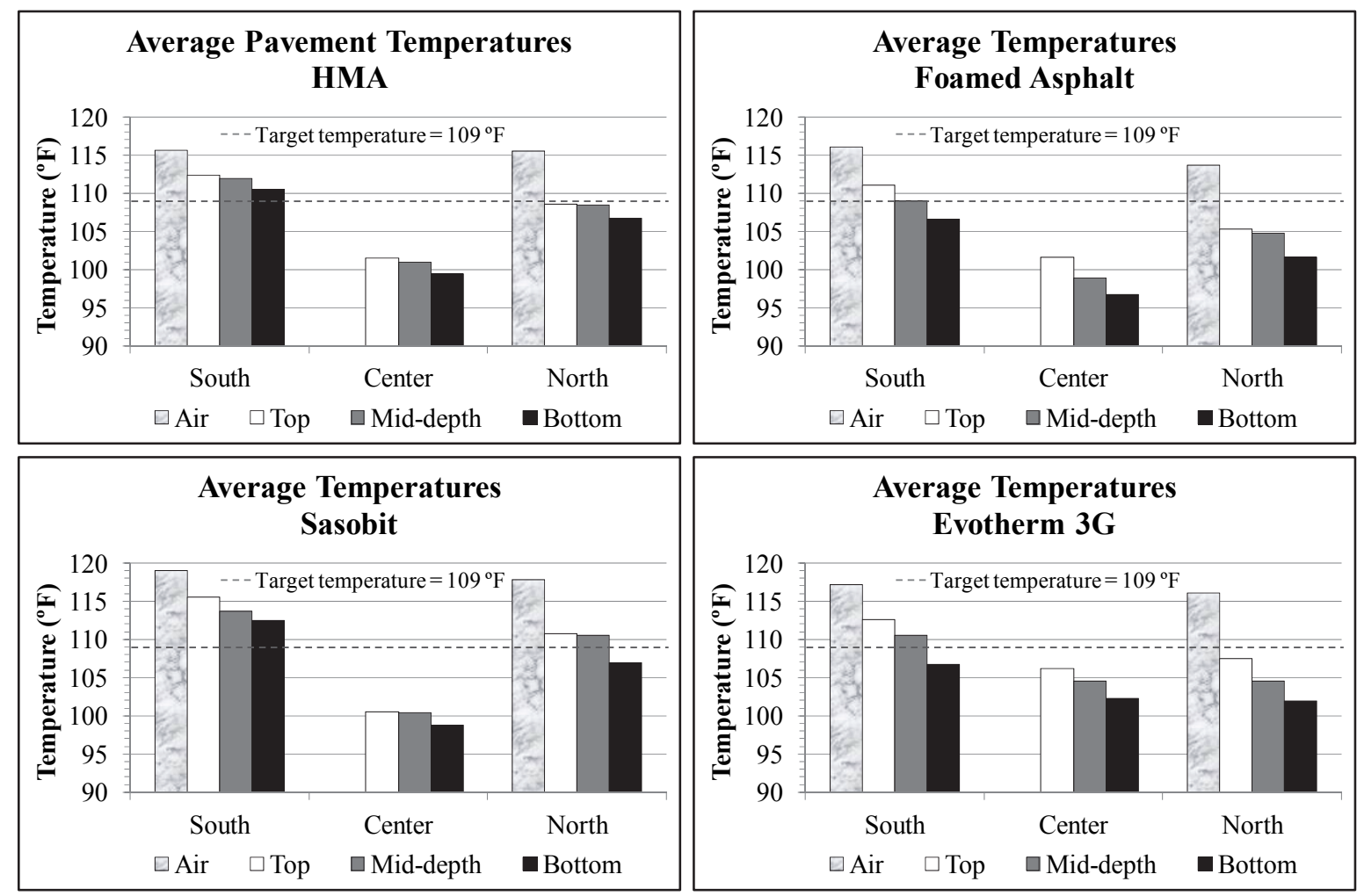
The target pavement temperature for this study was $109^{\circ} \mathrm{F}$, and it is indicated by a dashed line in the plots in Figure 19. An almost linear temperature gradient was observed in most cases, going from a higher temperature at the top of the asphalt layer to a lower temperature at the bottom. In some cases, the top and mid-depth temperatures were very similar. This was due to installation errors (i.e. I-buttons were installed at the same depth). The inside air temperature varied slightly from the north end to the south (the biggest difference was $3^{\circ} \mathrm{F}$ in Foamed Asphalt). This slight discrepancy was reflected in an average difference in pavement temperatures between the north and south ends of $5{ }^{\circ} \mathrm{F}$.

The temperatures at the top, mid-depth, and bottom of the asphalt were combined to determine the average pavement temperature at each location. These average temperatures were compared to the temperatures that were measured at mid-depth of the asphalt layer, and they were very similar in most cases. The average pavement temperatures for the south, center, and north areas of the four test items are presented in Figure 20.

Figure 20. Average pavement temperatures during traffic in three regions on each test item.

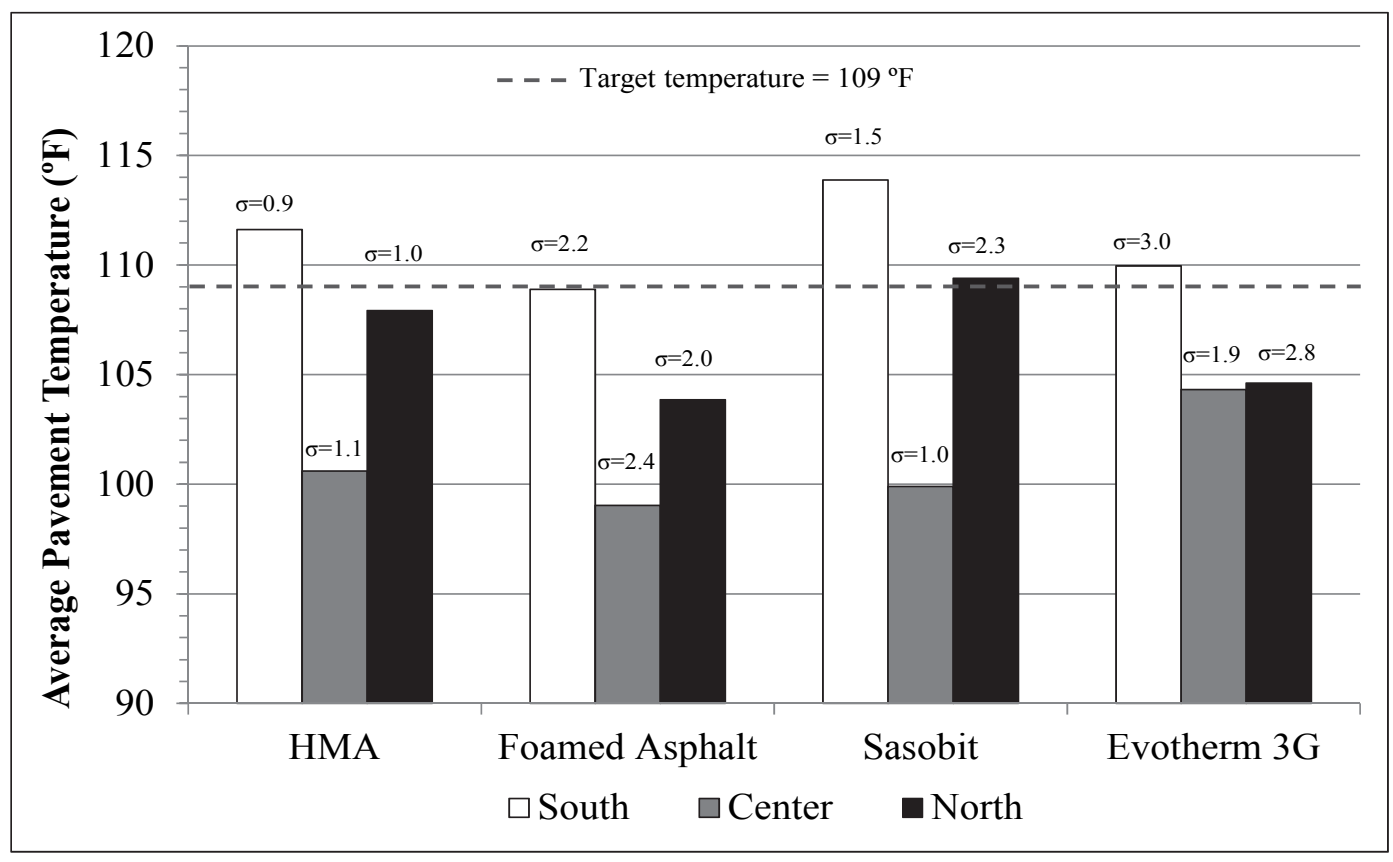

The temperature variation within each test item can be observed in Figure 20. Generally, the temperature variations were caused by the locations of the I-buttons in relationship to the heat vents and the efficiency of the heating system which caused a difference in the airflow between vents. Table 6 and Figure 21 show the locations of the I-buttons and their layout in relation to the vents. 
Table 6. I-buttons specific locations on each test item.

\begin{tabular}{|c|c|c|c|}
\hline Test Item & South I-Buttons & Center I-Buttons & North I-Buttons \\
\hline HMA & STA 0+3.5 & STA 0+27 & STA $0+46$ \\
\hline Foamed & STA 0+3.5 & STA 0+27 & STA $0+47$ \\
\hline Sasobit $₫$ & STA 0+5 & STA 0+26 & STA $0+44$ \\
\hline Evotherm ${ }^{\mathrm{TM}} 3 \mathrm{G}$ & STA $0+5$ & STA $0+24$ & STA $0+45$ \\
\hline
\end{tabular}

Figure 21. I-button layout in reference to the HVS heating system layout

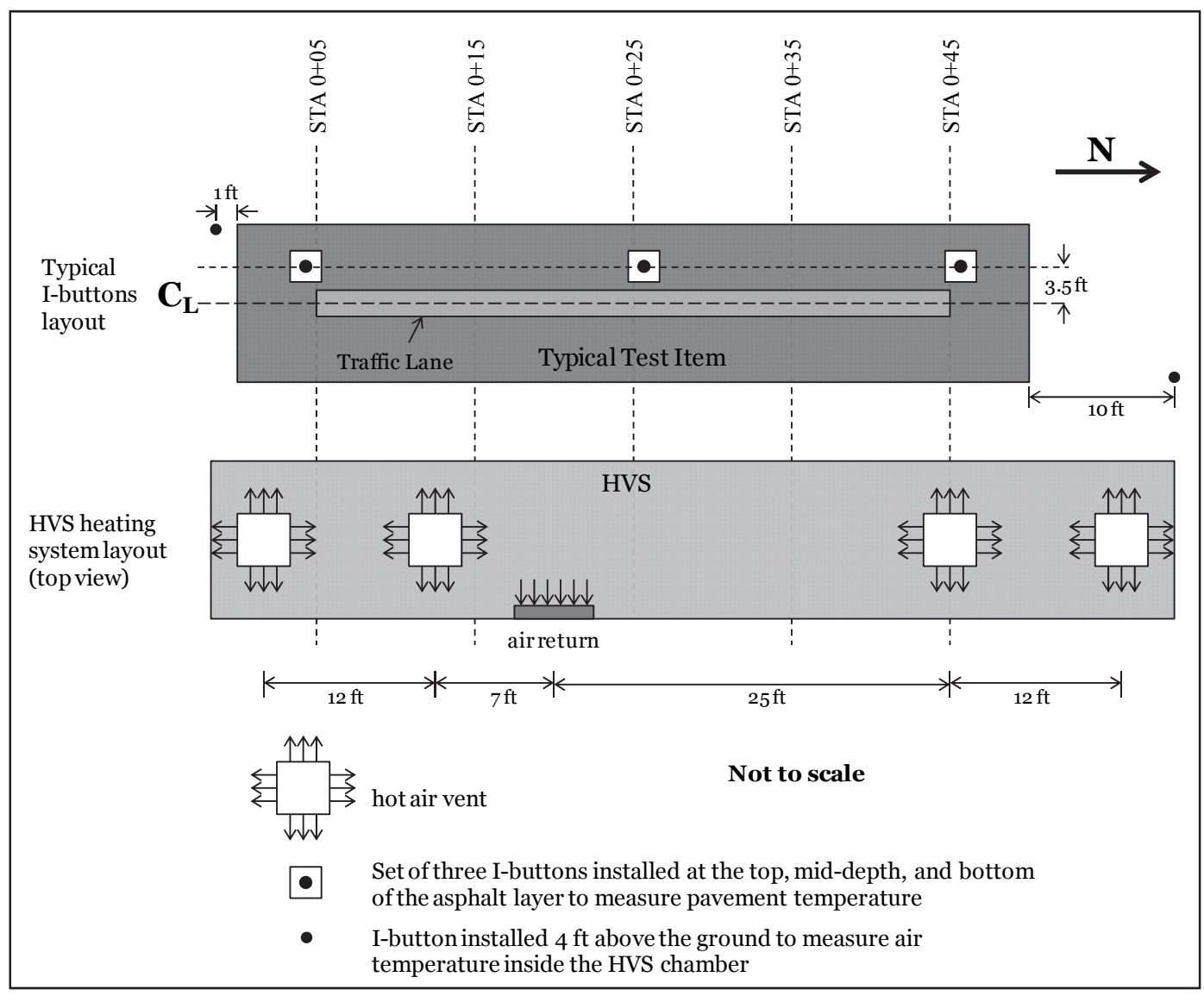

An infrared camera was used to capture the surface temperature variation, and examples of pictures of the four test items are shown in Figure 22. These pictures were taken from the south end of the test items. The temperatures at the north, center, and south areas of the items are represented by the three pointers shown. From these pictures, it is evident that the pavement temperature varied throughout the test area for all items. The average temperature difference between the south and center areas was $10^{\circ} \mathrm{F}$, between the center and north areas was $5{ }^{\circ} \mathrm{F}$, and $5{ }^{\circ} \mathrm{F}$ between the south and north areas. There were multiple variables that could have caused this temperature variation, including outside weather conditions, loss of 
heat through gaps between panels in the HVS chamber, and poor consistency of air distribution by the HVS heating system. Another reason could have been the pavement's ability to absorb heat, but it is difficult to determine which pavement absorbed more heat due to these other variables. Certainly, having different pavement temperatures affected the rutting performance of the test items as is discussed later in this report.

Figure 22. Typical surface temperatures as measured with infrared camera during testing.
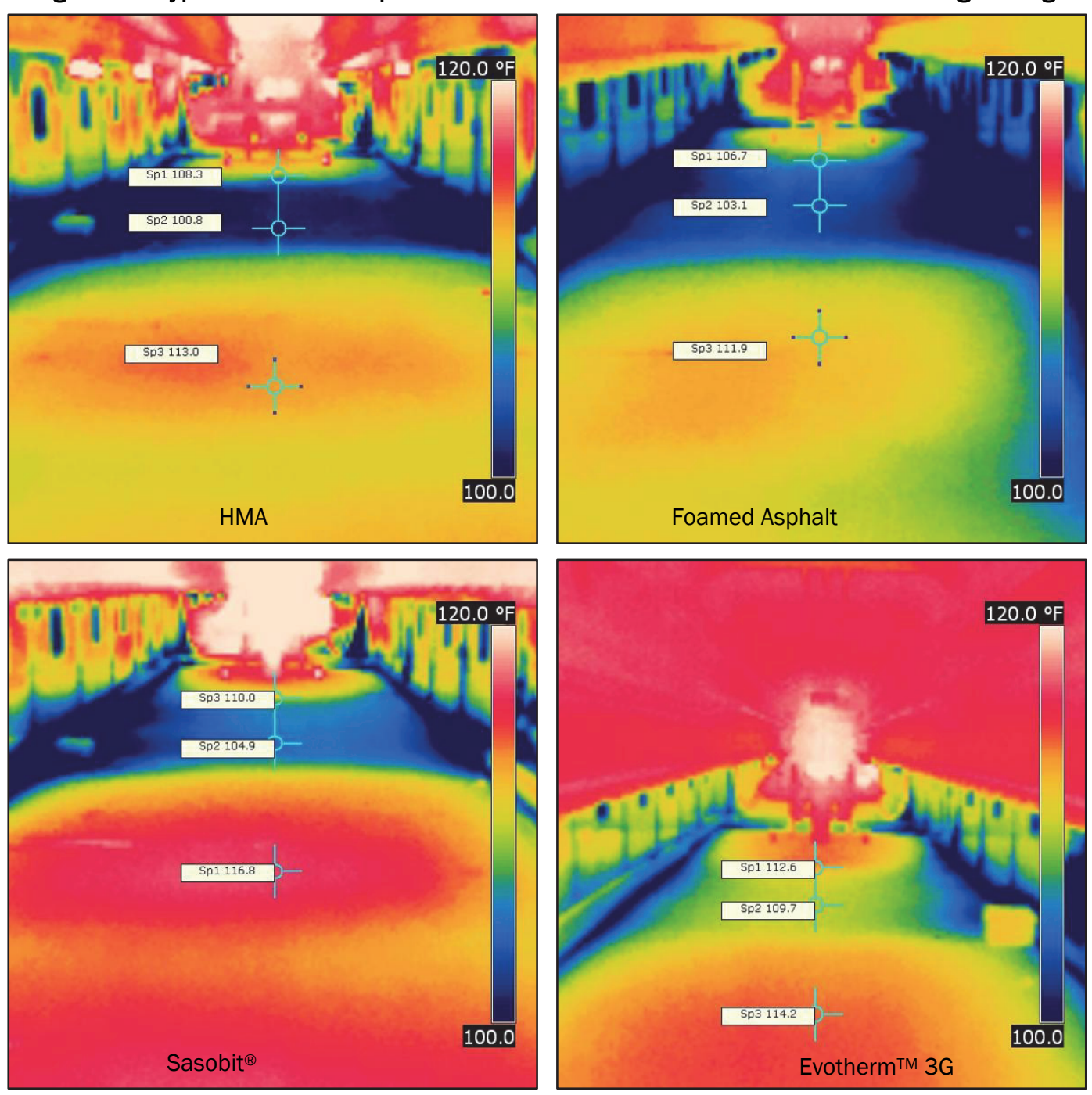

The average pavement temperature was calculated for each test item and plotted in Figure 23. In average, all test items were tested at temperatures lower than the target temperature of $109^{\circ} \mathrm{F}$. The largest temperature difference $\left(4^{\circ} \mathrm{F}\right)$ was between Sasobit $\AA$ and Foamed Asphalt. As shown in Figure 24, Foamed Asphalt was tested during the coolest period of the winter (average outside air temperature $44^{\circ} \mathrm{F}$ ), and the HVS-A heating 
system had trouble maintaining the test temperature inside the chamber, while the outside conditions were cold. As the chamber was opened to collect data after each traffic interval, the pavement also experienced heat loss and the pavement temperature decreased. Not enough time was provided between traffic intervals for the pavement to recover the heat lost and reach the test temperature. This caused the pavement temperature to stay lower than the test temperature of the other items.

Figure 23. Average pavement test temperatures of each test item.

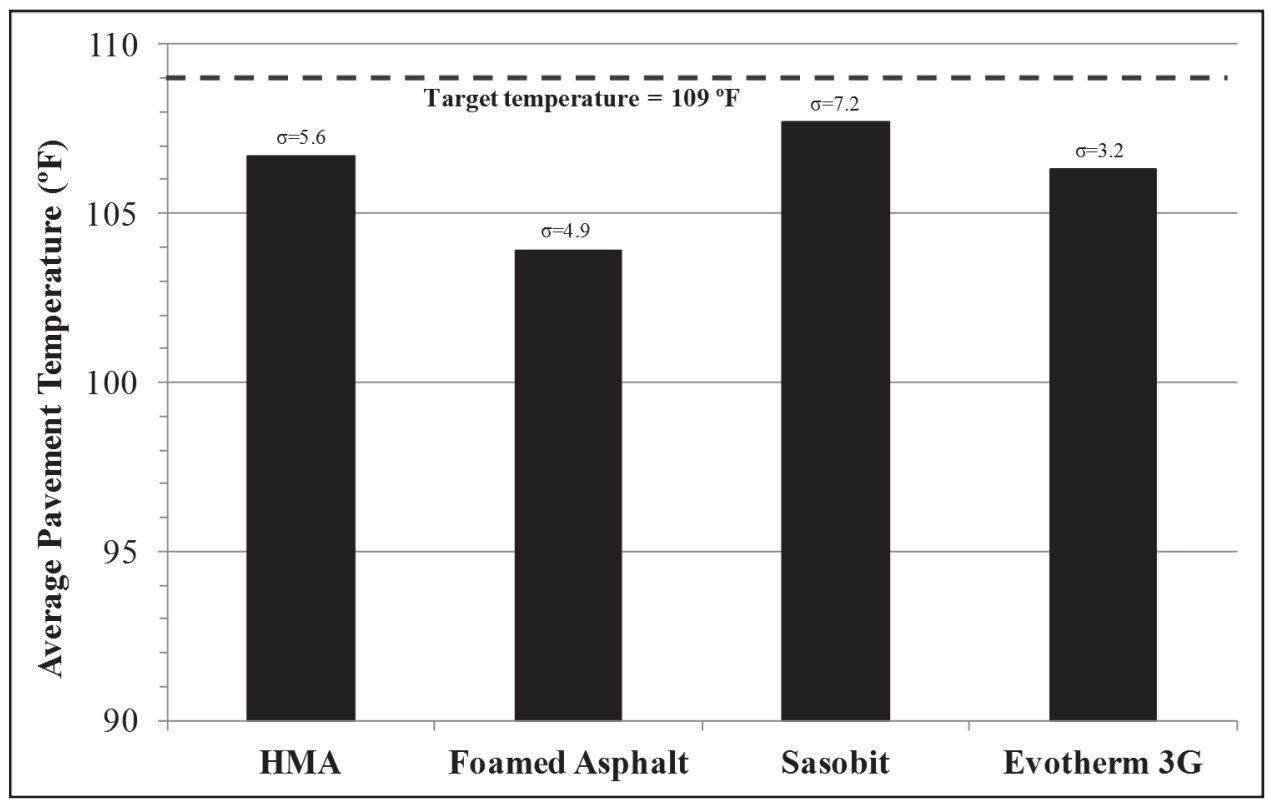

Figure 24. Average inside and outside air temperatures during traffic on each test item.

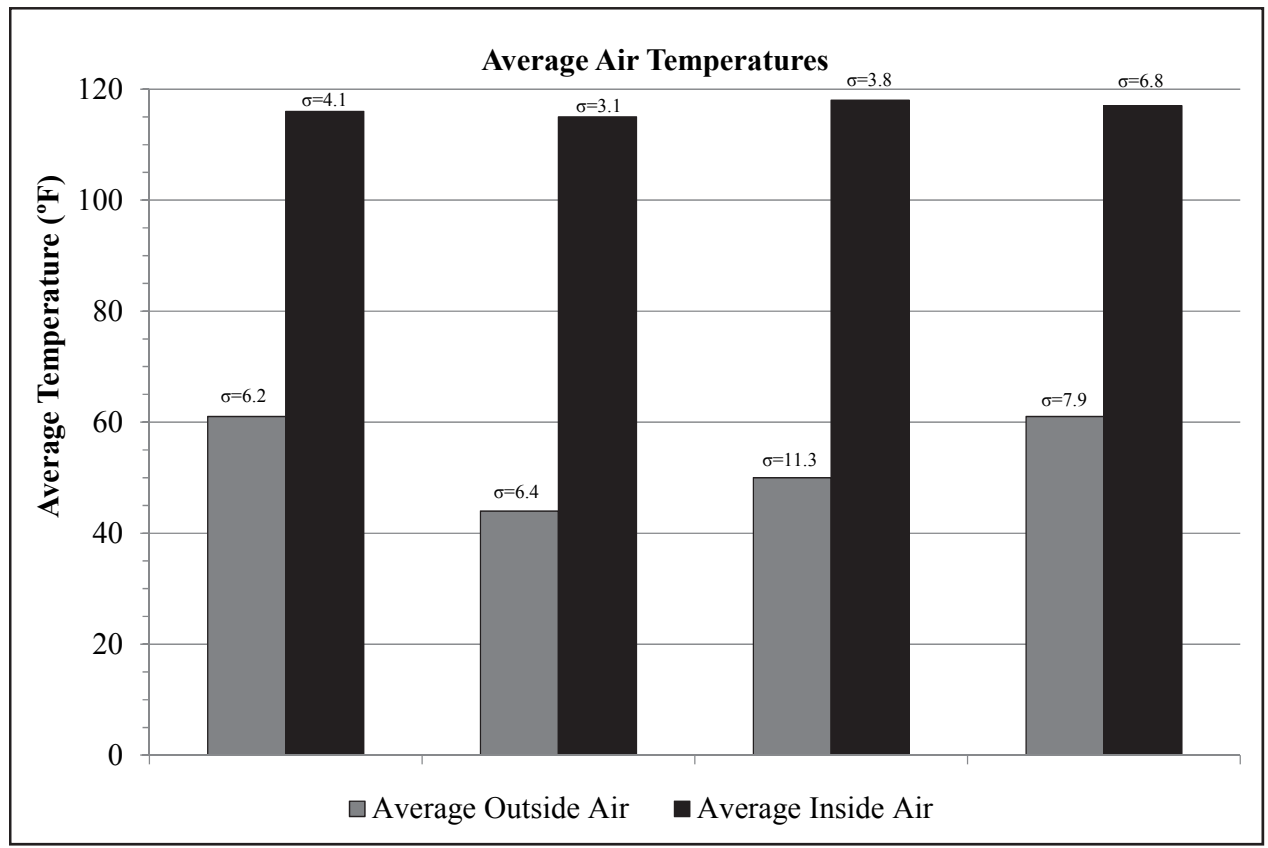




\subsection{Surface distresses}

Generally, rutting and cracks were the surface distresses observed in all four test items. Rutting is a load-related distress caused by an accumulation of vertical compressions (Collop, 1995). The presence of rutting indicates that a permanent deformation occurred in one or more of the layers of the pavement structure. This deformation occurs as a result of densification, shear movement or a combination of both. Figure 25 shows the rutting on the HMA after 3,326 passes. This rutting profile was typical in all four items. All items experienced pavement upheaval along the sides of the rut and at the ends of the traffic lane. Figure 26 shows the pavement upheaval at STA $0+15$ of the Foamed Asphalt item. Upheaval typically indicates that there is shear movement, or an outward and upward movement of material, somewhere within the pavement structure. The pavement uplifts at the ends of the traffic lane were generated as the wheel stopped to change directions during traffic. A depression was observed at STA $0+30$ in all four items after the first few passes of the F-15E wheel. This distress was attributed to the presence of a SDD, which was installed on top of the base course at that station. Insufficient compaction during gauge installation combined with the high stresses caused by the oversized plate of the SDD under loading could have caused the early base failure at that location. As shown in Figure 27, the absence of pavement uplift along the sides of the rut at that location indicated that failure was taking place in the sub-layers and not in the asphalt layer. Surface cracks were also observed at this location in all items as shown in Figure 28. Surface cracks were also observed around the SSGs in all four test items as shown in Figure 29. The cracks were observed on the surface of the rapid set epoxy that was used to install the gauges.

Figure 25. HMA rutting after 3,326 passes.

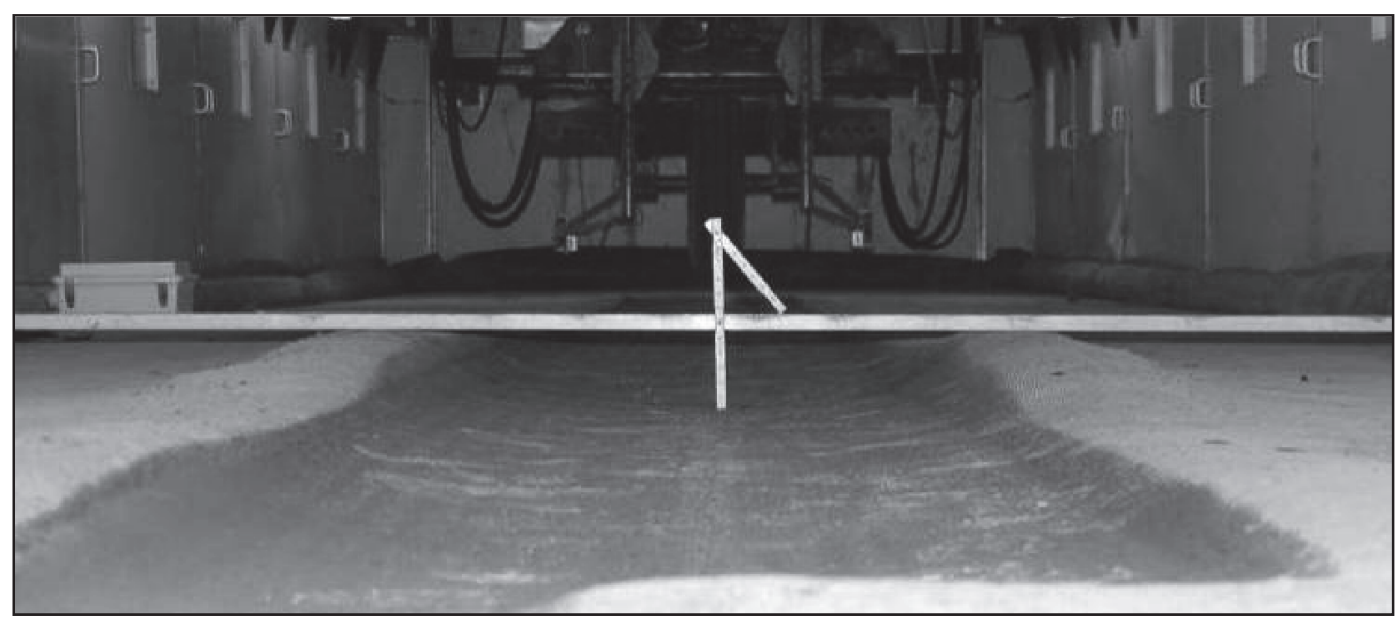


Figure 26. Foamed Asphalt upheaval west side of the rut (@ STA 0+15) after 5,906 passes.

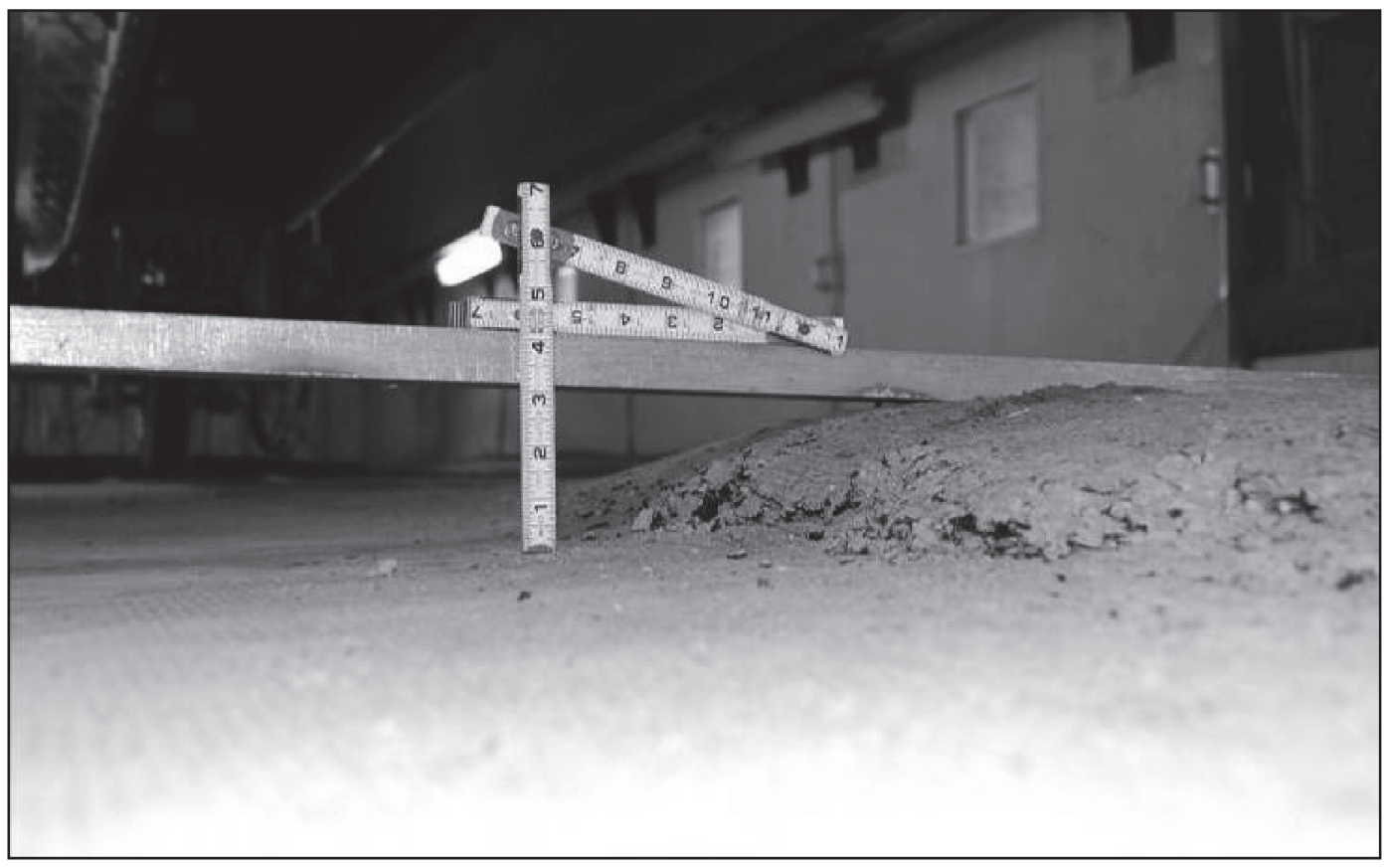

Figure 27. Evotherm ${ }^{\text {TM }} 3 G$ rutting at STA $0+30$ due to localized base failure after 741 passes.

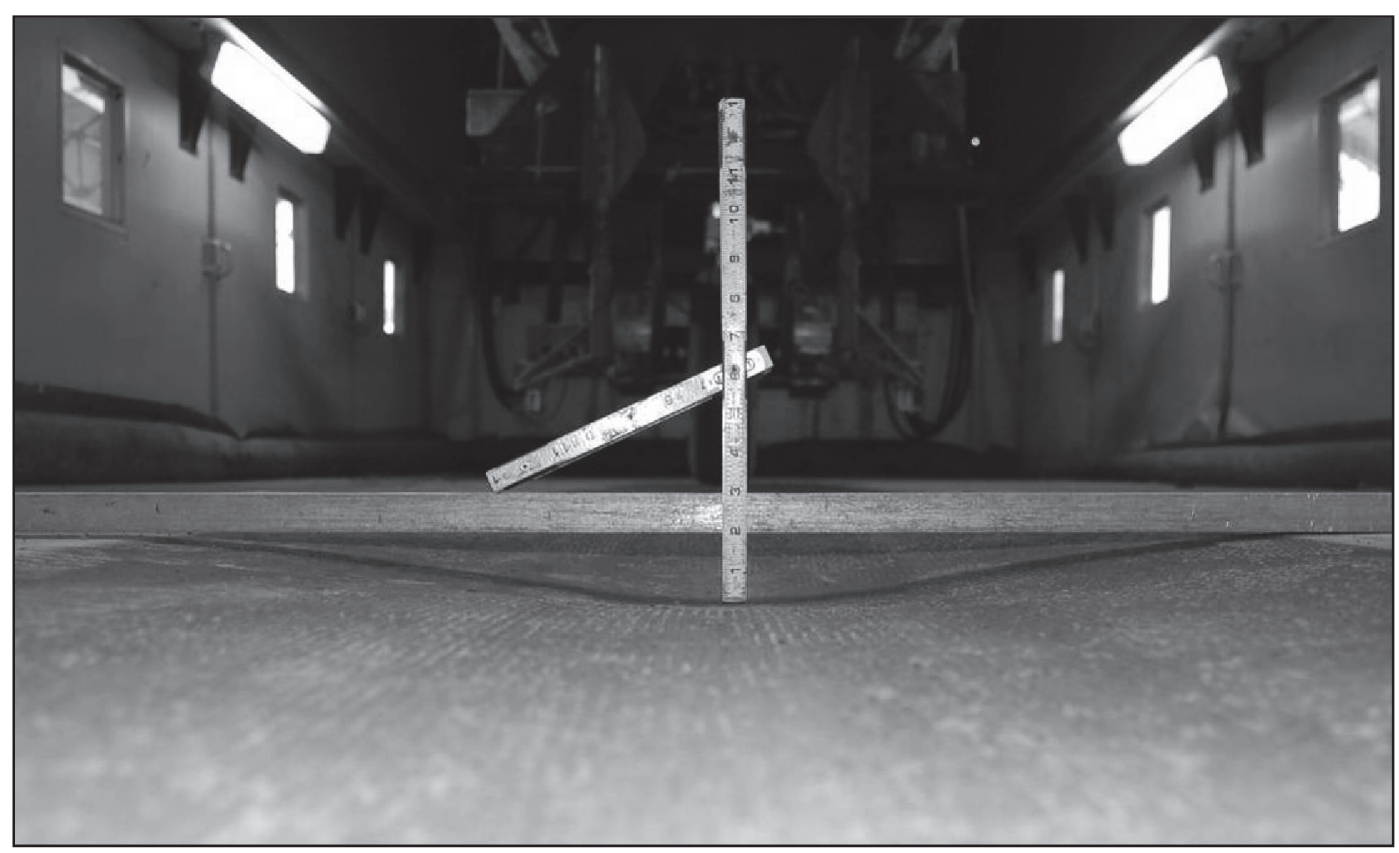


Figure 28. Typical cracks in asphalt surface at STA $0+30$.

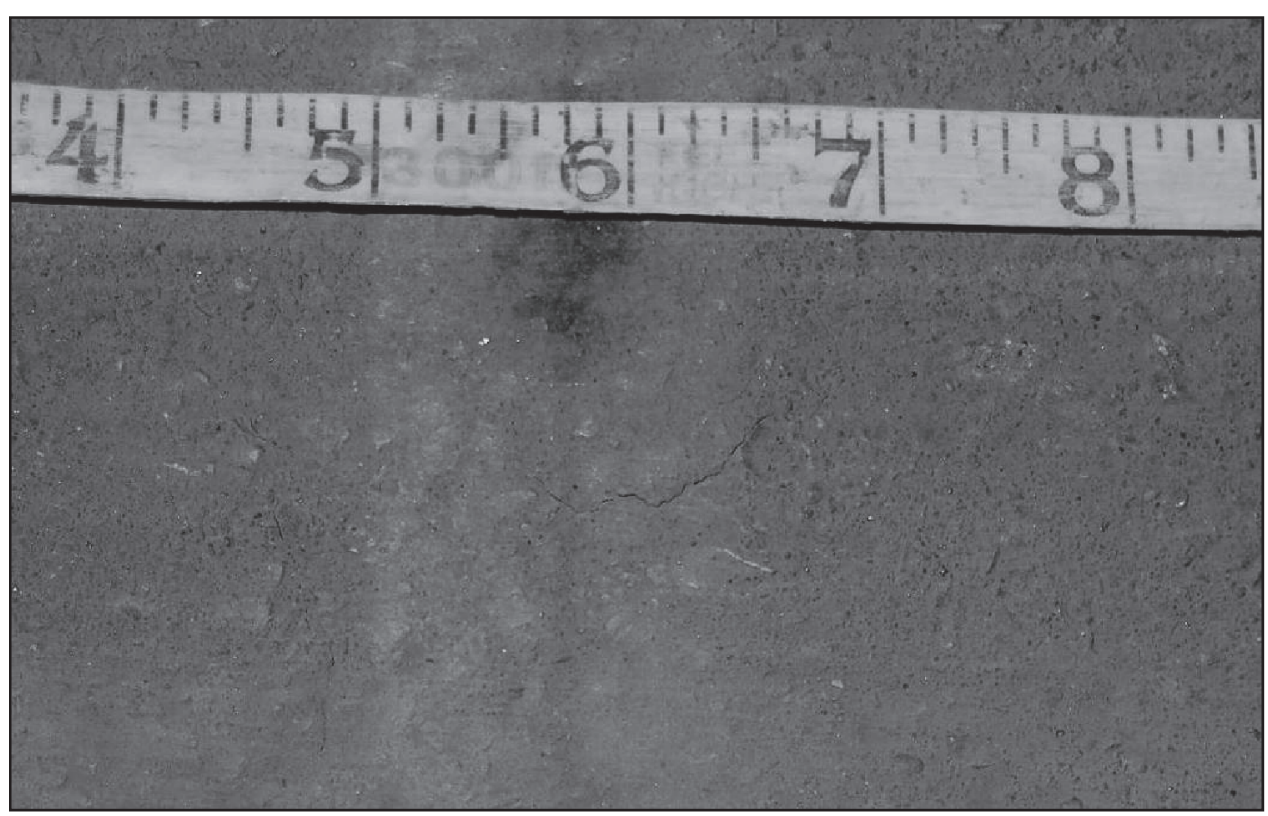

Figure 29. Typical cracks in asphalt surface at strain gauge location.

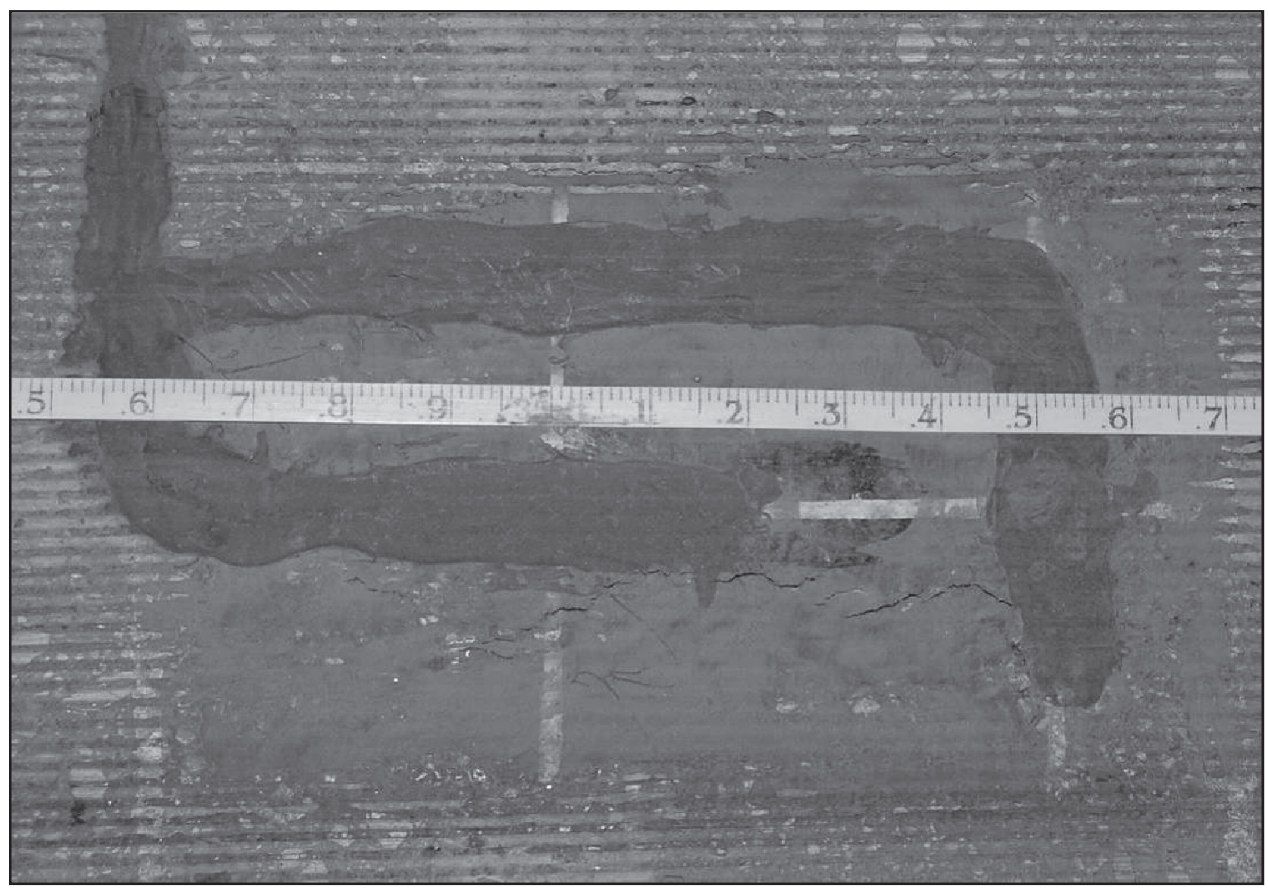

\subsection{Permanent deformation}

Figures 30-33 present the permanent deformation centerline profiles for all four test items. The data were normalized to zero starting at o passes. The failure criterion of $1 \mathrm{in}$. permanent deformation is marked with a horizontal dashed line. The average pavement temperatures are presented in a 
secondary axis for reference. Greater permanent deformations were observed at the stations where instrumentation was located. Also, in all four items, a difference in permanent deformation between the south and north ends of the traffic lane was observed. The area between stations $0+10$ and $\mathrm{O}+20$ had greater permanent deformation than the rest of the traffic lane in most of the test items. Specifically, STA $0+15$ had the greatest permanent deformation in all four test items, and it was attributed to the greater amount of heat that was coming out from the vent that was located close to that location, as it was discussed in the first section of this chapter. As traffic progressed, the heated pavement at that location deformed more quickly than the rest of the traffic lane, with the exception of STA o+30. At STA $\mathrm{O}+3 \mathrm{O}$, the pavement experienced large deformations in all four test items but, as discussed in the previous section, this failure was attributed to inadequate compaction of the base material during instrumentation installation. Therefore, the data from this station were treated as outliers and were not used in the calculation of average deformations. Other areas where excessive deformations were observed include the areas near STA $\mathrm{O}+05$ and STA $0+45$. These were the areas where the wheel stopped to change directions during traffic. These areas were also treated as outliers.

Figure 30. HMA centerline profiles and average pavement temperature.

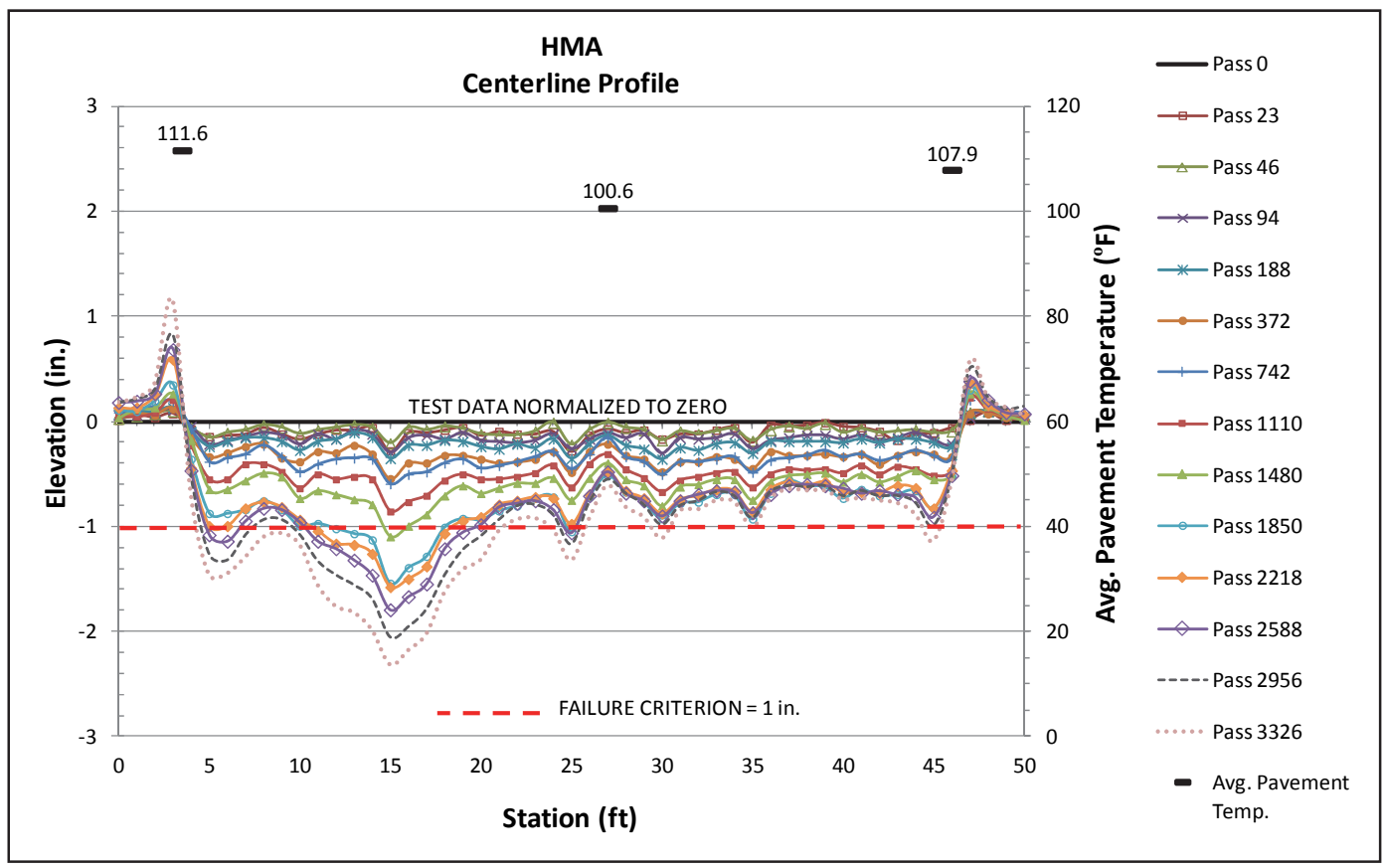


Figure 31. Foamed Asphalt centerline profiles and average pavement temperature.

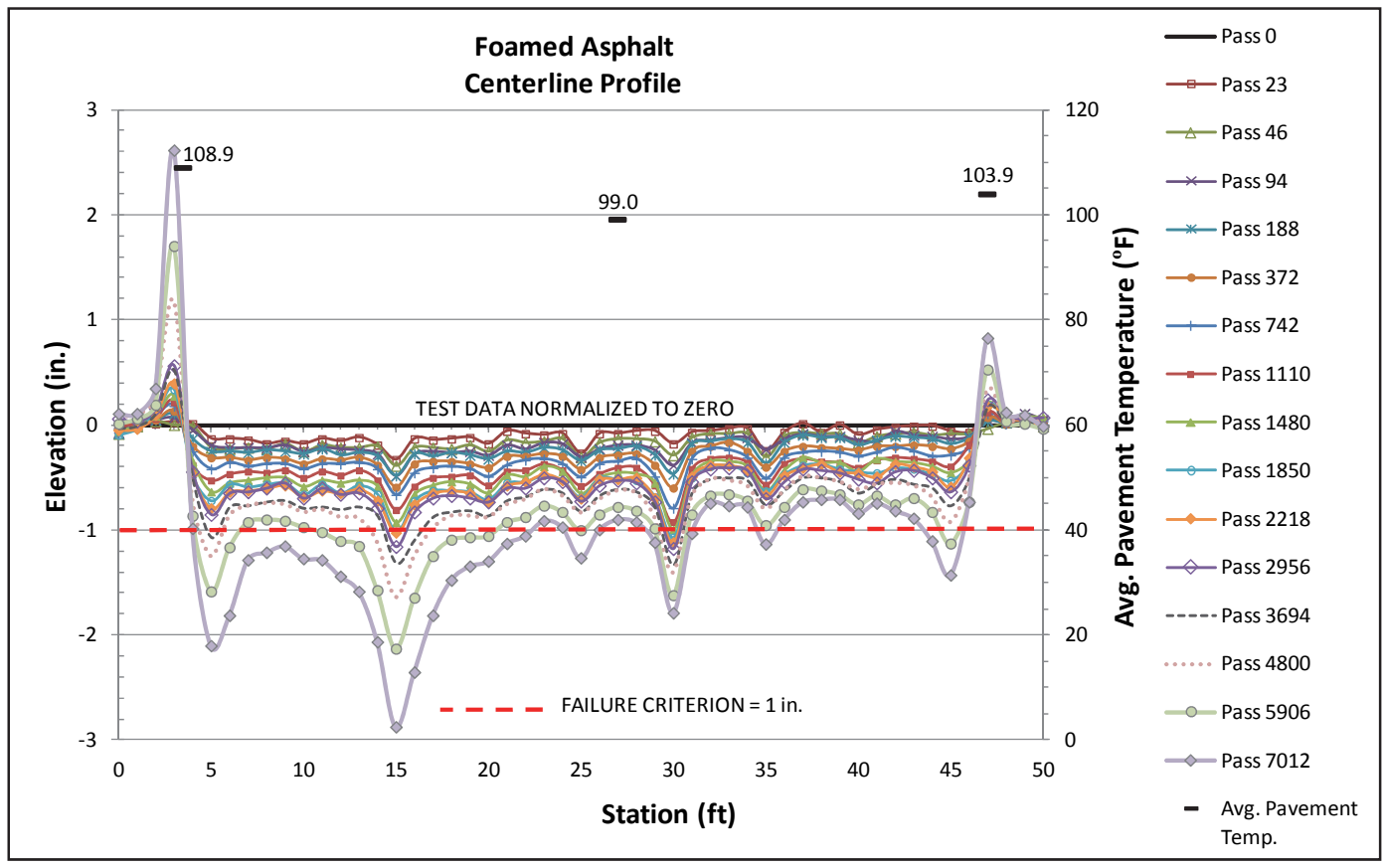

Figure 32. Sasobit $\circledast$ centerline profiles and average pavement temperature.

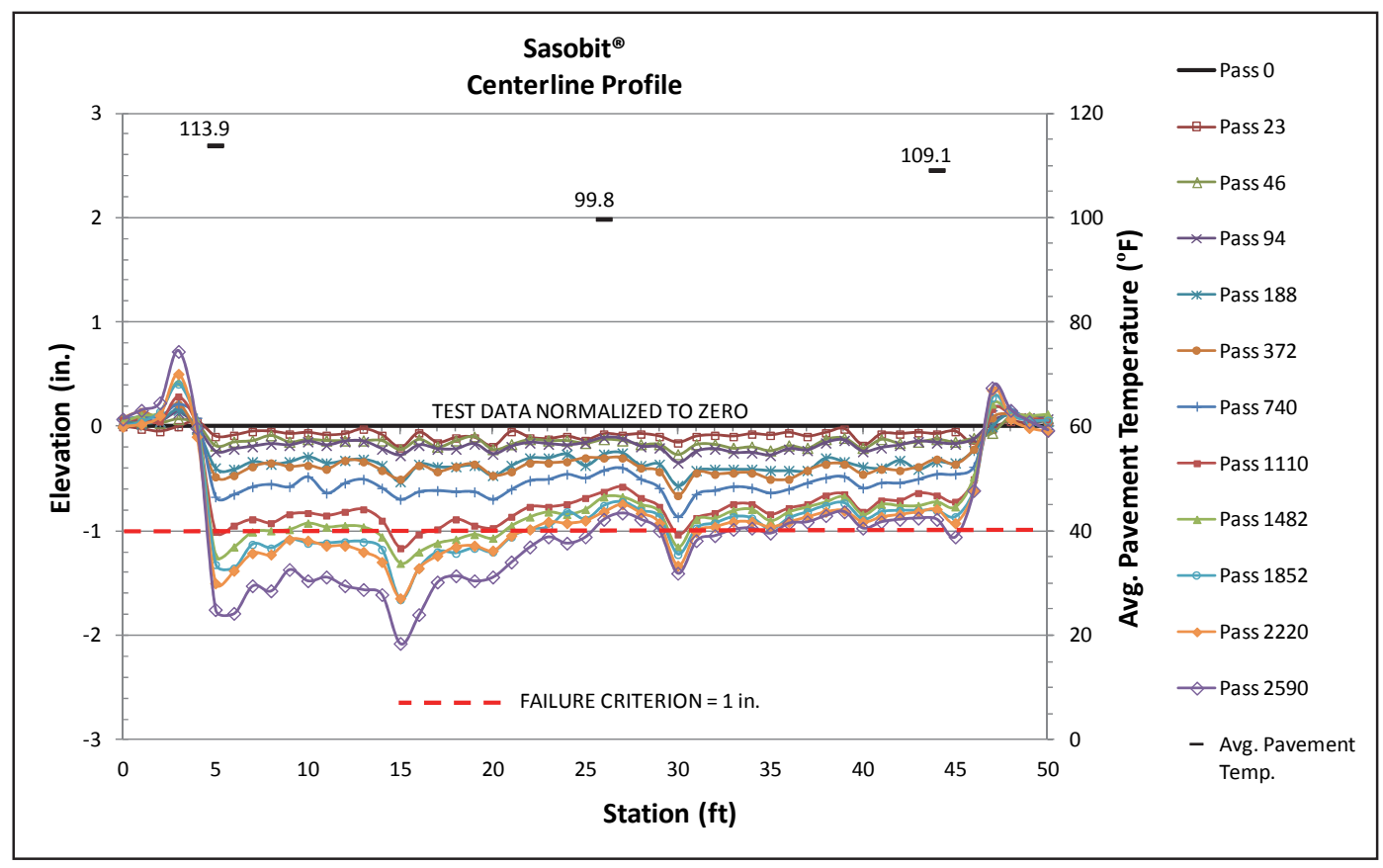


Figure 33. Evotherm ${ }^{\mathrm{TM}} 3 \mathrm{G}$ centerline profiles and average pavement temperature.

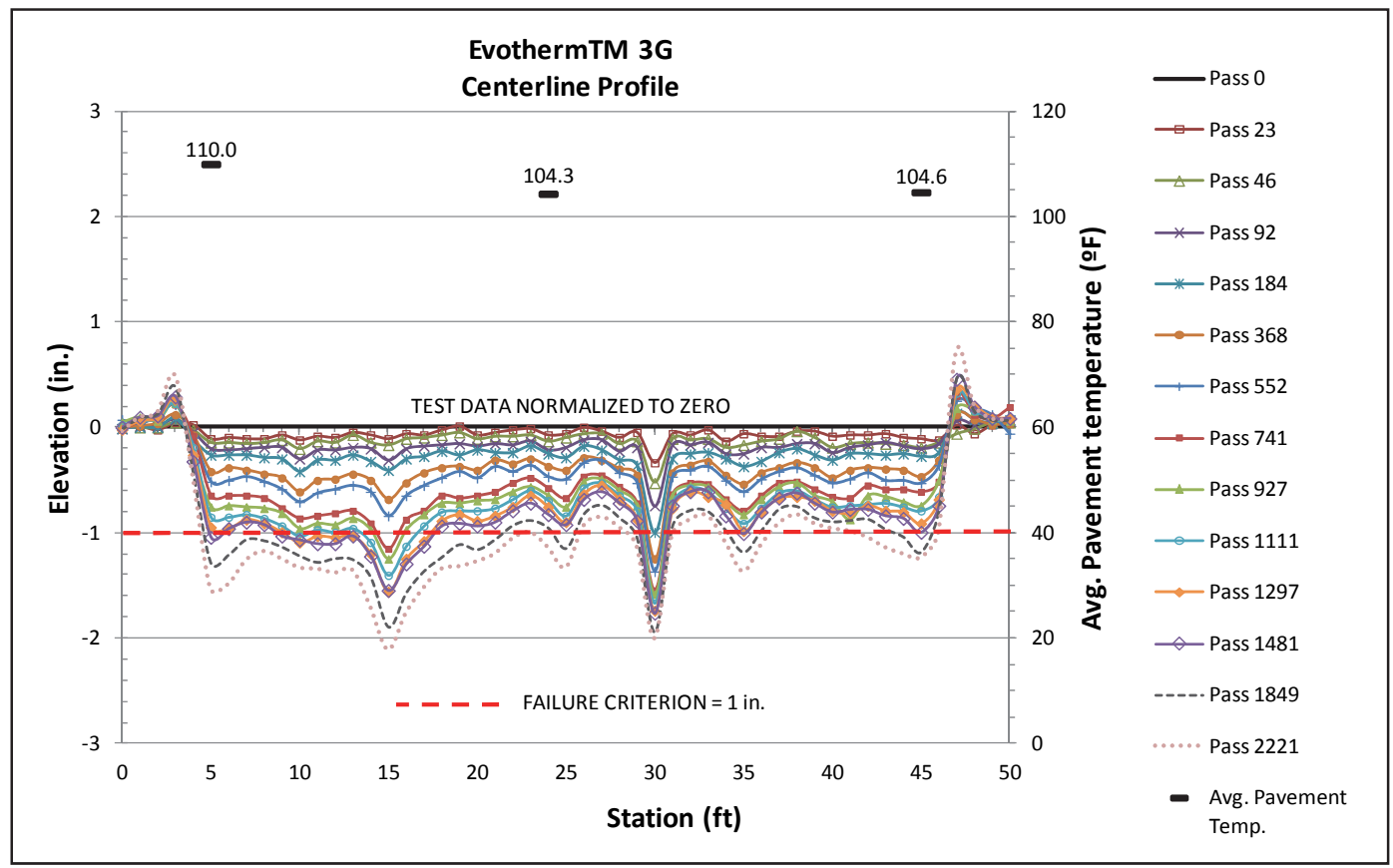

Evotherm ${ }^{\mathrm{TM}} 3 \mathrm{G}$ cross sections showing the representative permanent deformation at the three main areas of interest (south, center, and north) are presented in Figure 34. These cross sections show the typical rutting failure that was experienced by all the items under the F-15E simulated traffic. The cross sections measured at seven different stations on all four test items are presented in Appendix B. The humps on the sides showed that there was tertiary flow of the asphalt pavement during traffic. The STA $0+15$ cross section showed excessive rutting when compared to the other two cross sections for all test items. As traffic progressed, rutting at STA $\mathrm{O}+15$ increased rapidly due to the higher temperature, while rutting in the other areas increased at a slower rate, because the temperature was lower. Since the failure criterion was established at $1 \mathrm{in}$. of average centerline permanent deformation, STA $0+15$ was rutted excessively in order to allow the rest of the traffic lane to fail. As mentioned previously, traffic was discontinued when the items reached an average centerline permanent deformation of $1.2 \mathrm{in}$. After this point, the exposed aggregate in the humps on the sides of STA $0+15$ represented a tire hazard for the F-15E gear.

\subsection{Pavement stiffness}

FWD data were used to calculate the impulse stiffness modulus (ISM) of the pavement for each test item. ISM is the load (in thousands of pounds or kips) divided by the deflection (in.) of the sensor under the plate. Figure 35 
Figure 34. Evotherm ${ }^{\mathrm{TM}} 3 \mathrm{G}$ cross-section profiles.
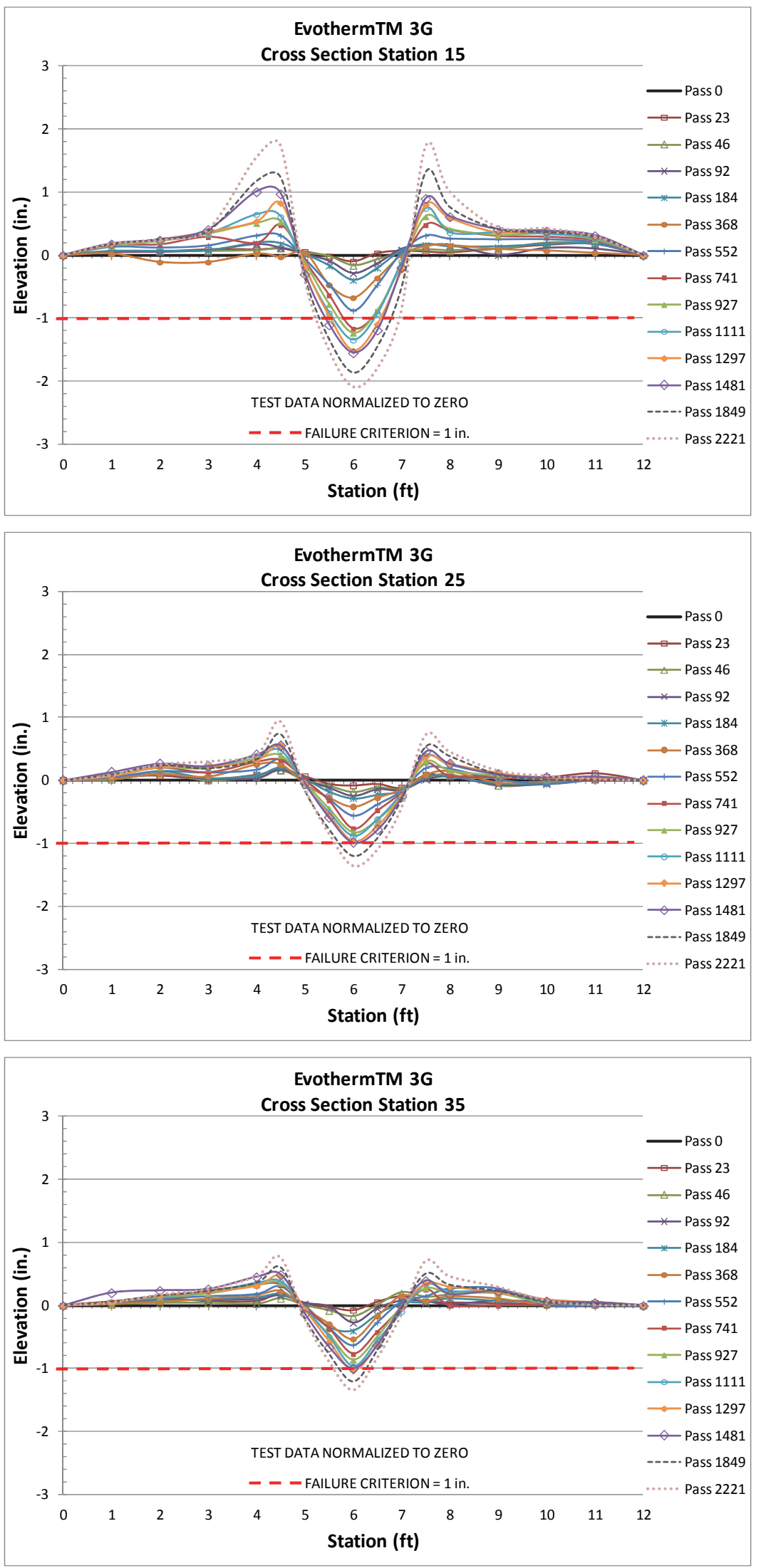
Figure 35. ISM values for all four test items.

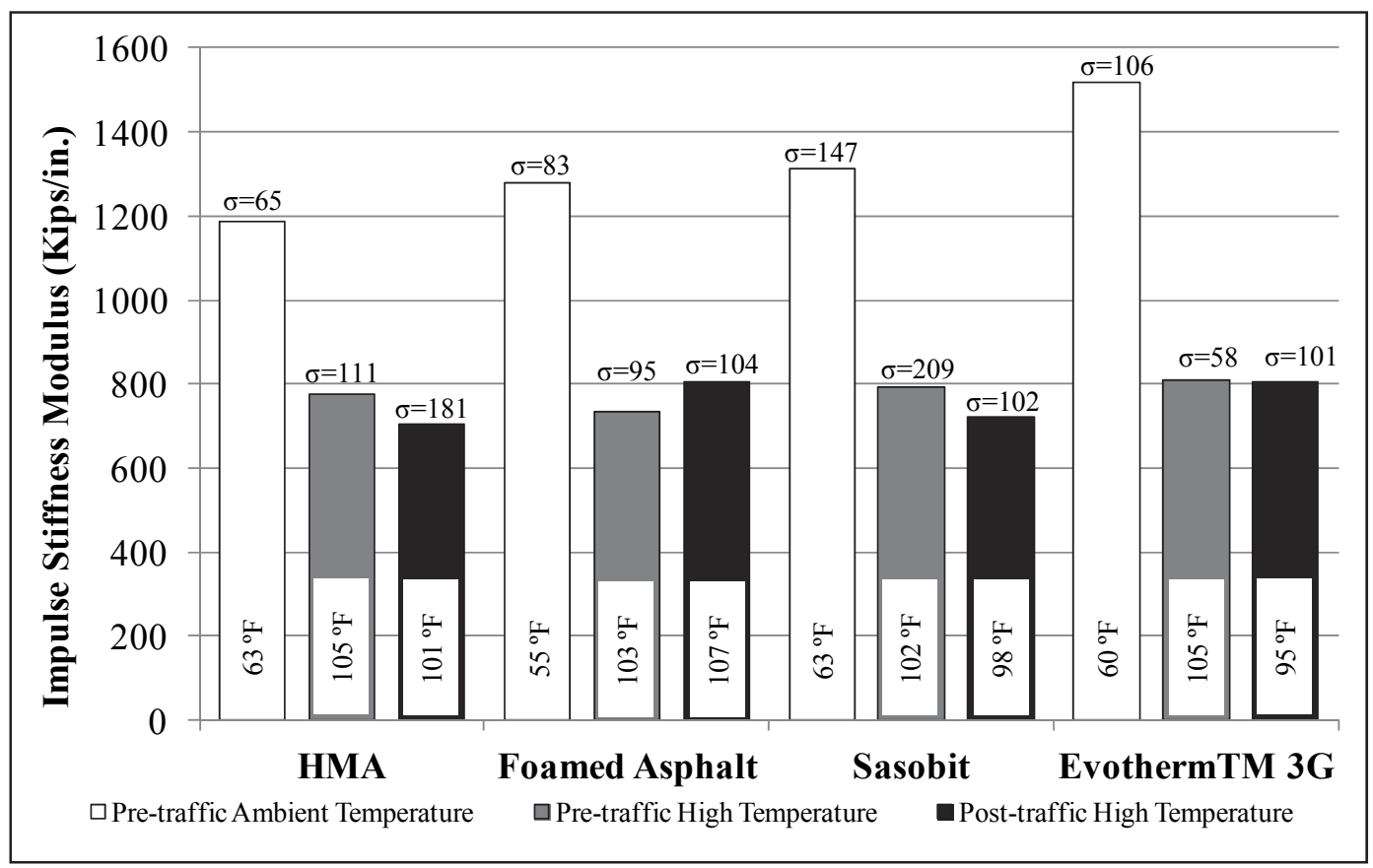

shows the average ISM values for each test item as calculated from data collected during FWD testing conducted before and after heat was applied to the pavement, and also after trafficking was discontinued. The raw FWD data are provided in Appendix C. The plot includes the standard deviation between seven data points from different locations. The pavement temperatures shown were determined by averaging the temperatures at the surface, mid-depth, and bottom of the asphalt measured at three locations within each test item at the time of each FWD test. Raw FWD data are available in Appendix C.

The initial differences in stiffness between items were not attributed to a specific technology but to the initial pavement temperature, which varied per test item. As expected, the stiffness of the asphalt pavement decreased as the temperature was increased. At the high temperature, no significant differences were observed across WMA technologies or when WMA was compared to HMA. There was little or no change in stiffness between before and after traffic for HMA and Evotherm ${ }^{\mathrm{TM}} 3 \mathrm{G}$. The stiffness of Foamed Asphalt increased a little after trafficking, while on the other hand, the stiffness of Sasobit $®$ decreased after trafficking. Differences in temperatures could have affected these stiffness values, producing mixed results. To place the FWD on each test item for testing, some of the protective panels in the HVS had to be removed, letting the heat escape for the duration of the test. When the outside temperature was lower, the heat 
escaped more quickly; this caused the differences in temperature and, thus, the differences in stiffness. Considering all the factors that affect the variability of the FWD test, the differences were minimal.

\subsection{Pavement response}

This section discusses the data that were collected with the instrumentation that was installed in the foundation layers. Even though the main focus of this report is on the performance of the asphalt layer, it is important to document the response of the foundation layers to show if there was any movement on the unbound layers during trafficking.

It is important to note that during trafficking some of the instruments were not able to record data due to problems during construction and installation or because their maximum capacity was reached during trafficking. During construction, some of the asphalt strain gauges were damaged by the paver machine when it drove over the sensors and no data could be collected from them during testing. During traffic, some of the surface strain gauges were damaged by the abrasive action of traffic loading, and some of them reached their maximum capacity very early during the test. Also during traffic, some of the SDDs started recording erroneous readings at irregular intervals. The source of error is unknown; however, it is anticipated that this malfunction was related to installation issues or to the SDDs themselves.

The following sections summarize the pavement response measurements from the dynamic slow roll tests and the dynamic sweep tests that were conducted at each traffic interval. Some examples of typical raw instrumentation data are available in Appendix D.

\subsubsection{Dynamic Slow Roll Test}

Table 7 provides a summary of the maximum pressures measured at the subgrade, subbase, and base layers in all four test items during dynamic slow roll tests. Figures 36-39 present the maximum pressures that were measured with the EPCs during the dynamic slow roll tests at each traffic interval. These plots include the maximum pressures measured when slow roll tests were conducted before heat was applied to the pavement (PreHeat). 
In general, the data show minimal changes in pressure with increasing passes. This is a good indication that there was no movement or densification of the unbound layers during trafficking, which was one of the main objectives for the design of this pavement structure. A noticeable increase in pressure was observed when heat was applied to the test items. When the asphalt pavement layer is cold, it is stiff and spreads the load more efficiently, reducing the pressure transmitted to the unbound layers. When the asphalt layer heats up, it becomes more flexible and transmits more pressure to the sub-layers. There was a decrease in pressure observed after 46 passes in the HMA, but the pressure increased again and stayed consistent for the rest of the trafficking. This could have been related to test errors. In the case of Sasobit $囚$, the two EPCs in the base layer showed a consistent difference in pressure at all traffic intervals as shown in Figure 40. This difference in pressure between two EPCs that were located at the same depth could have been related to the horizontal positioning of the instruments in relation to the traffic centerline and also to pavement temperature effects on the pressure measurements. Figure 41 shows the maximum pressure distribution with depth for all four items from the slow roll test data. This plot shows that the pressure applied by the F-15E wheel to the asphalt surface (325 psi) was well distributed through the base and subbase layers, and, thus, the effect on the subgrade was minimal. The pressure was reduced to approximately $15 \%$ at the bottom of the asphalt layer, to $60 \%$ at the bottom of the base, and $20 \%$ at the bottom of the subbase. The subgrade only received $5 \%$ of the applied surface pressure. This shows the efficiency of this pavement structure design in withstanding the heavy traffic loads for which it was designed.

Table 7. Maximum soil pressures during dynamic slow roll test.

\begin{tabular}{|l|l|l|l|l|}
\hline & $\begin{array}{l}\text { Subgrade Max. } \\
\text { Pressure (psi) } \\
(\mathbf{2 6} \text { in. deep) }\end{array}$ & $\begin{array}{l}\text { Subbase Max. } \\
\text { Pressure (psi) } \\
(16 \text { in. deep) }\end{array}$ & $\begin{array}{l}\text { Base Max } \\
\text { Pressure (psi) } \\
(6 \text { in. deep) }\end{array}$ & $\begin{array}{l}\text { Avg. Surface } \\
\text { Temp. }\left({ }^{\circ} \mathbf{F}\right)\end{array}$ \\
\hline HMA & 13.3 & 52.8 & 265.1 & 106.7 \\
\hline Foamed Asphalt & 11.8 & 66.3 & 291.6 & 103.9 \\
\hline Sasobit ${ }^{\circledR}$ & 10.9 & 92.2 & 293.4 & 107.7 \\
\hline Evotherm ${ }^{\text {TM } 3 G}$ & 14.8 & 93.1 & 257.9 & 106.3 \\
\hline
\end{tabular}


Figure 36. HMA maximum pressure measured at the base, subbase and subgrade during slow roll test at each pass level.

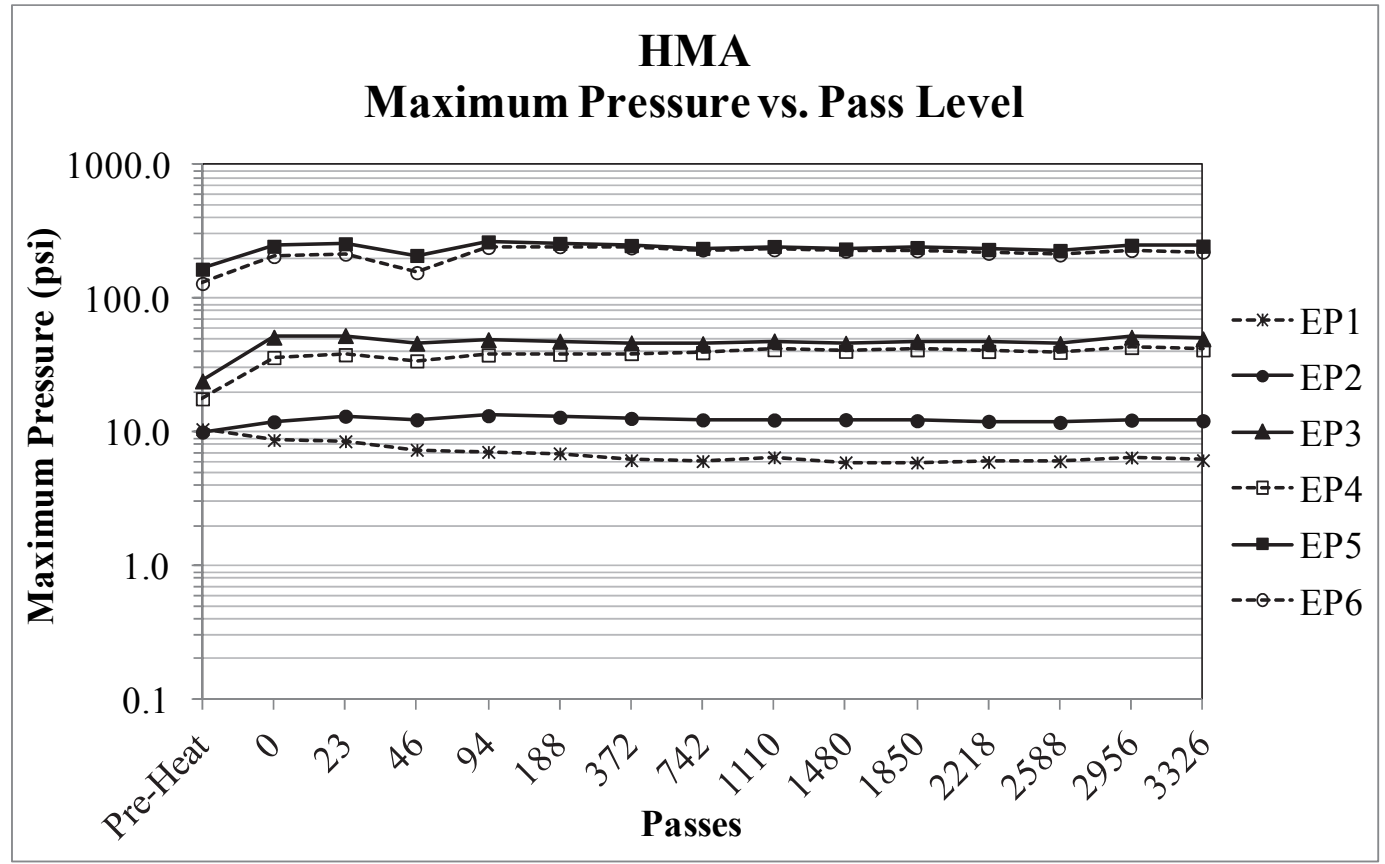

Figure 37. Foamed Asphalt maximum pressure measured at the base, subbase and subgrade during slow roll test at each pass level.

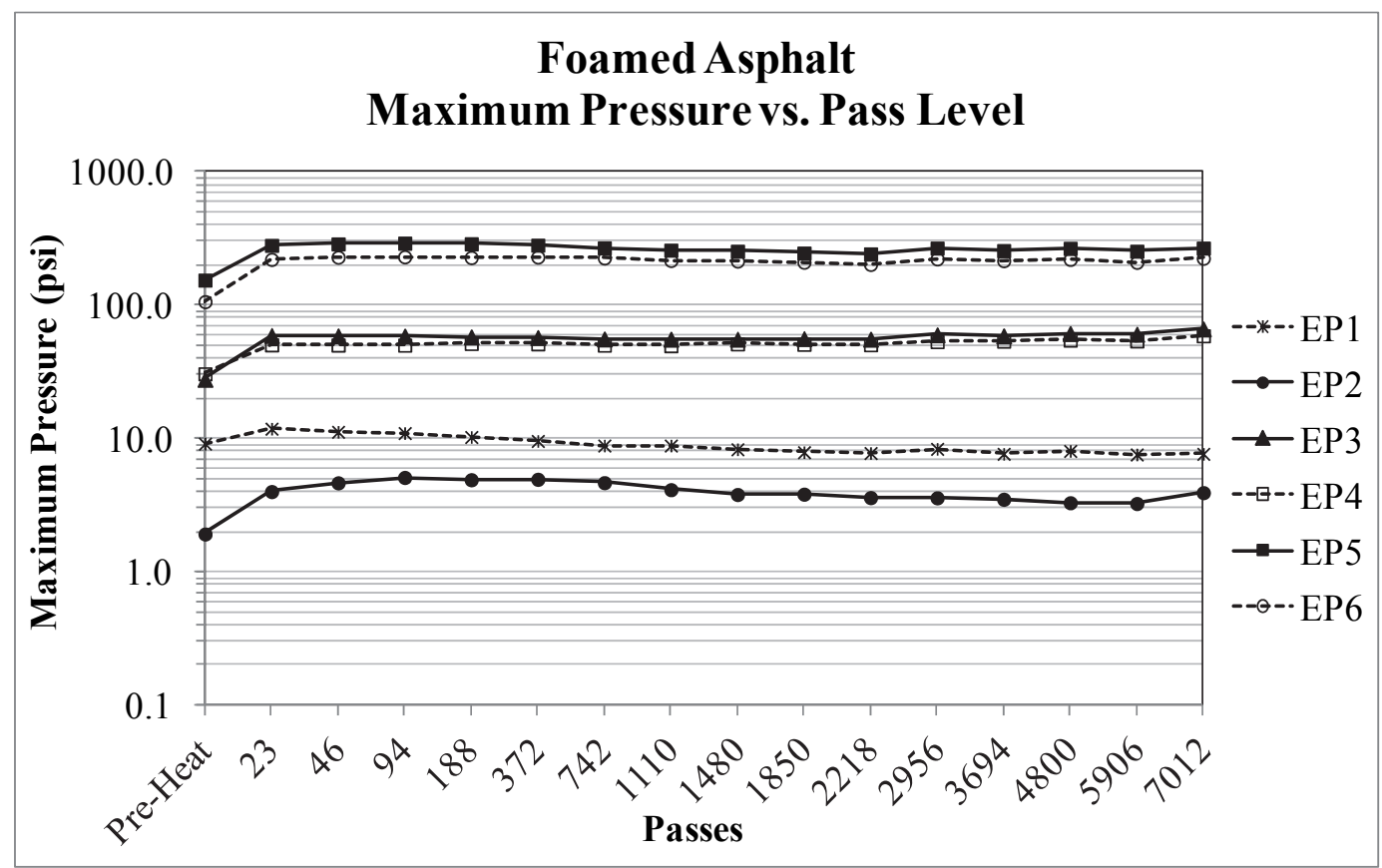


Figure 38. Sasobit $\circledast$ maximum pressure measured at the base, subbase and subgrade during slow roll test at each pass level.

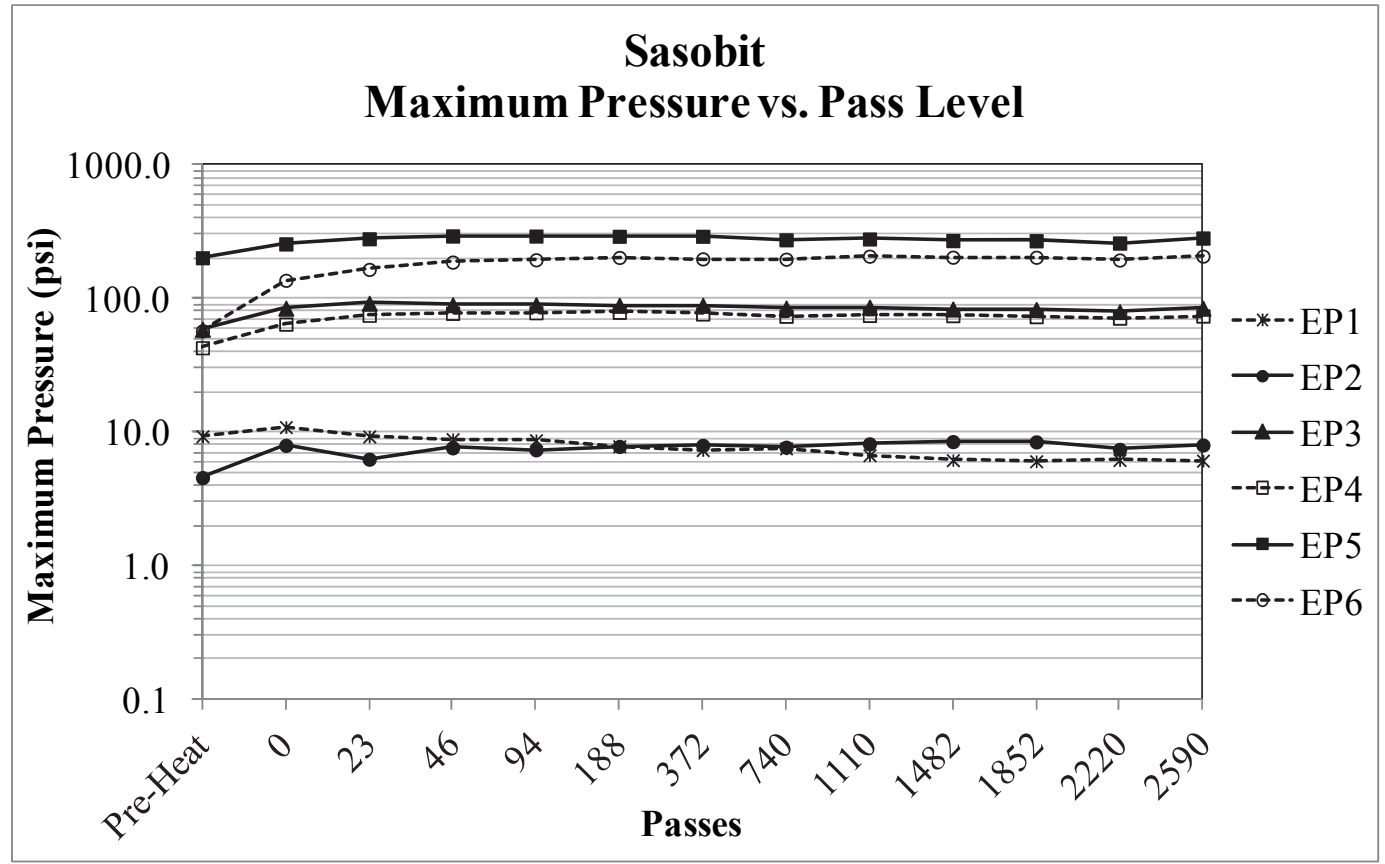

Figure 39. Evotherm ${ }^{\mathrm{TM}} 3 \mathrm{G}$ maximum pressure measured at the base, subbase and subgrade during slow roll test at each pass level.

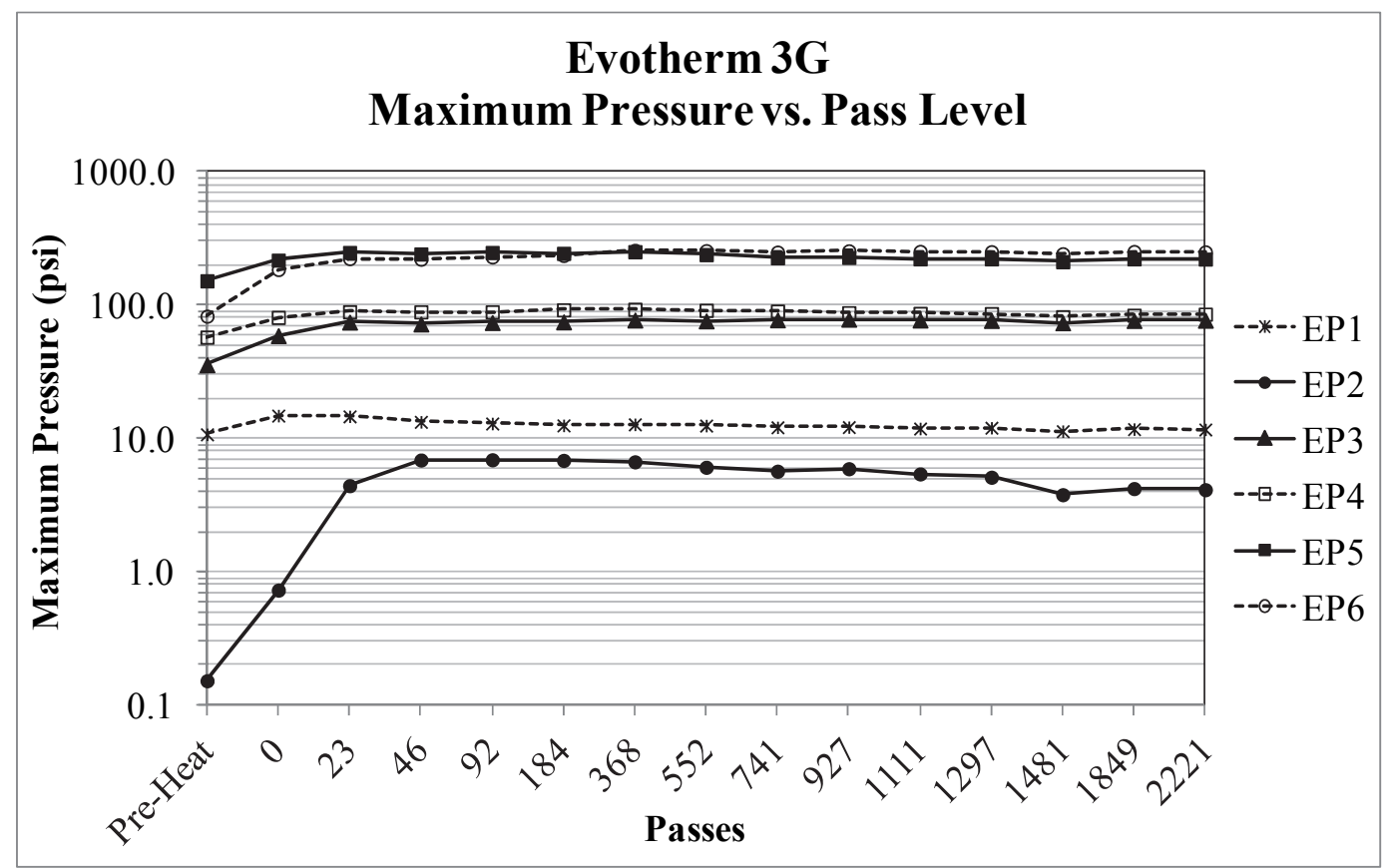


Figure 40. Pressure difference between EP5 and EP6 at the top of the base in Sasobit $\circledast$.

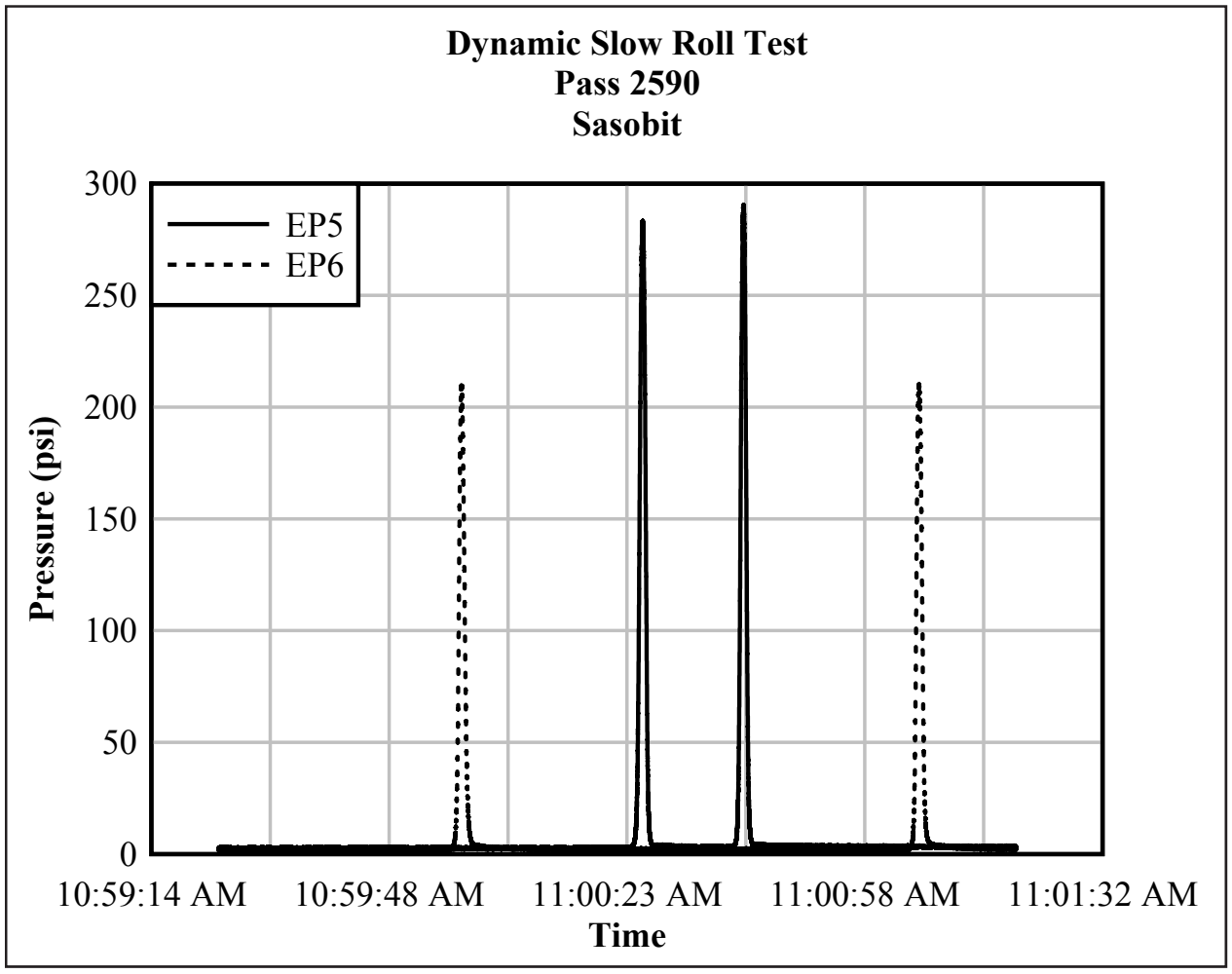

Figure 41. Maximum pressure distribution from dynamic slow roll test data.

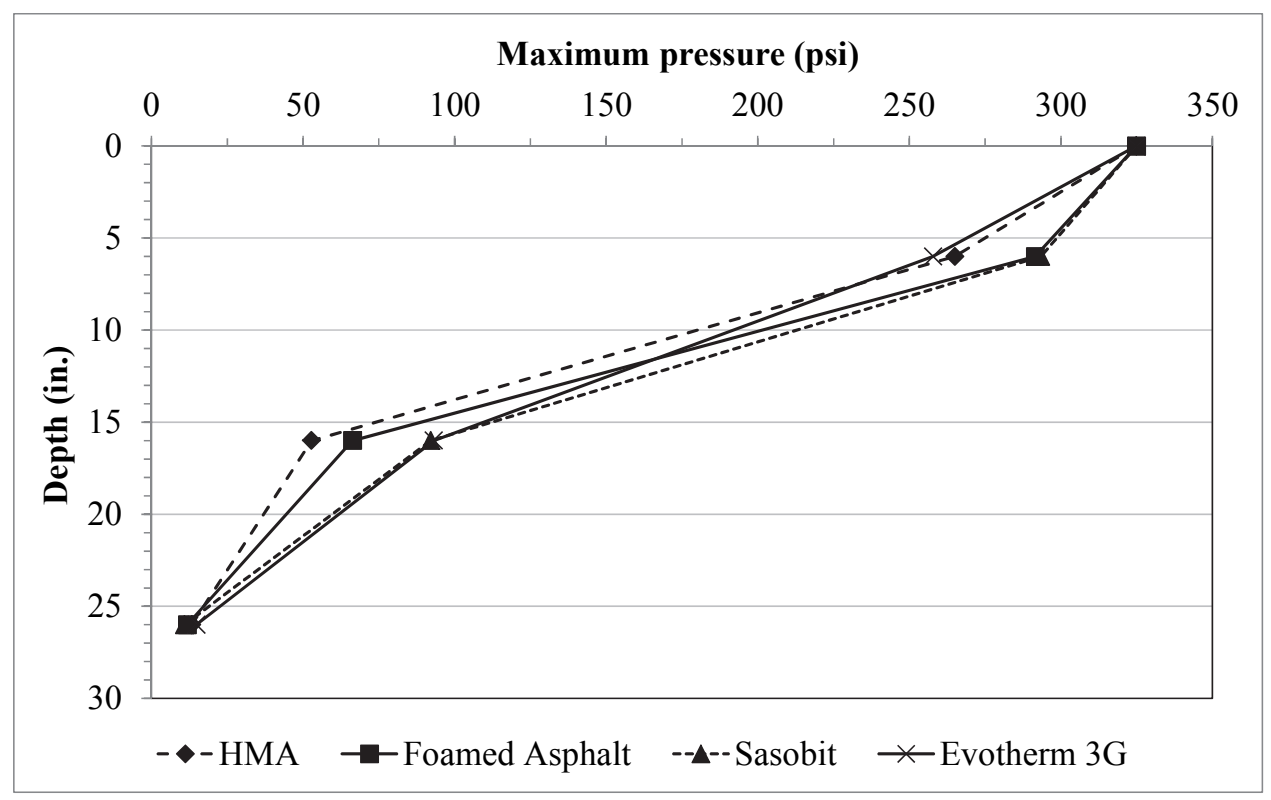


A summary of the maximum deflections measured at each sublayer with the SDDs during dynamic slow roll tests is presented in Table 8. The maximum deflections measured during the dynamic slow roll test at each pass level on each test item are presented in Figures 42-45. Some of the SDDs did not record any measurements during testing, and some of them failed during the test. Multiple factors affected the proper functioning of the SDDs. For example, during installation of the SDDs at the base course, the soil that was placed underneath the plate to level it and the backfill soil on top of the sensor could have been poorly compacted. This caused the large early deformations observed on the asphalt pavement at those locations in all four test items during traffic, as previously discussed. The deflection measured by the SDDs at the base course included the deformation from the poorly compacted fill material. Therefore, the magnitudes of the deflections were not considered to represent movement of the unbound layers. However, the deflection trend lines indicate minimal or no movement of the subbase and subgrade layers in all test items where data were recorded.

Table 8. Maximum deflections measured with the SDDs during dynamic slow roll tests.

\begin{tabular}{|c|c|c|c|c|}
\hline \multirow[b]{2}{*}{ Test Item } & \multicolumn{3}{|c|}{ Maximum Deflection (in.) } & \multirow{2}{*}{$\begin{array}{l}\text { Avg. Surface Temp. } \\
\left({ }^{\circ} \mathrm{F}\right)\end{array}$} \\
\hline & Subgrade & Subbase & Base & \\
\hline HMA & 0.04 & 0.07 & $0.16^{a}$ & 106.7 \\
\hline Foamed Asphalt & 0.05 & $\mathrm{~b}^{\mathrm{b}}$ & $0.24^{c}$ & 103.9 \\
\hline Sasobit $\AA$ & $b$ & 0.04 & $0.22^{c}$ & 107.7 \\
\hline Evotherm ${ }^{\mathrm{TM}} 3 \mathrm{G}$ & $L^{b}$ & ${ }^{b}$ & 0.34 & 106.3 \\
\hline
\end{tabular}

a Instrument failed after the third traffic interval was applied.

$\mathrm{b}$ Instrument did not record data during the test.

c Instrument failed before trafficking was completed. 
Figure 42. HMA maximum deflection measured at the base, subbase and subgrade during dynamic slow roll test at each pass level.

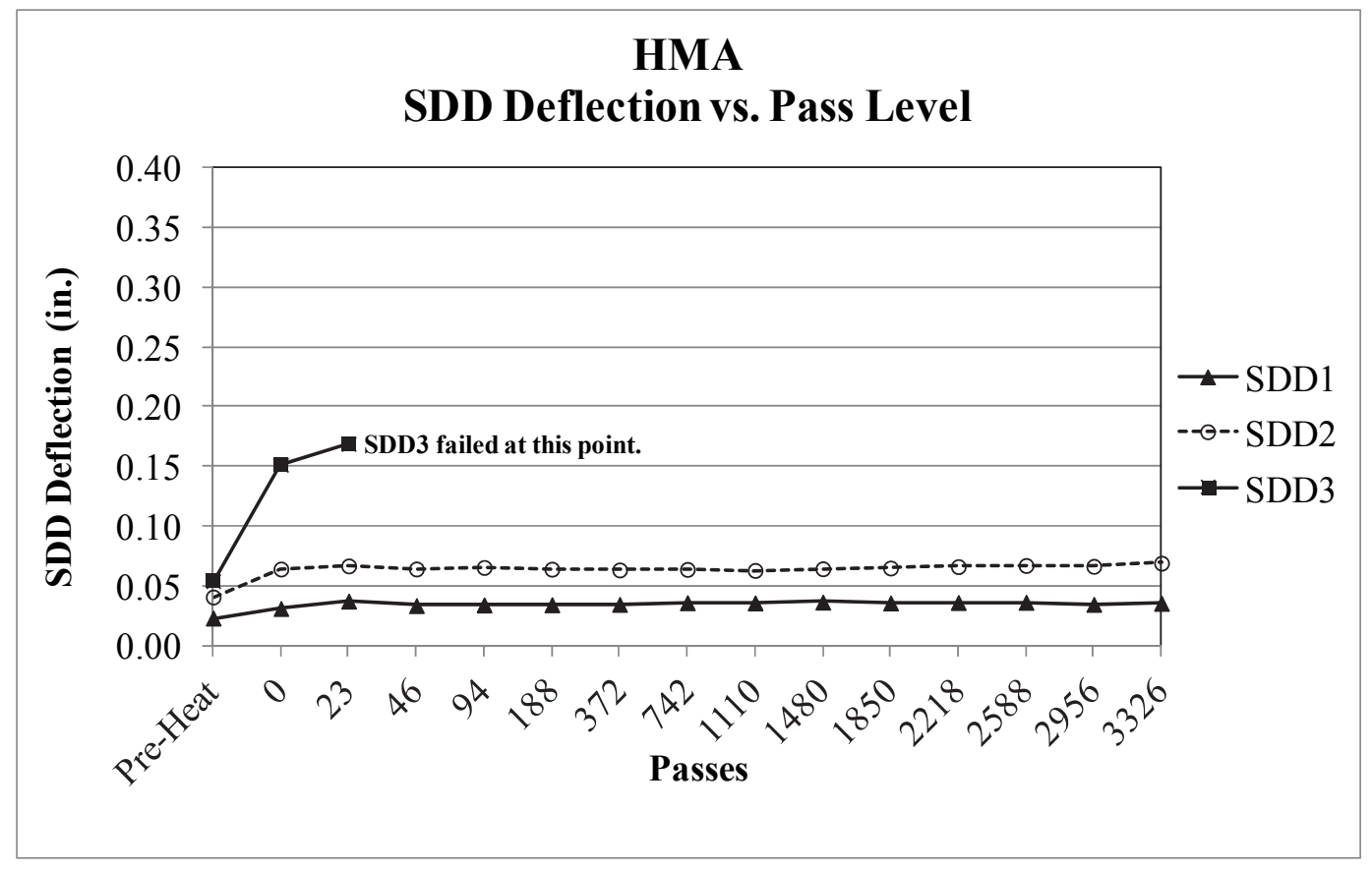

Figure 43. Foamed Asphalt maximum deflection measured at the base, subbase and subgrade during dynamic slow roll test at each pass level.

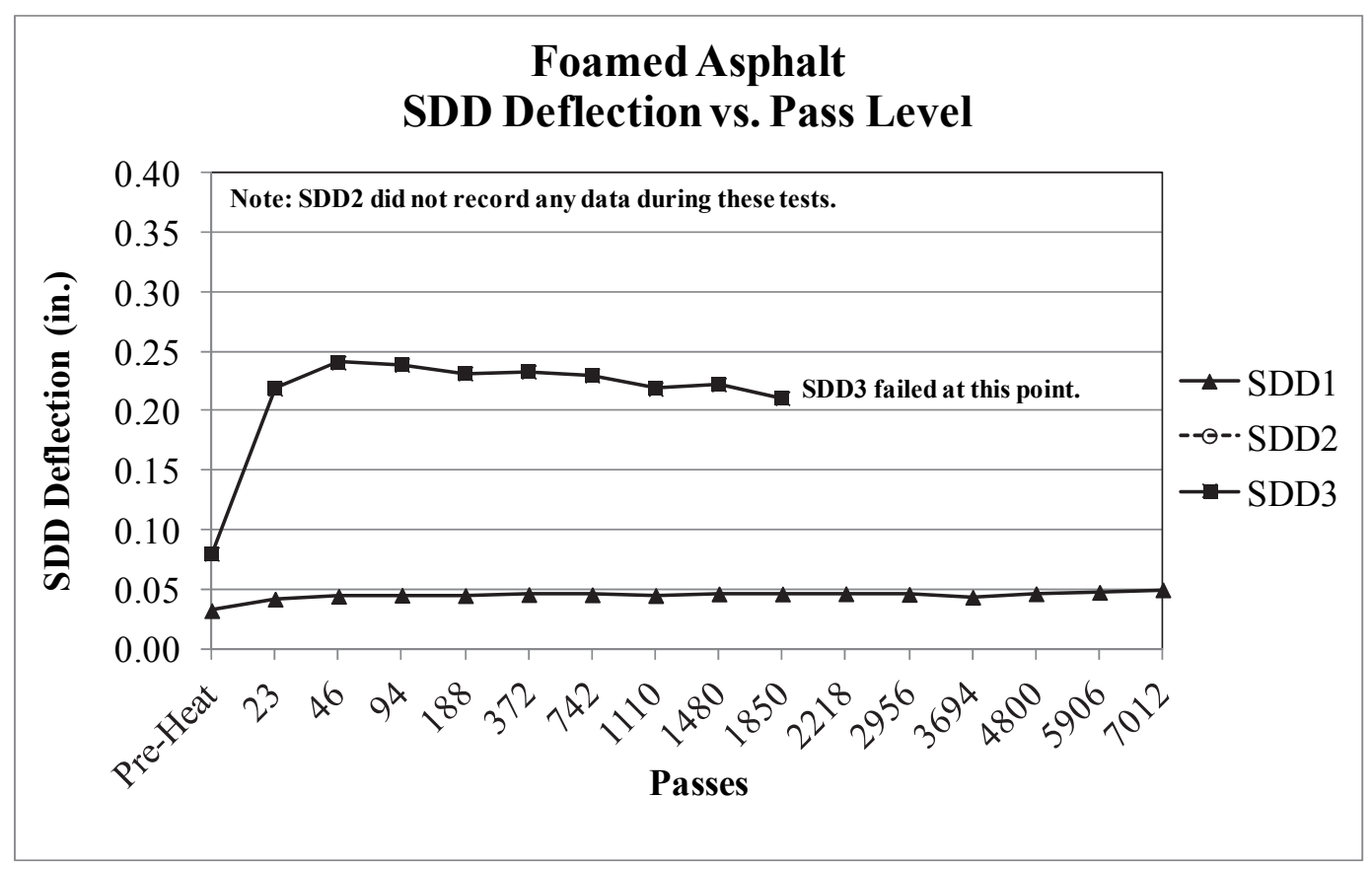


Figure 44. Sasobit $\circledast$ maximum deflection measured at the base, subbase and subgrade during dynamic slow roll test at each pass level.

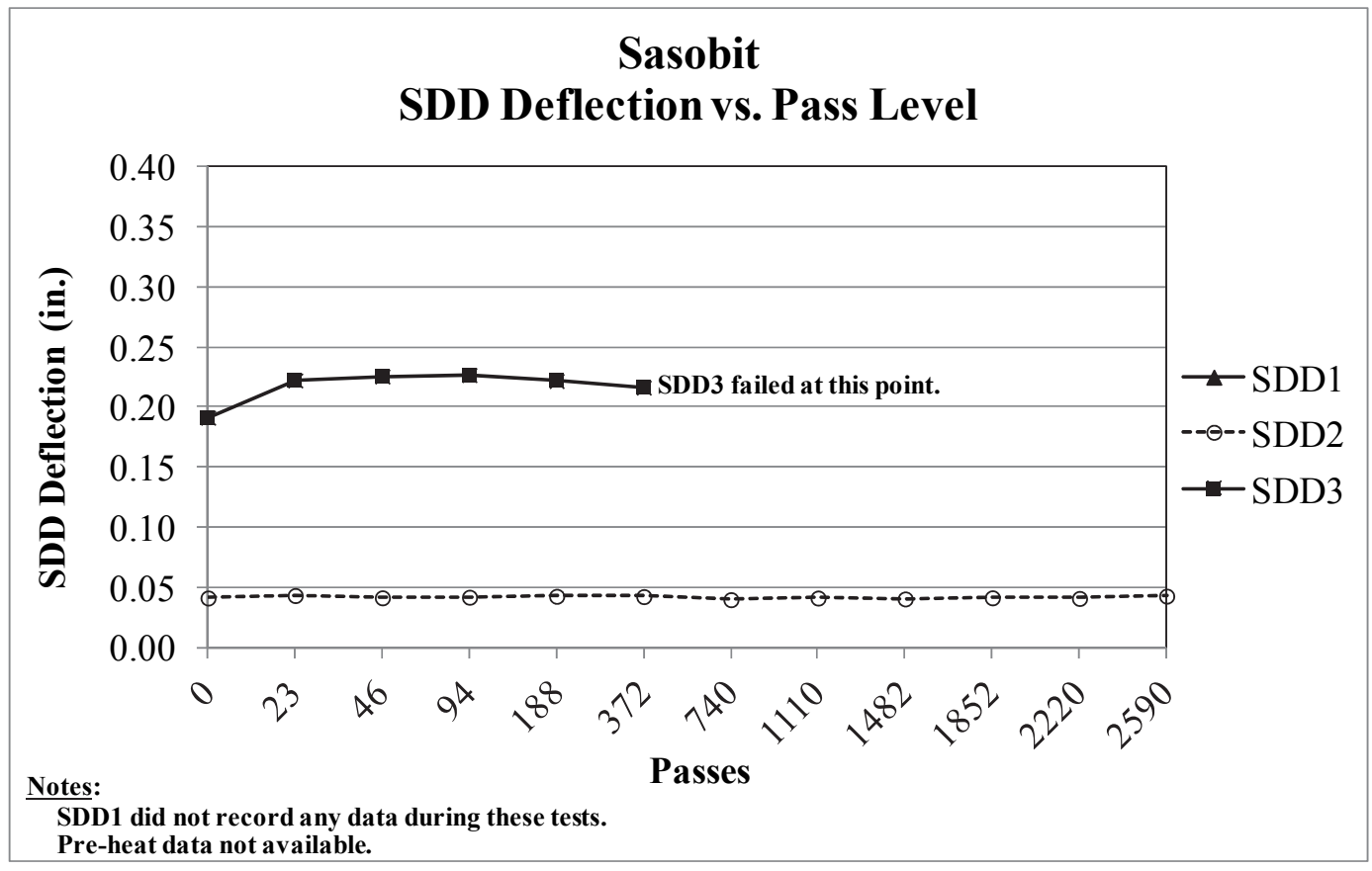

Figure 45. Evotherm ${ }^{\mathrm{TM}} 3 \mathrm{G}$ maximum deflection measured at the base, subbase and subgrade during dynamic slow roll test at each pass level.

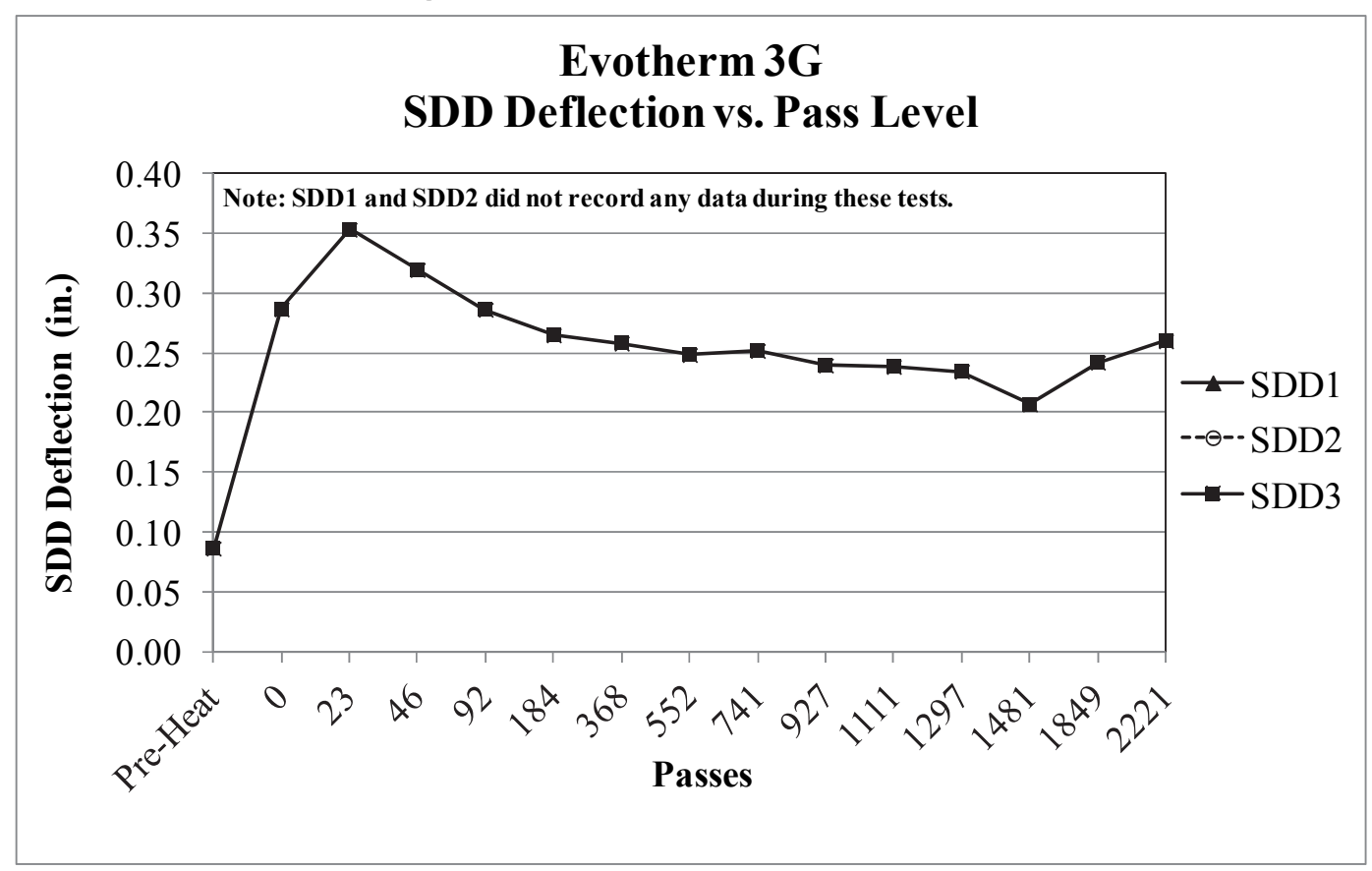




\subsubsection{Dynamic sweep test}

Table 9 provides a summary of the maximum pressures measured at the subgrade, subbase, and base layers in all four test items during the dynamic sweep test. Figures 46-49 present the maximum pressures that were measured with the EPCs during the dynamic sweep tests at each traffic interval. These data also show minimal changes in pressure with number of passes. In general, the maximum pressures measured during the dynamic sweep test were very similar to those measured during the dynamic slow roll test. The highest pressure measured in the subbase was on Evotherm ${ }^{\mathrm{TM}} 3 \mathrm{G}$, and this item had the lowest pressure measured at the base. Sasobit $囚$ had the highest pressures measured at the base. The pressures measured in the subgrade were similar in all four items.

Table 9. Maximum soil pressures during dynamic sweep test.

\begin{tabular}{|c|c|c|c|c|}
\hline Test Item & $\begin{array}{l}\text { Subgrade Max. } \\
\text { Pressure (psi) } \\
\text { (26 in. deep) }\end{array}$ & $\begin{array}{l}\text { Subbase Max. } \\
\text { Pressure (psi) } \\
\text { (16 in. deep) }\end{array}$ & $\begin{array}{l}\text { Base Max } \\
\text { Pressure (psi) } \\
\text { (6 in. deep) }\end{array}$ & $\begin{array}{l}\text { Avg. Surface } \\
\text { Temp. }\left({ }^{\circ} \mathrm{F}\right)\end{array}$ \\
\hline HMA & 13.5 & 52.3 & 282.6 & 106.7 \\
\hline Foamed Asphalt & 12.2 & 62.7 & 283.3 & 103.9 \\
\hline Sasobit $\AA$ & 11.8 & 90.9 & 293.2 & 107.7 \\
\hline Evotherm $^{\mathrm{TM}} 3 \mathrm{G}$ & 14.6 & 93.3 & 262.8 & 106.3 \\
\hline
\end{tabular}

Figure 46. HMA maximum pressure measured at the base, subbase and subgrade during the first 23 passes of each data collection interval.

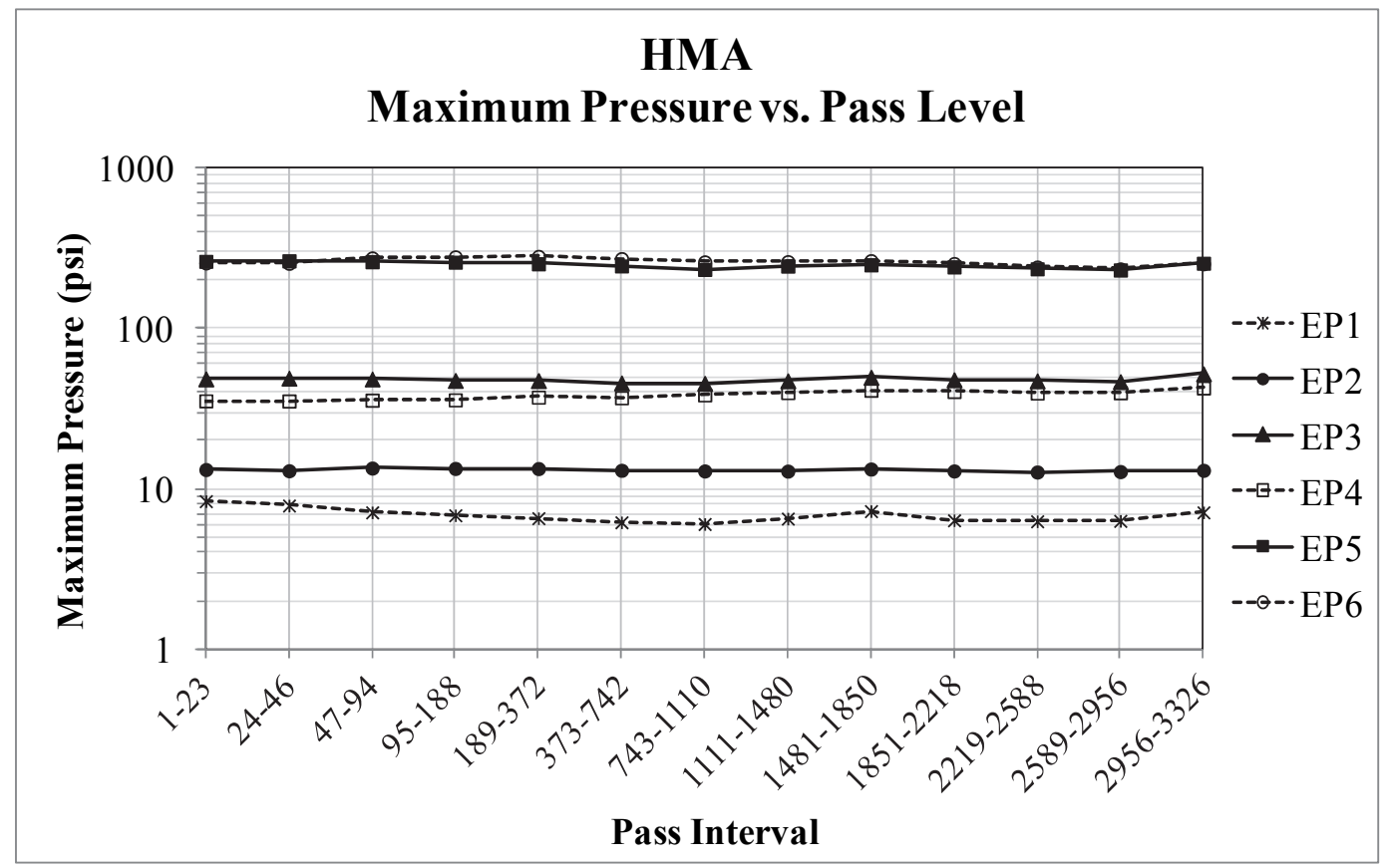


Figure 47. Foamed Asphalt maximum pressure measured at the base, subbase and subgrade during the first 23 passes of each data collection interval.

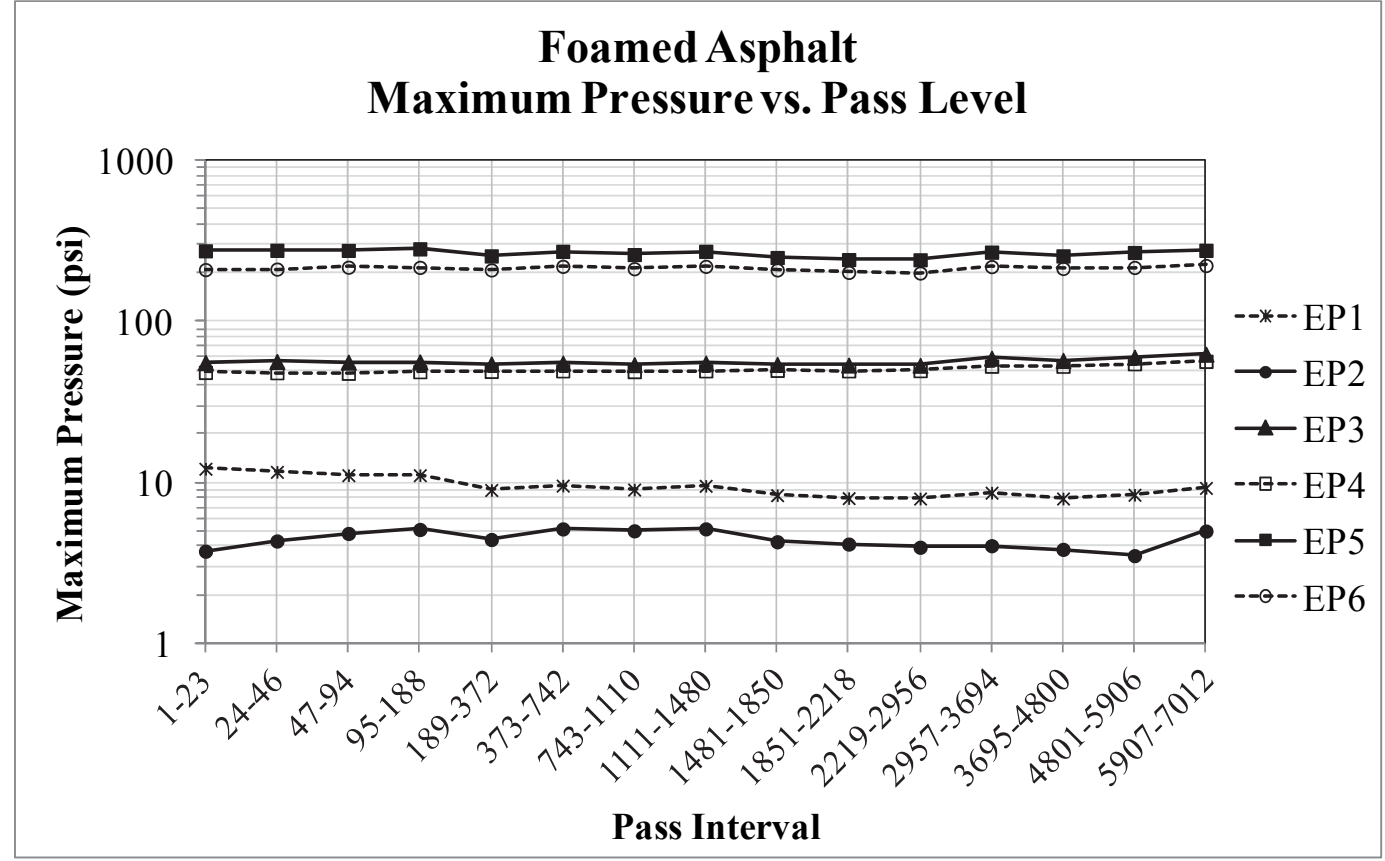

Figure 48. Sasobit $\circledast$ maximum pressure measured at the base, subbase and subgrade during the first 23 passes of each data collection interval.

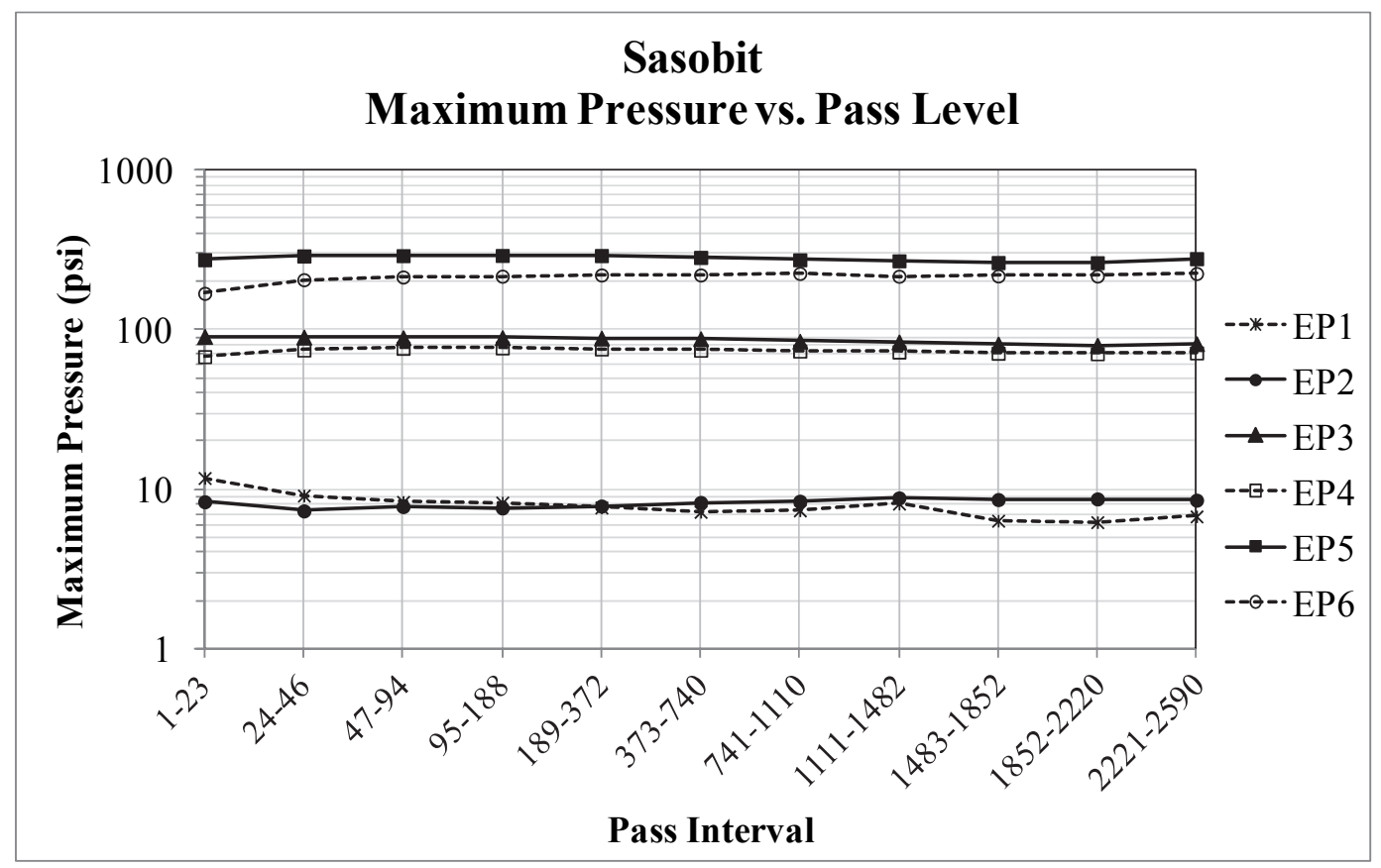


Figure 49. Evotherm ${ }^{\mathrm{TM}} 3 \mathrm{G}$ maximum pressure measured at the base, subbase and subgrade during the first 23 passes of each data collection interval.

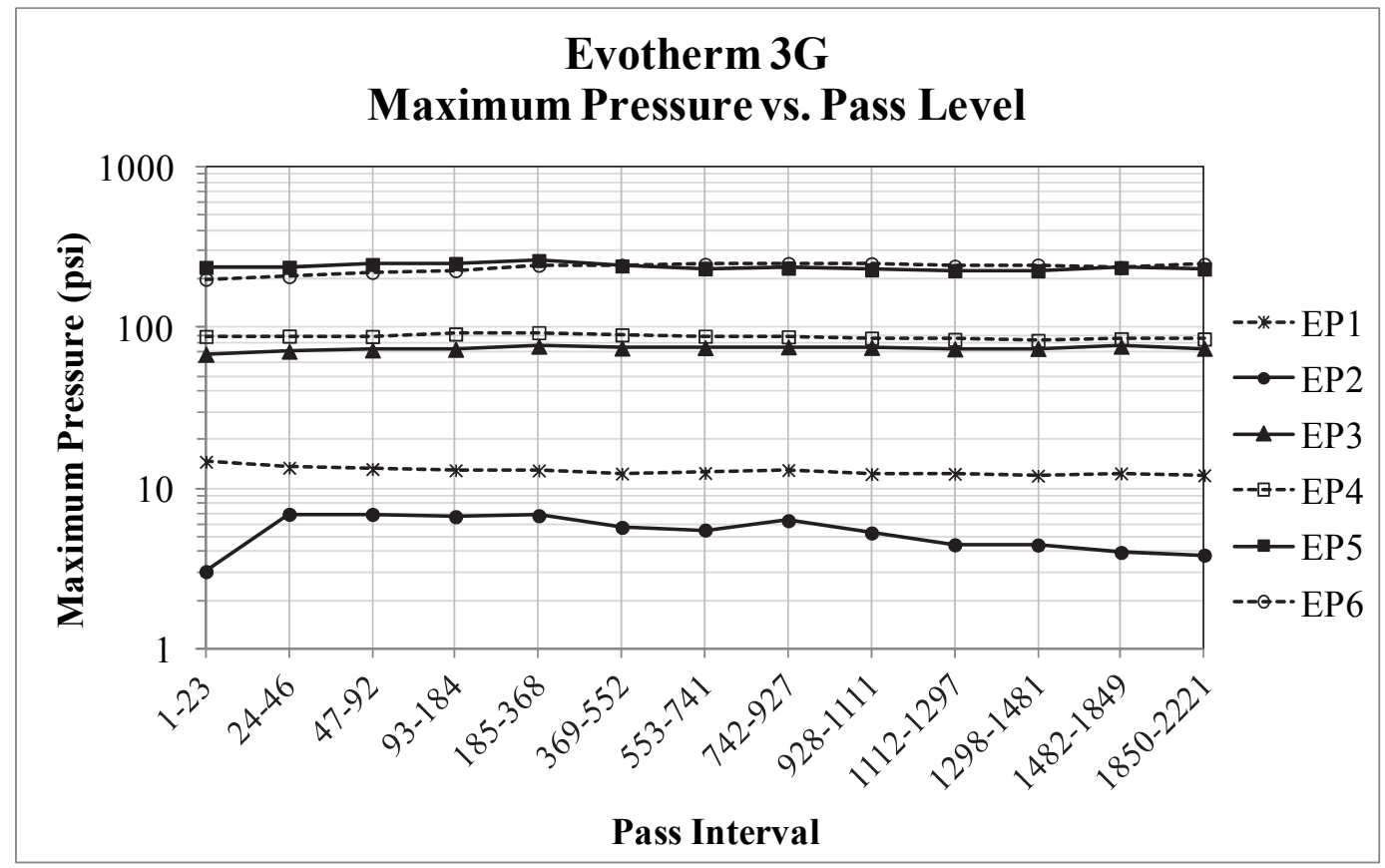

Figure 50 shows the typical difference in pressure observed between the two EPCs in the base layer (EP5 and EP6). The horizontal gap between both bell-shaped curves in the plot is due to the way the wheel trafficked over one EPC first and then over the other going in one direction. The vertical difference shows the difference in pressure between these two EPCs, which is believed to be caused by the horizontal positioning of the instruments relative to the load application and also to pavement temperature effects on the pressure measurements. Figure 51 shows the maximum pressure distribution with depth for all four items from the dynamic sweep test data. This plot is very similar to the one obtained from the dynamic slow roll data, and it confirms the efficiency of the pavement structure in withstanding the heavy traffic loads for which it was designed. 
Figure 50. Pressure difference between EP5 and EP6 at the top of the base in Sasobit $\circledast$.

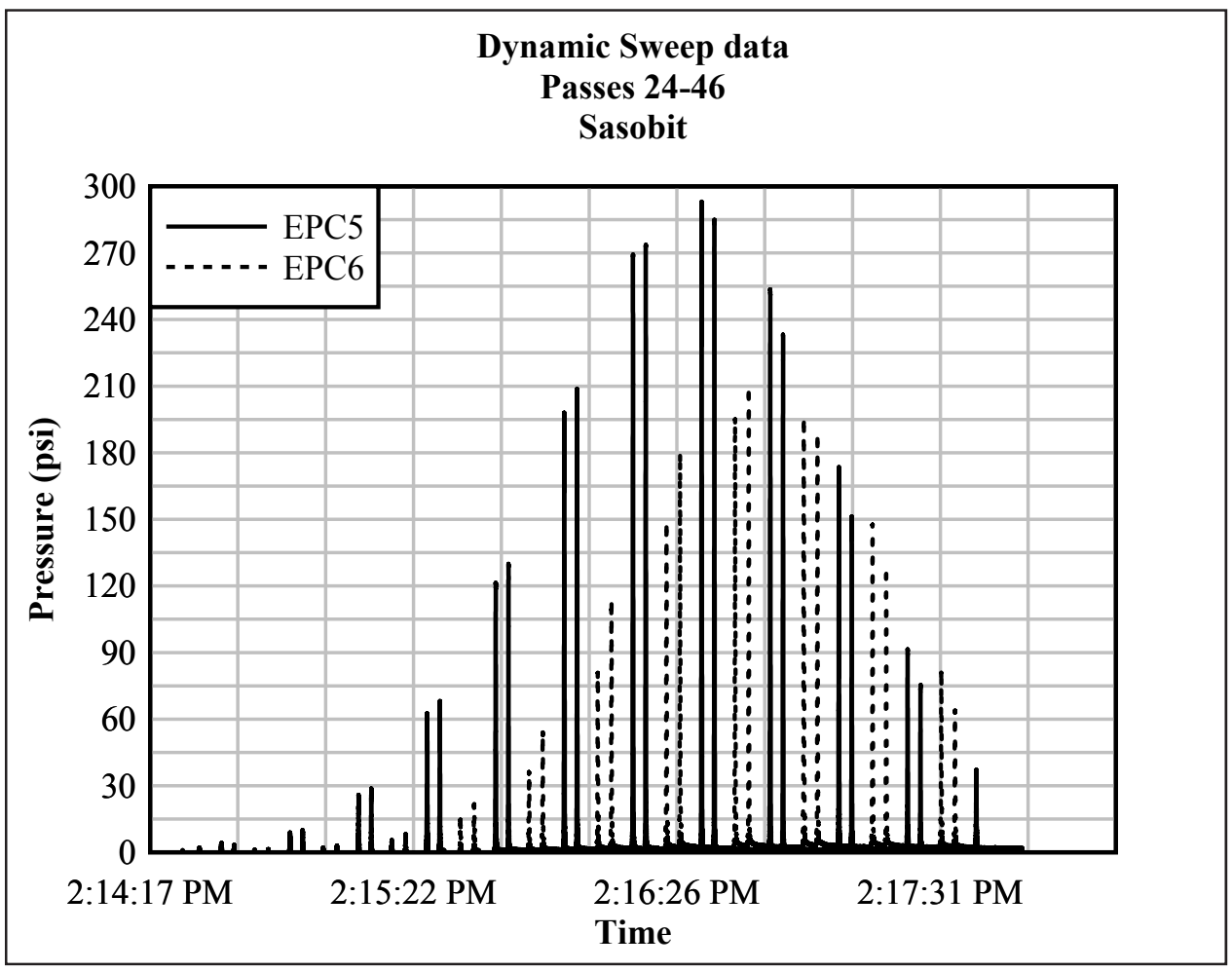

Figure 51. Maximum pressure distribution from dynamic sweep test data.

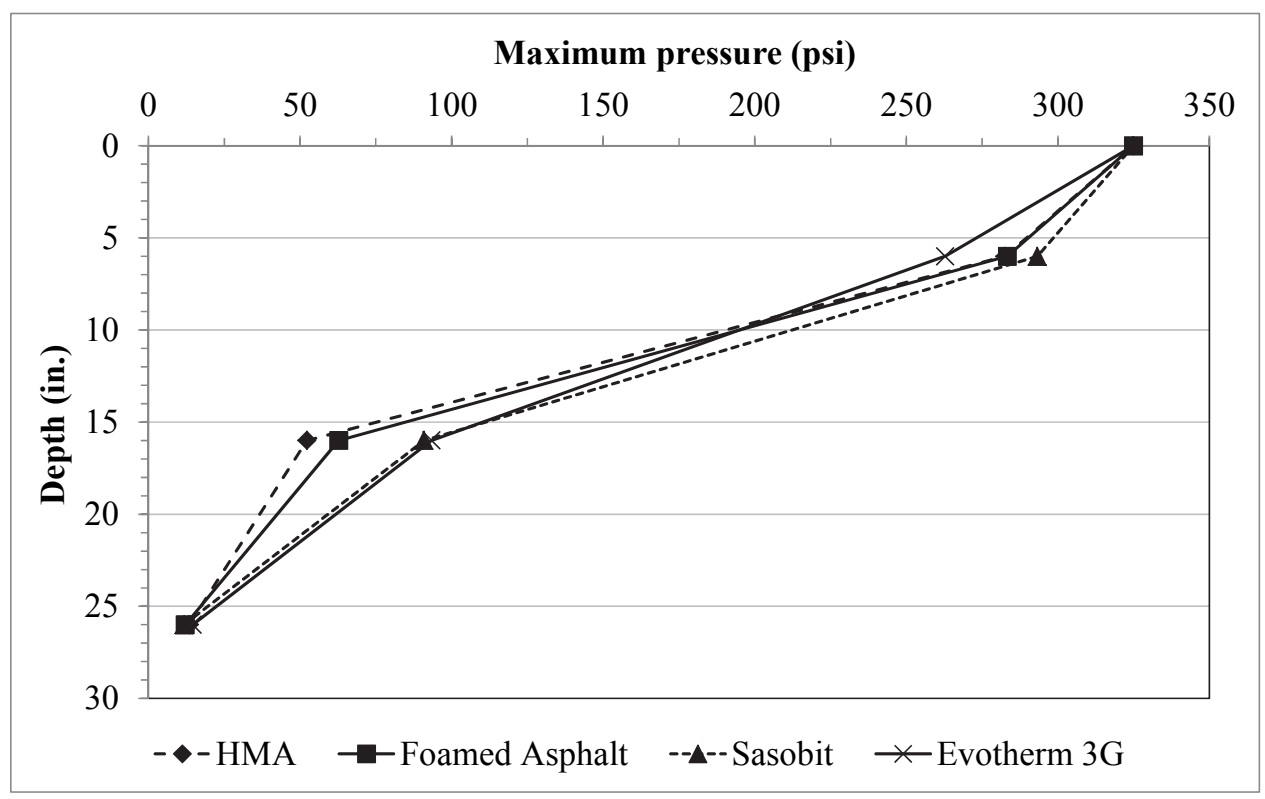

The maximum deflections measured at each sub-layer with the SDDs during dynamic sweep tests are presented in Table 10. The maximum deflections measured during the dynamic sweep test at each pass level on each test item are presented in Figures 52-55. As previously discussed, 
some of the SDDs did not record any data during testing, and some of them failed during the test. Deflection behavior under the dynamic sweep test was very similar to that observed during dynamic slow roll test, showing negligible change in deflection with traffic on the sub-layers where measurements were recorded.

Table 10. Maximum deflections measured with the SDDs during dynamic sweep tests.

\begin{tabular}{|l|l|l|l|l|}
\hline \multirow{2}{*}{ Test Item } & \multicolumn{3}{|c|}{ Maximum Deflection (in.) } & Avg. Surface Temp. \\
\cline { 2 - 5 } & Subgrade & Subbase & Base & $\left({ }^{\circ} \mathrm{F}\right)$ \\
\hline HMA & 0.04 & 0.06 & $0.14^{\mathrm{a}}$ & 106.7 \\
\hline Foamed Asphalt & 0.05 & $-{ }^{\mathrm{b}}$ & $0.21^{\mathrm{c}}$ & 103.9 \\
\hline Sasobit ${ }^{\circledR}$ & $-^{\mathrm{b}}$ & 0.04 & $0.20^{\mathrm{c}}$ & 107.7 \\
\hline Evotherm & & & \\
\hline
\end{tabular}

a Instrument failed after the second traffic interval applied.

b Instrument did not record data during the test.

c Instrument failed before trafficking was completed.

Figure 52. HMA maximum deflection measured at the base, subbase and subgrade during dynamic sweep test at each pass level.

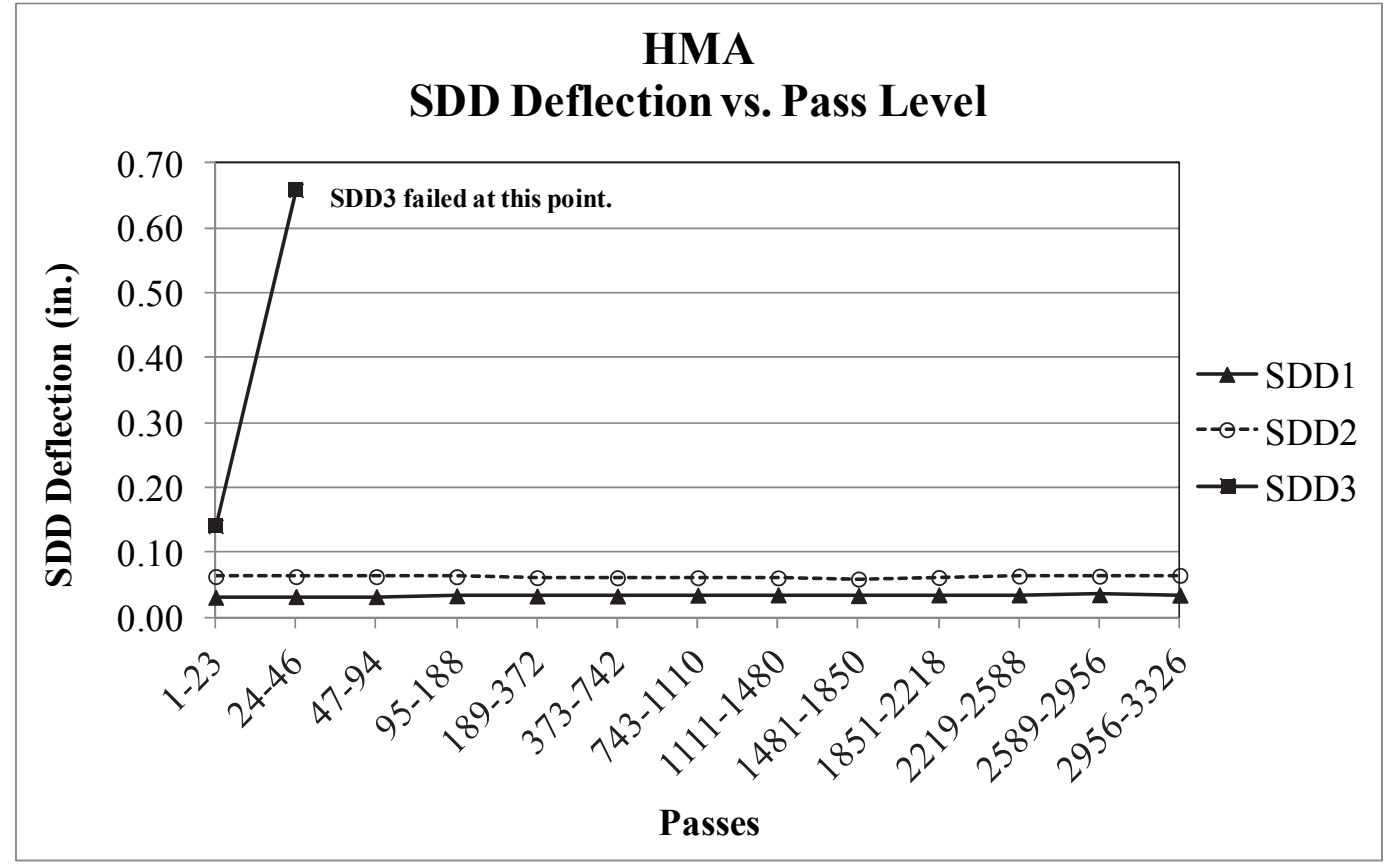


Figure 53. Foamed Asphalt maximum deflection measured at the base, subbase and subgrade during dynamic sweep test at each pass level.

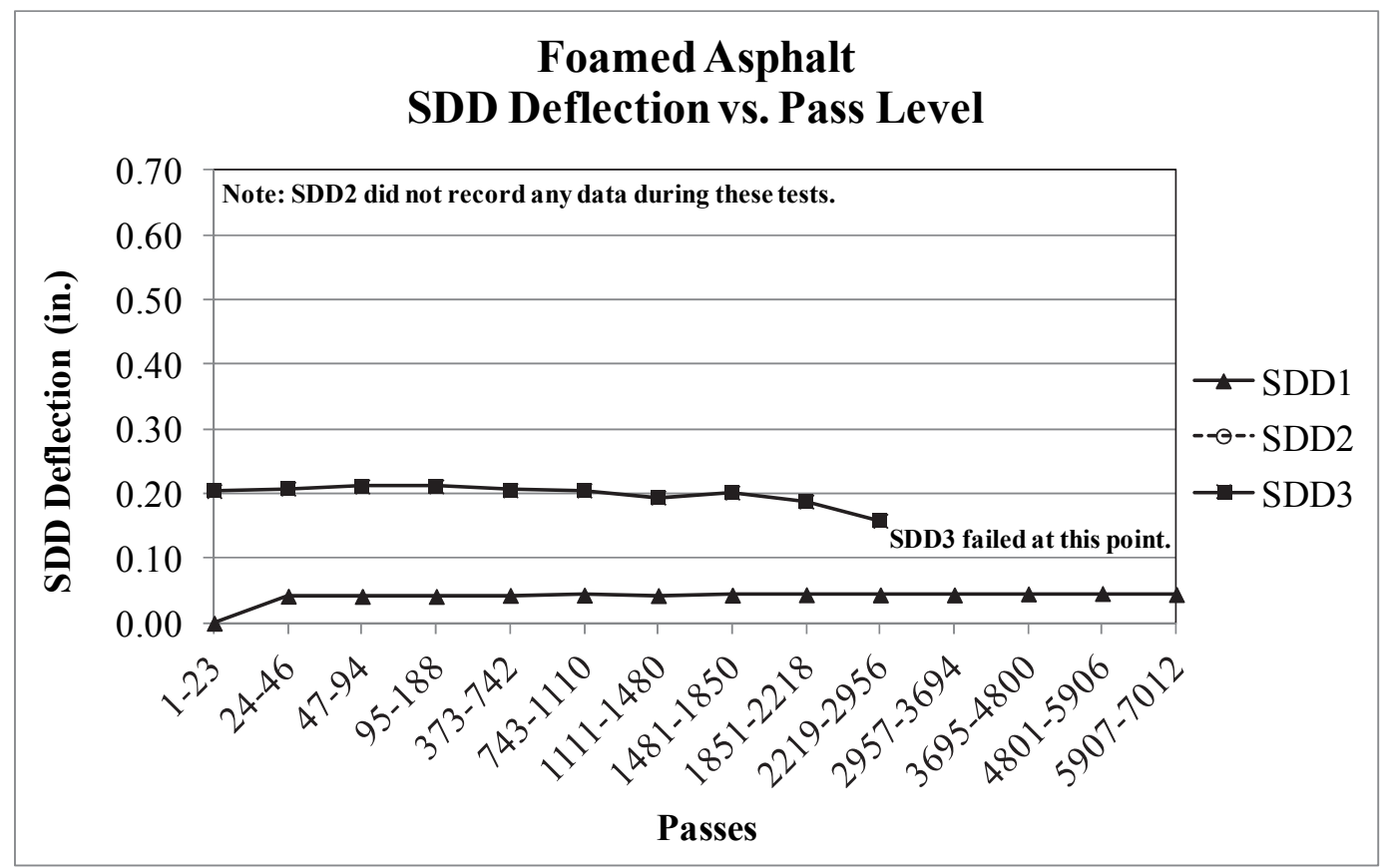

Figure 54. Sasobit $\circledast$ maximum deflection measured at the base, subbase and subgrade during dynamic sweep test at each pass level.

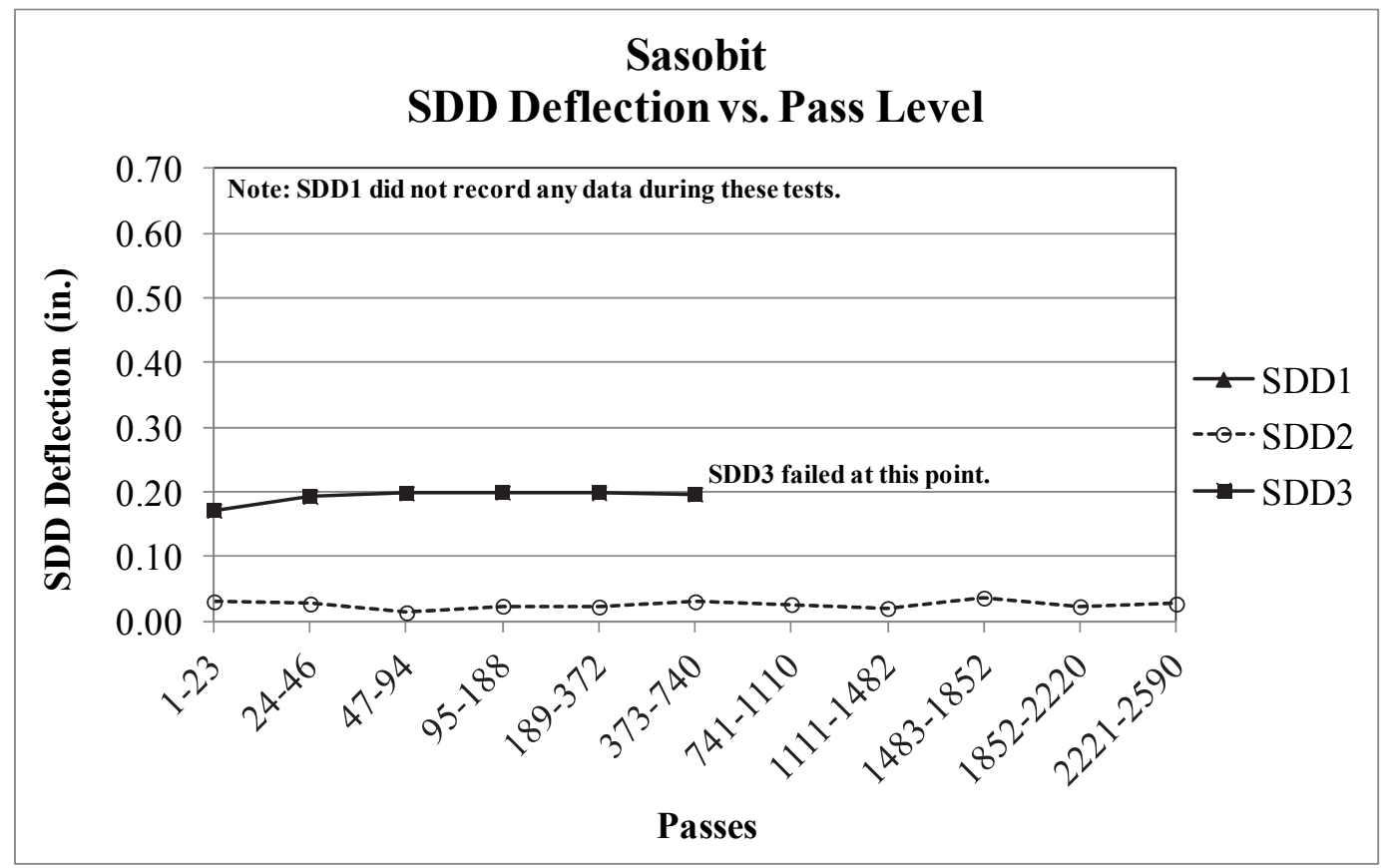


Figure 55. Evotherm ${ }^{\mathrm{TM}} 3 \mathrm{G}$ maximum deflection measured at the base, subbase and subgrade during dynamic sweep test at each pass level.

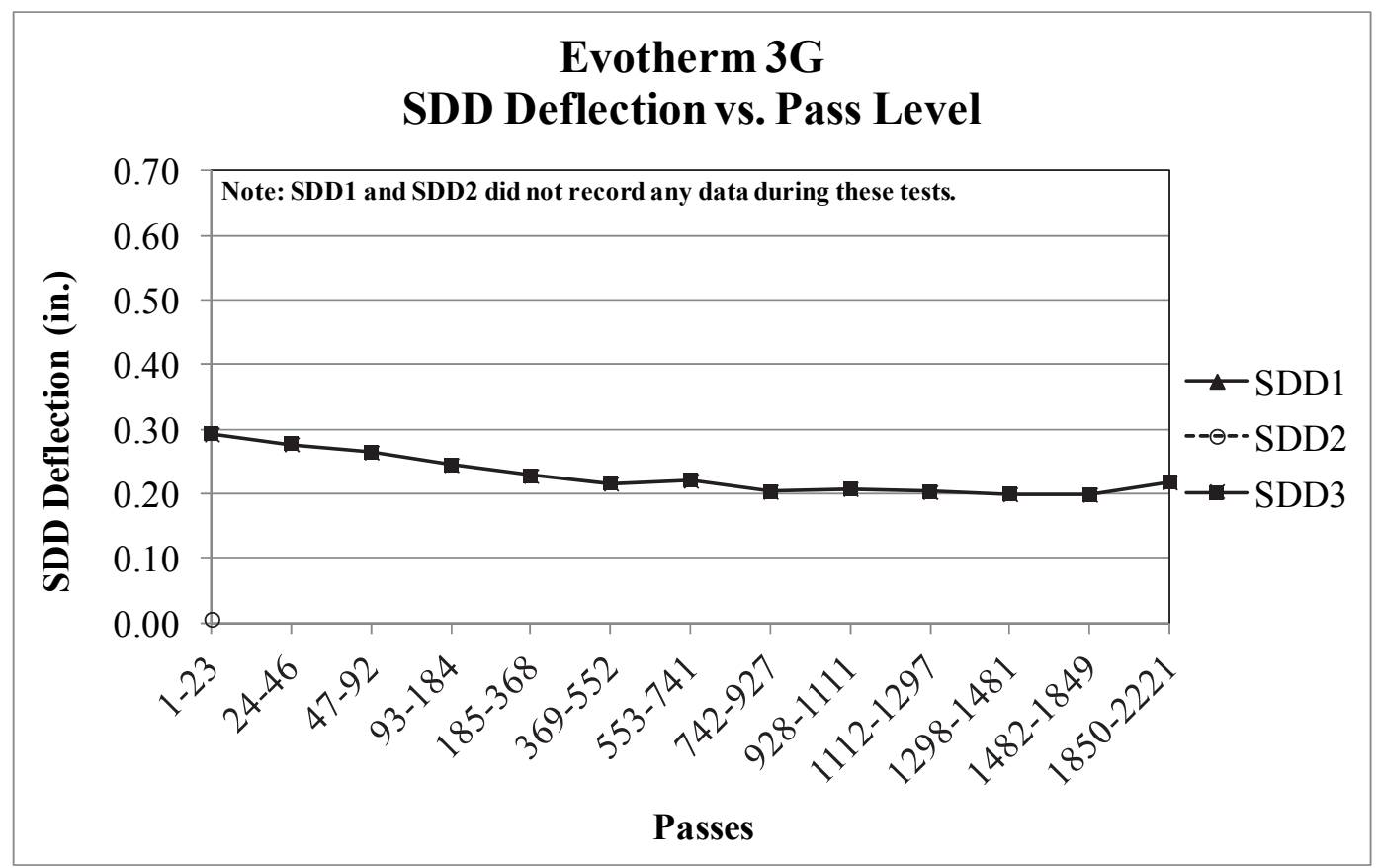

\subsubsection{Strain gauges}

Only a limited amount of data was recorded by some of the surface and asphalt strain gauges because most of them failed early during trafficking. Failure of some surface strain gauges generally occurred after 100 passes of the F-15 load cart, while others failed earlier after only 23 passes. Failure of most of the asphalt strain gauges occurred during construction when the paver drove over the gauges. Even after carefully following the manufacturer's installation instructions, less than $30 \%$ of the gauges survived the paving. The few gauges that survived construction did not last long during trafficking. As a consequence, very limited data were obtained from the asphalt strain gauges.

The limited data collected with the surface and asphalt strain gauges did not produce trends that could lead to conclusive observations on the strain behavior of the asphalt pavement. For the future, it is recommended to explore the use of different types of gauges or to improve installation procedures so that the life of the instruments can be extended to a point where enough data can be collected to produce useful results. 


\subsection{Forensic evaluation}

A total of four trenches (each crossing two test items) were excavated on the test section six months after trafficking was completed. Two trenches per test item were used to analyze post traffic conditions: one at the south end (between stations $0+16$ and $0+19$ ), and one on the north end (between stations $0+36$ and $0+39$ ). Tables 11-12 list the post traffic field measurements of CBR, moisture content and nuclear gauge dry density collected at the center of the trenches (stations $0+17.5$ and $0+37.5$ ). The changes in these soil properties were calculated by comparing post-traffic measurements collected at STA $0+17.5$ and $0+37.5$ with after construction measurements collected at STA $0+15$ and $0+35$, respectively. These changes are presented in Figure 56. A negative value represents a decrease in the corresponding soil property after traffic. In general, minimum densification was observed in all layers. The changes in density (mostly negative) can be attributed to the variability of the nuclear density gauge test. The moisture contents decreased with time, and the CBR's increased mostly in the subbase layer. Since minimum densification was observed in any of the layers, the CBR increase was attributed to the change in moisture content. The subbase consisted of clay gravel that tends to gain strength quickly with small changes in moisture content (Rushing et al., 2013). Surprisingly, the moisture content of the subgrade decreased in Items 2 and 4; however, these changes did not affect the CBR. The moisture content and the CBR of the base layer were not affected by traffic operations or time, as no significant changes in these properties were observed. 
Table 11. Post-test field measurements at STA 0+17.5.

\begin{tabular}{|c|c|c|c|c|c|c|c|c|}
\hline Item & $\begin{array}{l}\text { Foundation } \\
\text { Layer }\end{array}$ & $\begin{array}{l}\text { Test } \\
\text { Location }\end{array}$ & $\begin{array}{l}\text { Dry } \\
\text { Density } \\
\left(\mathrm{lb} / \mathrm{ft}^{3}\right)\end{array}$ & $\begin{array}{l}\text { Moisture } \\
\text { Content } \\
(\%)\end{array}$ & CBR (\%) & $\begin{array}{l}\text { Change } \\
\text { in Dry } \\
\text { Density } \\
\left(\mathrm{lb} / \mathrm{ft}^{3}\right)\end{array}$ & $\begin{array}{l}\text { Change in } \\
\text { Moisture } \\
\text { Content } \\
(\%)\end{array}$ & $\begin{array}{l}\text { Change in } \\
\text { CBR (\%) }\end{array}$ \\
\hline \multirow[t]{6}{*}{ HMA } & \multirow[t]{2}{*}{ Base } & Center & 132.7 & 1.5 & 100 & -7.6 & -0.9 & 0.0 \\
\hline & & Outside & 132.7 & 1.6 & 100 & -7.6 & -0.8 & 0.0 \\
\hline & \multirow[t]{2}{*}{ Subbase } & Center & 123.9 & 4.7 & 100 & 1.2 & -1.8 & 76.0 \\
\hline & & Outside & 123.9 & 4.7 & 100 & 1.2 & -1.8 & 76.0 \\
\hline & \multirow[t]{2}{*}{ Subgrade } & Center & 95.6 & 22.4 & 21 & -1.2 & -2.1 & 8.0 \\
\hline & & Outside & 95.6 & 23.2 & 19 & -1.2 & -1.3 & 6.0 \\
\hline \multirow[t]{6}{*}{ Foamed Asphalt } & \multirow[t]{2}{*}{ Base } & Center & 140.9 & 2.1 & 97 & 3.1 & 0.0 & -3.0 \\
\hline & & Outside & 140.2 & 2.7 & 100 & 2.3 & 0.6 & 0.0 \\
\hline & \multirow[t]{2}{*}{ Subbase } & Center & 118.4 & 5.9 & 91 & -7.4 & -0.8 & 55.0 \\
\hline & & Outside & 118.7 & 7.1 & 25 & -7.1 & 0.4 & -11.0 \\
\hline & \multirow[t]{2}{*}{ Subgrade } & Center & 94.9 & 21.9 & 21 & -1.2 & -0.2 & 5.0 \\
\hline & & Outside & 94.9 & 21.5 & 18 & -1.2 & -0.6 & 2.0 \\
\hline \multirow[t]{6}{*}{ Sasobit $®$} & \multirow[t]{2}{*}{ Base } & Center & 135.8 & 1.4 & 100 & 1.3 & -0.6 & 0.0 \\
\hline & & Outside & 135.8 & 1 & 100 & 1.3 & -1.0 & 0.0 \\
\hline & \multirow[t]{2}{*}{ Subbase } & Center & 120.5 & 3.2 & 95 & -5.5 & -2.4 & 60.0 \\
\hline & & Outside & 125.8 & 3.1 & 100 & -0.2 & -2.5 & 65.0 \\
\hline & \multirow[t]{2}{*}{ Subgrade } & Center & 90.6 & 22.6 & 19 & -2.9 & -1.0 & 3.0 \\
\hline & & Outside & 92.7 & 23.4 & 26 & -0.8 & -0.2 & 10.0 \\
\hline \multirow[t]{6}{*}{ Evotherm ${ }^{\mathrm{TM}} 3 \mathrm{G}$} & \multirow[t]{2}{*}{ Base } & Center & 136.4 & 1.4 & 100 & 1.0 & -0.1 & 0.0 \\
\hline & & Outside & 136.9 & 1.7 & 100 & 1.5 & 0.2 & 0.0 \\
\hline & \multirow[t]{2}{*}{ Subbase } & Center & 128.7 & 3.6 & 92 & 4.1 & -2.2 & 70.0 \\
\hline & & Outside & 118.1 & 4.6 & 68 & -6.5 & -1.2 & 46.0 \\
\hline & \multirow[t]{2}{*}{ Subgrade } & Center & 93.6 & 21.3 & 24 & -1.3 & -4.4 & 8.0 \\
\hline & & Outside & 89.9 & 22.8 & 21 & -5.0 & -2.9 & 5.0 \\
\hline
\end{tabular}

Notes:

- Changes were calculated comparing post traffic measurements collected at STA 0+16 with after construction measurements collected at STA $0+15$ on each test item.

- A negative value represents a decrease in the corresponding soil property.

- Dry densities were measured with nuclear density gauge per ASTM D 6938.

- CBR and moisture content were measure through CBR field testing per ASTM D 4429. 
Table 12. Post-test field measurements at STA 0+37.5.

\begin{tabular}{|c|c|c|c|c|c|c|c|c|}
\hline Item & $\begin{array}{l}\text { Foundation } \\
\text { Layer }\end{array}$ & $\begin{array}{l}\text { Test } \\
\text { Location }\end{array}$ & $\begin{array}{l}\text { Dry } \\
\text { Density } \\
\left(\mathrm{lb} / \mathrm{ft}^{3}\right)\end{array}$ & $\begin{array}{l}\text { Moisture } \\
\text { Content } \\
\text { (\%) }\end{array}$ & CBR (\%) & $\begin{array}{l}\text { Change } \\
\text { in Dry } \\
\text { Density } \\
\left(\mathrm{lb}^{\prime} \mathrm{ft}^{3}\right)\end{array}$ & $\begin{array}{l}\text { Change in } \\
\text { Moisture } \\
\text { Content } \\
(\%)\end{array}$ & $\begin{array}{l}\text { Change } \\
\text { in CBR } \\
(\%)\end{array}$ \\
\hline \multirow[t]{6}{*}{ HMA } & \multirow[t]{2}{*}{ Base } & Center & 139.4 & 0.9 & 100 & 3.3 & -0.7 & 0.0 \\
\hline & & Outside & 139.4 & 1.2 & 100 & 3.3 & -0.4 & 0.0 \\
\hline & \multirow[t]{2}{*}{ Subbase } & Center & 126.4 & 5 & 100 & -0.2 & -1.7 & 70.0 \\
\hline & & Outside & 126.4 & 4.4 & 100 & -0.2 & -2.3 & 70.0 \\
\hline & \multirow[t]{2}{*}{ Subgrade } & Center & 96.2 & 22.8 & 18 & 0.6 & -0.5 & 4.0 \\
\hline & & Outside & 91.4 & 23.7 & 19 & -4.2 & 0.4 & 5.0 \\
\hline \multirow[t]{6}{*}{ Foamed Asphalt } & \multirow[t]{2}{*}{ Base } & Center & 137.4 & 1.8 & 96 & -1.8 & -0.2 & -4.0 \\
\hline & & Outside & 137.4 & 1.9 & 100 & -1.8 & -0.1 & 0.0 \\
\hline & \multirow[t]{2}{*}{ Subbase } & Center & 120.5 & 3.1 & 100 & -3.8 & -5.6 & 76.0 \\
\hline & & Outside & 128.3 & 5 & 100 & 4.0 & -3.7 & 76.0 \\
\hline & \multirow[t]{2}{*}{ Subgrade } & Center & 91.5 & 21.4 & 22 & -4.9 & -3.4 & 6.0 \\
\hline & & Outside & 91.8 & 22.2 & 23 & -4.6 & -2.6 & 7.0 \\
\hline \multirow[t]{6}{*}{ Sasobit $\AA$} & \multirow[t]{2}{*}{ Base } & Center & 140.4 & ${ }^{a}$ & ${ }^{a}$ & 2.6 & ${ }^{a}$ & ${ }^{a}$ \\
\hline & & Outside & 136.2 & 1.4 & 92 & -1.6 & 0.3 & -8.0 \\
\hline & \multirow[t]{2}{*}{ Subbase } & Center & 126.6 & 4.1 & 82 & -1.2 & -1.6 & 38.0 \\
\hline & & Outside & 121 & 5.3 & 48 & -6.8 & -0.4 & 4.0 \\
\hline & \multirow[t]{2}{*}{ Subgrade } & Center & 90.2 & 21.9 & 22 & -0.7 & -0.9 & 7.0 \\
\hline & & Outside & 85.5 & 22.9 & 17 & -5.4 & 0.1 & 2.0 \\
\hline \multirow[t]{6}{*}{ Evotherm $^{\mathrm{TM}} 3 \mathrm{G}$} & \multirow[t]{2}{*}{ Base } & Center & 134.2 & 2 & 97 & -5.9 & 0.3 & -3.0 \\
\hline & & Outside & 138.6 & 2.2 & 100 & -1.5 & 0.5 & 0.0 \\
\hline & \multirow[t]{2}{*}{ Subbase } & Center & 122.5 & 4.6 & 69 & -4.9 & -1.8 & 24.0 \\
\hline & & Outside & 121 & 5 & 53 & -6.4 & -1.4 & 8.0 \\
\hline & \multirow[t]{2}{*}{ Subgrade } & Center & 90.8 & 22.3 & 24 & -4.7 & -1.0 & 10.0 \\
\hline & & Outside & 89 & 23.4 & 11 & -6.5 & 0.1 & -3.0 \\
\hline
\end{tabular}

a Data is not available.

Notes:

- Changes were calculated comparing post traffic measurements collected at STA 0+16 with after construction measurements collected at STA $0+15$ on each test item.

- A negative value represents a decrease in the corresponding soil property. 
Figure 56. Changes in soil properties after traffic.

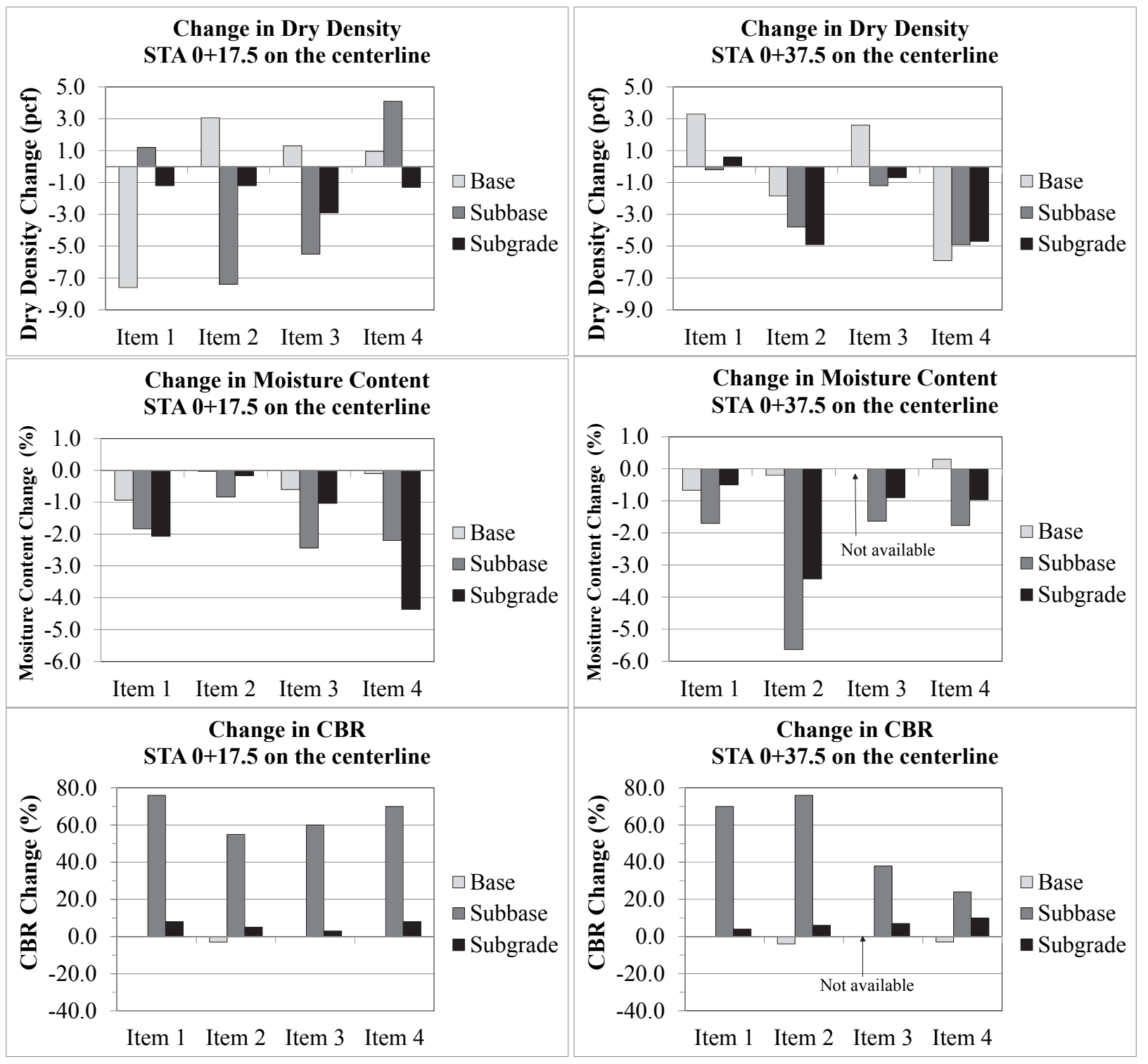

Table 13 presents a comparison between the before and after trafficking layer thicknesses as measured at the centerline of each test item at stations $0+17.5$ and $0+37.5$. It is important to note that the thicknesses before traffic were measured at stations $0+15$ and $0+35$ on the centerline. However, these stations are close enough to be used for general comparison. The final survey data collected from the trenches are presented in Figures 57 through 64. These figures show the as-built (or before traffic) layer surface for reference (dotted lines). Generally, the changes in thickness observed on the subgrade and subbase layers are negligible in all four test items. Some of these changes could have been associated with the trenching process or with the difference caused by comparing measurements from two different 
stations. Thickness changes in the base layer were also minimal in all four items, with some minimum movement observed on Item 3 (Sasobit $\AA$ ) and Item 4 (Evotherm ${ }^{\mathrm{TM}} 3 \mathrm{G}$ ). Any movement observed on the base layer, especially between stations $0+15$ and $0+20$ could have been caused by the traffic loads being carried directly by the base once the asphalt layer failed completely.

Table 13. Comparison of before and after traffic layer thicknesses.

\begin{tabular}{|c|c|c|c|c|c|c|c|}
\hline \multirow[b]{3}{*}{ Item } & \multirow[b]{3}{*}{ Layer } & \multicolumn{6}{|c|}{ Thickness at centerline (in.) } \\
\hline & & \multicolumn{3}{|c|}{ South } & \multicolumn{3}{|c|}{ North } \\
\hline & & $\begin{array}{l}\text { Before } \\
\text { Traffica }^{a}\end{array}$ & \begin{tabular}{|l|} 
After \\
Traffic $^{b}$
\end{tabular} & Change $^{c}$ & $\begin{array}{l}\text { Before } \\
\text { Traffic }^{\text {a }}\end{array}$ & $\begin{array}{l}\text { After } \\
\text { Traffic }^{b}\end{array}$ & Change ${ }^{c}$ \\
\hline \multirow{4}{*}{ HMA } & Subgrade & 22.0 & 22.0 & 0.0 & 22.0 & 22.0 & 0.0 \\
\hline & Subbase & 12.0 & 12.0 & 0.0 & 13.1 & 13.3 & 0.2 \\
\hline & Base & 9.3 & 9.0 & -0.3 & 9.2 & 8.7 & -0.5 \\
\hline & $A C$ & 4.3 & 3.1 & -1.2 & 4.2 & 4.1 & -0.1 \\
\hline \multirow{4}{*}{ Foam } & Subgrade & 22.0 & 22.0 & 0.0 & 22.0 & 22.0 & 0.0 \\
\hline & Subbase & 12.8 & 12.3 & -0.4 & 12.1 & 12.4 & 0.2 \\
\hline & Base & 9.2 & 9.2 & 0.0 & 9.8 & 10.0 & 0.2 \\
\hline & $A C$ & 4.3 & 3.1 & -1.2 & 4.2 & 3.6 & -0.7 \\
\hline \multirow{4}{*}{ Sasobit $\circledast$} & Subgrade & 22.0 & 22.0 & 0.0 & 22.0 & 22.0 & 0.0 \\
\hline & Subbase & 12.0 & 12.4 & 0.4 & 12.2 & 12.0 & -0.2 \\
\hline & Base & 9.6 & 8.0 & -1.6 & 9.4 & 8.8 & -0.7 \\
\hline & $A C$ & 4.4 & 4.2 & -0.1 & 4.1 & 4.2 & 0.1 \\
\hline \multirow{4}{*}{ Evotherm ${ }^{\mathrm{TM}} 3 \mathrm{G}$} & Subgrade & 22.0 & 22.0 & 0.0 & 22.0 & 22.0 & 0.0 \\
\hline & Subbase & 11.7 & 12.2 & 0.5 & 12.8 & 13.3 & 0.6 \\
\hline & Base & 10.8 & 9.9 & -0.9 & 9.6 & 9.2 & -0.5 \\
\hline & $A C$ & 4.2 & 3.3 & -0.9 & 4.3 & 3.9 & -0.4 \\
\hline
\end{tabular}

a Before traffic thicknesses were measured at STA 0+15 (south) and STA 0+35 (north).

b After traffic thicknesses were measured at STA 0+17.5 (south) and STA 0+37.5 (north).

c Negative values represent decreases in thickness. 
Figure 57. HMA south.

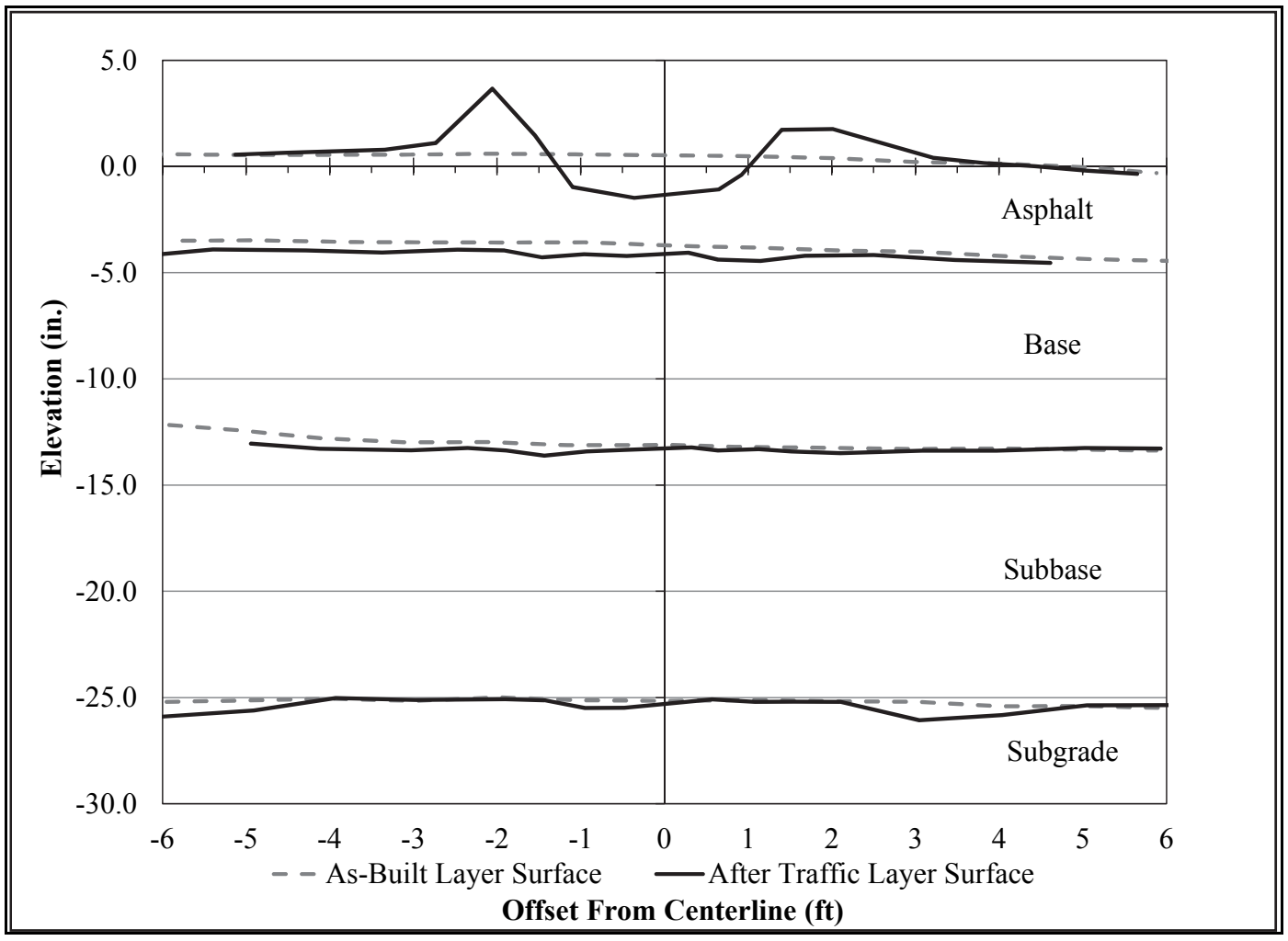

Figure 58. HMA north.

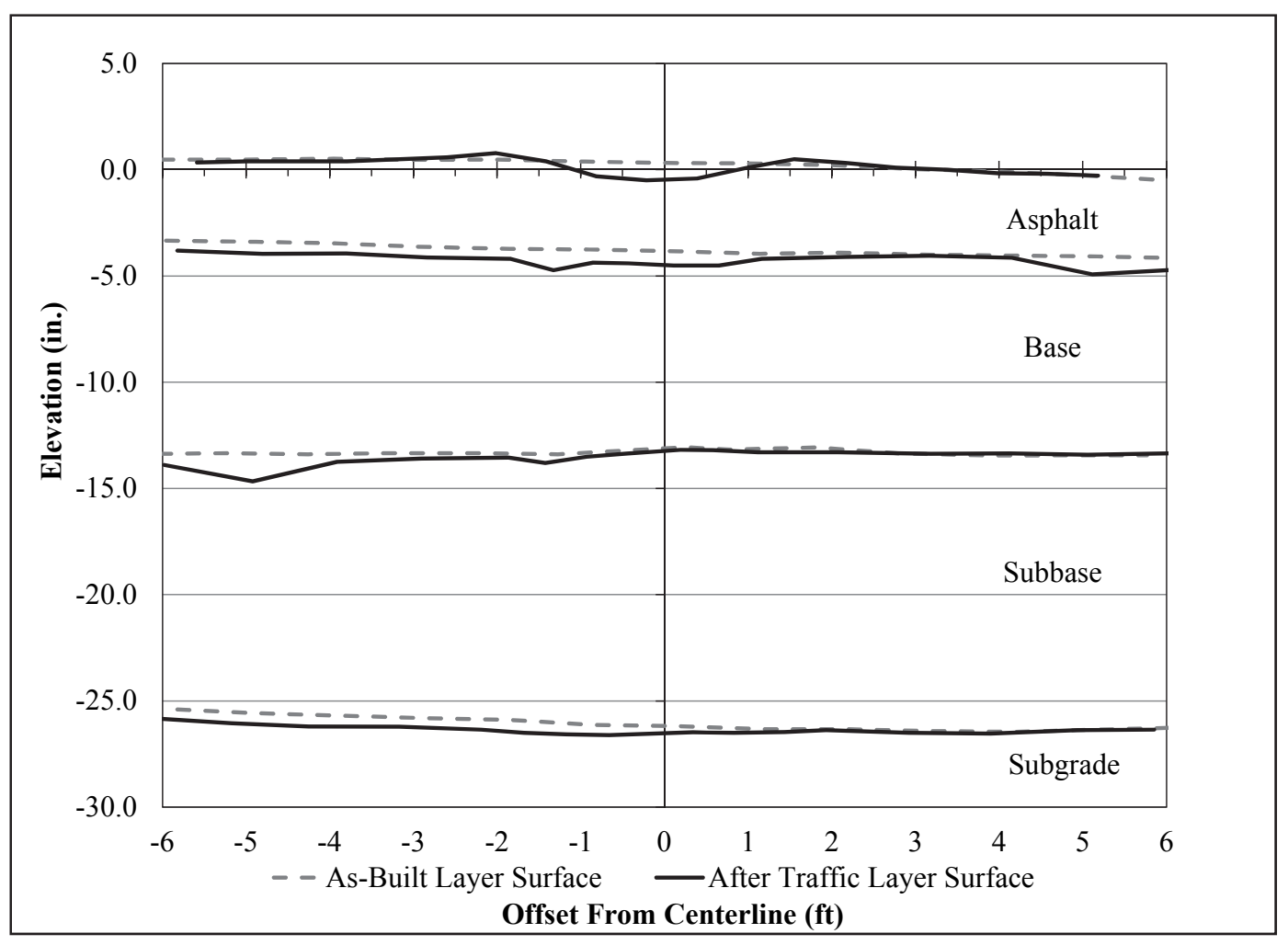


Figure 59. Foamed Asphalt south.

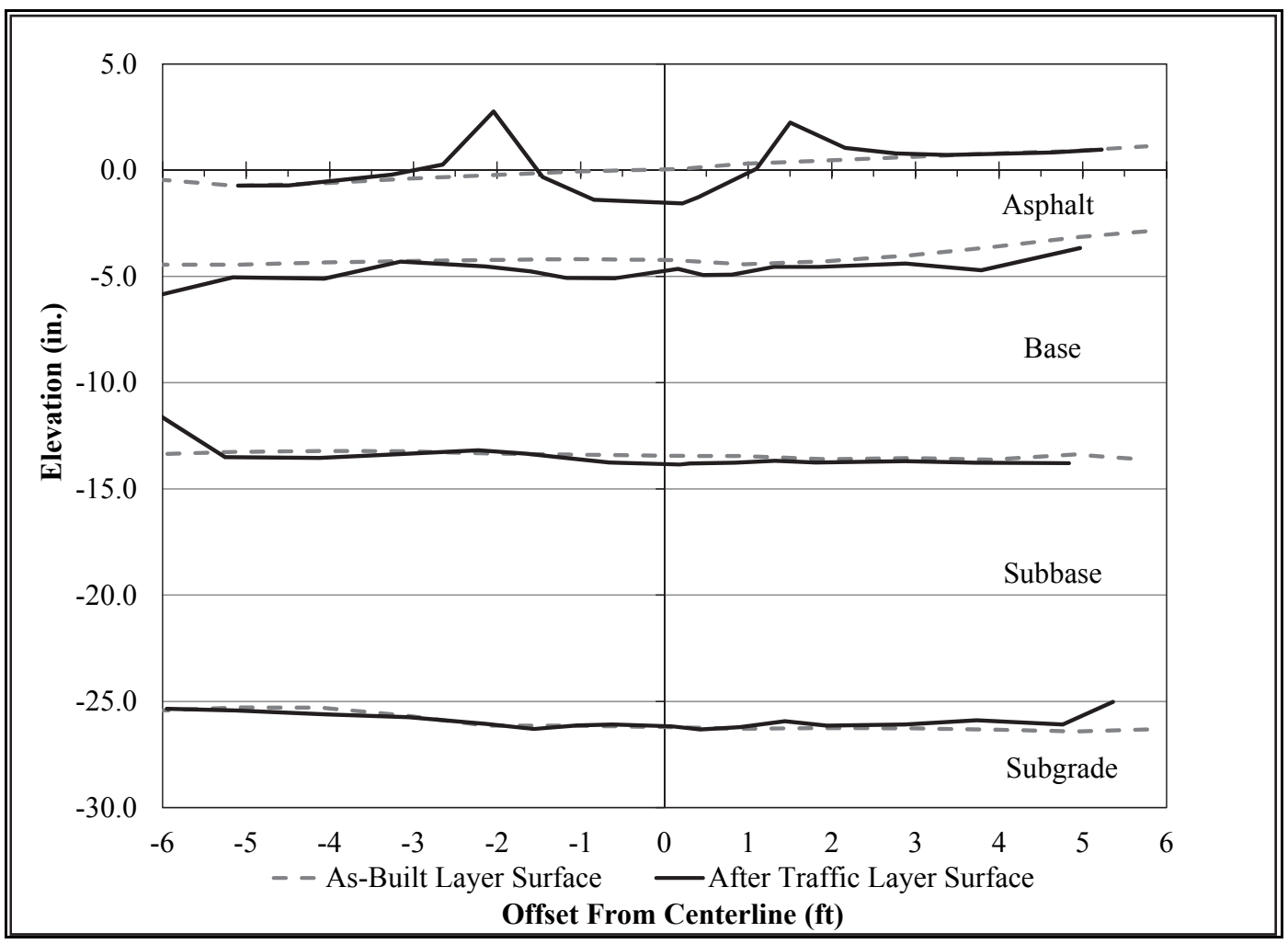

Figure 60. Foamed Asphalt north.

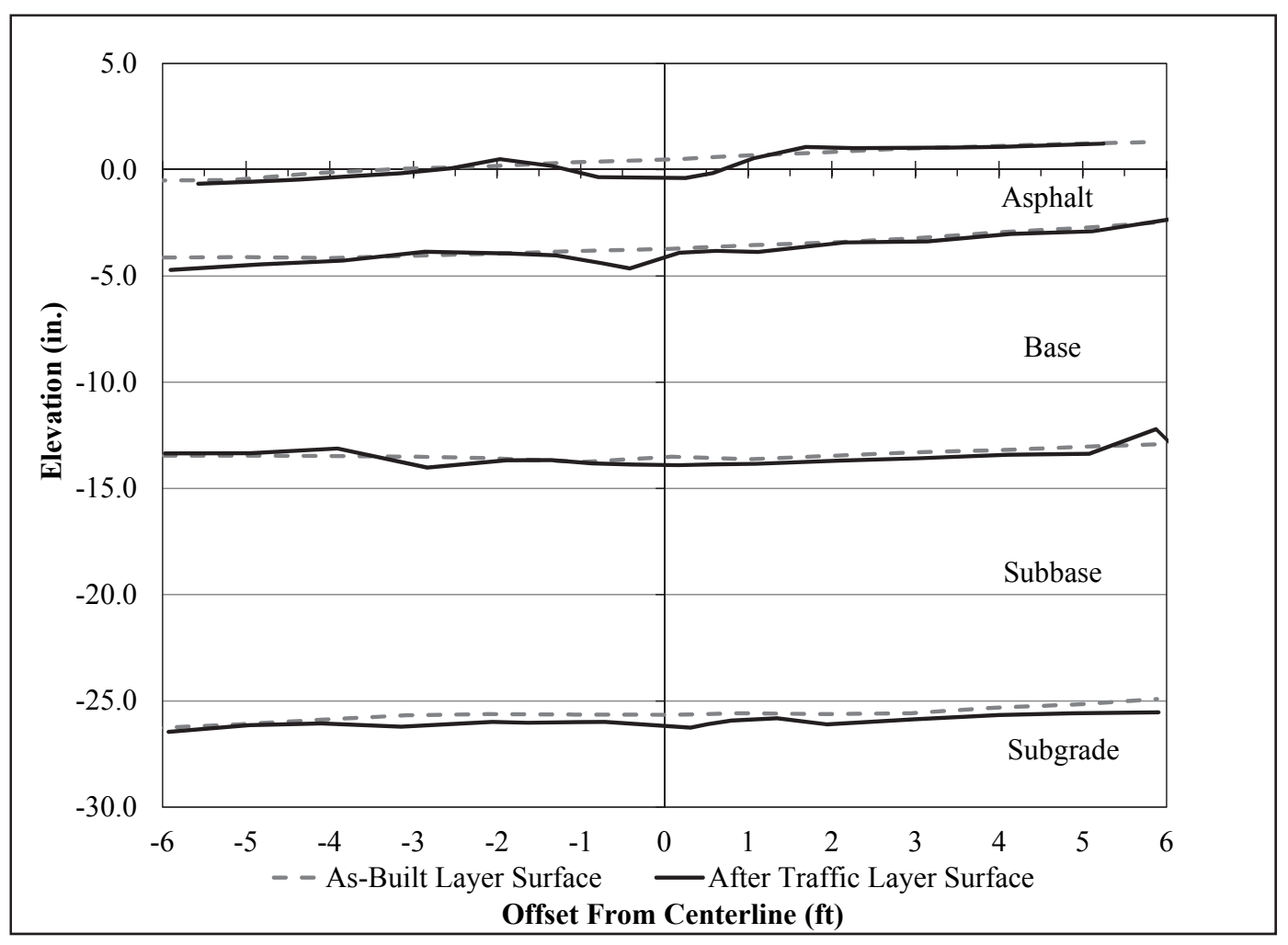


Figure 61. Sasobit $₫$ south.

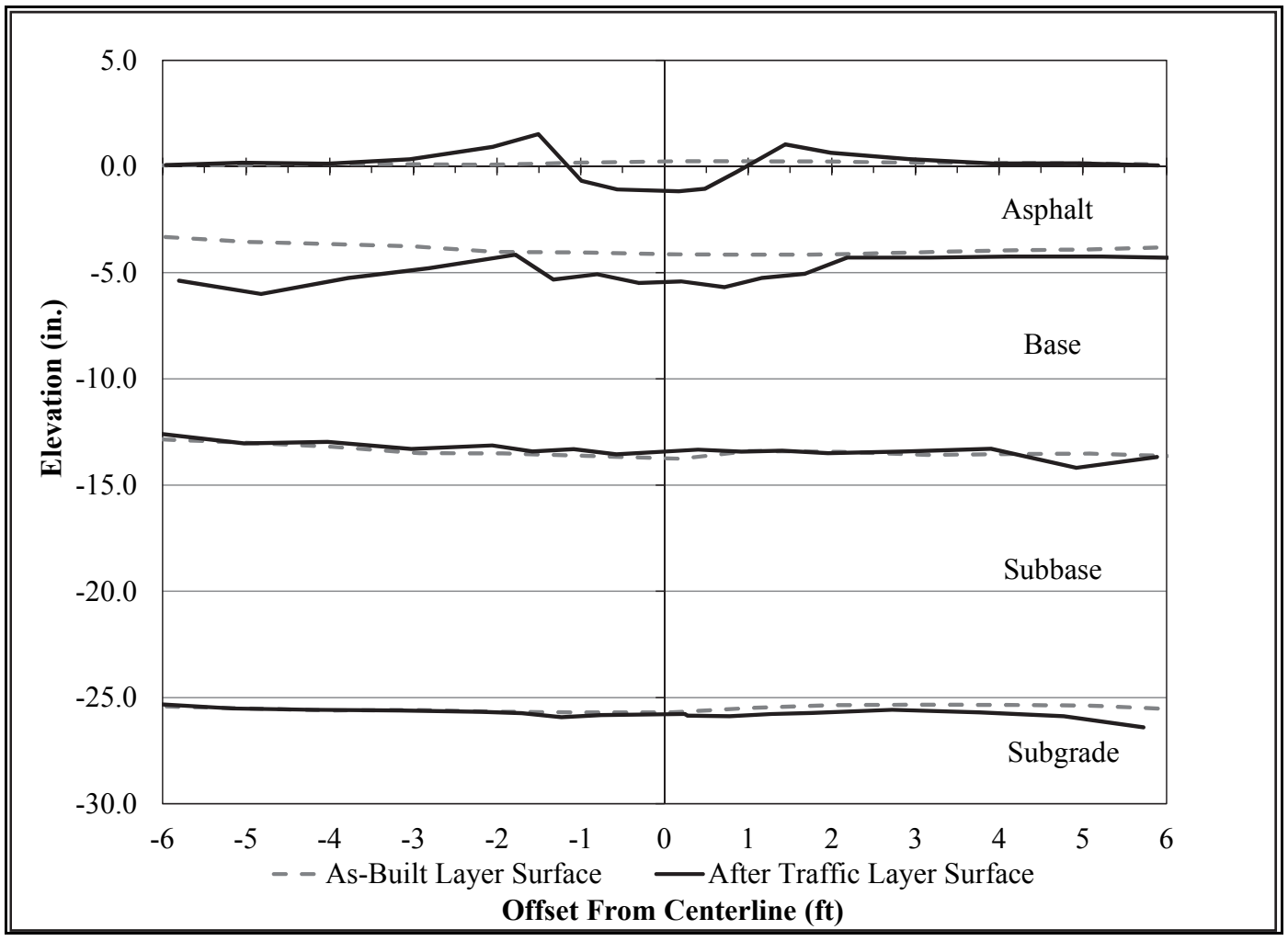

Figure 62. Sasobit ${ }^{\circledR}$ north.

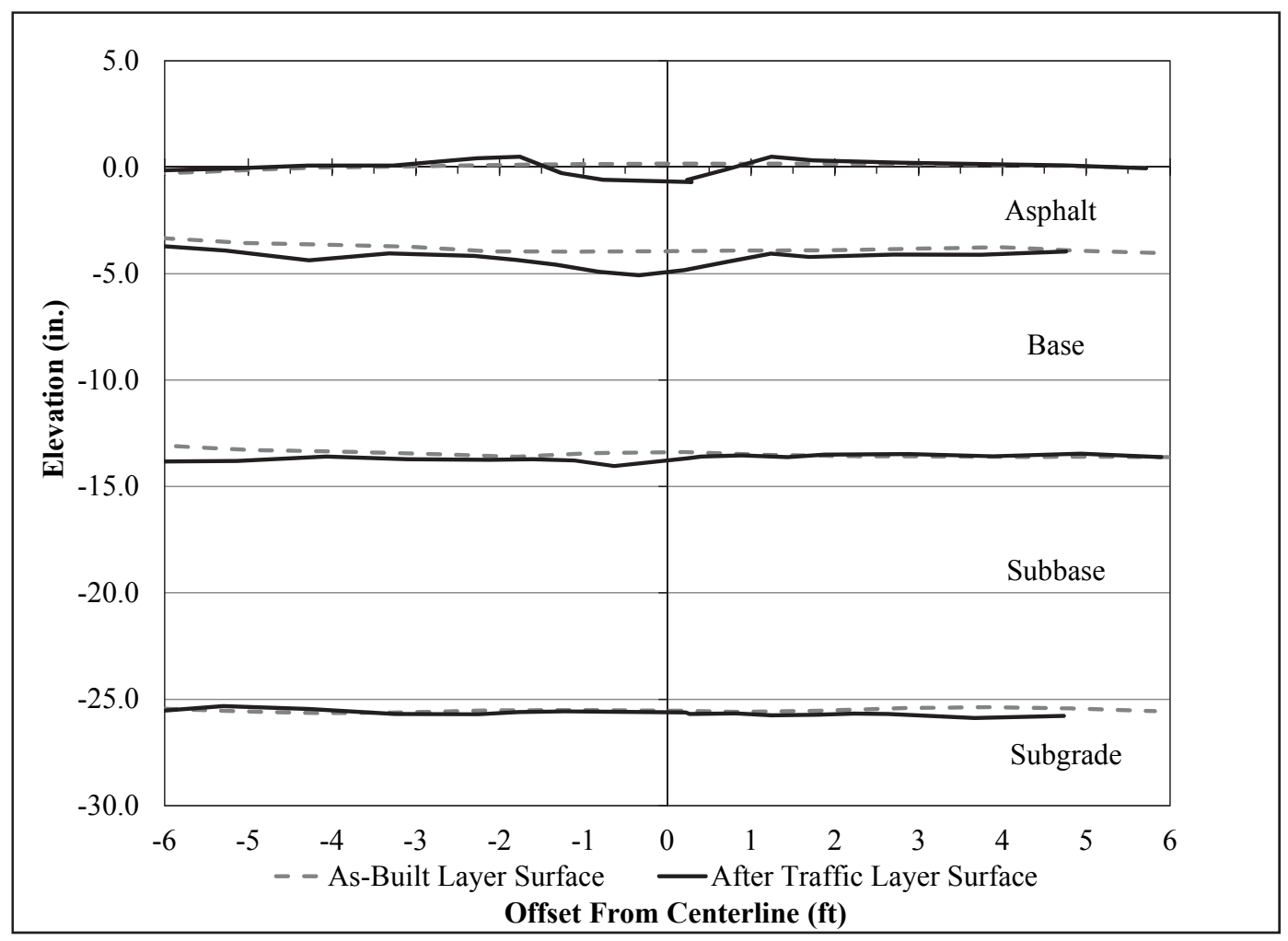


Figure 63. Evotherm ${ }^{\mathrm{TM}} 3 \mathrm{G}$ south.

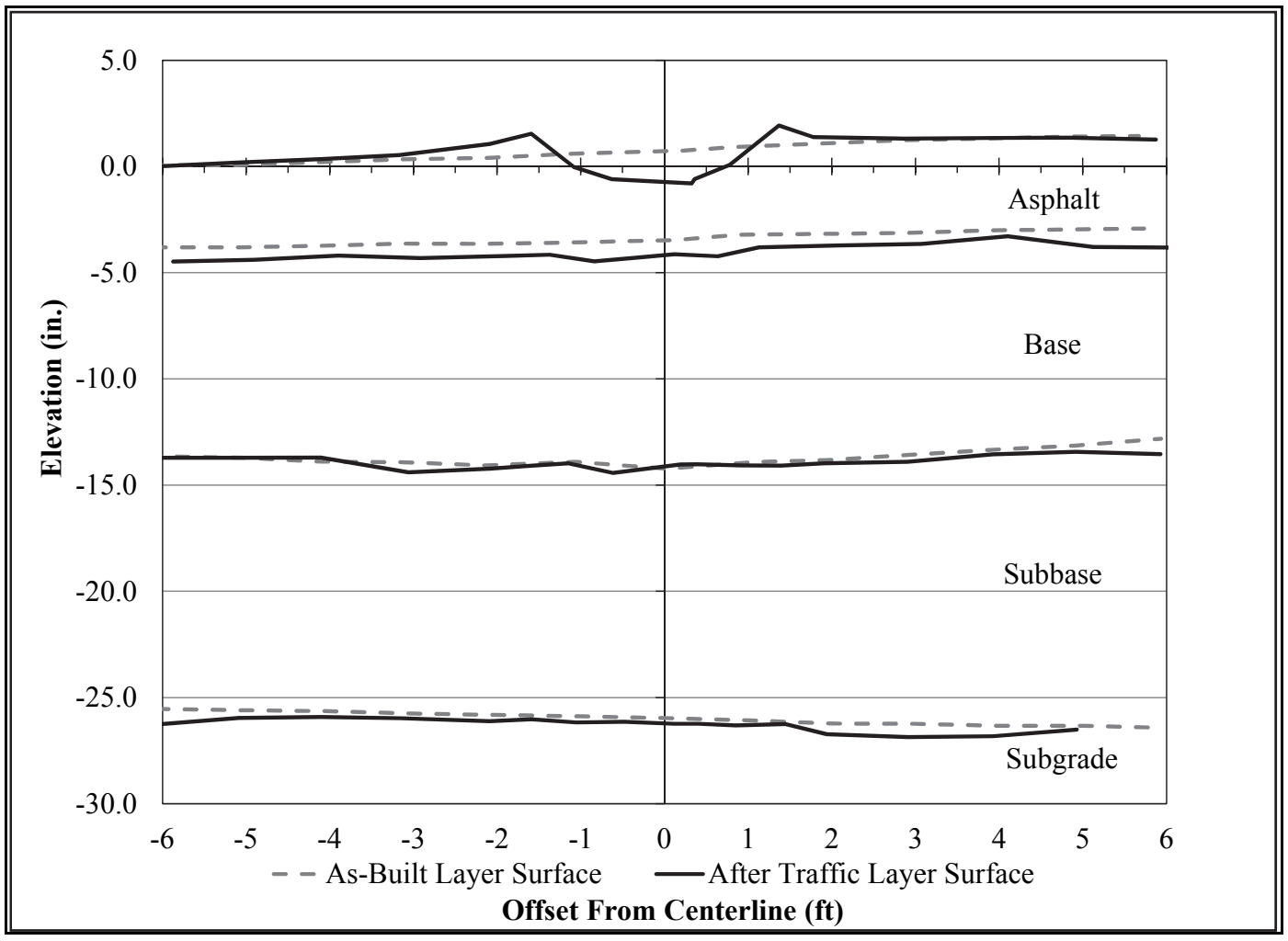

Figure 64. Evotherm ${ }^{\mathrm{TM}} 3 \mathrm{G}$ north.

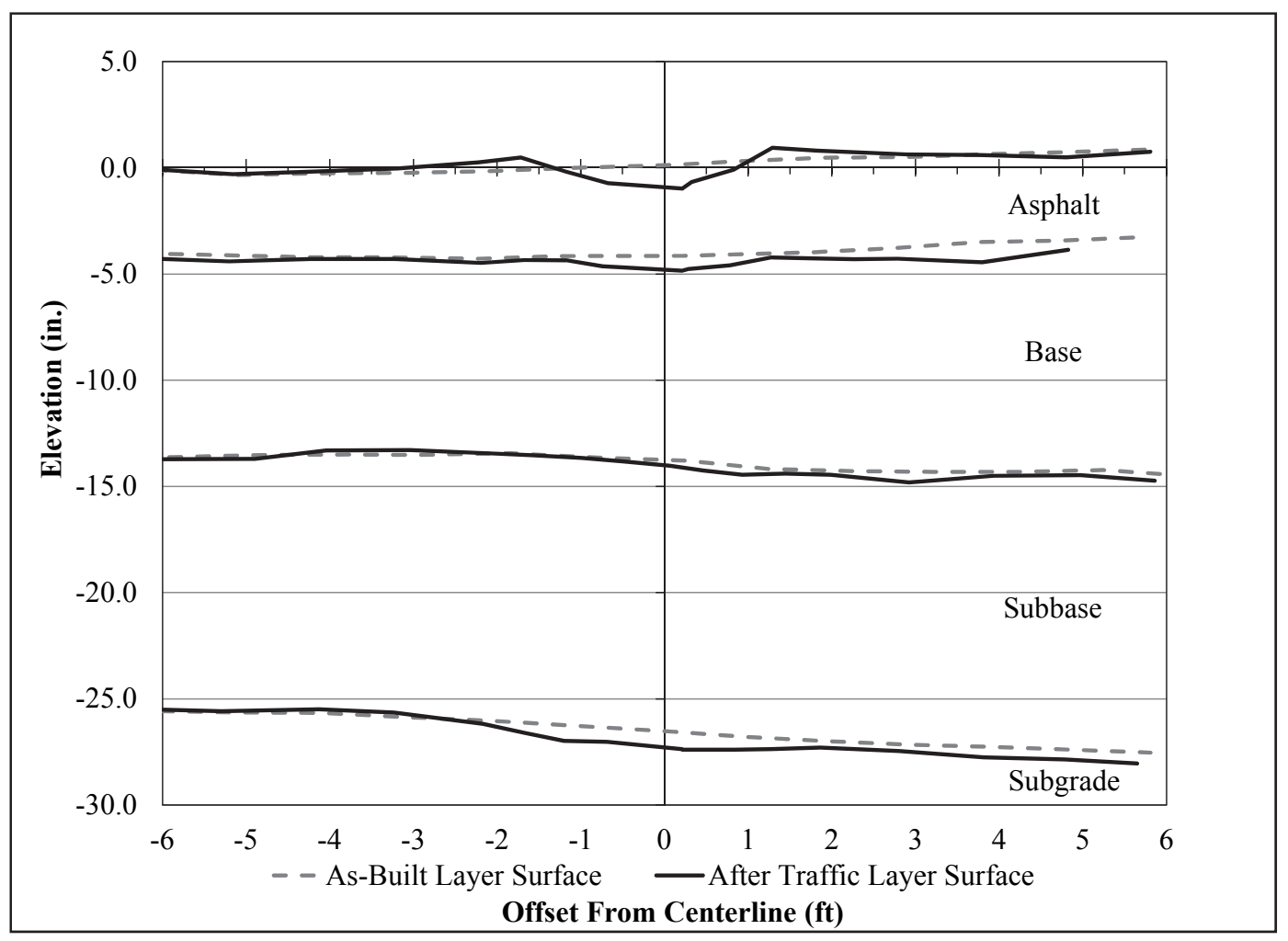


Pictures of the trenches showing the final conditions of the pavement structure in all four items at both locations (north and south) are shown in Figures 65 through 72 . These pictures show no evidence of significant movement of the sub-layers after trafficking and confirm the observations from the instrumentation data.

Figure 65. HMA South Trench (STA 0+16).

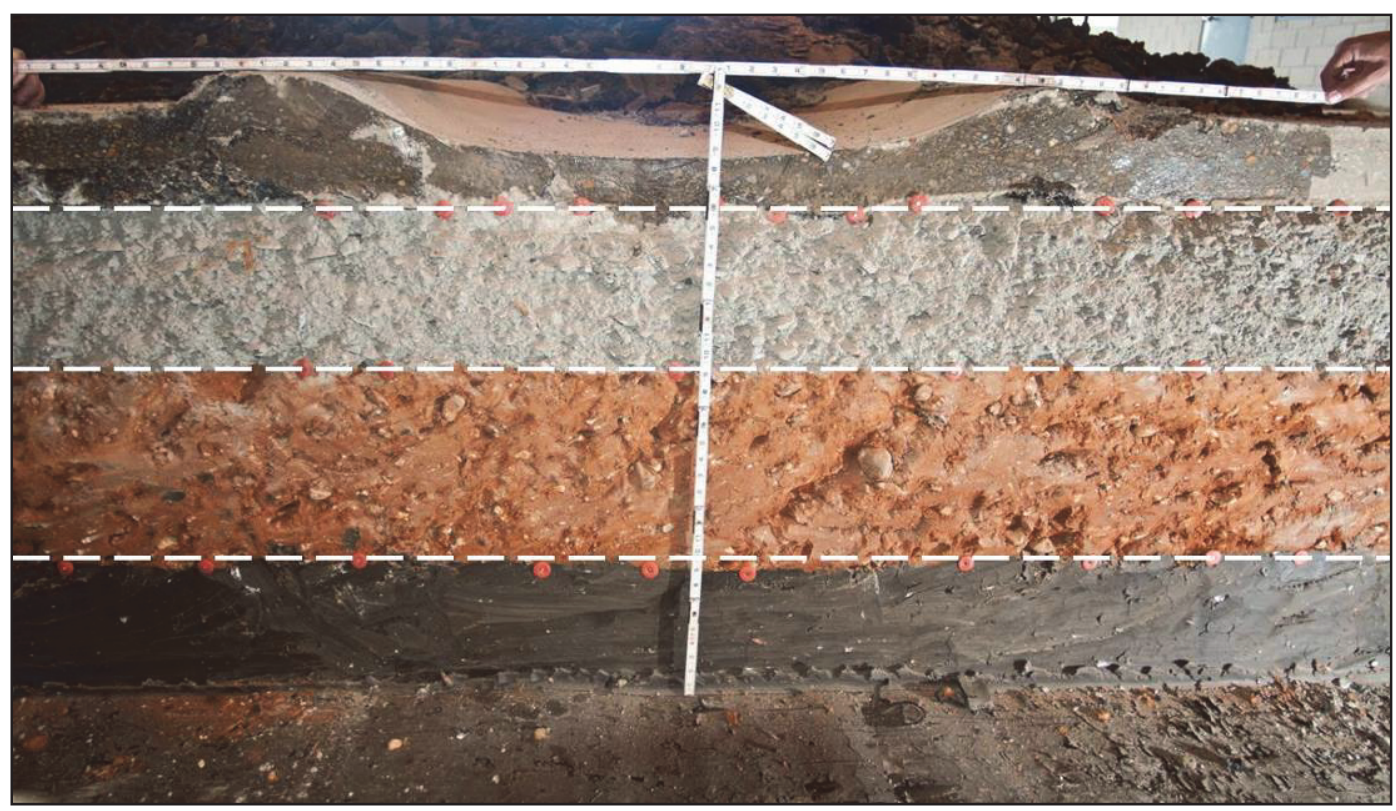

Figure 66. HMA North Trench (STA 0+36).

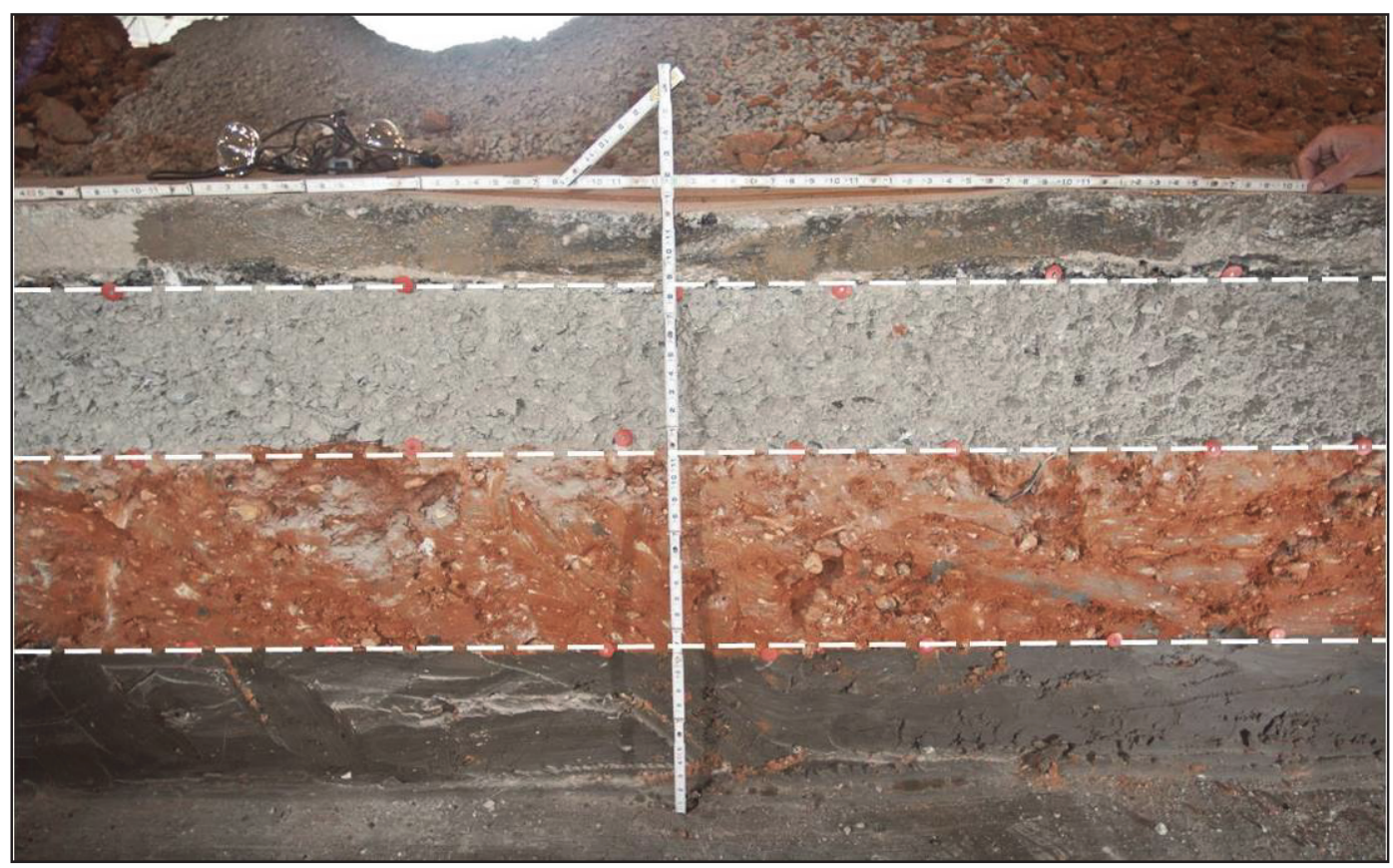


Figure 67. Foamed Asphalt South Trench (STA 0+16).

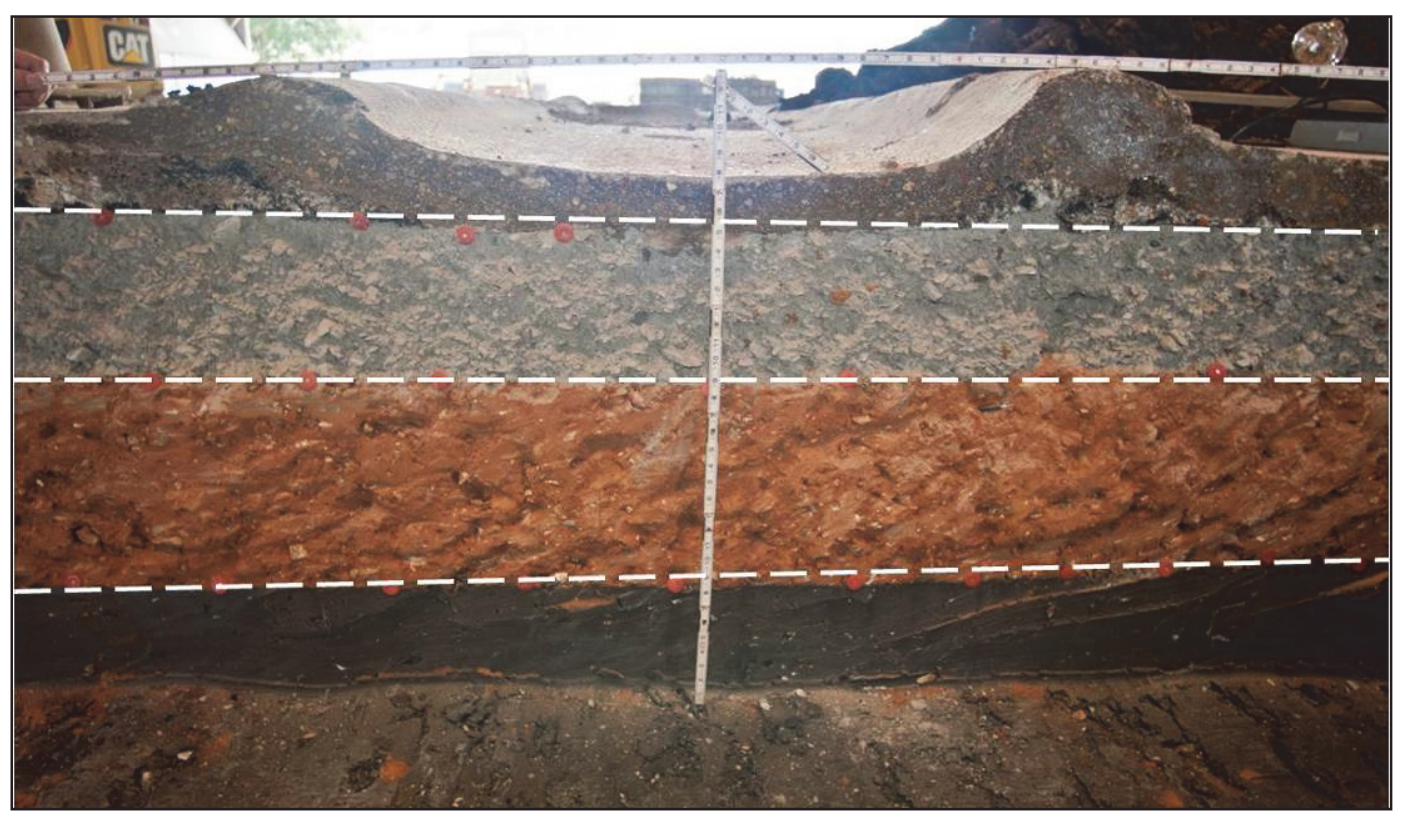

Figure 68. Foamed Asphalt North Trench (STA 0+36).

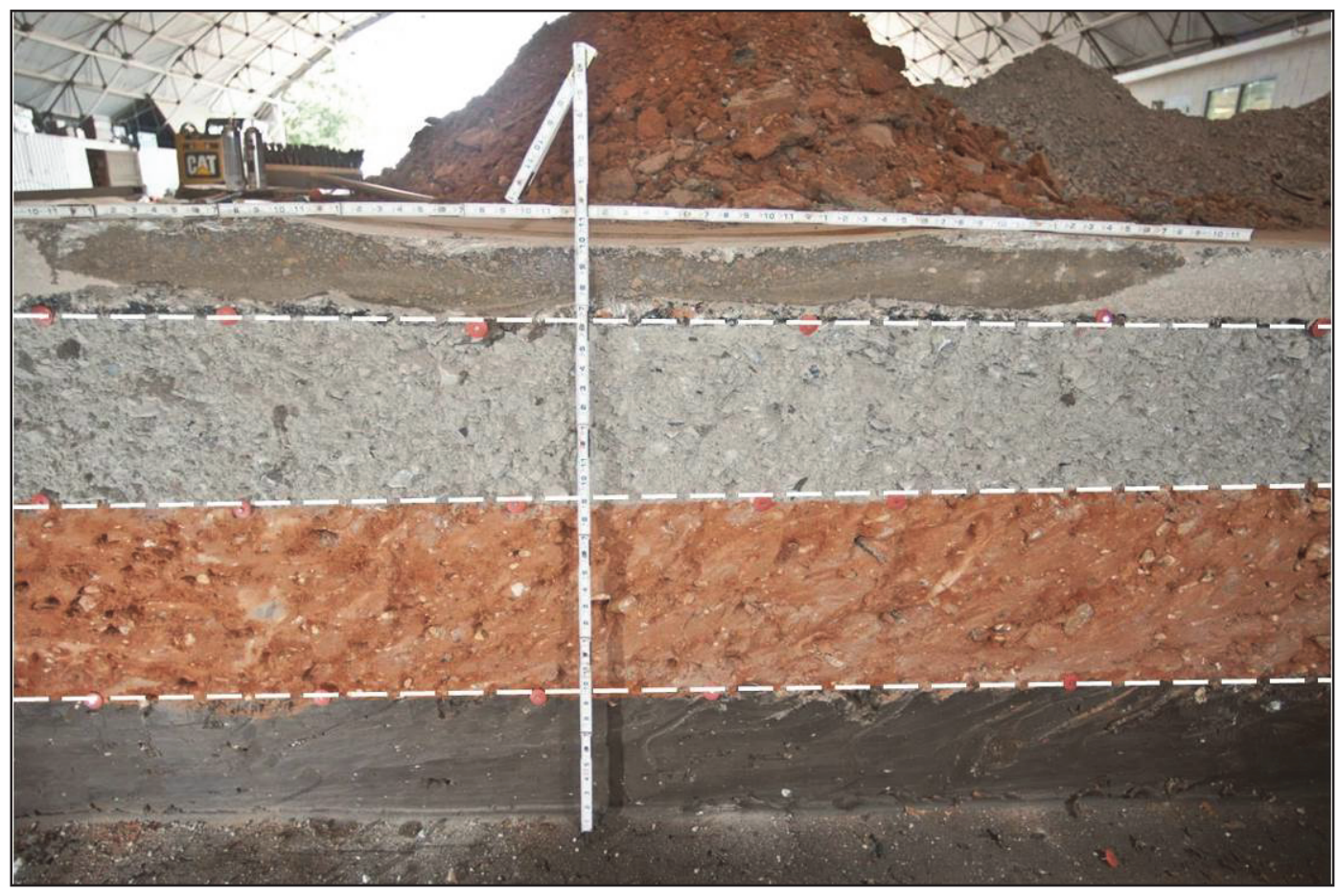


Figure 69. Sasobit $₫$ South Trench (STA 0+16).

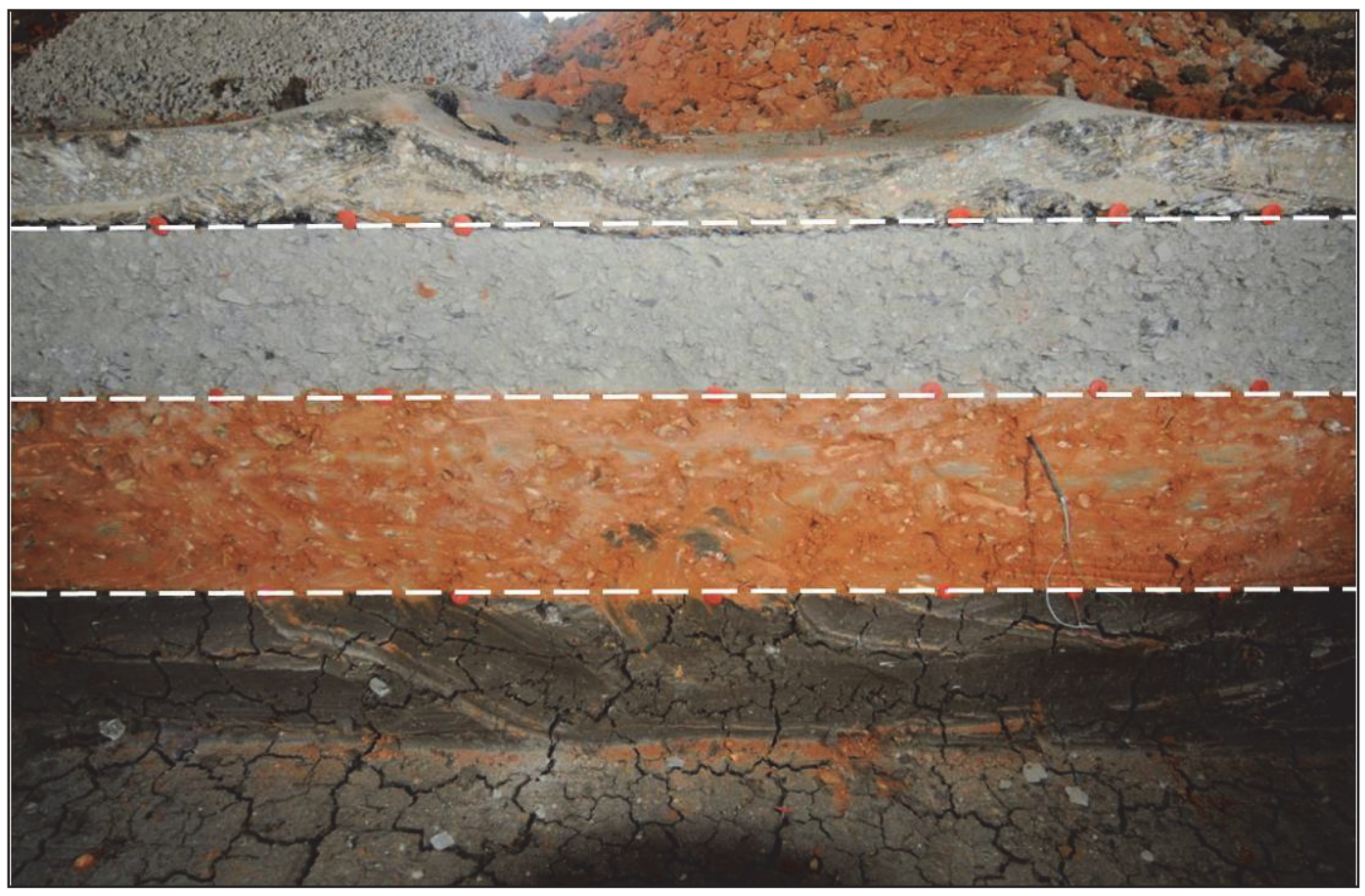

Figure 70. Sasobit $\circledast$ North Trench (STA 0+36).

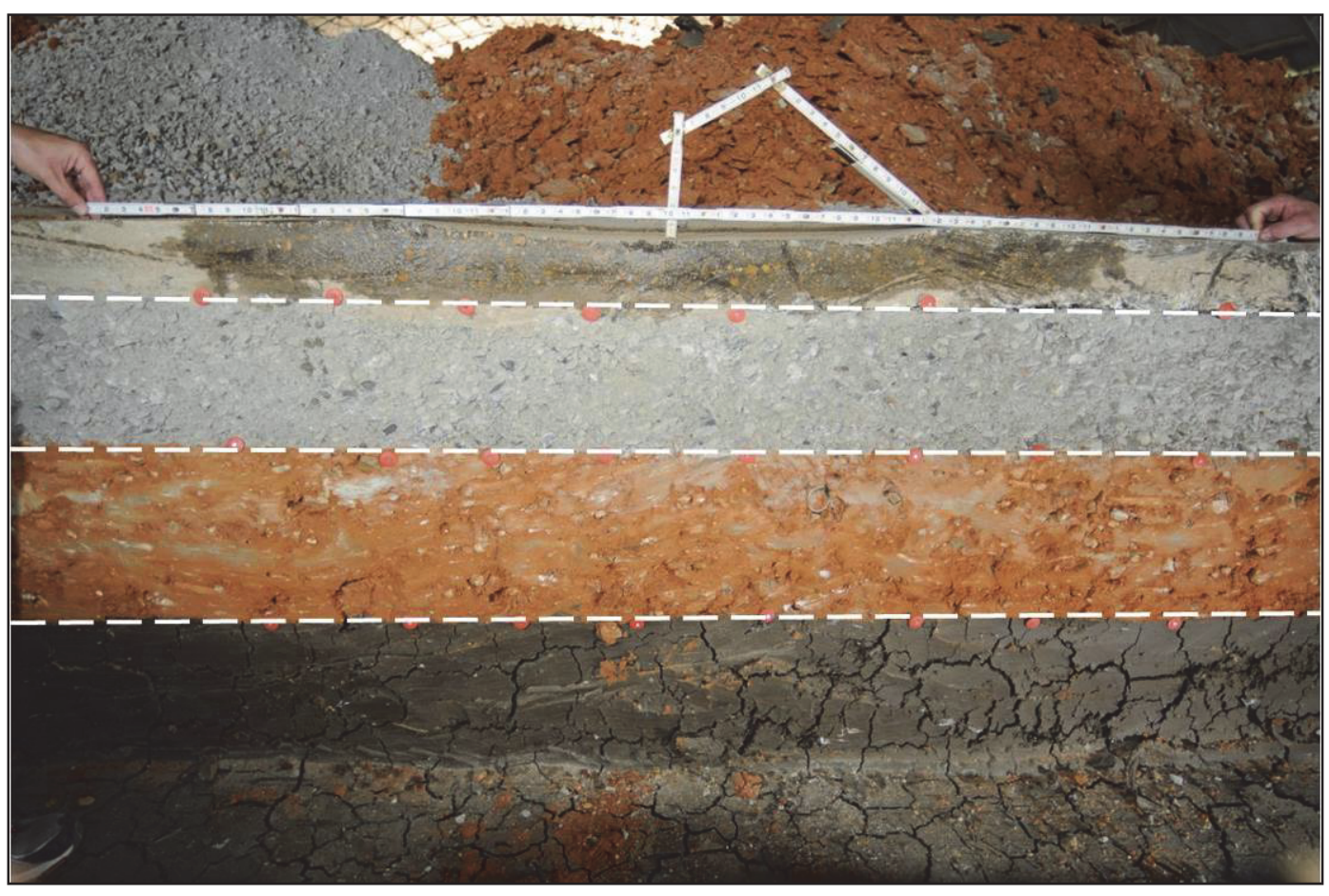


Figure 71. Evotherm ${ }^{\text {TM }} 3 G$ South Trench (STA 0+16).

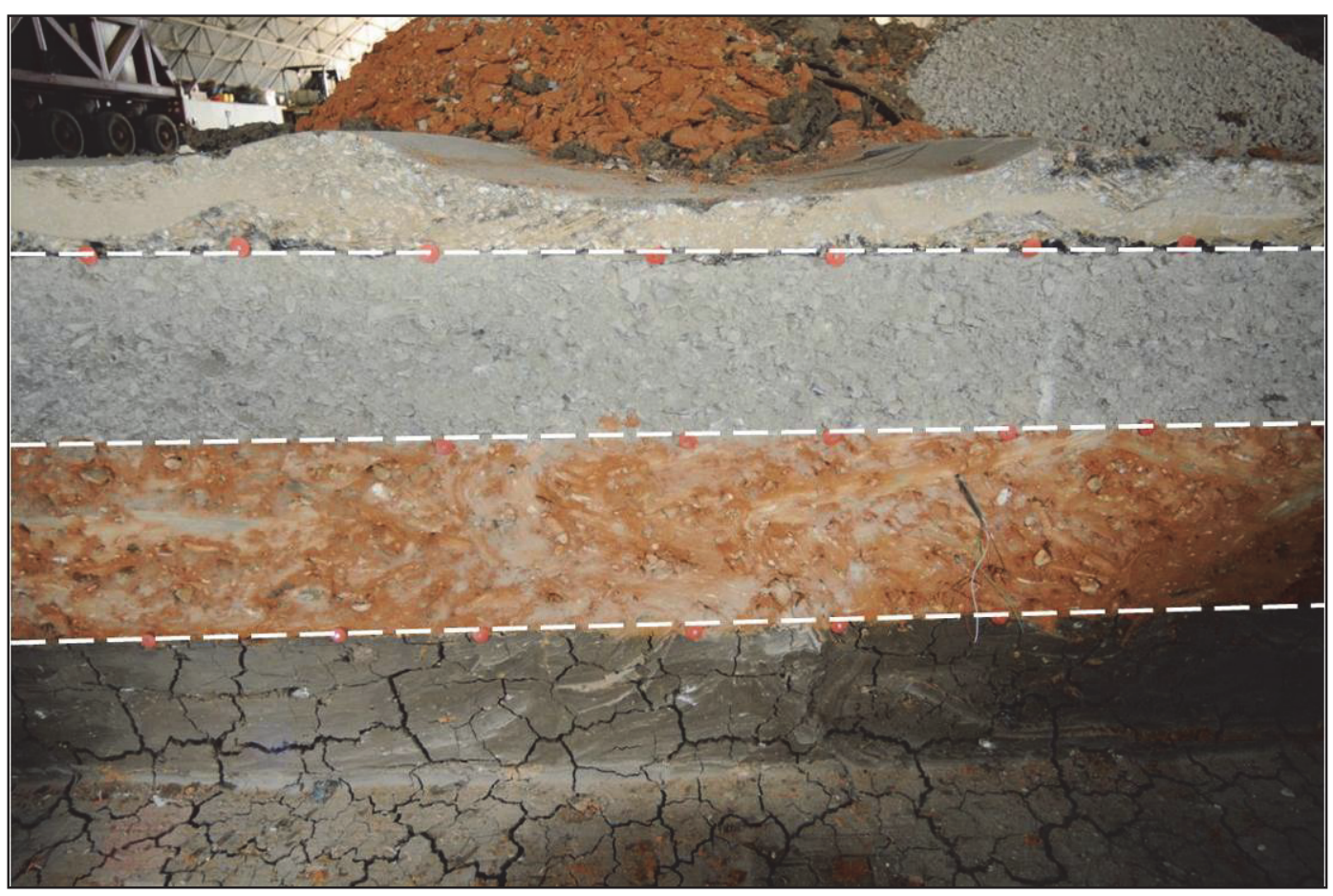

Figure 72. Evotherm ${ }^{\text {TM }} 3 G$ North Trench (STA 0+36).

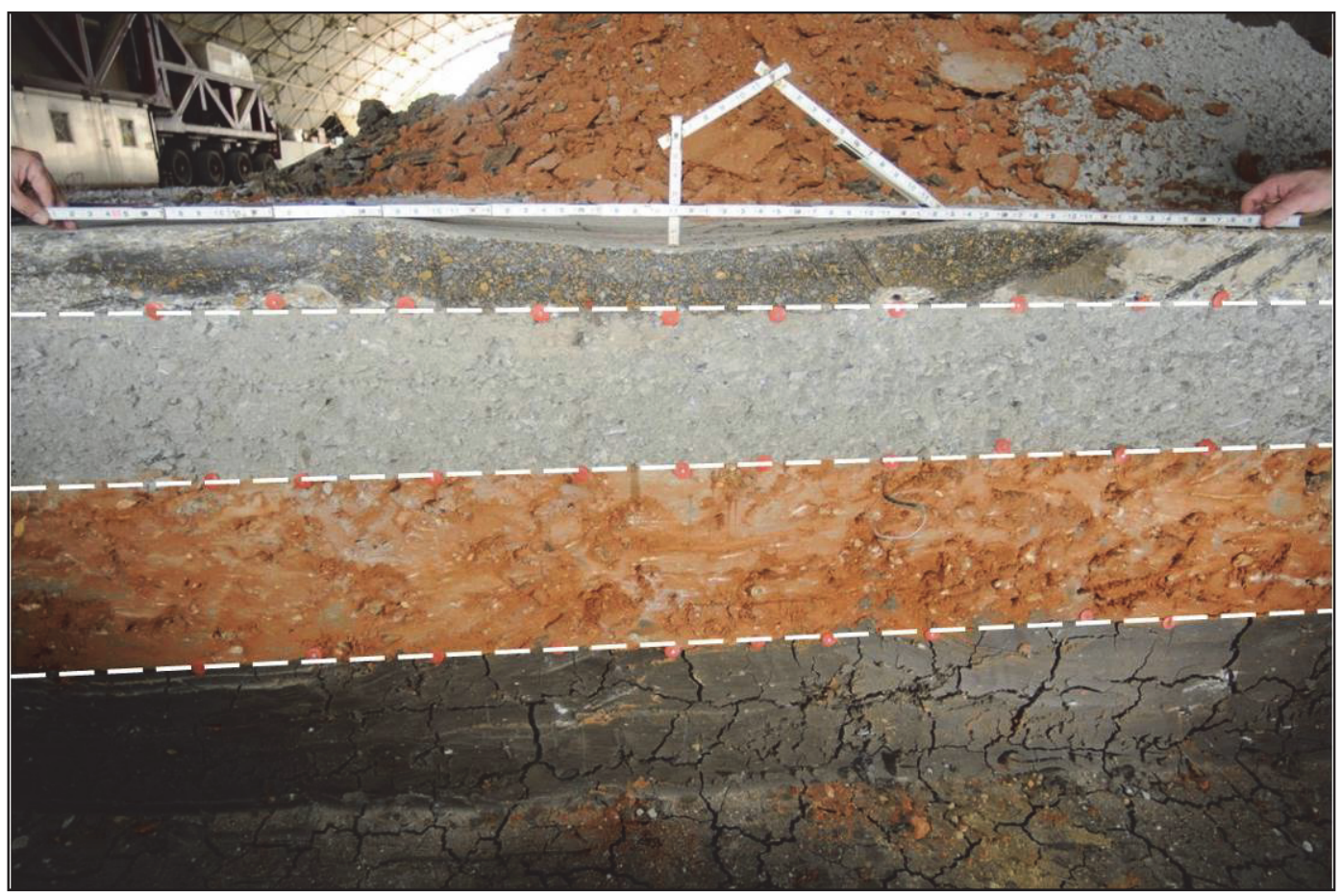




\section{Analysis and Discussion of Results}

\subsection{Rutting overview}

The average centerline permanent deformation of all four test items as trafficking progressed is shown in Figure 73. Failure was determined from Figure 73 by calculating the number of passes that caused 1 in. of average permanent deformation at the centerline (data at STA $0+30$ were omitted from the average for reasons discussed in Chapter 4). Table 14 lists the failure data for the four test items. All test parameters were consistently similar in all four test items except the variation in pavement temperature discussed previously. The pavement test temperatures reported are the average of all nine I-buttons (three depths at three locations) during trafficking.

Figure 73. Actual average permanent deformation overview.

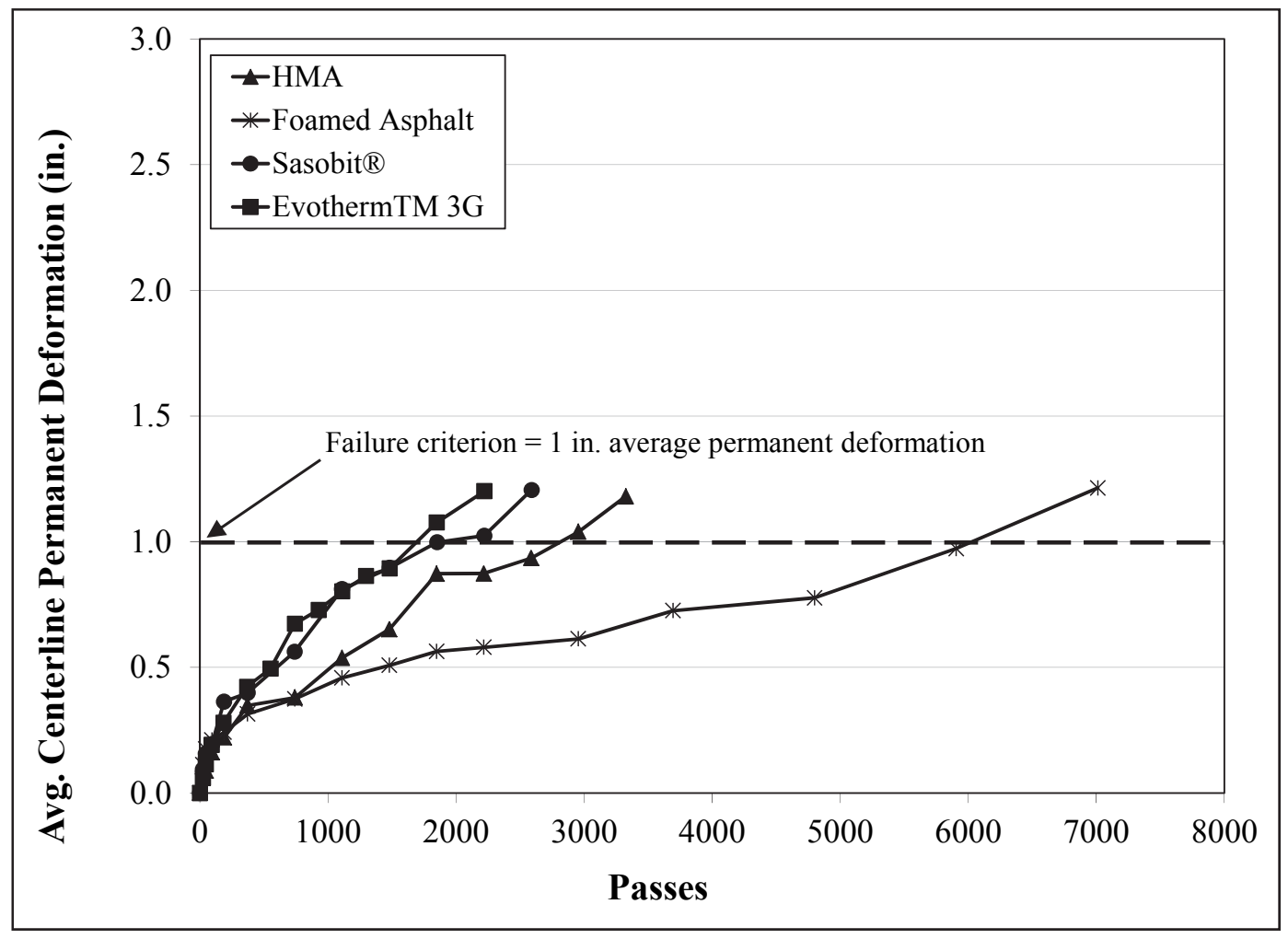


Table 14. Actual failure data.

\begin{tabular}{|l|l|l|}
\hline Test Item & $\begin{array}{l}\text { Number of Passes to } \\
\text { Failure }\end{array}$ & $\begin{array}{l}\text { Average Pavement } \\
\text { Temperature }\left({ }^{(} \mathrm{F}\right)\end{array}$ \\
\hline HMA (control) & 2,900 & 106.7 \\
\hline Foamed Asphalt & 6,000 & 103.9 \\
\hline Sasobit $\AA$ & 1,900 & 107.7 \\
\hline Evotherm ${ }^{\text {TM } 3 G}$ & 1,850 & 106.3 \\
\hline
\end{tabular}

Figure 73 shows the actual rutting performance of the four mixes evaluated, and it ranks them in the following order from best to worst performer: 1) Foamed Asphalt, 2) HMA, 3) Sasobit $\left(\right.$, and 4) Evotherm ${ }^{\mathrm{TM}} 3 \mathrm{G}$. Foamed Asphalt doubled the performance of HMA and tripled the performance of the other two warm mixes. Foamed Asphalt was tested during the coldest ambient temperature period as compared to the other test items. This resulted in greater heat loss from the test section, as described previously, and consequently a lower average test temperature. This temperature difference is believed to have contributed to the greater rutting resistance of Foamed Asphalt as compared to the other warm-mixes and the HMA. Furthermore, previous laboratory results from Doyle et al. (2013) from rutting tests conducted on the same mixtures indicated that the rutting performance of Foamed Asphalt was generally lower than that of HMA.

These results showed that most WMA mixtures had a slightly lower rutting resistance than the HMA mixture. It is important to note that the WMA mixtures were trafficked before the HMA (Evotherm ${ }^{\mathrm{TM}} 3 \mathrm{G}$ was tested 22 weeks after construction, Sasobit $\AA 26$, Foamed Asphalt 31 and HMA 34). In-place curing time could have an influence on the performance of WMA as compared to HMA. Doyle et al. (2013) evaluated the effects of curing time on rutting performance using specimens cored from the test sections at different times after construction and testing for laboratory rutting performance in the Asphalt Pavement Analyzer (APA). Results indicated that the performance of WMA was generally less than that of HMA. However, performance of all the mixtures improved with cure time after construction, and performance of WMA ultimately exceeded the initial performance of the HMA. This suggests that WMA initially may have a slightly greater propensity for rutting, but that allowing the pavement to cure adequately will alleviate the problem.

It is also important to note that the asphalt mixture used in this study was intentionally selected to be more rut susceptible than the majority of airfield 
mixtures. A mixture with a more rut resistant aggregate gradation and/or a polymer-modified binder would be more rut resistant overall and, thus any initial tenderness from using WMA would be less of a concern.

\subsection{Pavement structural performance}

The pavement structure in this study was conservatively designed for the purpose of isolating failure to the asphalt surface layer. Pavement structural response was evaluated during testing via FWD testing and instrumentation readings. FWD data in general showed no significant change in pavement stiffness throughout the test on any of the test items, considering all the factors that could have affected the variability of the test.

Figure 74 shows a summary of the pavement response as measured with the earth pressure cells embedded in the different sub-layers. No change in pressure due to traffic was observed on any of the sub-layers in all four test items, which indicates that their structural integrity was not affected during traffic. After evaluating all the structural data, it was successfully demonstrated that the rutting performance of the four test items was not influenced by the structural capacity of the pavement sub-layers, but only by the capacity and properties of the surface asphalt mix.

Figure 74. Average maximum pressures measured at each pavement unbound layer.

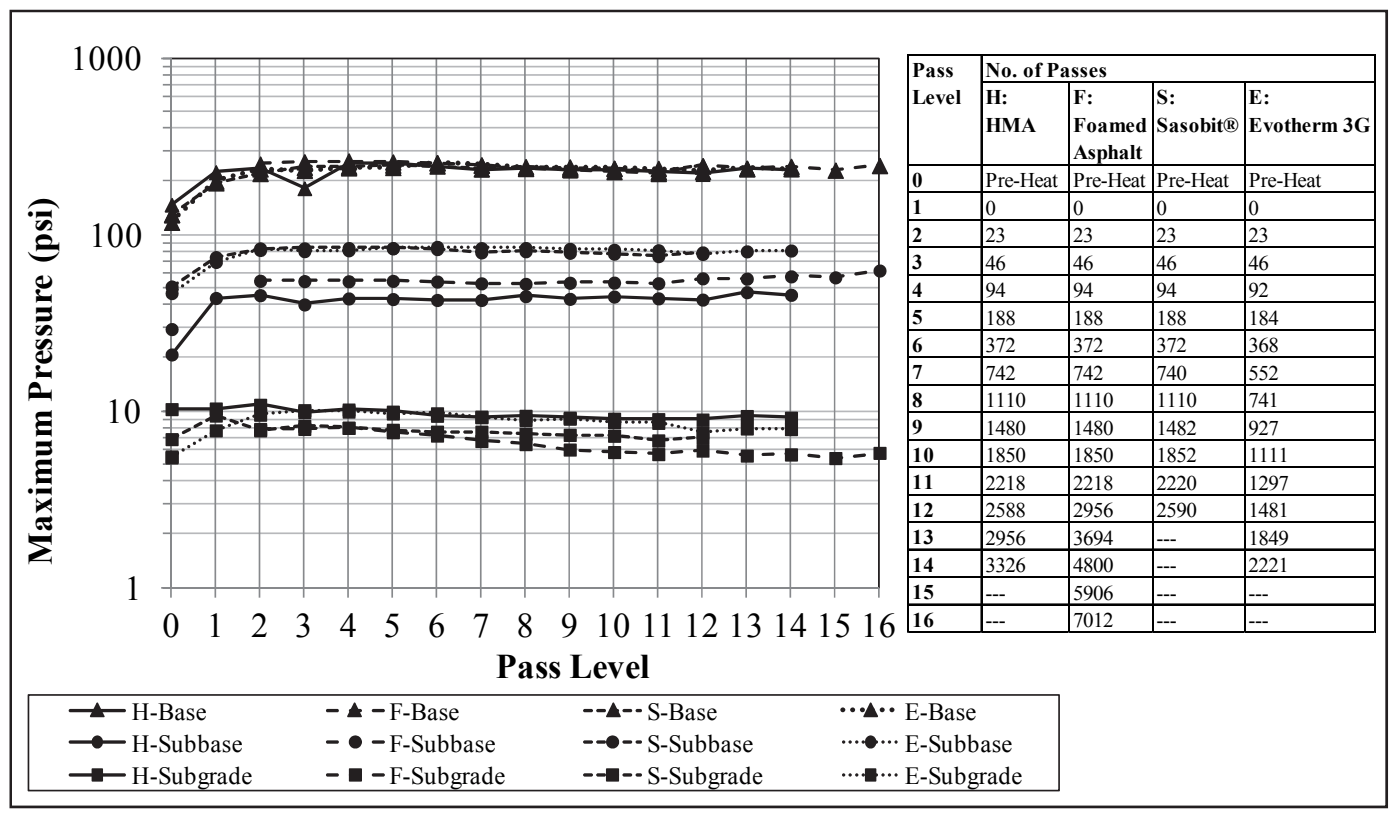




\subsection{Forensics}

The data collected after traffic during the forensic evaluation support the data recorded by instrumentation. No significant changes in the soil properties that would have affected the rutting performance of the test items were observed after traffic. The subbase showed a big increase in CBR, but since the densification of that layer was minimal the change was attributed to the loss of moisture content with time, which is typical of that clay gravel soil. The changes in layer thickness were minimal or negligible.

Considering all the data obtained on the behavior of the pavement structure including the data from the trenches, it was determined that the sub-layers behaved as designed. That is to say, no movement was observed on the sub-layers and the permanent deformation observed on the asphalt layer was not associated with any structural failure but only to asphalt mixture failure due to the harsh traffic conditions (high temperature and high tire pressure) to which it was exposed. 


\section{Grooving of WMA Surfaced Airfield Pavements}

An additional area of potential concern with use of WMA on the surface of airfield runway pavements is the material response to surface grooving, which is often required to provide high skid resistance for aircraft braking, particularly in wet conditions. If the asphalt binder in WMA is softer than that of comparable HMA due to reduced binder aging during production and placement, the WMA mixture may be more likely to experience groove closure or collapse, which could result in loss of desired skid resistance or chipping of aggregate from the groove edges, which could represent potential foreign object damage (FOD).

Current specifications for military airfields (UFGS 320126.71 ) and for civilian airfields (FAA AC 150/5320-12C) both require use of rectangular grooves of nominal dimensions $1 / 4$ in. wide by $1 / 4$ in. deep and spaced 1 $1 / 2$ in. center to center. The nominal groove depth of $1 / 4$ in. is allowed a tolerance of $\pm 1 / 16$ in. Grooves are oriented perpendicular to the direction of traffic. New asphalt pavements are required to cure for at least 30 days before surface grooving is performed.

The dimensions of the grooves and the loads acting on them are shown in Figure 75. The vertical pressure will be approximately equal to the tire pressure; therefore, higher tire pressure aircraft will likely result in higher damage potential. The failure mechanism is somewhat analogous to a geotechnical slope failure where the slope angle $(\varphi)$ will be dependent on temperature and asphalt mixture, aggregate, and binder properties. The shear failure plane will not be a direct path, but will instead occur in the asphalt mastic phase of asphalt mixture between individual aggregate particles. Horizontal shear stresses are also induced during aircraft braking.

After HVS traffic operations were completed on the WMA test section, the untested areas of each test item were used to evaluate grooving of WMA. The main objectives of this part of the study were to assess any potential problems associated with grooving the surface of WMA airfield pavements and specifically to compare the performance of grooved WMA to that of grooved HMA. 
Figure 75 . Groove diagram and suggested failure mechanism (not to scale).

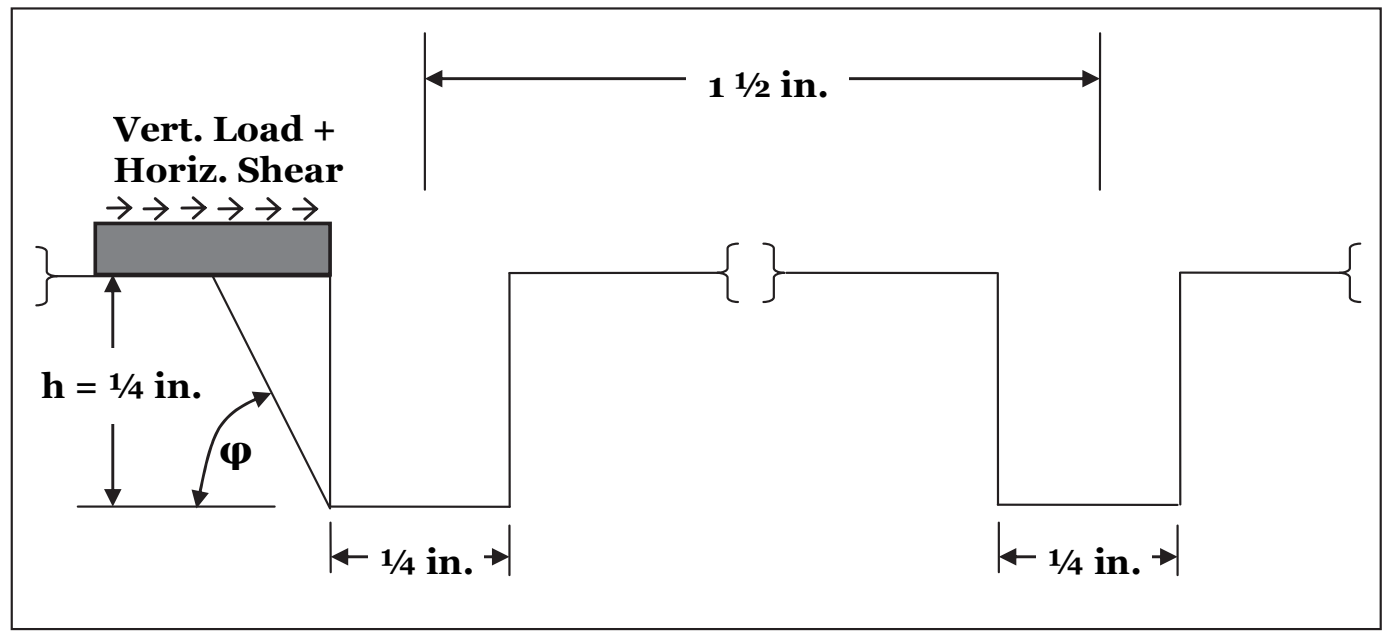

\subsection{Evaluation procedure}

For this experiment, factors of mixture type and curing temperature were considered. Four test items were evaluated: three WMA mixtures (Sasobit $\AA$, Evotherm ${ }^{\mathrm{TM}} 3 \mathrm{G}$, and Foamed Asphalt) and one HMA. The pavement areas that were not trafficked with the HVS-A were used for the evaluation.

During the first 18 weeks after placement, all test items experienced air exposure, and the ambient temperatures of summer and fall (mid-June to November). However, since the test items were located in a covered test facility, there was no exposure to direct solar radiation (i.e., pavement was $100 \%$ shaded) or to rain. After that and during the winter months of November to mid-February, each pavement test item was exposed to an elevated temperature of approximately $109^{\circ} \mathrm{F}$ for two to three weeks while accelerated traffic testing was conducted. After HVS traffic operations were completed, the HVS was removed from the test items, and the grooves were not cut until six months later.

The areas that were not trafficked by the HVS-A, but that were still under the temperature chamber, were used for the grooving evaluation along with the pavement that was exposed to ambient conditions outside the HVS-A at all time. Therefore, for this grooving evaluation, two sample units were evaluated per test item: 1) pavement cured at ambient and at elevated temperatures and 2) pavement that was cured only at ambient temperature. Table 15 describes the experimental design and the eight factor-level treatment combinations tested. Figure 76 shows the physical layout of the experiment. 
Table 15. Factor/level combinations for WMA grooving evaluation.

\begin{tabular}{|l|l|l|}
\hline \multirow{2}{*}{ Factor 1: Mix Type } & \multicolumn{2}{|c|}{ Factor 2: Curing Conditions } \\
\cline { 2 - 3 } & $\begin{array}{l}\text { Pavement Cured at Ambient and } \\
\text { Elevated Temperature }\end{array}$ & $\begin{array}{l}\text { Pavement Cured only at Ambient } \\
\text { Temperature }\end{array}$ \\
\hline HMA-Control & HMA 1 & HMA 2 \\
\hline WMA-Foamed Asphalt & Foam 1 & Foam 2 \\
\hline WMA-Sasobit $\circledast$ & Sasobit 1 & Sasobit 2 \\
\hline WMA-EvothermTM 3G & Evotherm 1 & Evotherm 2 \\
\hline
\end{tabular}

Figure 76. Layout of WMA grooving evaluation experimental design (not to scale).

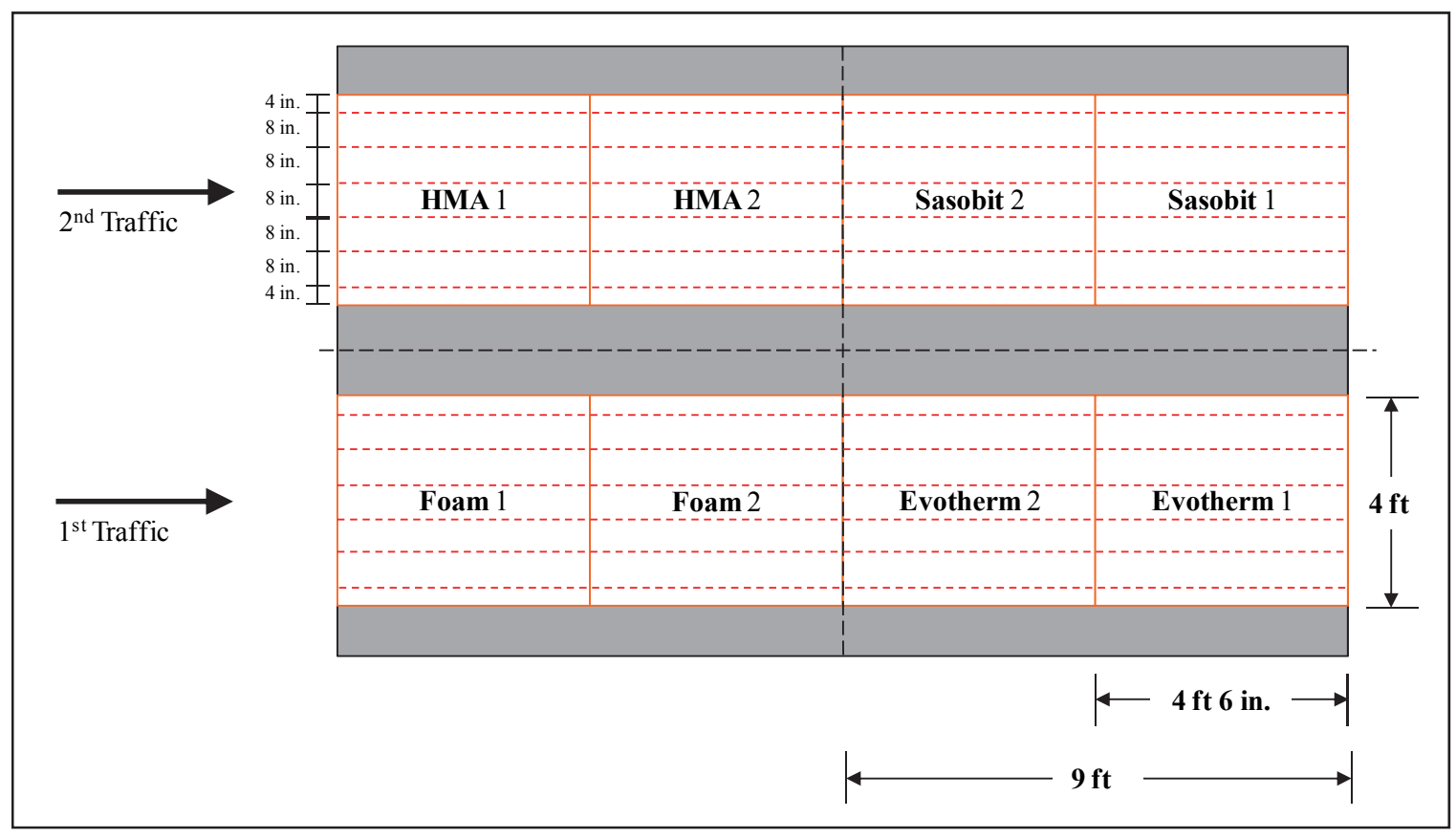

The grooving evaluation was conducted six months after HVS-A traffic operations were completed, which is about one year after construction. This allowed conducting the evaluation during the summer when pavement temperatures are elevated. The grooves were cut individually on the asphalt surface using a concrete saw (MK Diamond Model MK-1614K Premium). The grooves were cut following the depth and spacing specifications on UFGS 320126.71 and FAA AC 150/5320-12C. Once the grooves were cut, the surface was washed and swept to facilitate baseline measurements of groove depth and length.

Simulated F-15 aircraft traffic was applied using the load cart shown in Figure 77. Traffic operations were completed in two applications (as shown in Figure 76): the Foamed Asphalt and Evotherm ${ }^{\mathrm{TM}} 3 \mathrm{G}$ were trafficked first and then the HMA and Sasobit $囚$. The traffic pattern was a block 
distribution with a pass to coverage ratio of one, such that all areas received the same amount of traffic. Six lanes spaced at 8 in. were trafficked with ten passes each for a total of sixty (6o) passes per coverage. Traffic was paused after each coverage interval for data collection. Traffic was continued until full groove closure was observed in more than $50 \%$ of a sample unit. Data collection for each item consisted of visual assessment, photographs of the pavement surface, and measurements of the length of damaged groove sections. The total length of grooves was measured initially. Then, the length of partial and full groove closure was measured after each coverage interval. Partial groove closure was defined as less than $1 / 8$ in. closure, and full groove closure was defined as $1 / 8$ - to $1 / 4$ in. closure. Groove closure was evaluated by measuring the partial and full closures (expressed as a percentage of total groove length) using the following equation:

Groove Closure $($ percent $)=$ percent full closure $+1 / 2($ percent partial closure $)($ Eq. 1$)$

Figure 77. F-15 load cart.

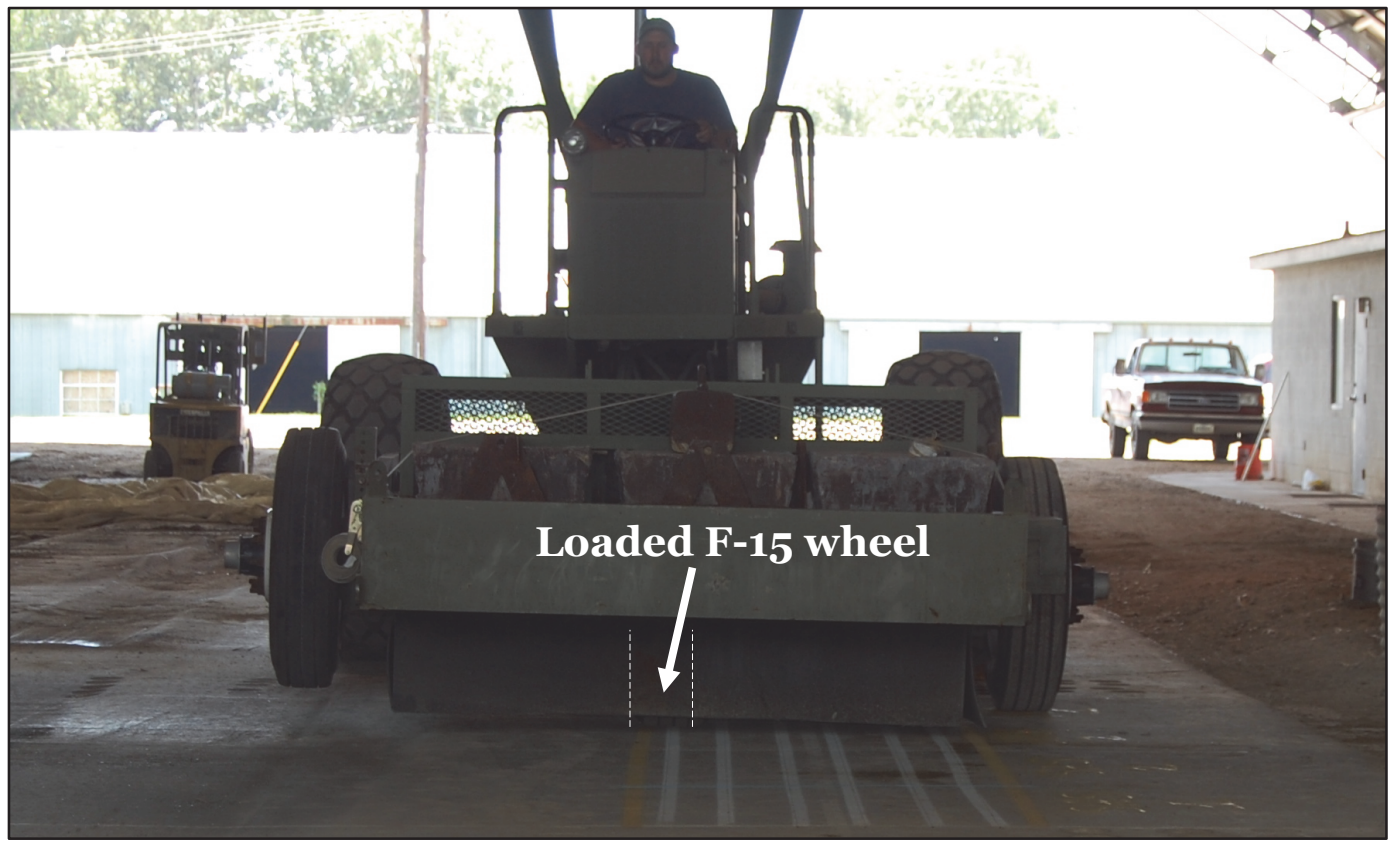

\subsection{Results}

Figure 78 shows the typical initial conditions of the grooves before traffic was applied. Most of the grooves met the specifications for depth and spacing, even though they were cut individually and not using a grooving machine. However, some of the grooves where shallower than the depth tolerance; therefore, groove closure took longer or never occurred in those areas. Figure 79 shows a typical grooved area that experienced partial and 
full groove closure. In partial groove closure, the pavement still have some of the skid resistance initially provided by the grooves, but when the grooves are fully closed, that resistance is completely lost, which could cause problems, especially in runways where additional surface friction is essential. Another problem associated with groove failure could be foreign object damage (FOD) from loose aggregate and asphalt material that falls off the groove walls.

Figure 78. Typical grooves before traffic.

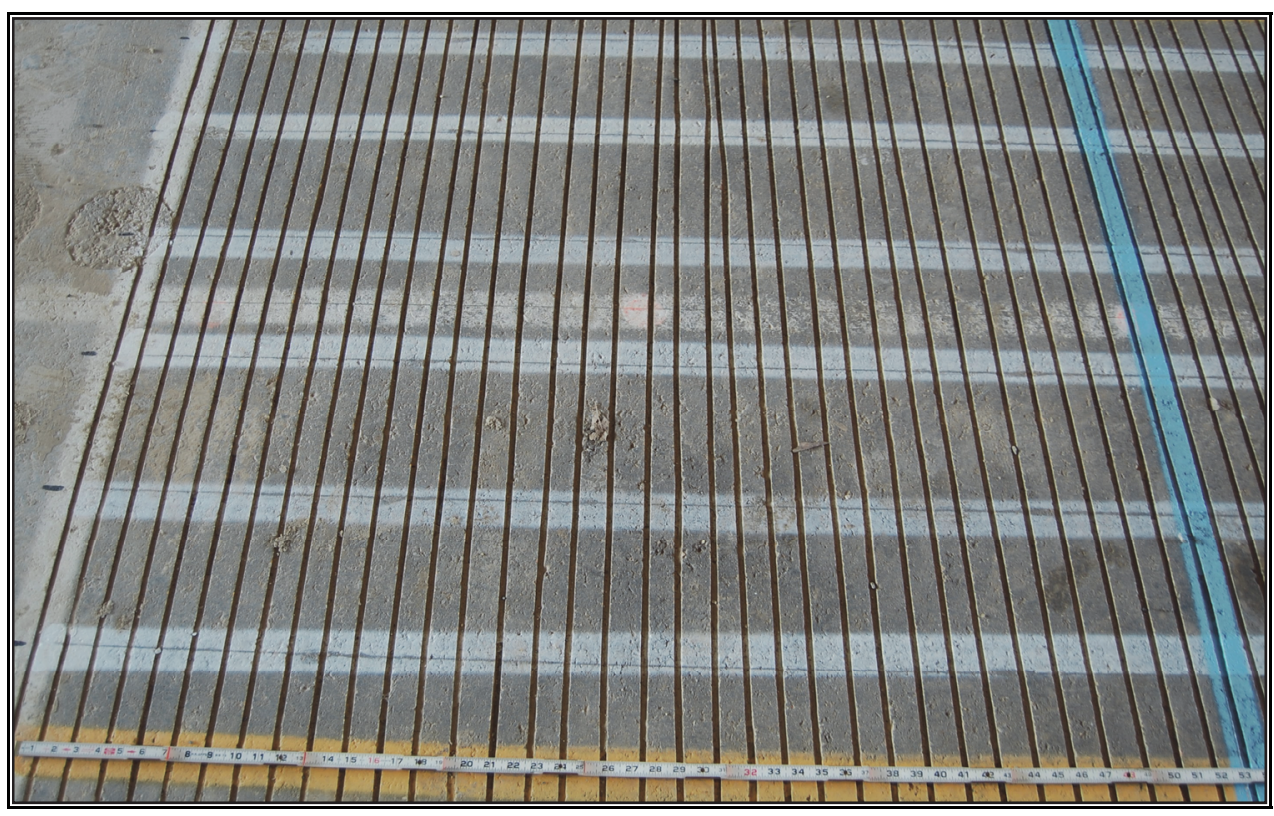

Figure 79. Typical partial groove closure and full groove closure.

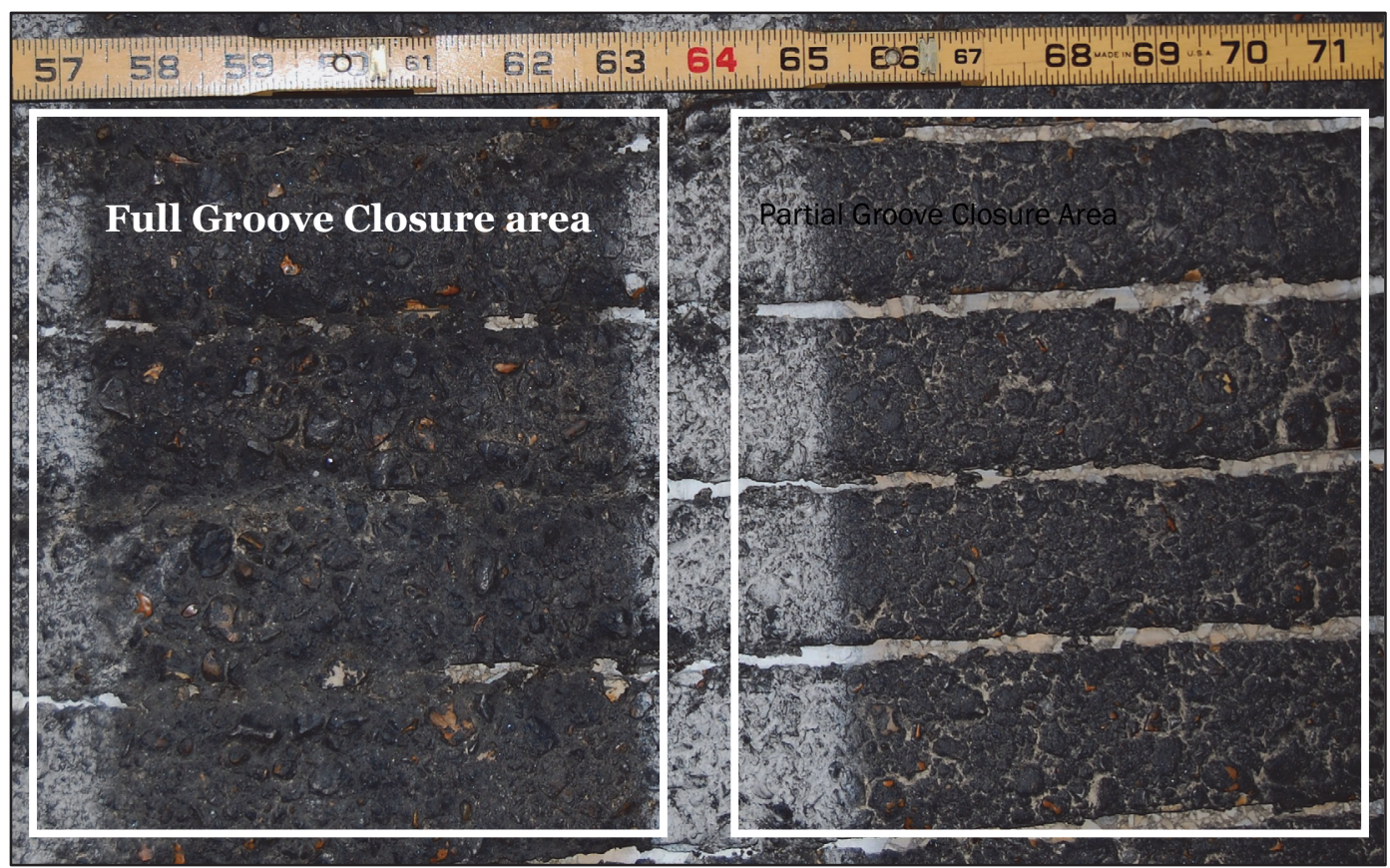


Groove closure results are shown in Figure 80. Pavement surface temperatures were monitored using a temperature laser camera at each pass level and are shown in Figure 81. Of all the mixtures under both curing conditions, Sasobit $\AA$ was the top performer. Sasobit $\AA$ performed better than HMA even when both were trafficked at the same time and at the same surface temperatures. The pavement surface temperatures were very consistent for HMA and Sasobit@. At the beginning trafficking, the pavement surface temperatures for Evotherm ${ }^{\mathrm{TM}} 3 \mathrm{G}$ and Foamed Asphalt were about $10^{\circ} \mathrm{F}$ lower than those of Sasobit $\AA$ and HMA. Then, halfway through trafficking the temperature increased and that difference was about $5^{\circ} \mathrm{F}$.

Figure 80. Groove closure at each pass level.

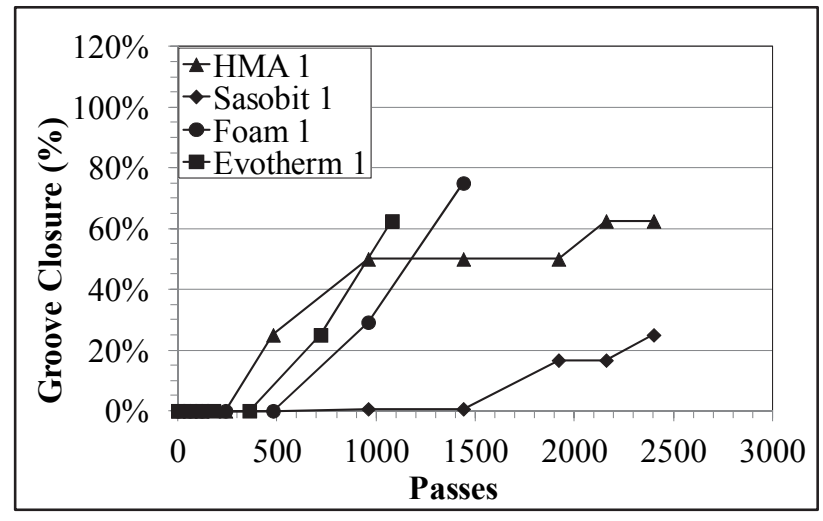

a) Pavement cured at high temperature

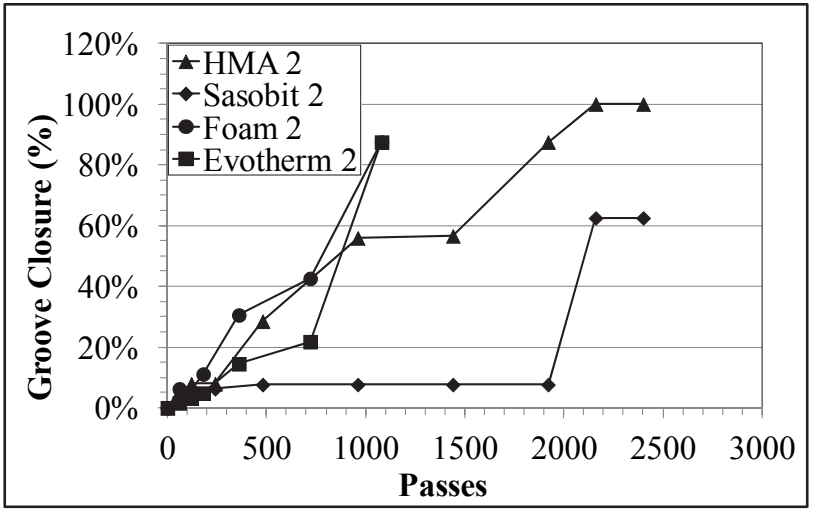

b) Pavement cured at ambient temperature

Figure 81. Pavement surface temperature at each pass level.

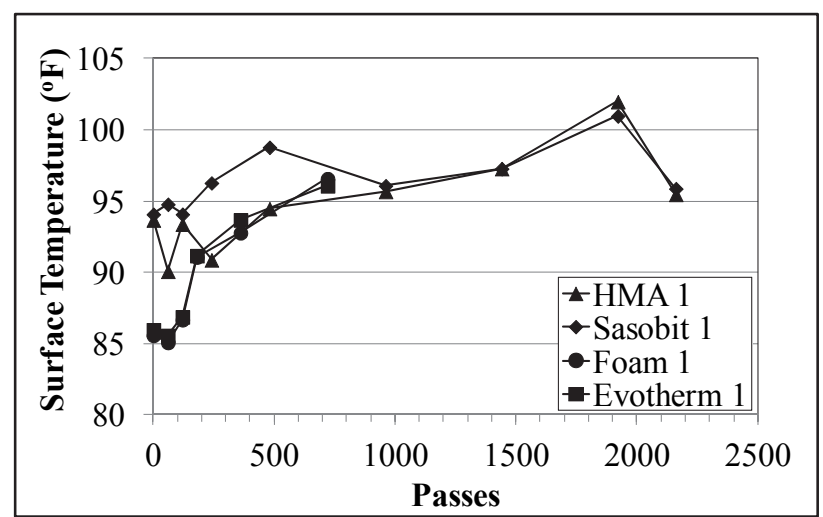

a) Pavement cured at high temperature

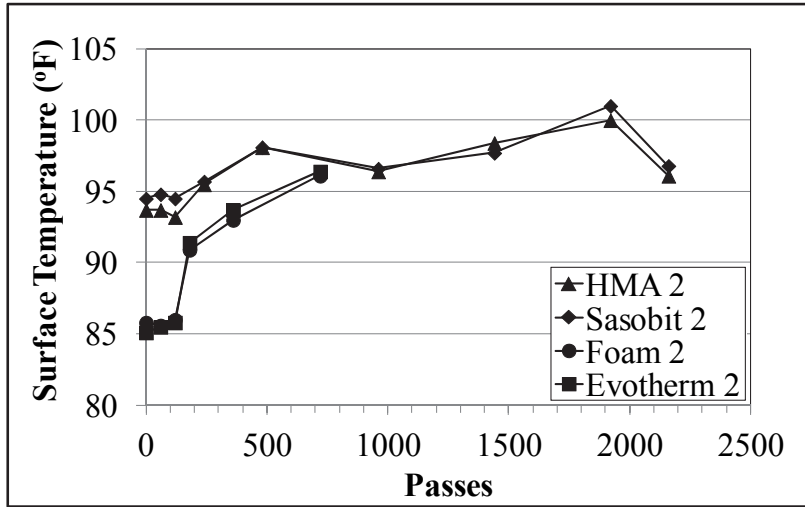

b) Pavement cured at ambient temperature

Considering the sample units that were cured at a higher temperature, the performance of all WMA mixtures was better than HMA for the first 1,000 passes. This shows that proper curing time reduces the potential for groove closure in both HMA and WMA. The sample units that were only cured at 
ambient temperatures still show Sasobit $\AA$ performing better than HMA, and Evotherm ${ }^{\mathrm{TM}} 3 \mathrm{G}$ and Foamed Asphalt performed worse than HMA.

In general, WMA performed as well as HMA under different pavement curing conditions. This indicates that pavement that is properly cured before grooving (30 days per UFGS 320126.71 and FAA AC 150/5320-12C) should not exhibit groove closure problems, unless closure is caused by other mixture issues (i.e. mixture tenderness). The use of polymer-modified asphalts, a common practice on airfield pavements, should reduce the potential for groove closure, if any, of both HMA and WMA mixtures. 


\section{Conclusions and Recommendations}

\subsection{Conclusions}

The following conclusions were drawn from the evaluation of the full-scale WMA test section under F-15 aircraft traffic at high temperatures:

- Inconsistent test temperatures between test items and within each test item somewhat affected the results. Generally, temperatures were higher on the south end of the test items causing greater deformations on the pavement in those areas. Also, the test temperature varied between test items. However, general comparisons between the performance of WMA and HMA could still be made.

- Rutting performance of WMA was slightly poorer than that of HMA. Considering that WMA may initially have slightly greater susceptibility to rutting than comparative HMA due to reduced aging of the binder during production, trafficking the HMA first may have led to different results.

- The pavement structural behavior as measured by FWD testing and instrumentation readings showed consistent performance throughout the duration of the traffic operations. This demonstrated that the rutting performance of the four test items was not influenced by the structural capacity of the pavement sub-layers but only by the properties of the surface asphalt mix.

- The forensic evaluation revealed that no measurable movement occurred in the sub-layers. This confirmed that the permanent deformation observed in the asphalt layer was not associated with any structural failure but only to asphalt mixture failure due to the harsh traffic conditions to which it was exposed.

- From the grooving evaluation, WMA performed as well as HMA under different pavement curing conditions. This indicates that WMA pavement that is properly cured before grooving should not exhibit groove closure under normal traffic unless there are other mixture issues.

\subsection{Recommendations}

After evaluating the full-scale performance of WMA under simulated heavy aircraft traffic, WMA is recommended as a viable alternative to 
HMA for wearing surfaces on airfields. Long-term performance of WMA compared to HMA should be documented through trial sections placed on active military airfields. Both HMA and WMA mixtures utilizing the same source materials should be placed and their performance monitored for at least two years. 


\section{References}

AASHTO Designation T 166. 2012. Bulk specific gravity $\left(G_{m b}\right)$ of compacted hot-mix asphalt (HMA) using saturated surface-dry specimens. Washington, DC: American Association of State Highway and Transportation Officials.

ASTM. 2011. Standard practice for classification of soils for engineering purposes. Designation: D 2487-11. West Conshohocken, PA: American Society for Testing and Materials.

Collop, A. C., D. Cebon, and M. S. A. Hardy. 1995. Viscoelastic approach to rutting in flexible pavements. Journal of Transportation Engineering 121(1):82-83.

Doyle, J. D., J. F. Rushing, and M. Mejías-Santiago. 2013. Laboratory performance testing of warm-mix asphalt (WMA) technologies for airfield pavements. ERDC/GSL TR-13-41. Vicksburg, MS: US Army Engineer Research and Development Center.

FAA. 1997. Measurement, construction, and maintenance of skid-resistant airport pavement surfaces. Federal Aviation Administration Advisory Circular 150(5320-12C):45.

HQ-AFCESA. 2011. Warm-mix asphalt. ETL 11-3. Air Force Civil Engineer Support Agency.

HQ Army, Navy, Air Force. 2001b. Pavement design for airfields. Unified Facilities Criteria (UFC) 3-260-02. Washington, DC: Headquarters, Departments of the Army, Navy, and Air Force.

Mejías-Santiago, M., J. D. Doyle, I. L. Howard, and E. R. Brown. 2012. Evaluation of warm-mix asphalt technologies for use on airfield pavements. ERDC/GSL TR12-3. Vicksburg, MS: US Army Engineer Research and Development Center.

NCHRP 704. 2011. A performance-related specification for hot-mix asphalt. Washington, DC: National Cooperative Highway Research Program.

Rushing, J. F., M. Mejías-Santiago, and J. D. Doyle. 2013. Comparing production and placement of warm-mix asphalt (WMA) to traditional hot-mix asphalt (HMA) for constructing airfield pavements. ERDC/GSL TR-13-35. Vicksburg, MS: US Army Engineer Research and Development Center.

Unified Facilities Guide Specification 3212 15.16. 2012. Warm-mix asphalt (WMA) for airfields. Washington, DC: United States Department of Defense.

United Facilities Guide Specification 3201 26.71. 2008. Grooving for airfield pavements. Washington, DC: United States Department of Defense.

Witczak, M. V. 1992. Effective temperature analysis for permanent deformation of asphaltic mixtures. A-001 MIDAS Study. 


\section{Appendix A: Raw temperature data}

Figure A1. HMA pavement temperature range - south end.

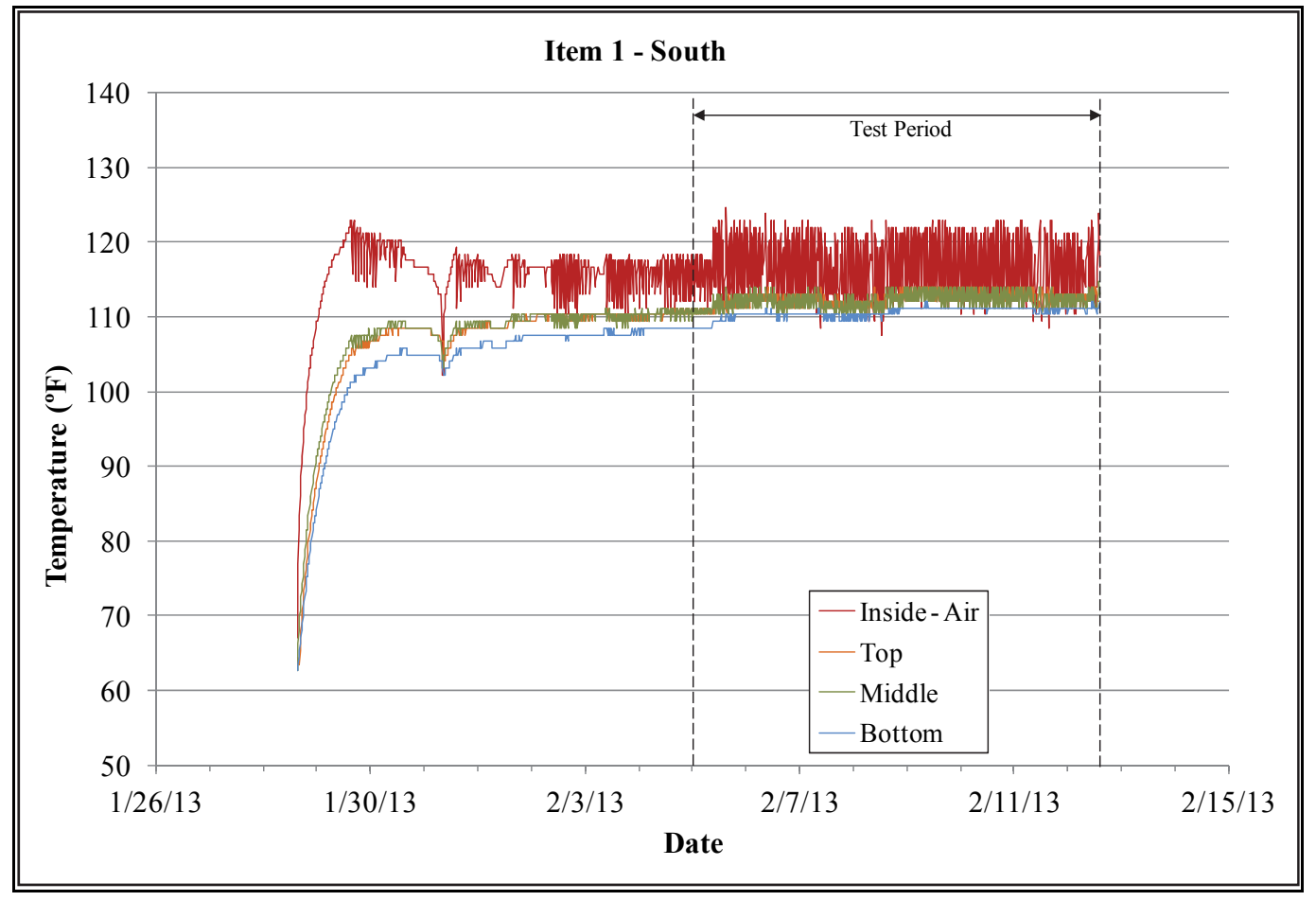

Figure A2. HMA pavement temperature range - center of the item.

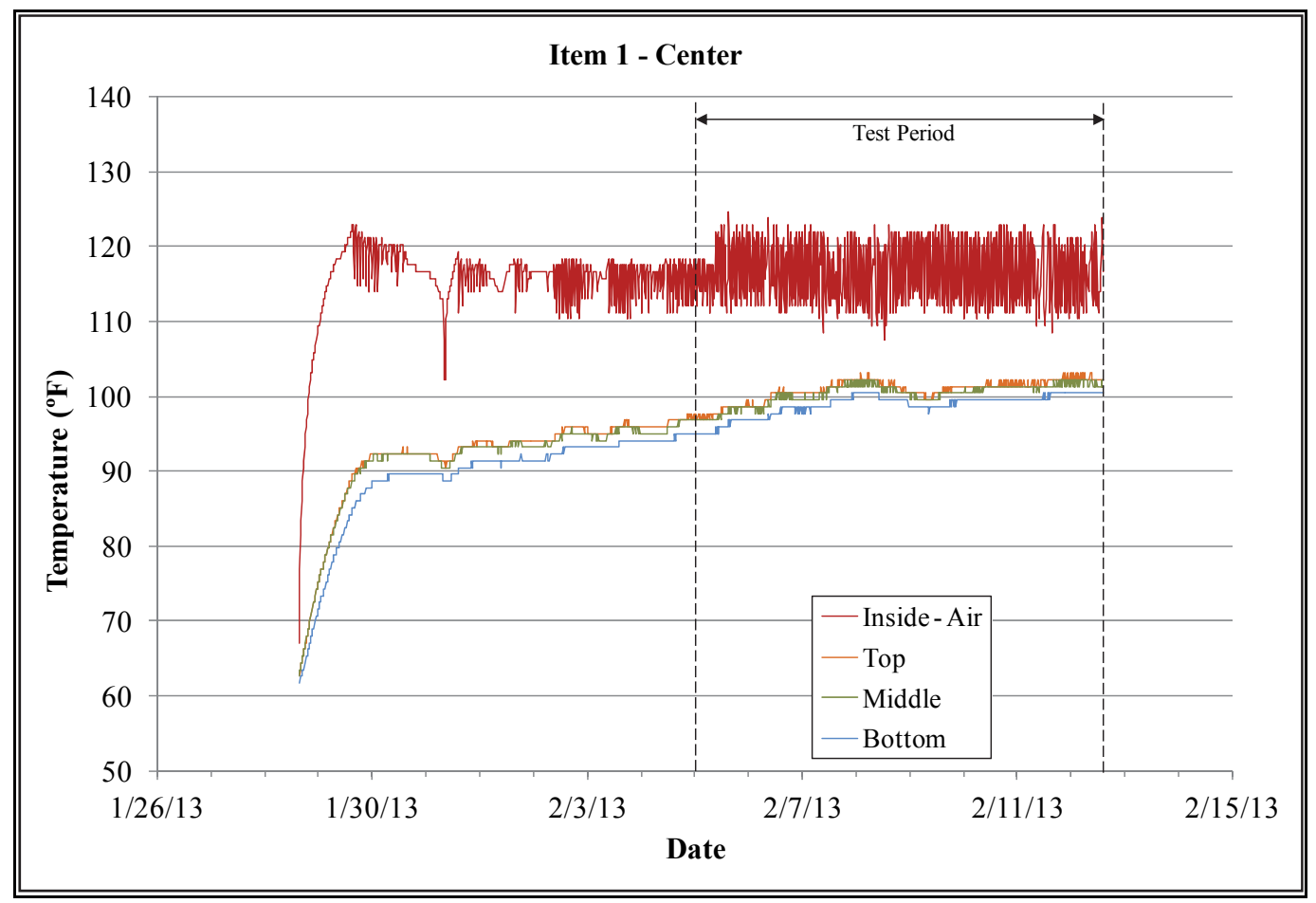


Figure A3. HMA pavement temperature range - north end

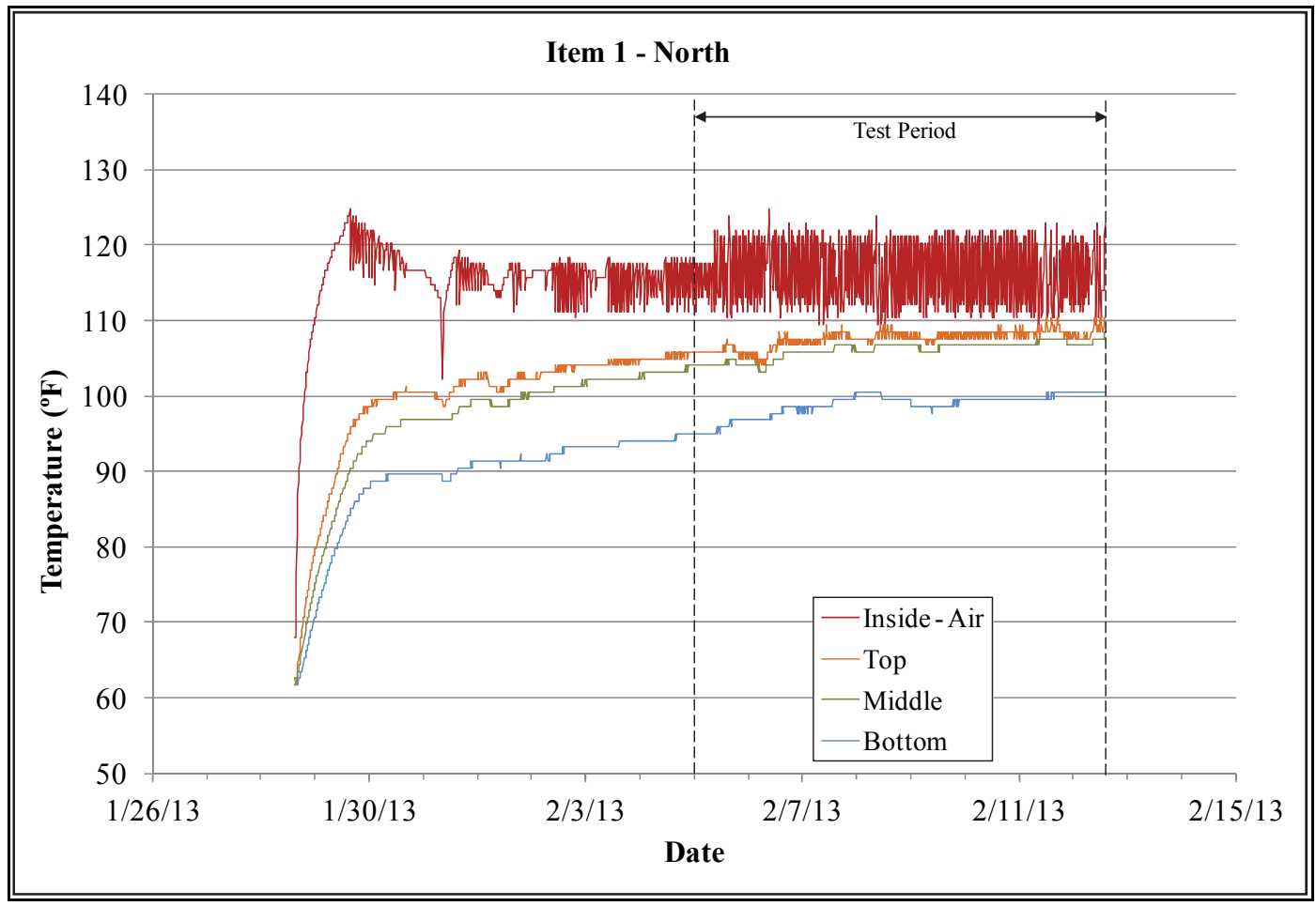

Figure A4. Foamed Asphalt pavement temperature range - south end.

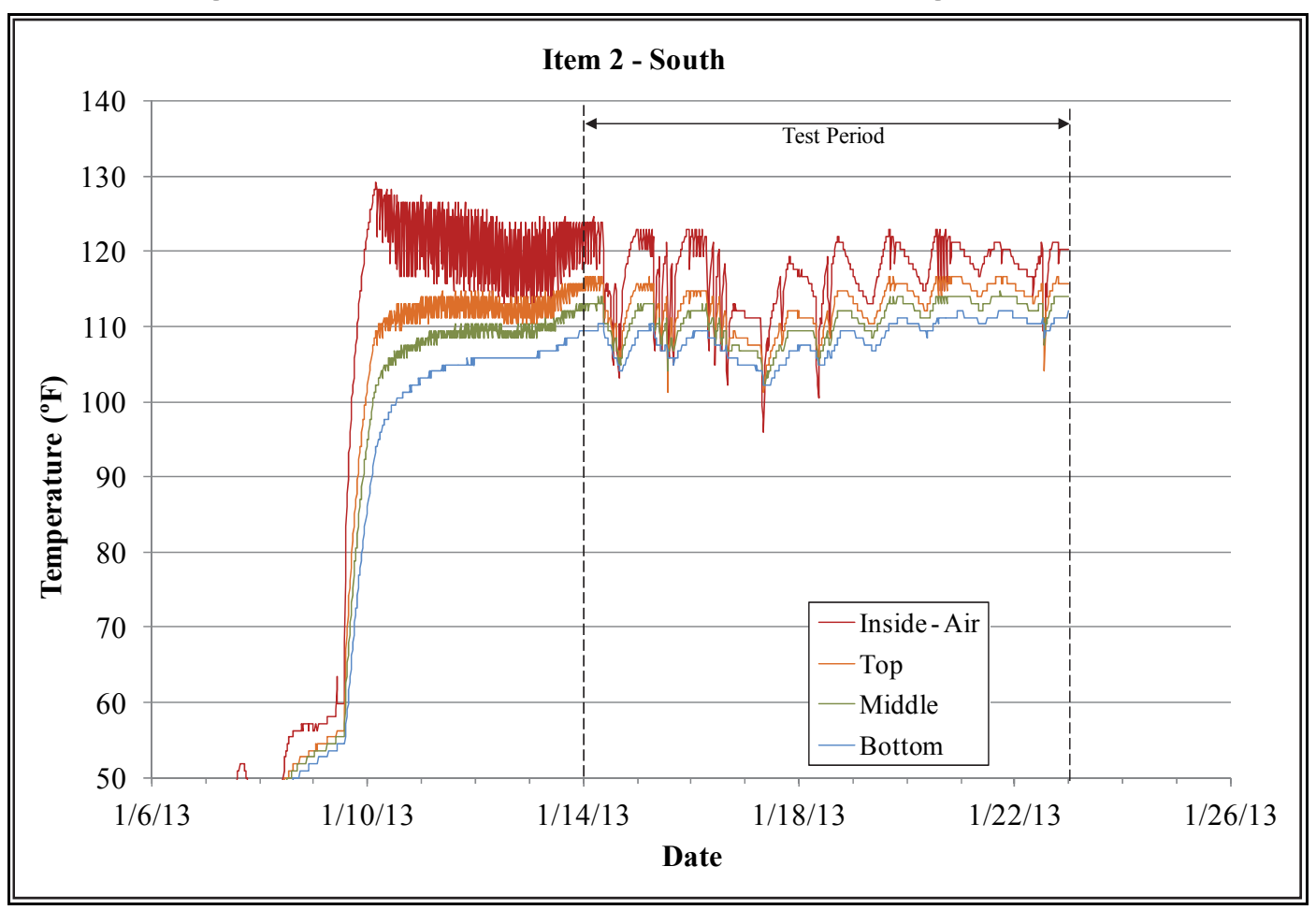


Figure A5. Foamed Asphalt pavement temperature range - center of the item.

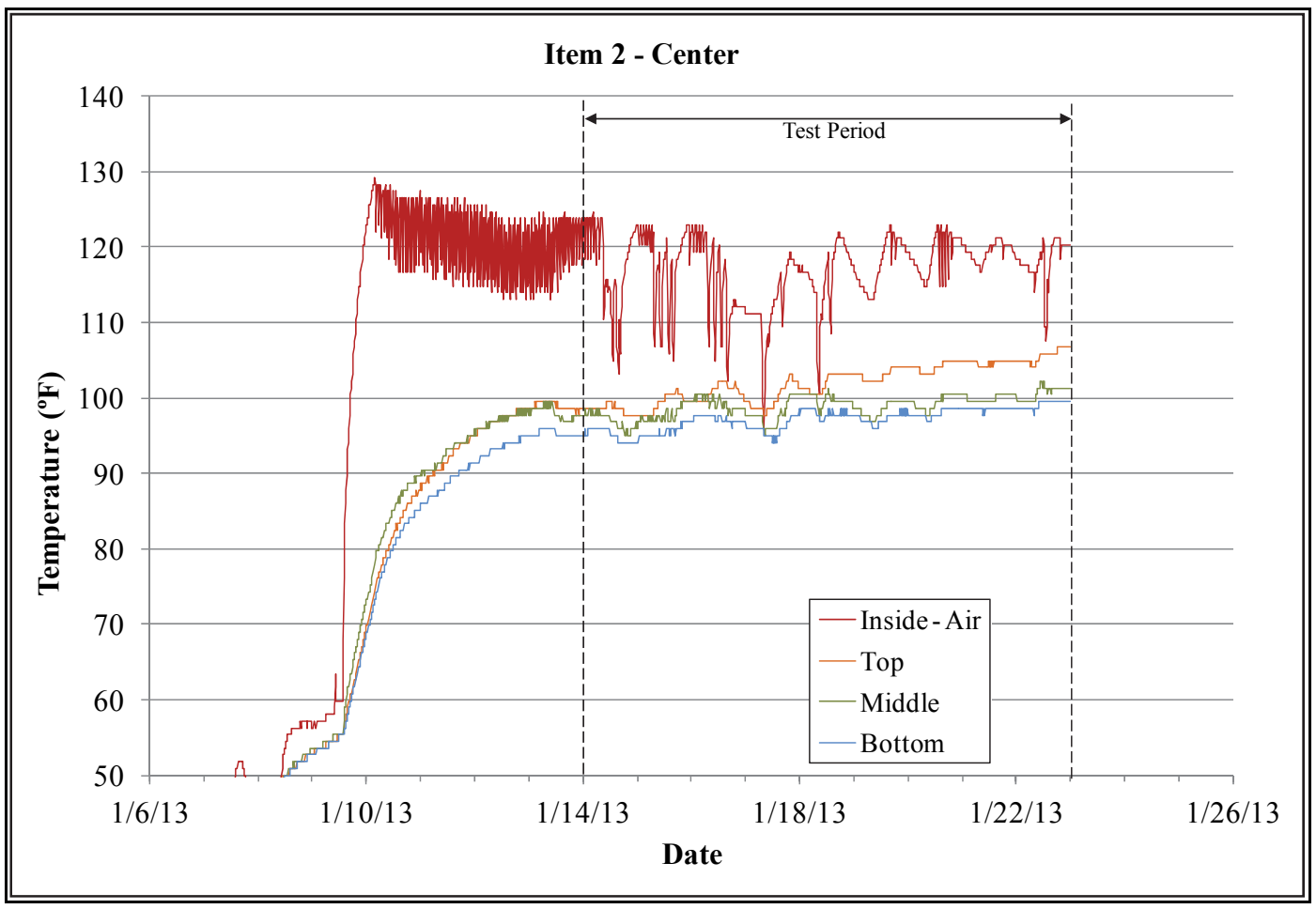

Figure A6. Foamed Asphalt pavement temperature range - north end.

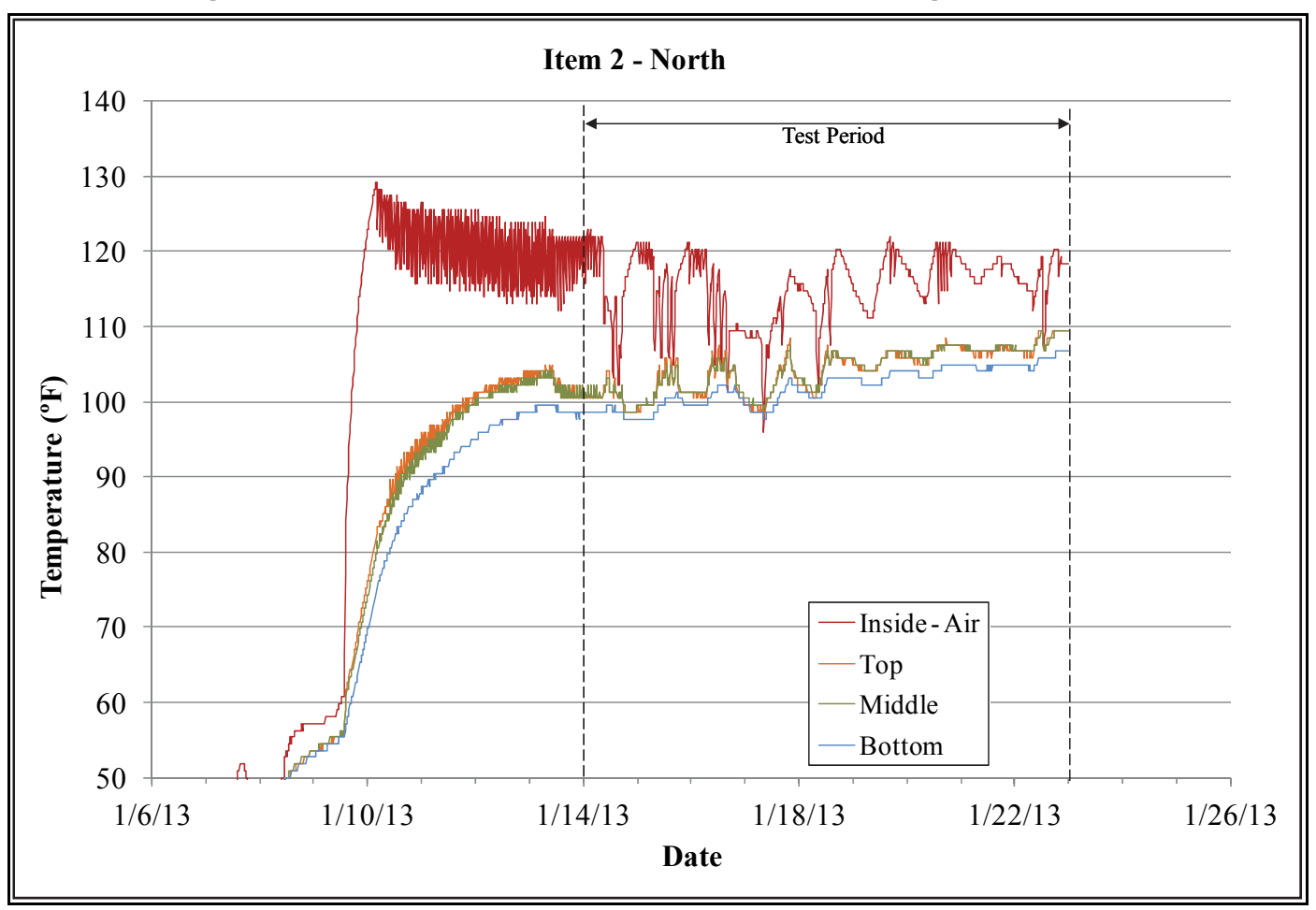


Figure A7. Sasobit $₫$ pavement temperature range - south end.

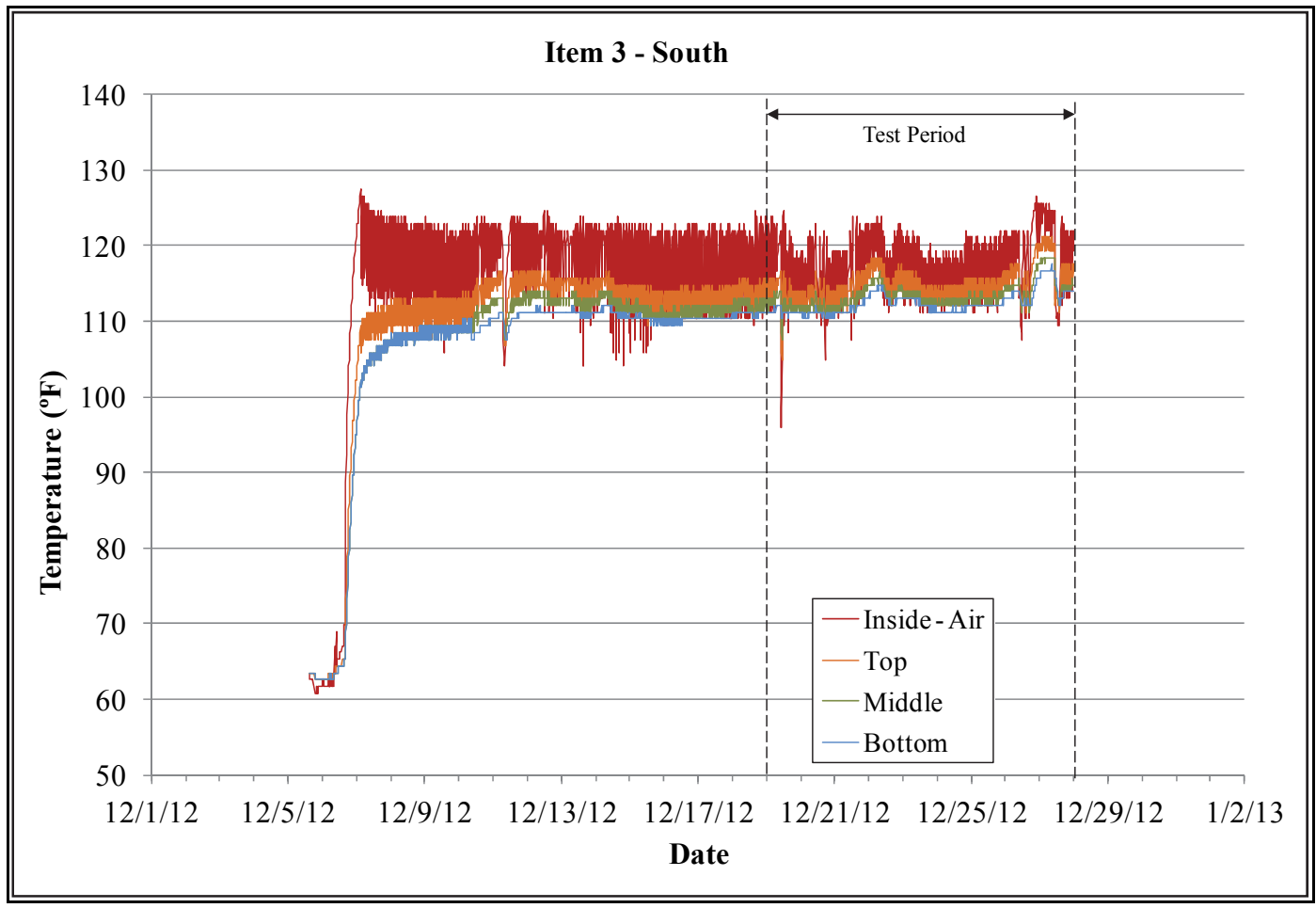

Figure A8. Sasobit ${ }^{\circledR}$ pavement temperature range - center of the item.

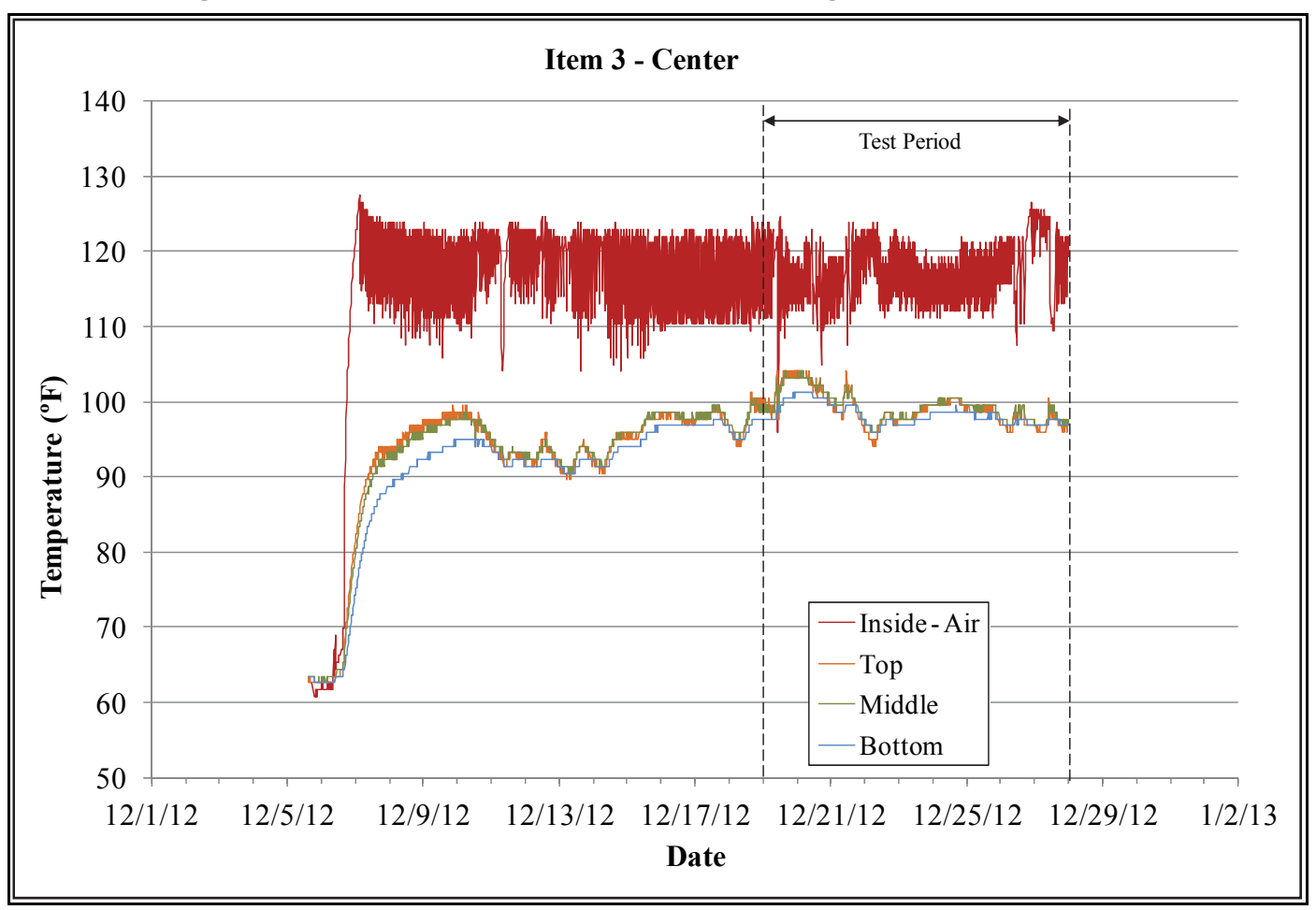


Figure A9. Sasobit ${ }^{\circledR}$ pavement temperature range - north end.

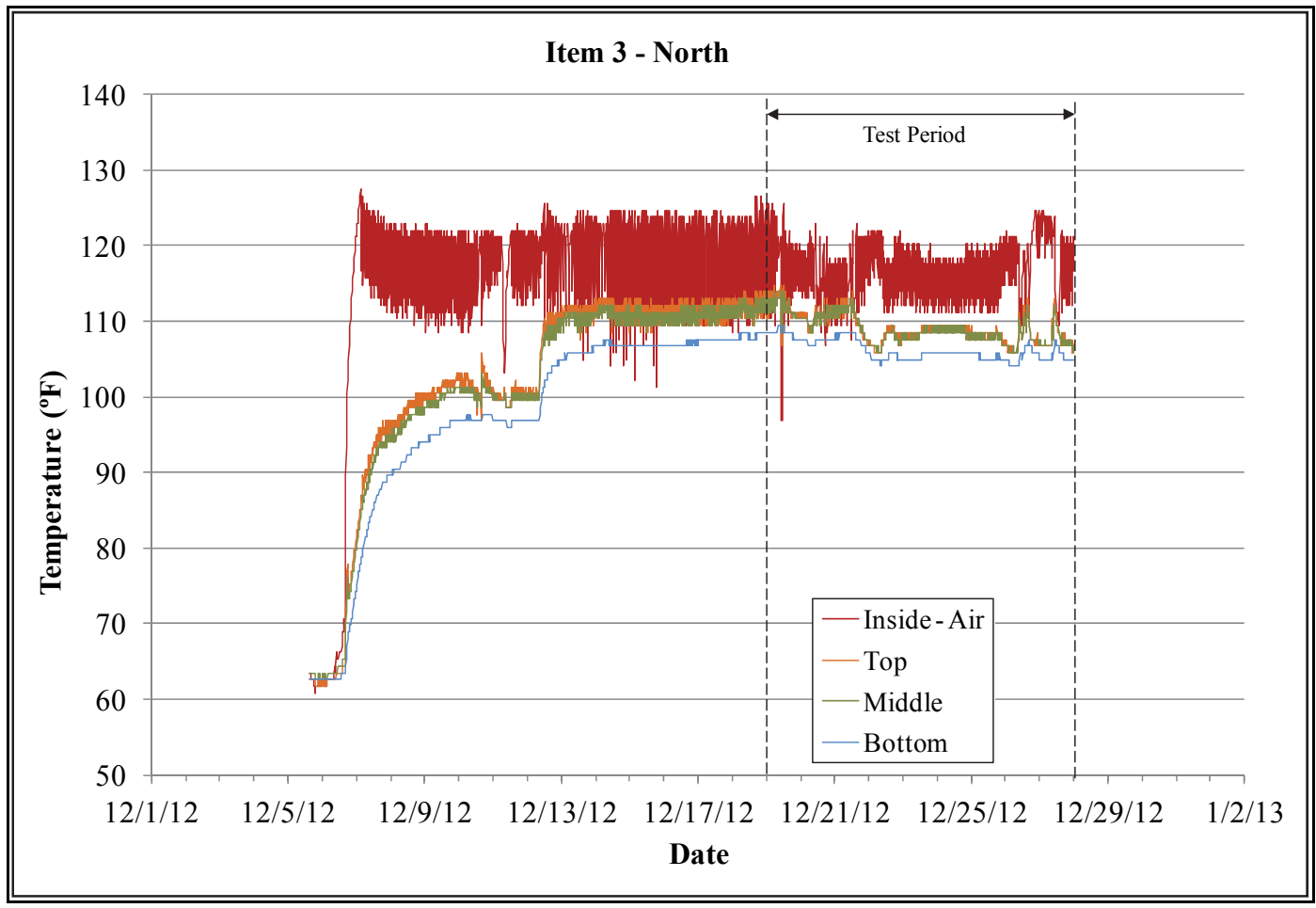

Figure A10. Evotherm ${ }^{\mathrm{TM}} 3 \mathrm{G}$ pavement temperature range - south end.

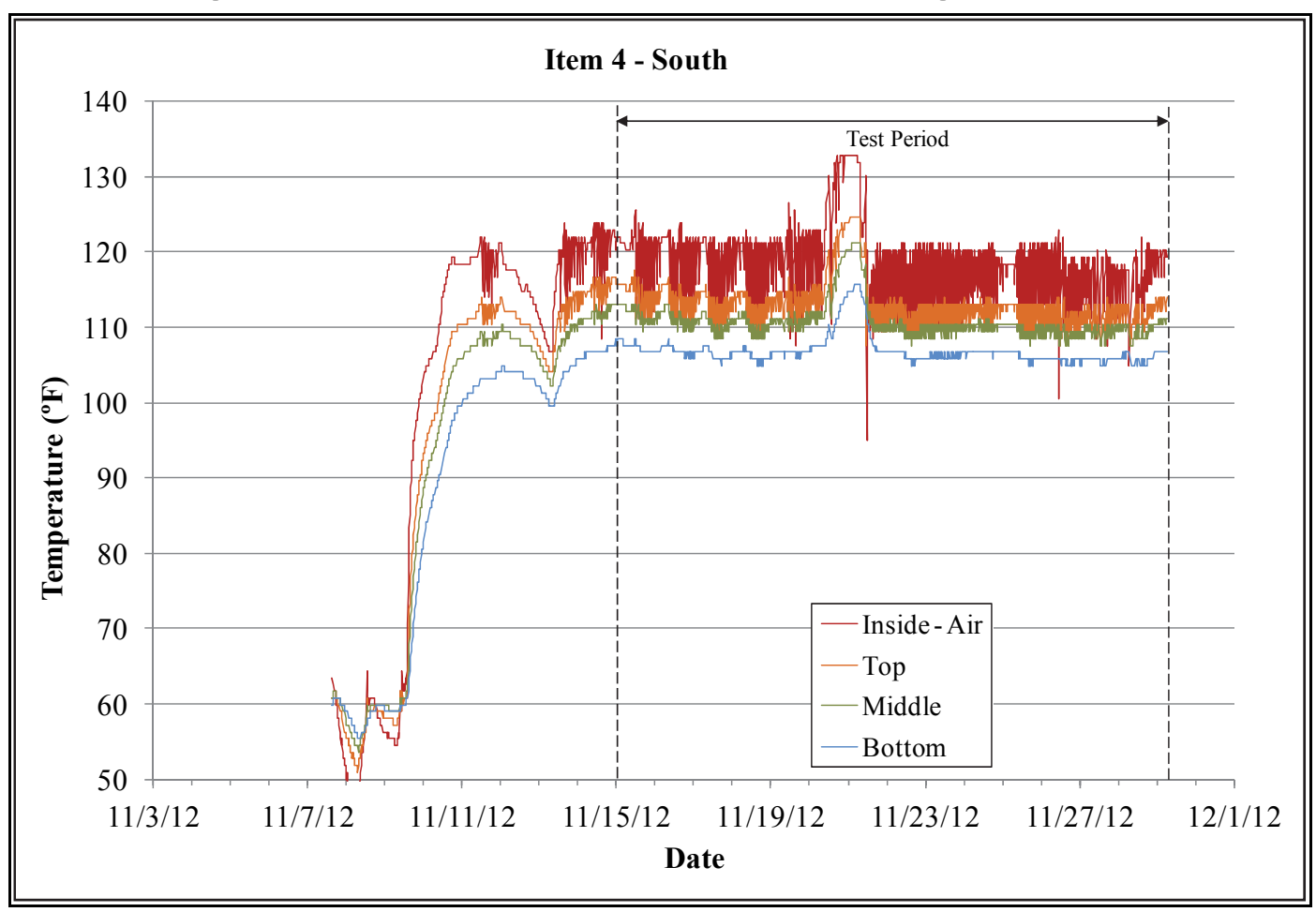


Figure A11. Evotherm ${ }^{\mathrm{TM}} 3 \mathrm{G}$ pavement temperature range - center of the item.

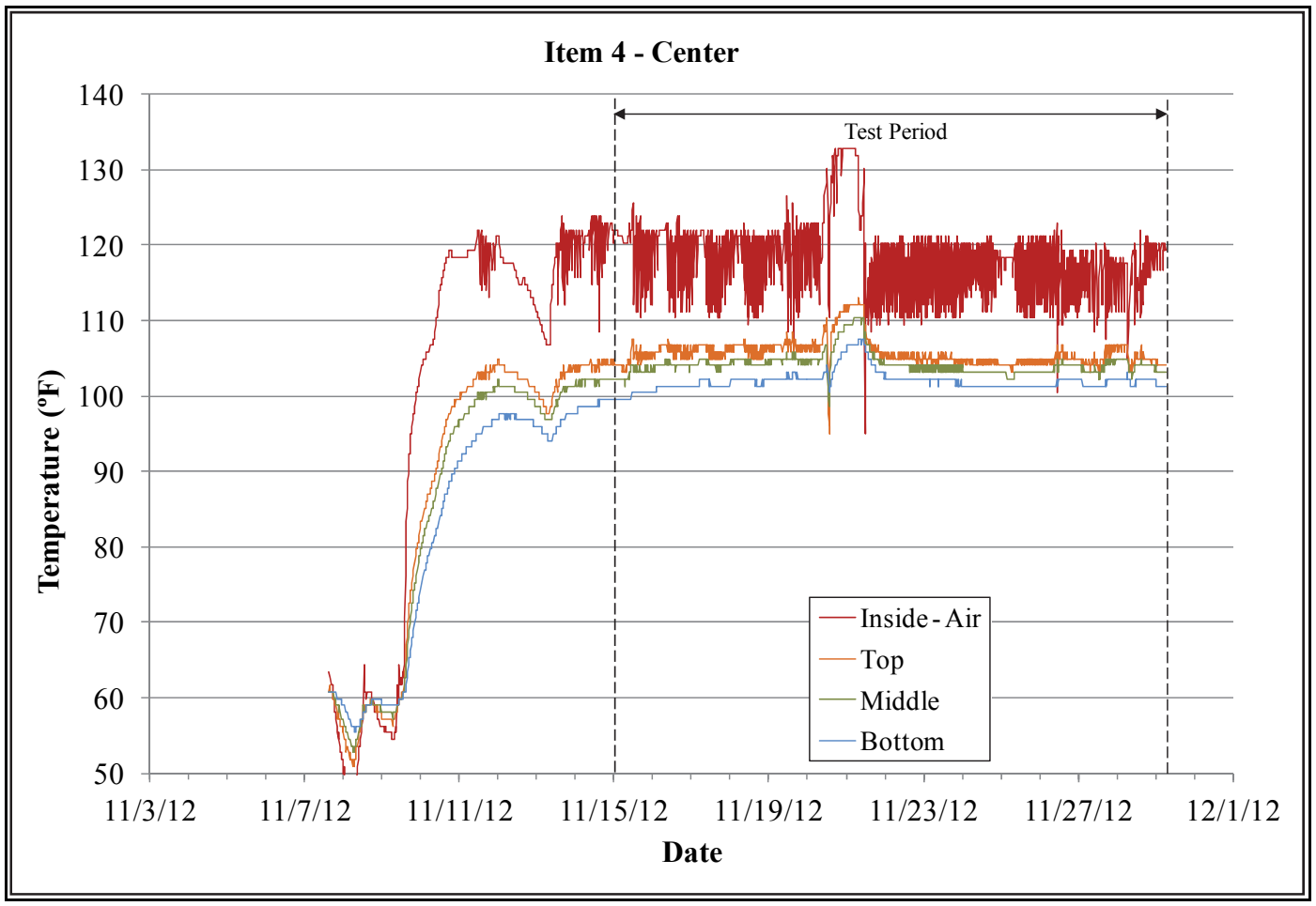

Figure A12. Evotherm ${ }^{\mathrm{TM}} 3 \mathrm{G}$ pavement temperature range - north end.

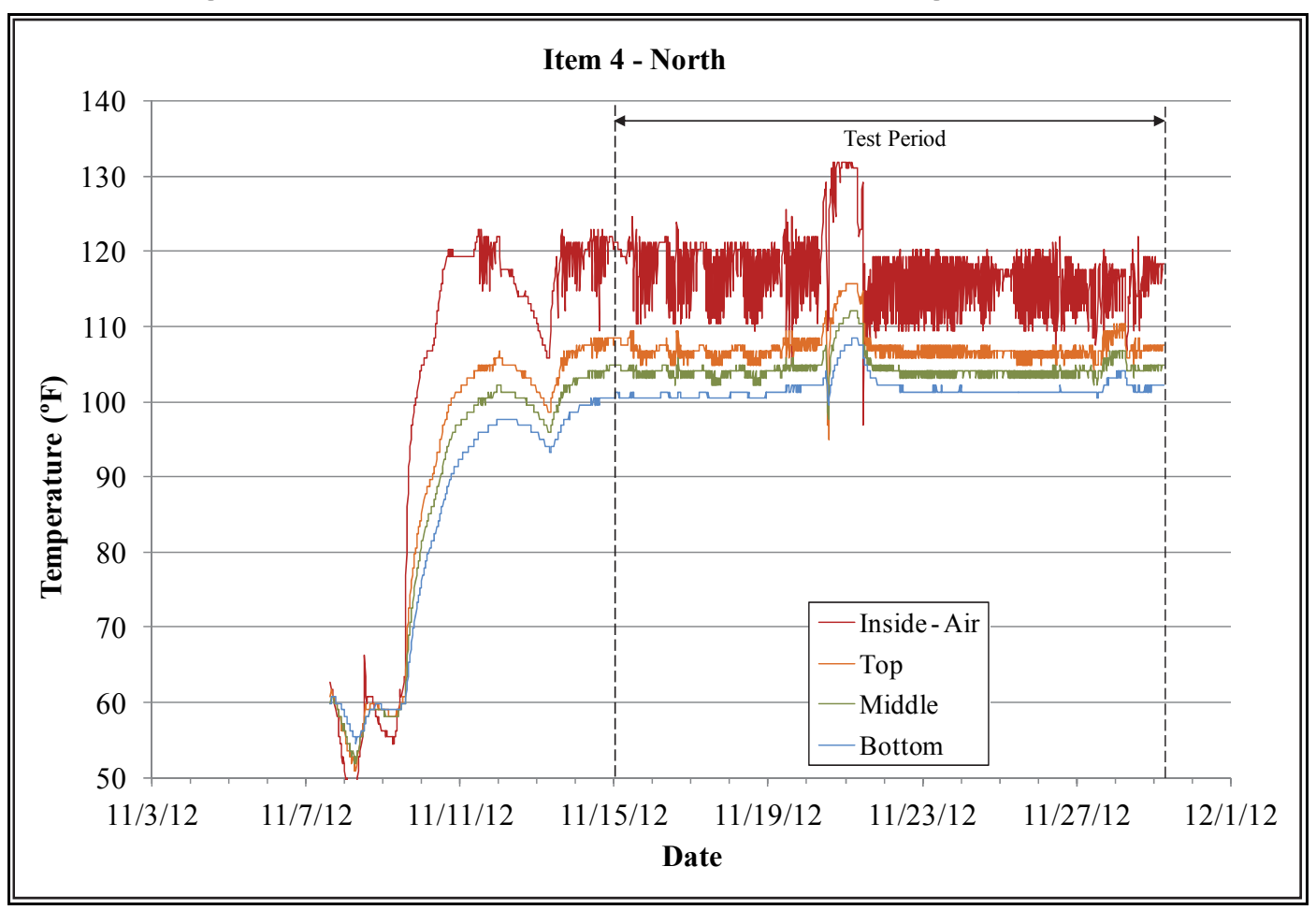




\section{Appendix B: Permanent deformation data}

Figure B1. HMA cross section permanent deformation at STA 0+10.

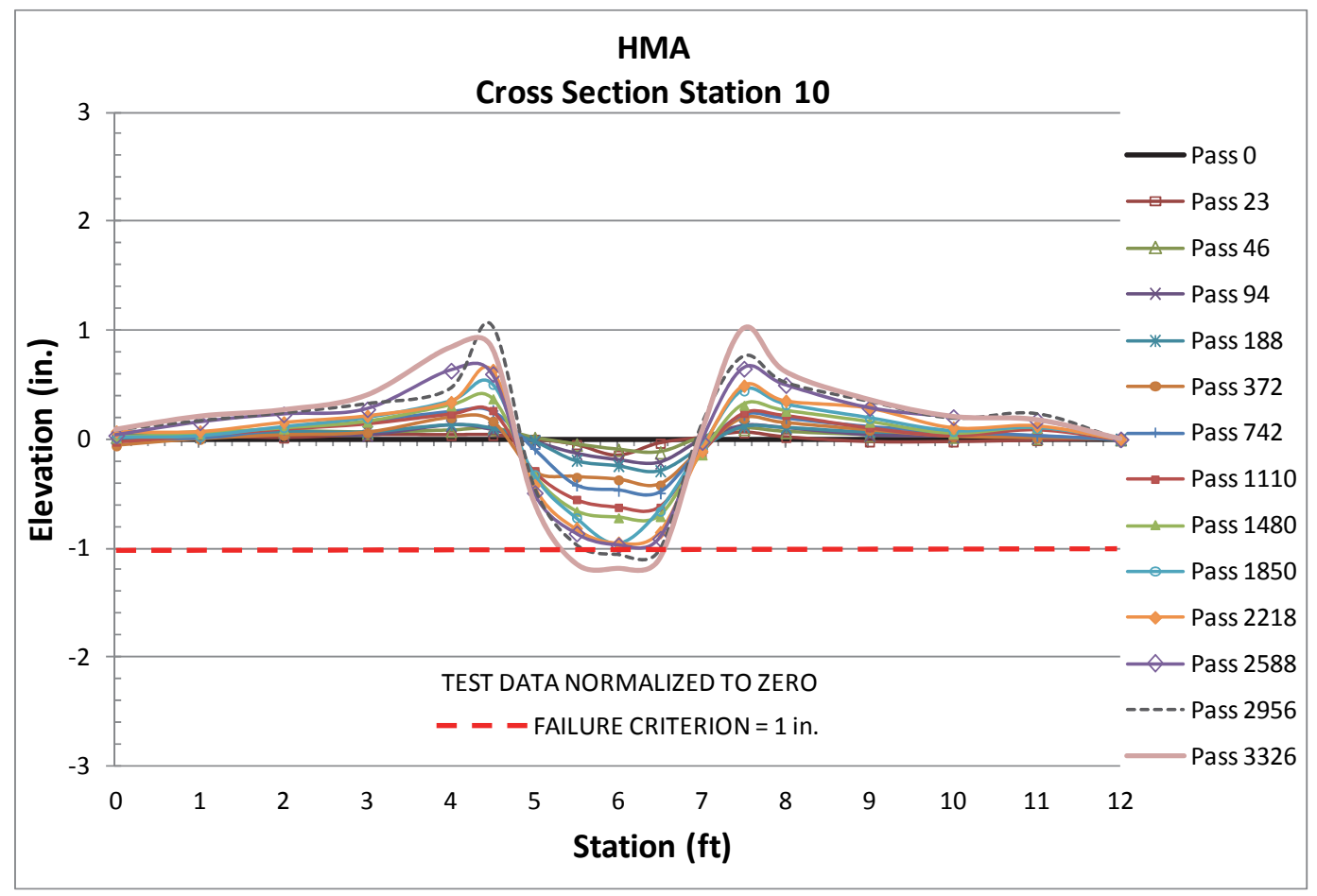

Figure B2. HMA cross section permanent deformation at STA 0+15.

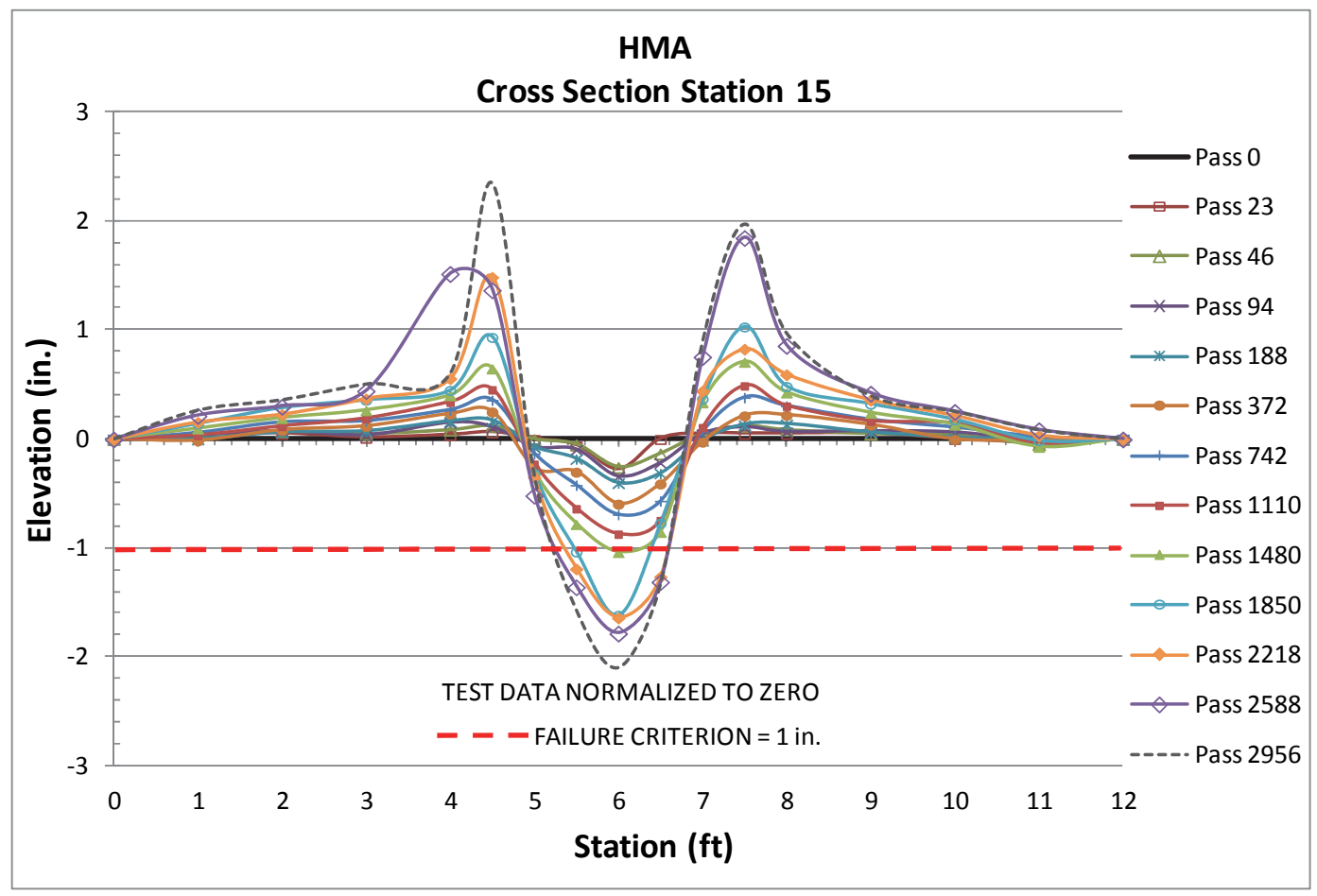


Figure B3. HMA cross section permanent deformation at STA 0+20.

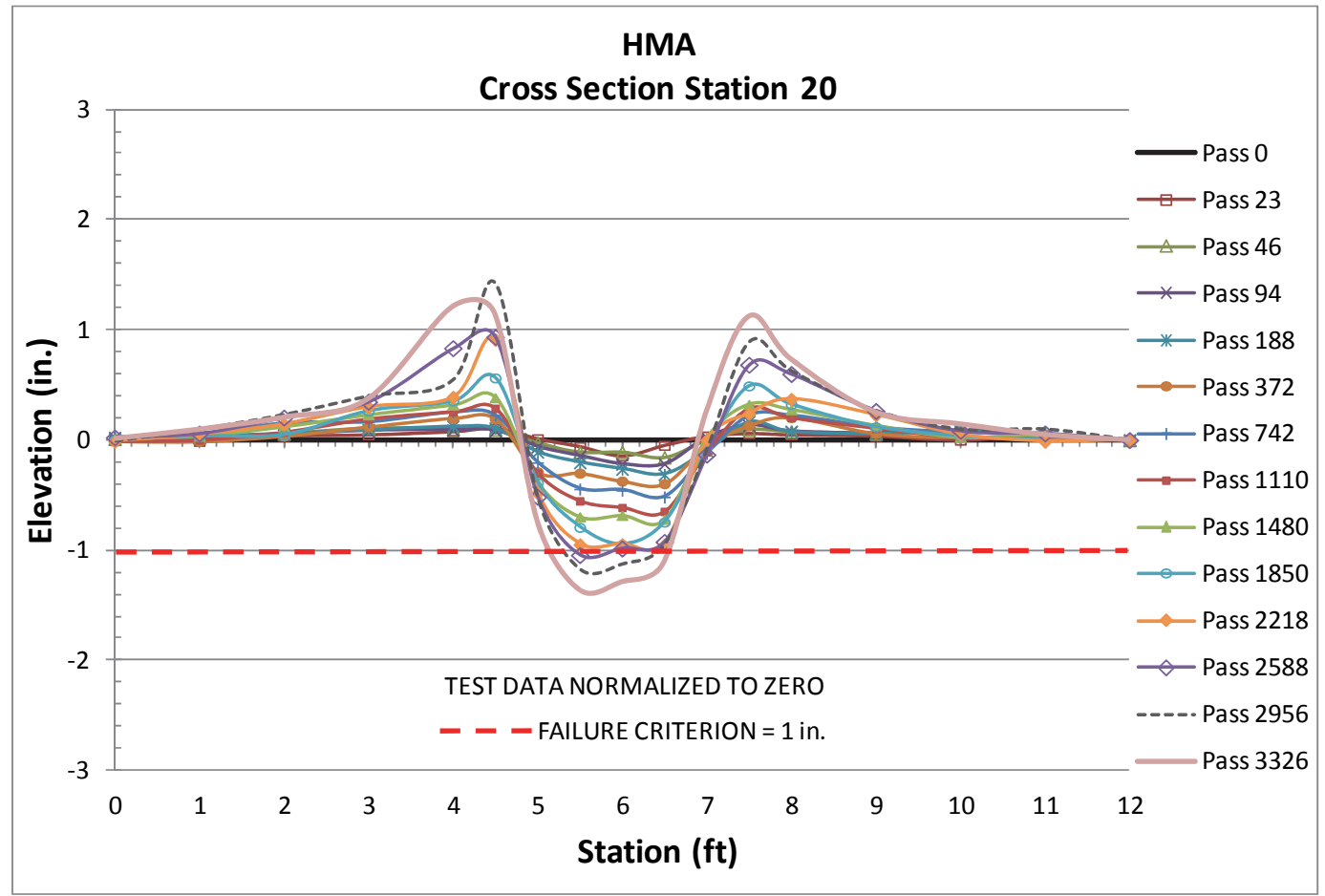

Figure B4. HMA cross section permanent deformation at STA 0+25.

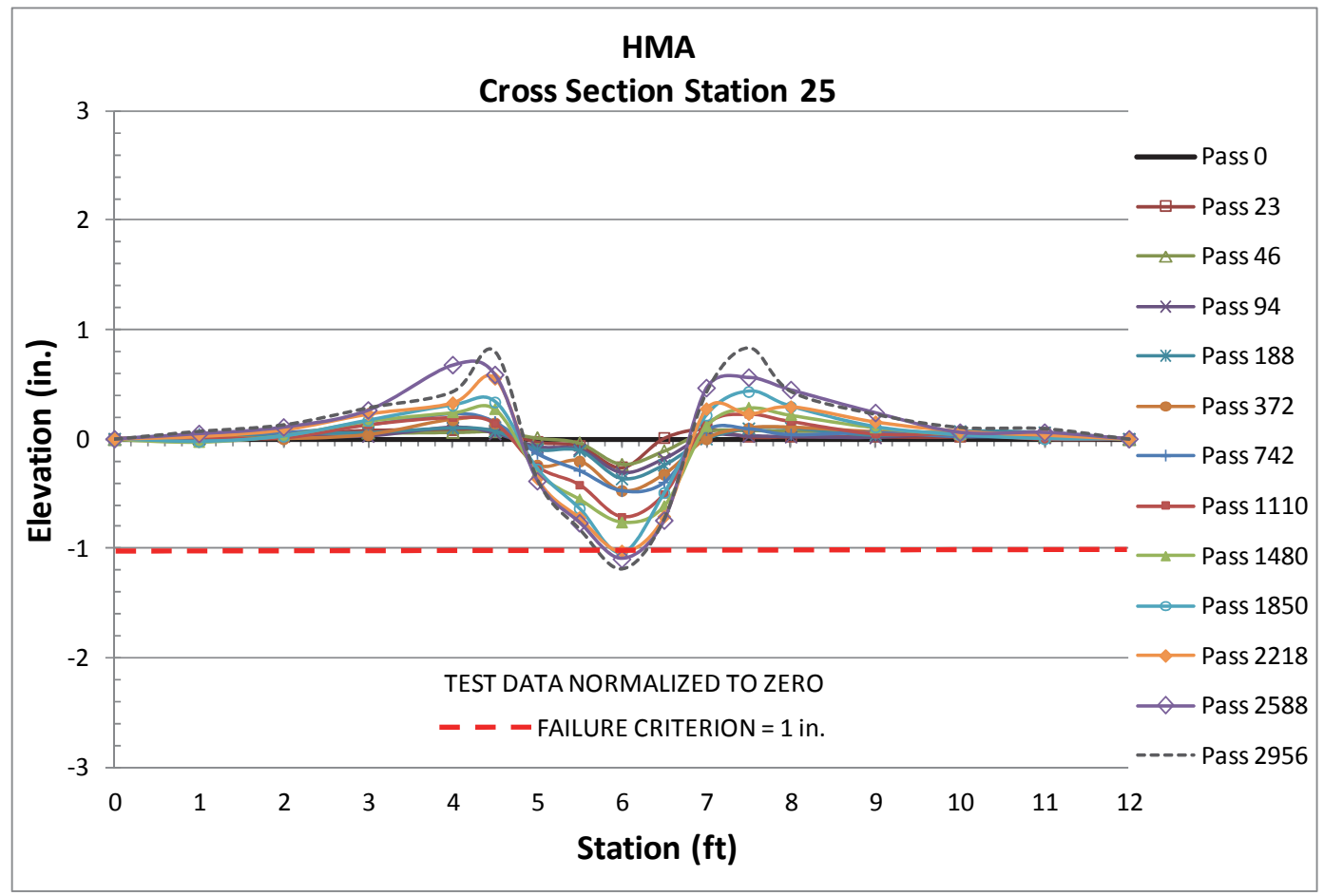


Figure B5. HMA cross section permanent deformation at STA $0+30$.

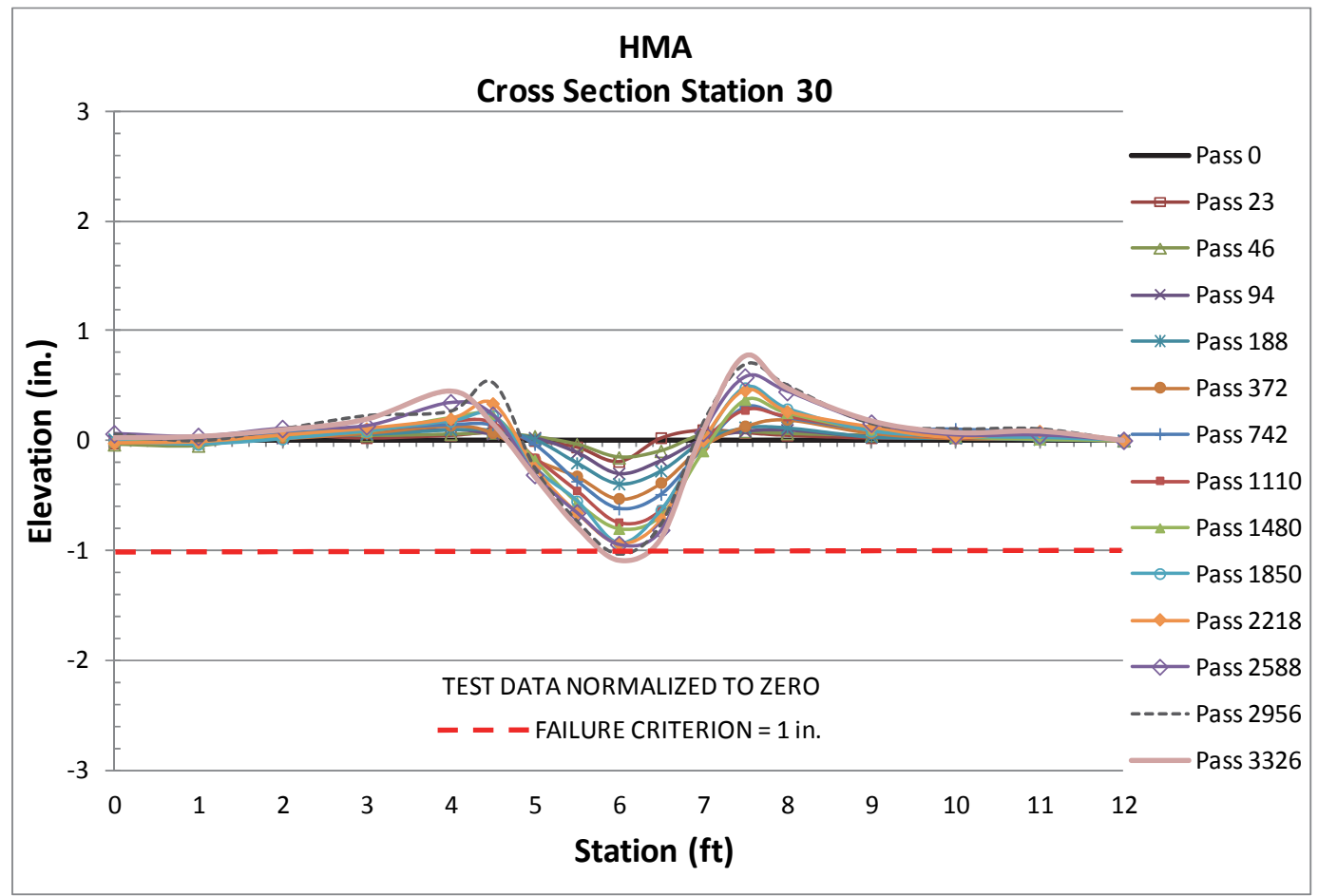

Figure B6. HMA cross section permanent deformation at STA 0+35.

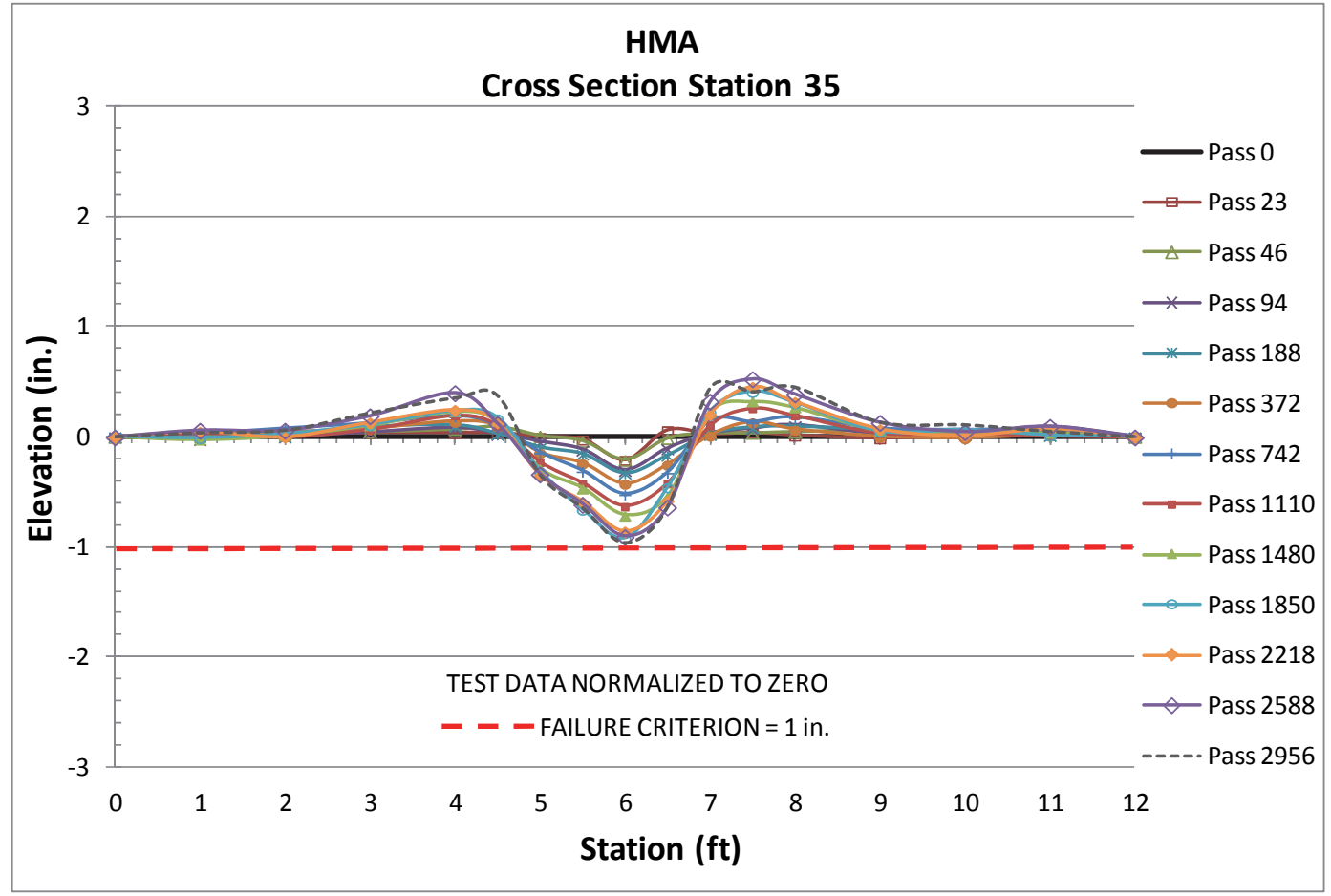


Figure B7. HMA cross section permanent deformation at STA $0+40$.

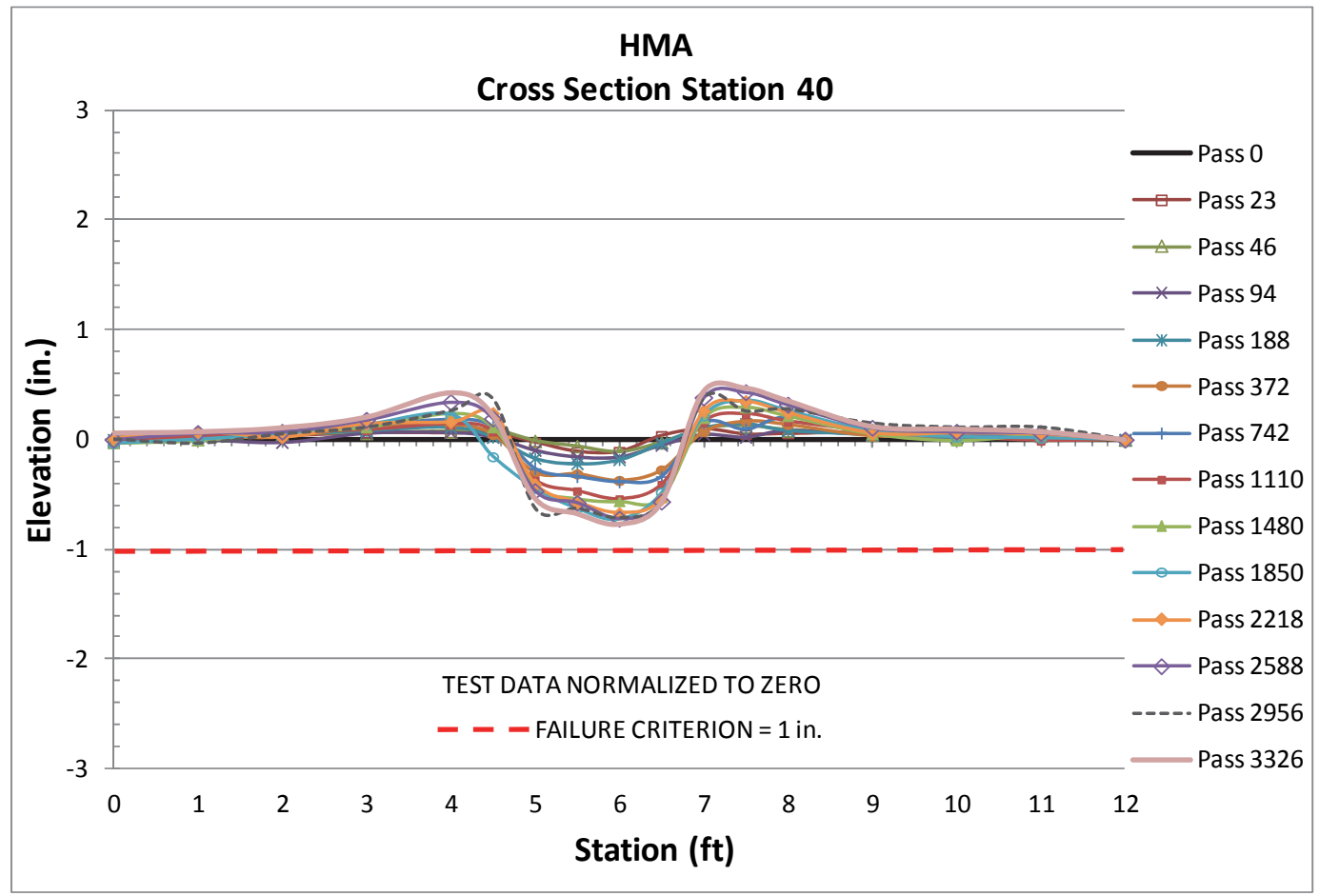

Figure B8. Foamed Asphalt cross section permanent deformation at STA 0+10.

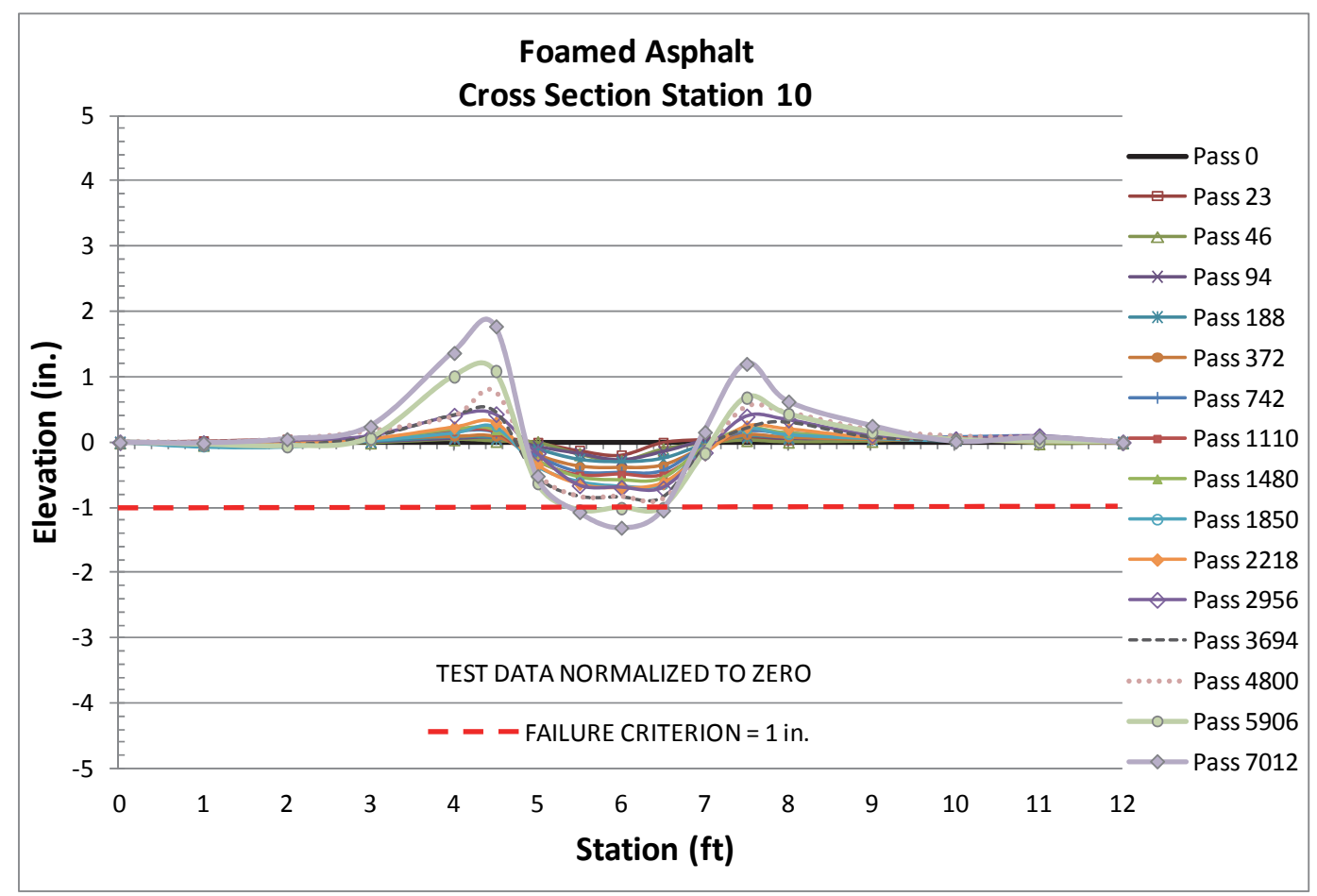


Figure B9. Foamed Asphalt cross section permanent deformation at STA 0+15.

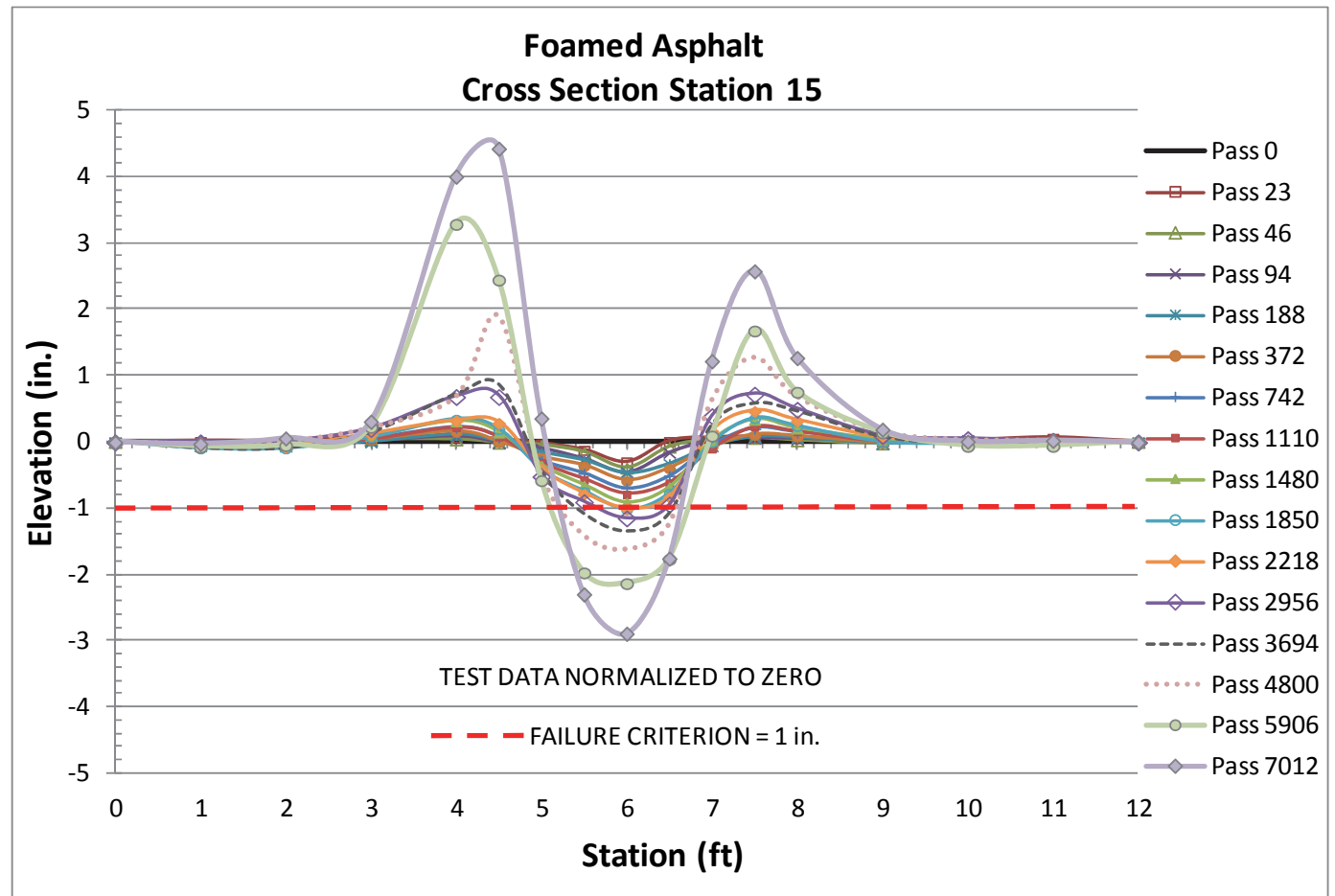

Figure B10. Foamed Asphalt cross section permanent deformation at STA 0+20.

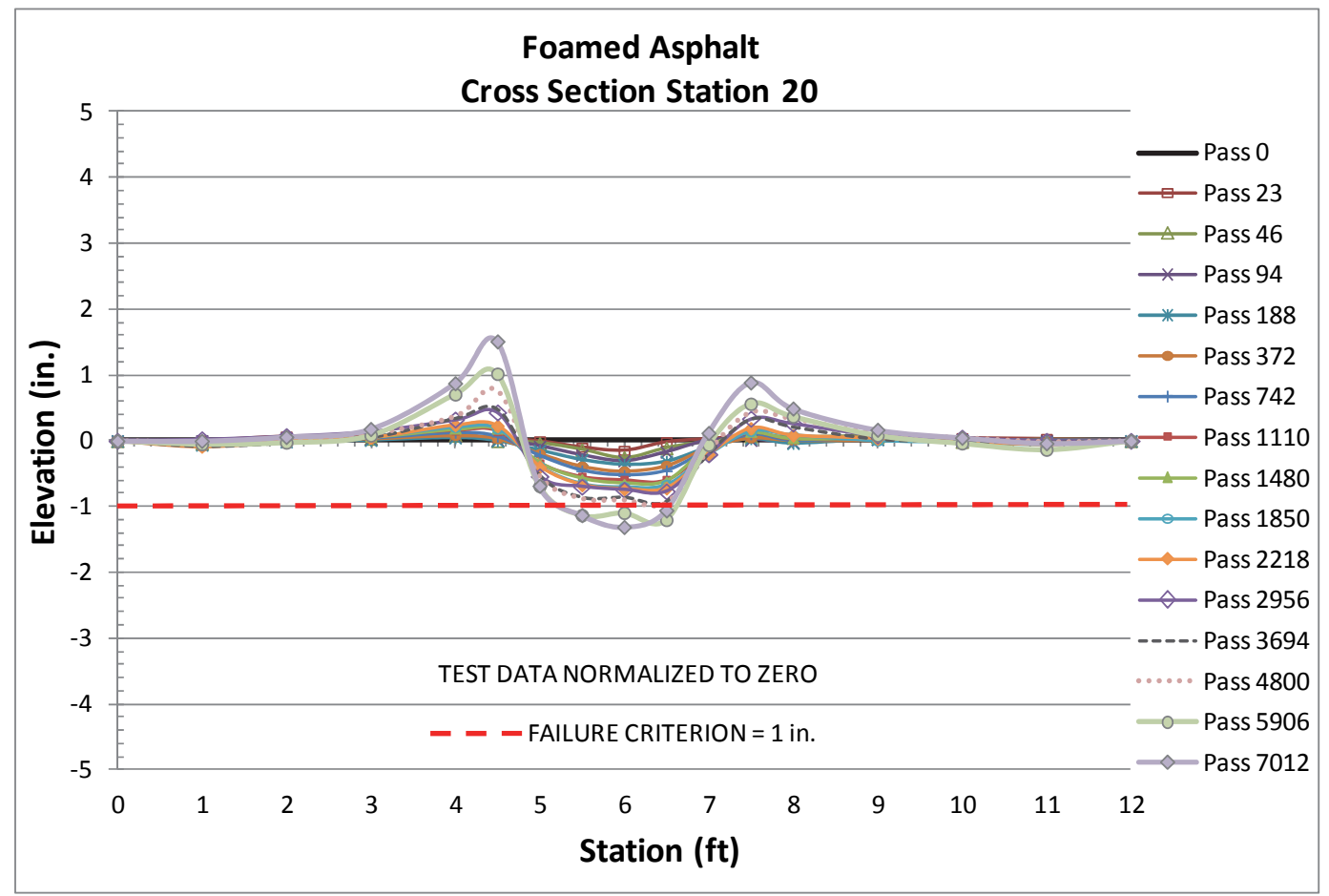


Figure B11. Foamed Asphalt cross section permanent deformation at STA 0+25.

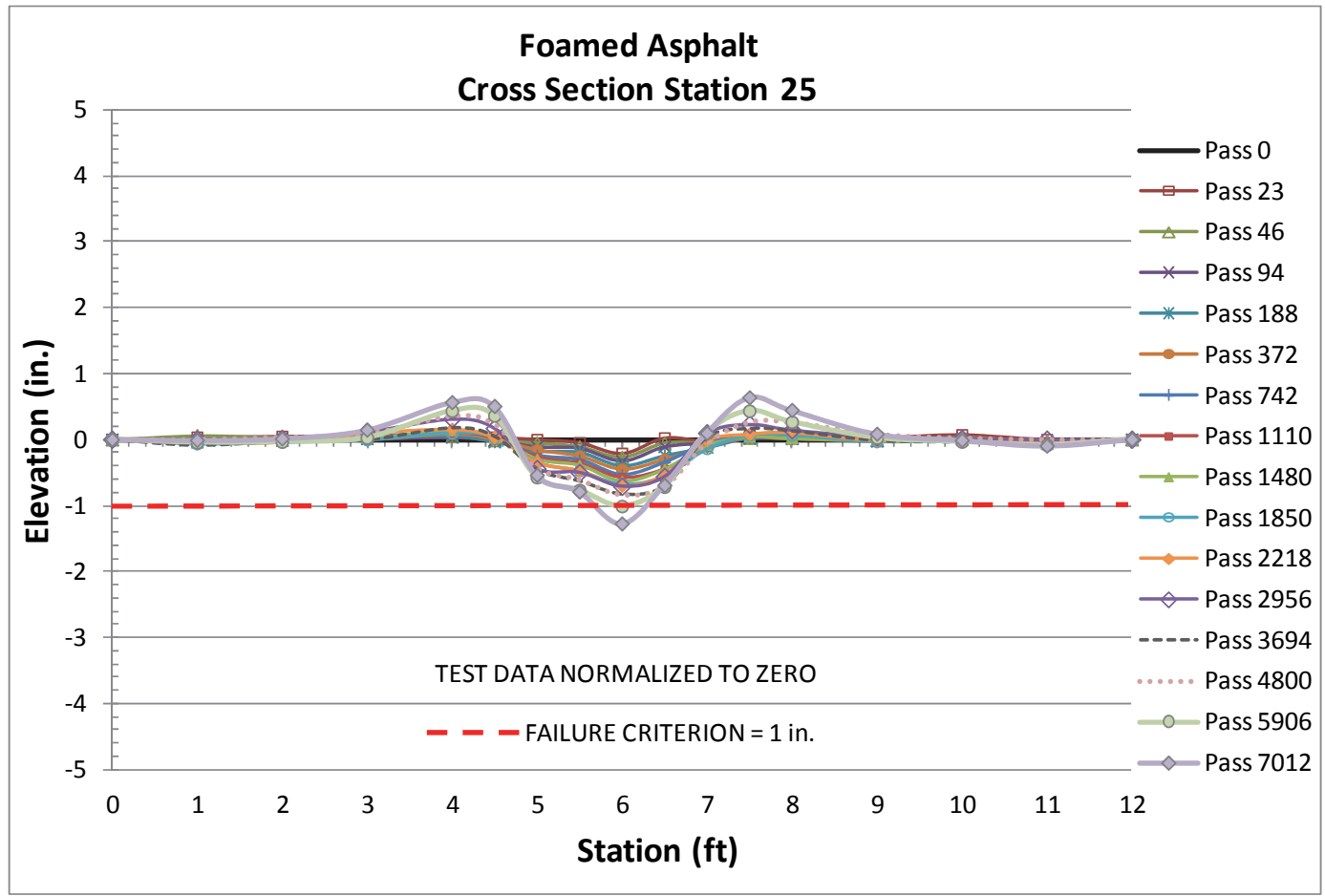

Figure B12. Foamed Asphalt cross section permanent deformation at STA 0+30.

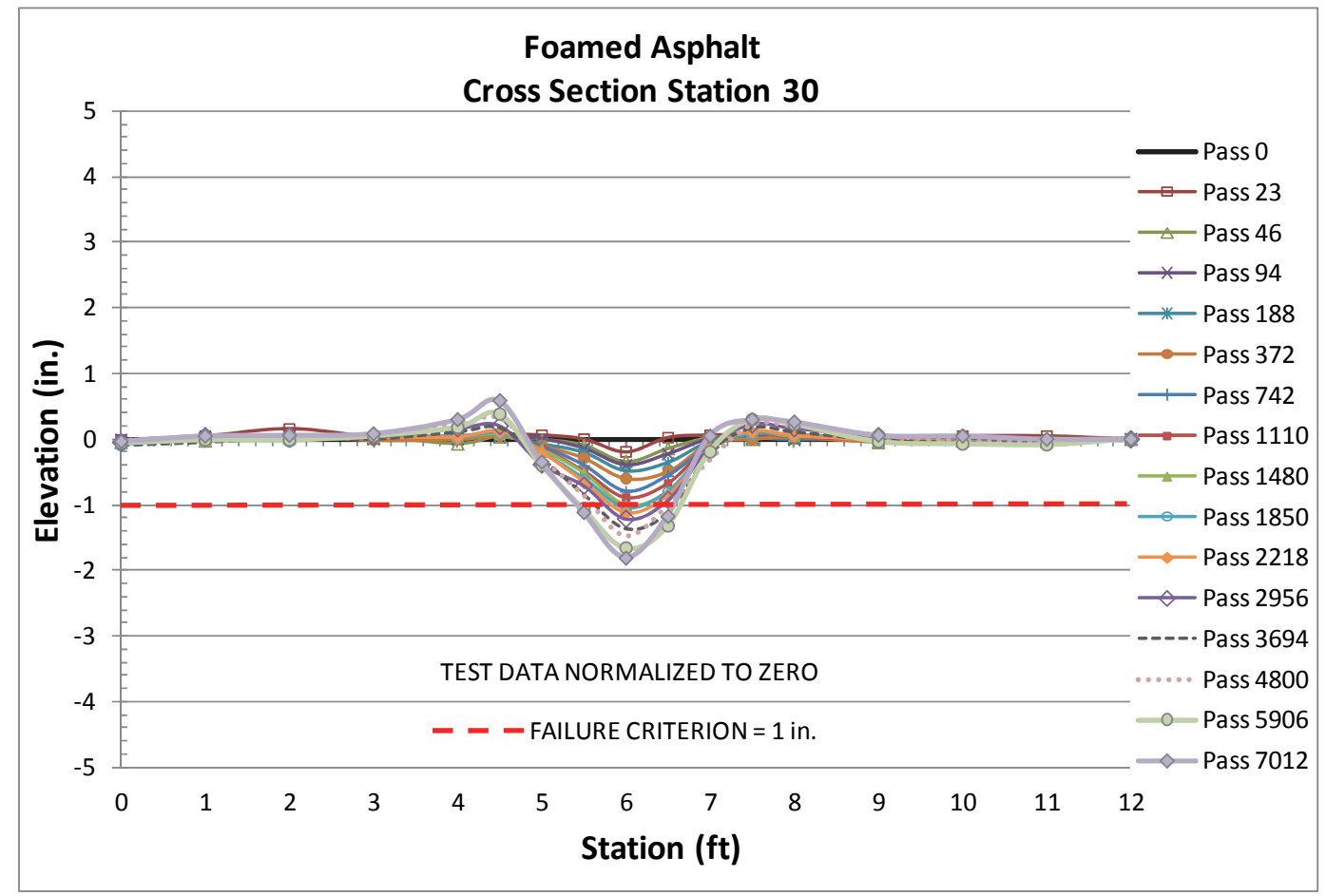


Figure B13. Foamed Asphalt cross section permanent deformation at STA 0+35.

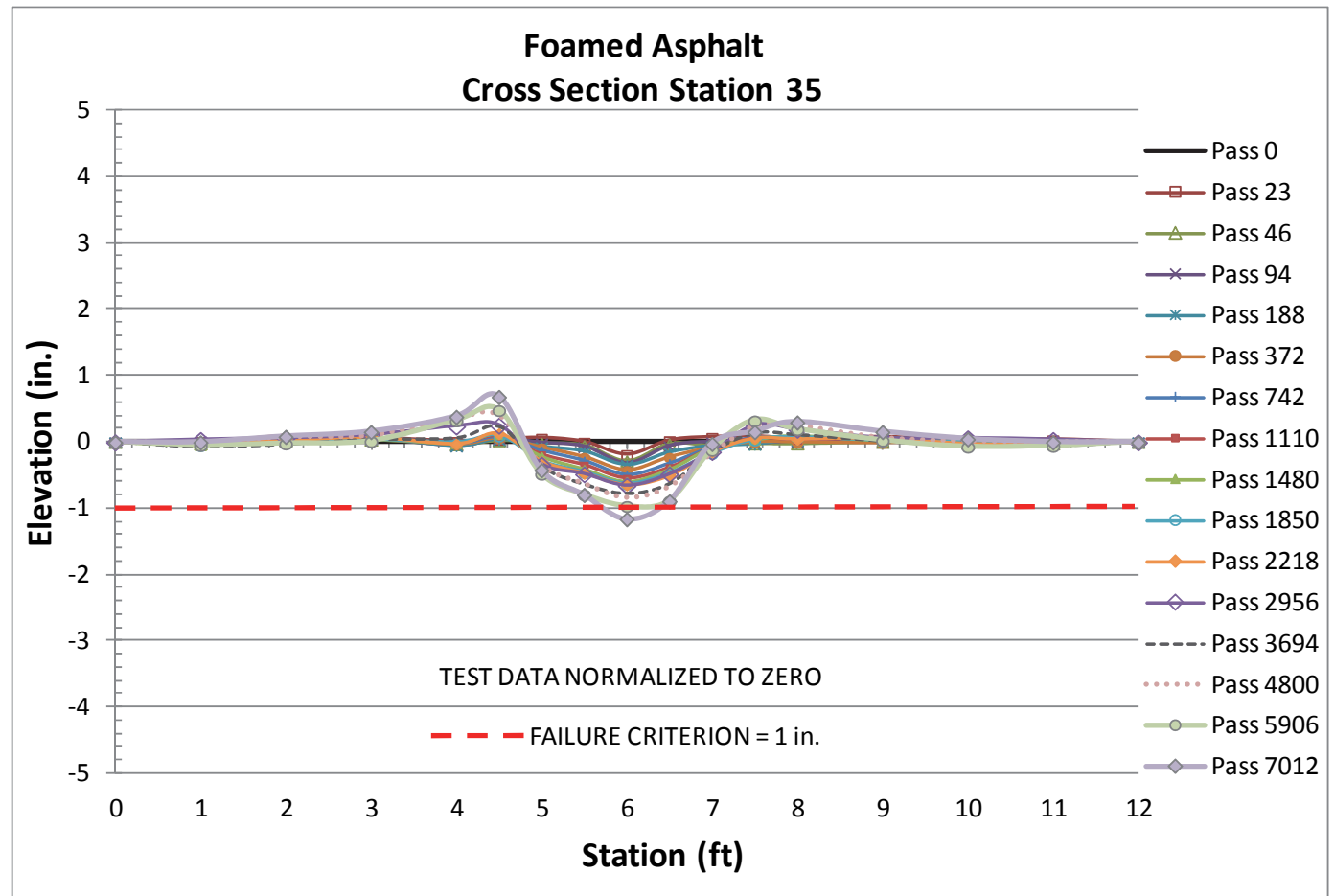

Figure B14. Foamed Asphalt cross section permanent deformation at STA 0+40.

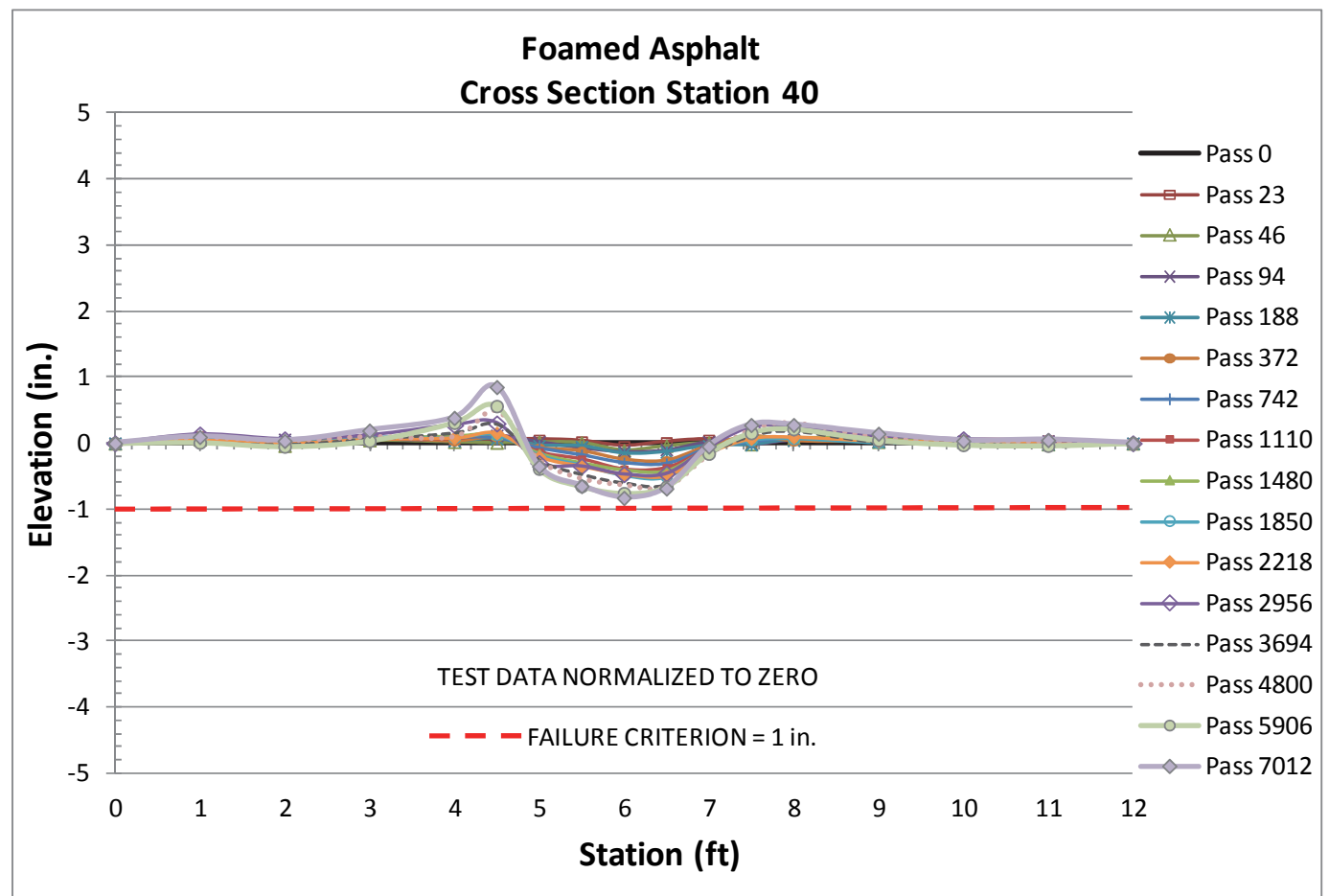


Figure B15. Sasobit $\circledast$ cross section permanent deformation at STA $0+10$.

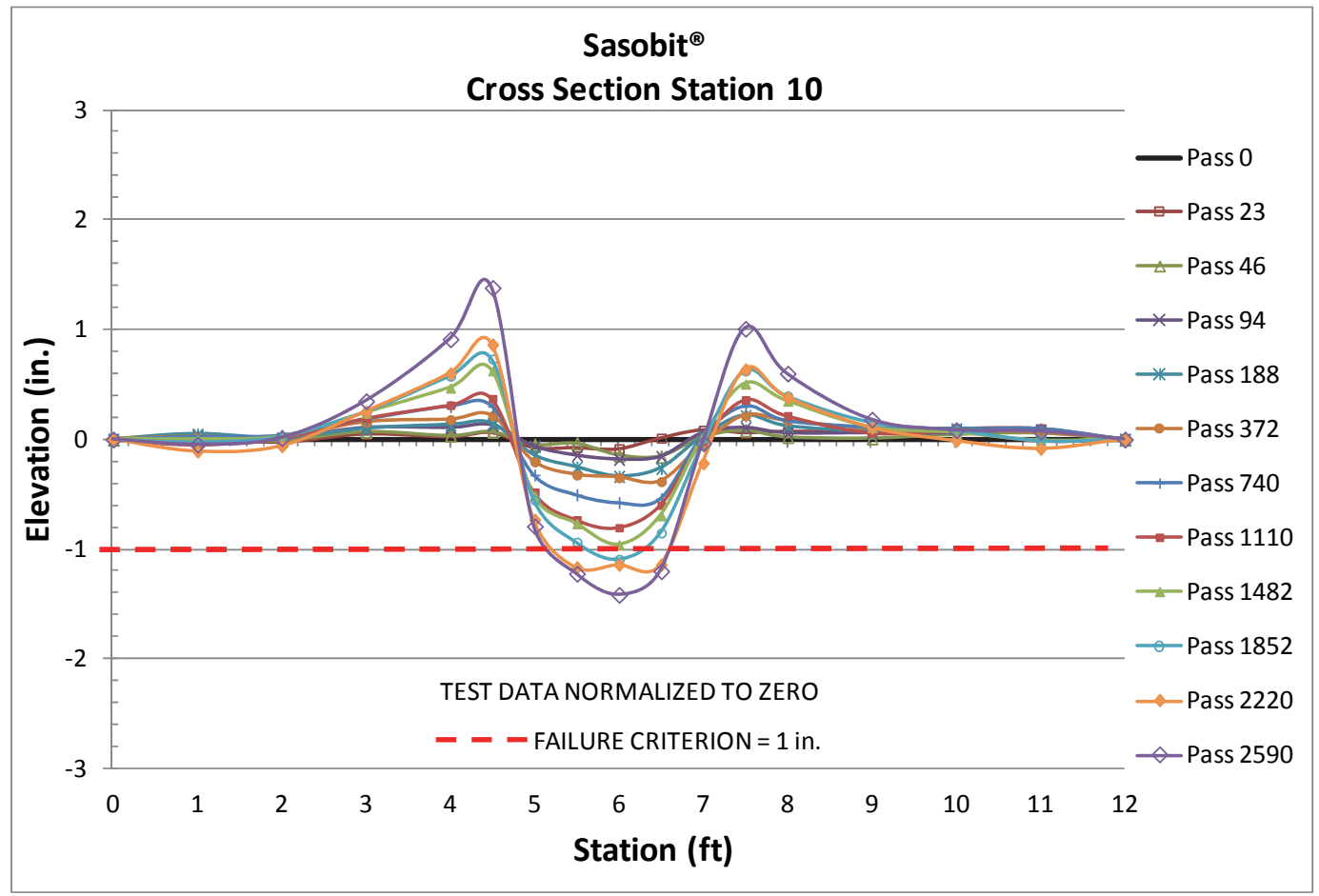

Figure B16. Sasobit ${ }^{8}$ cross section permanent deformation at STA 0+15.

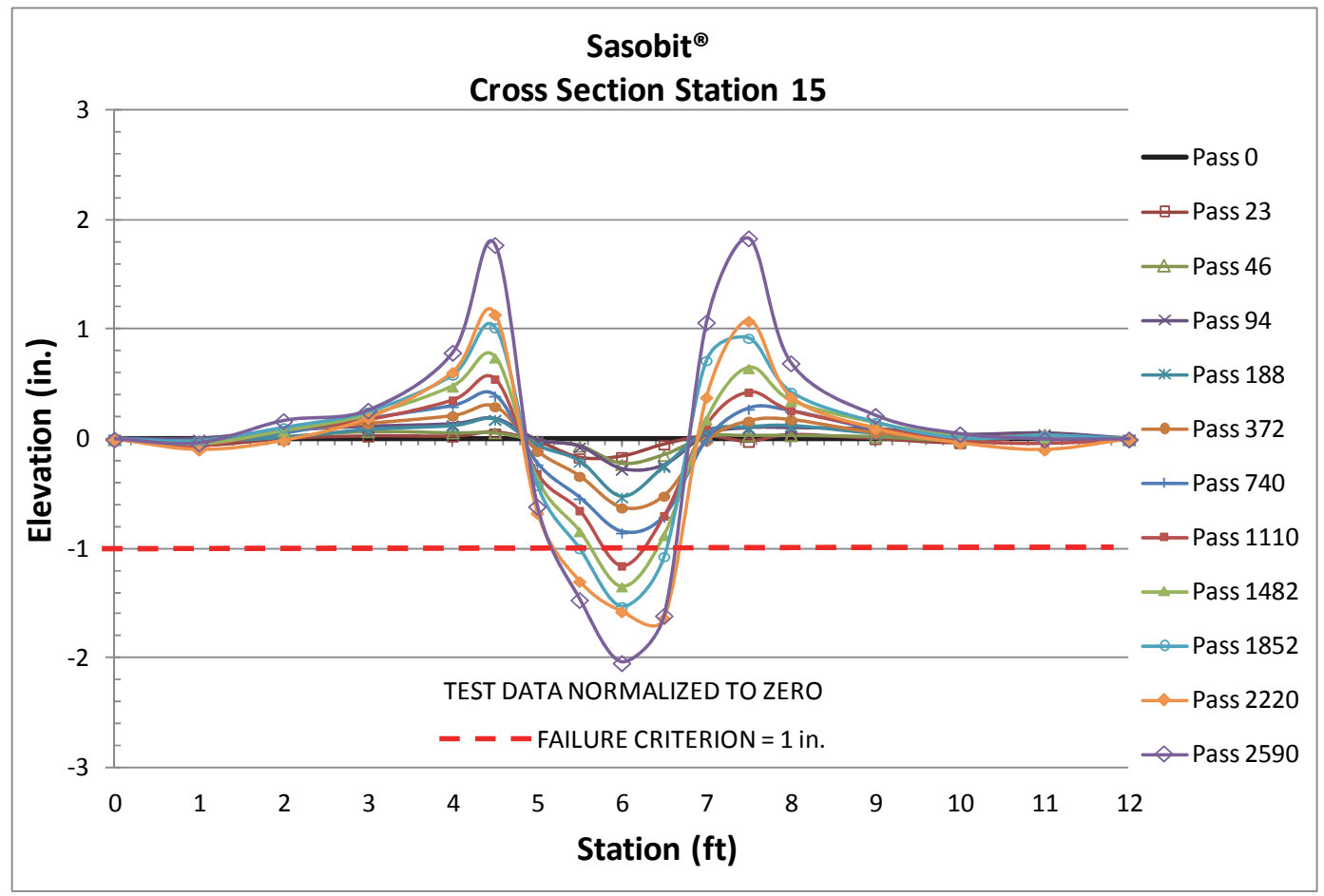


Figure B17. Sasobit $₫$ cross section permanent deformation at STA 0+20.

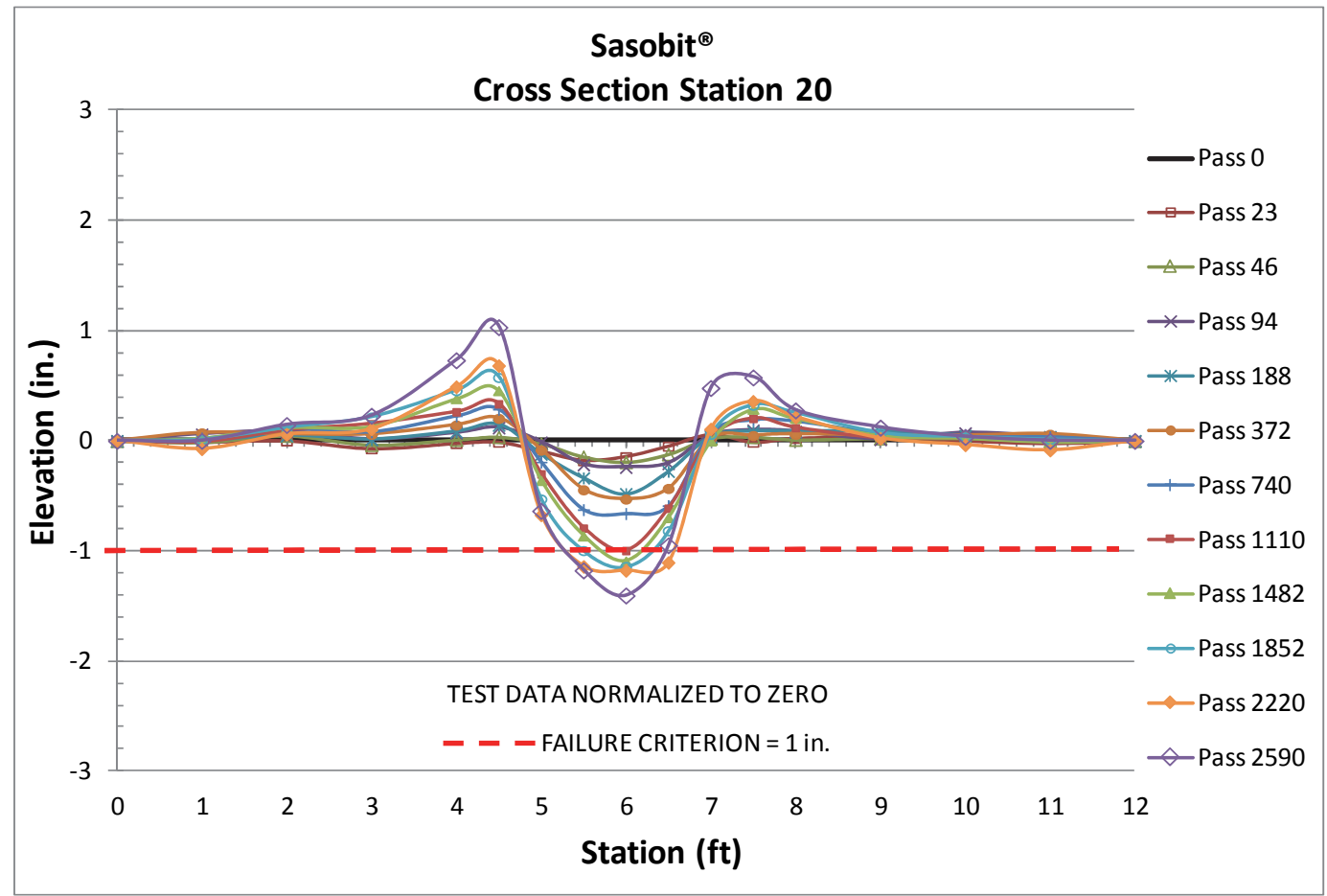

Figure B18. Sasobit $₫$ cross section permanent deformation at STA 0+25.

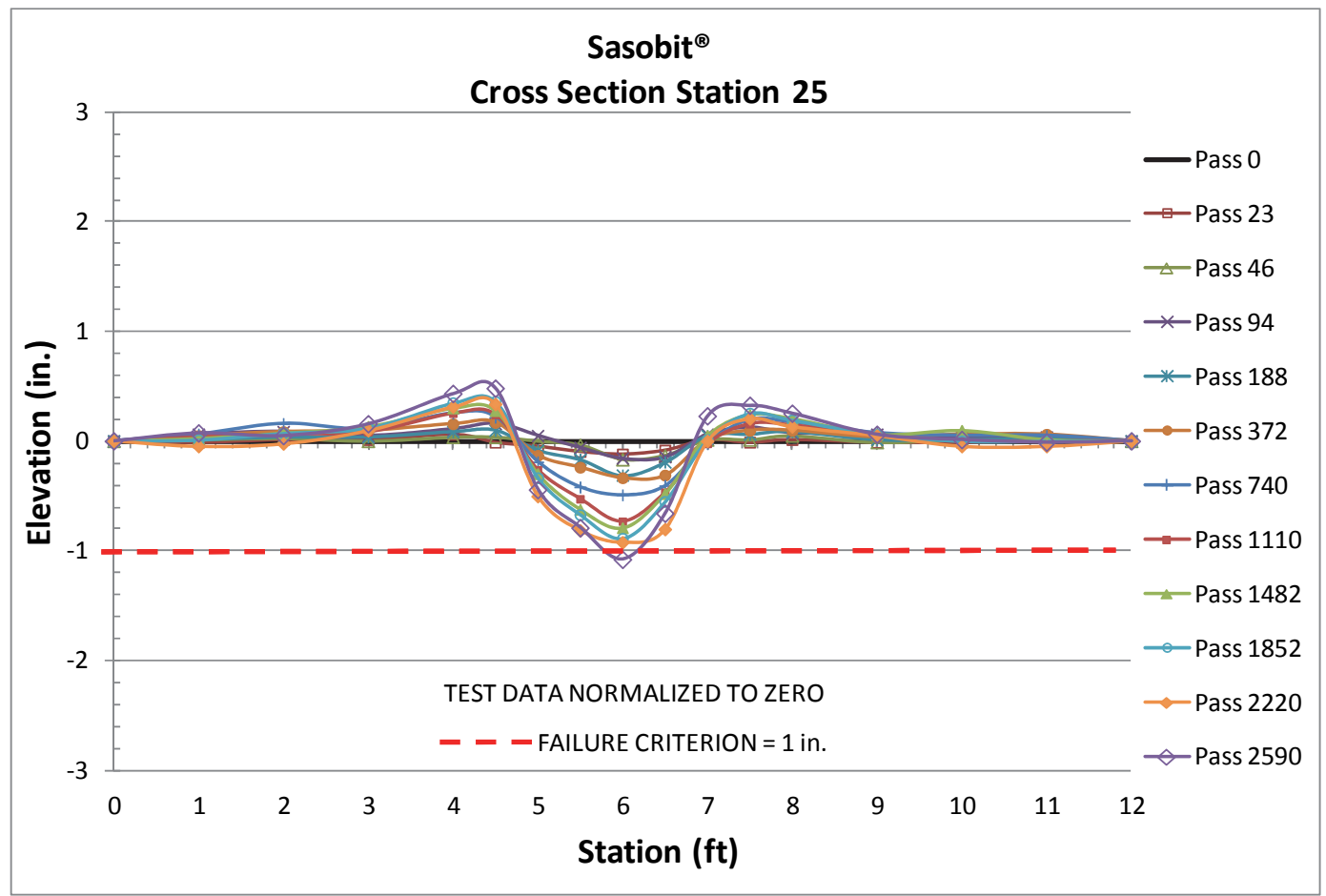


Figure B19. Sasobit $₫$ cross section permanent deformation at STA $0+30$.

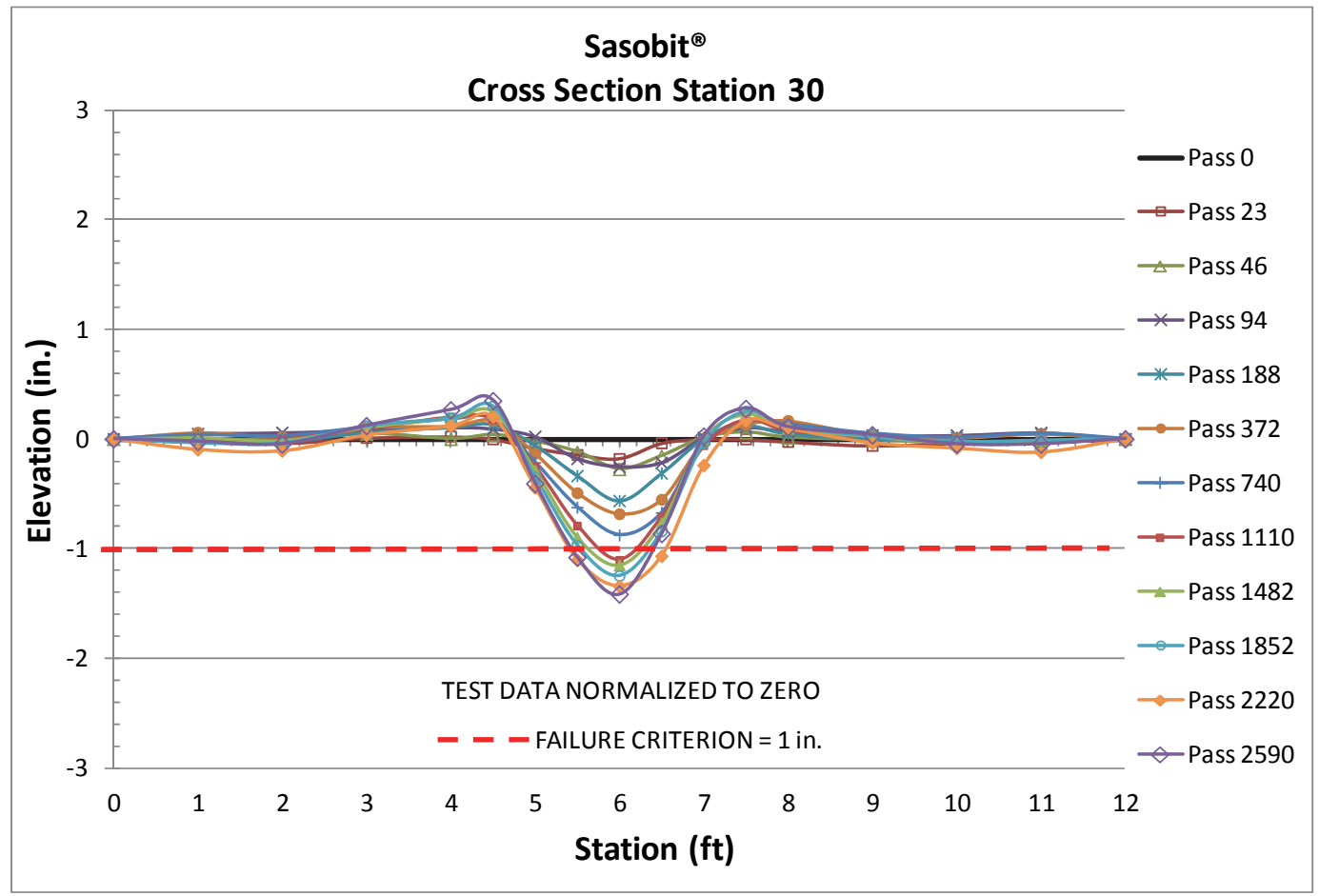

Figure B20. Sasobit ${ }^{8}$ cross section permanent deformation at STA 0+35.

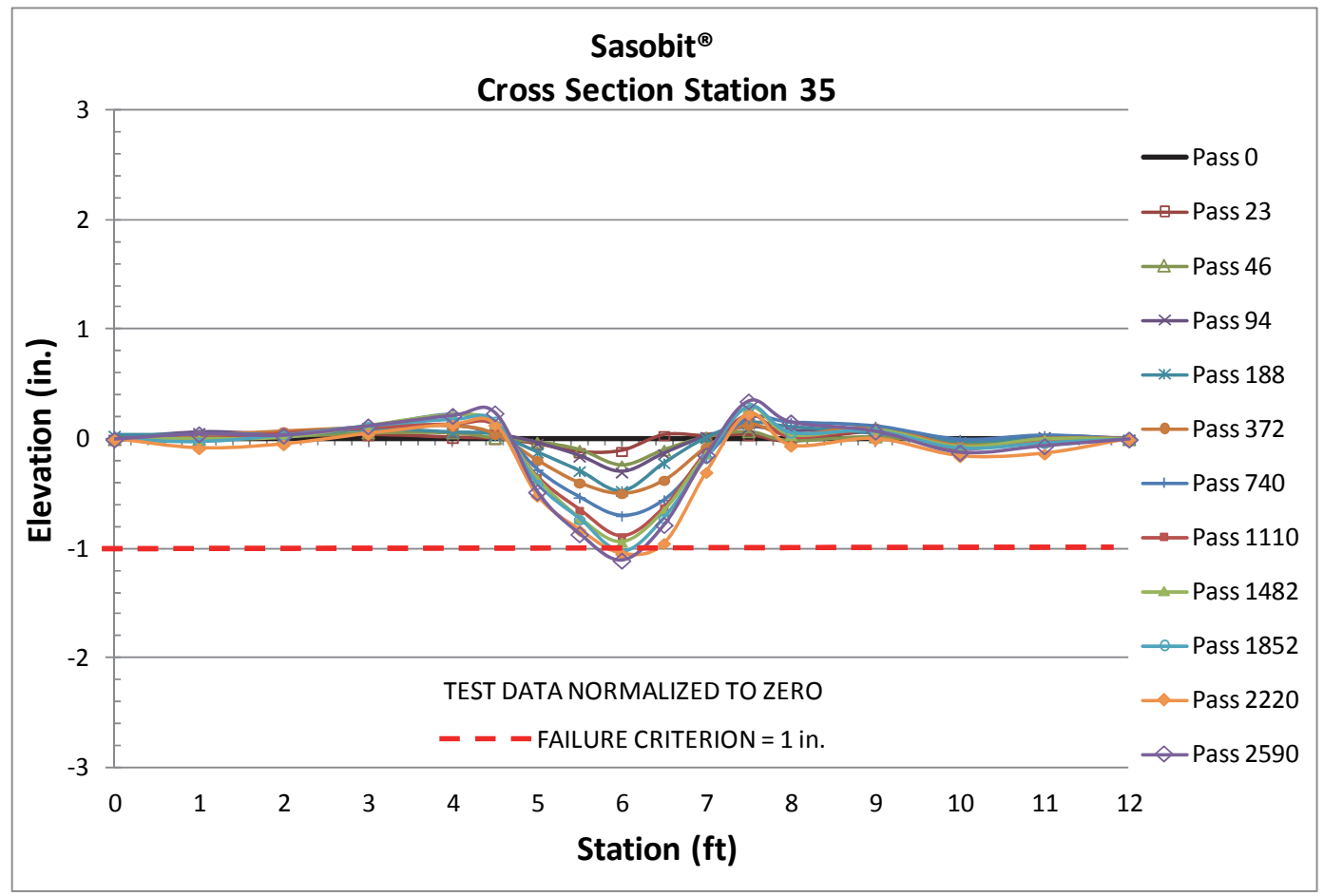


Figure B21. Sasobit $\AA$ cross section permanent deformation at STA $0+40$.

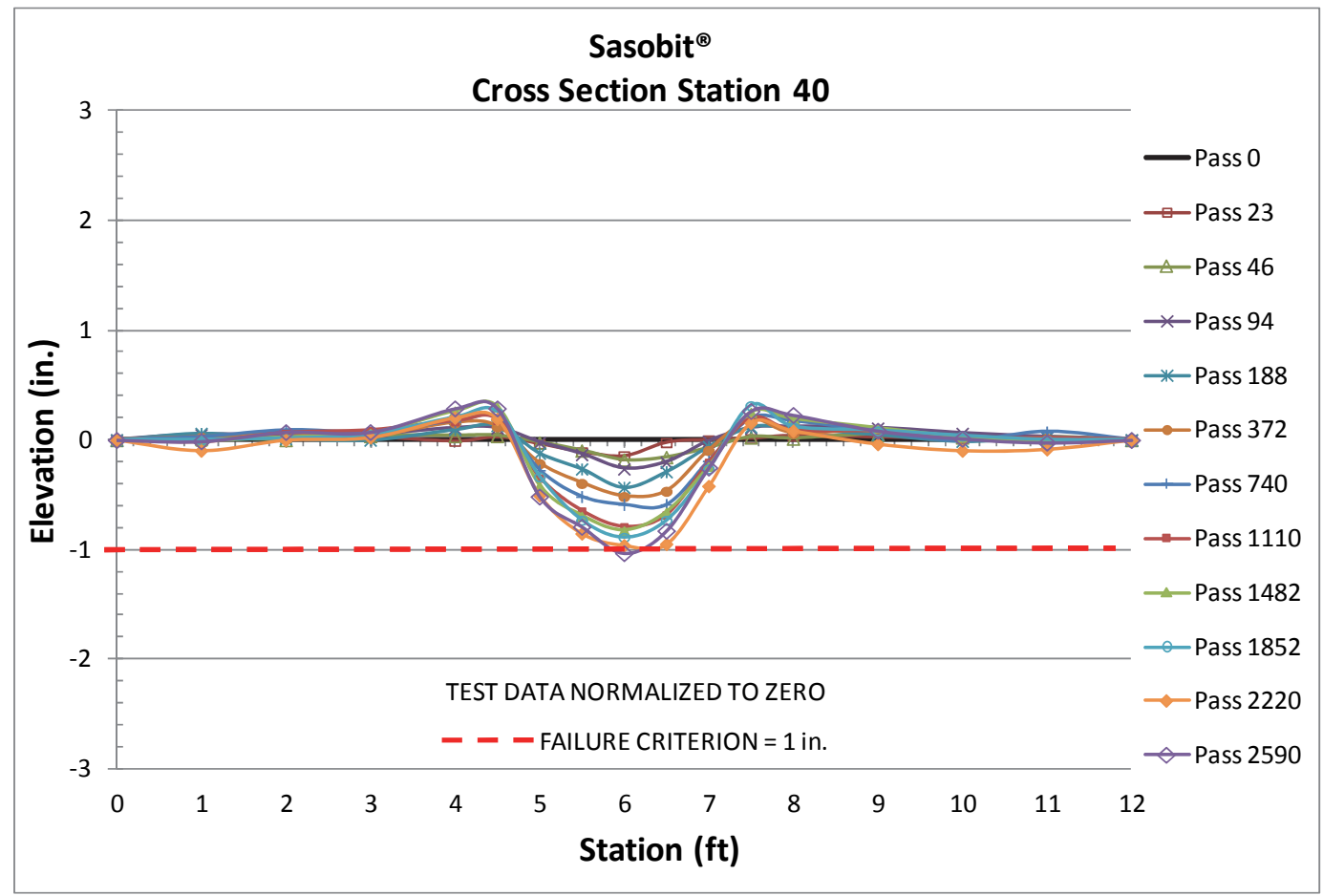

Figure B22. Evotherm ${ }^{\mathrm{TM}} 3 \mathrm{G}$ cross section permanent deformation at STA $0+10$.

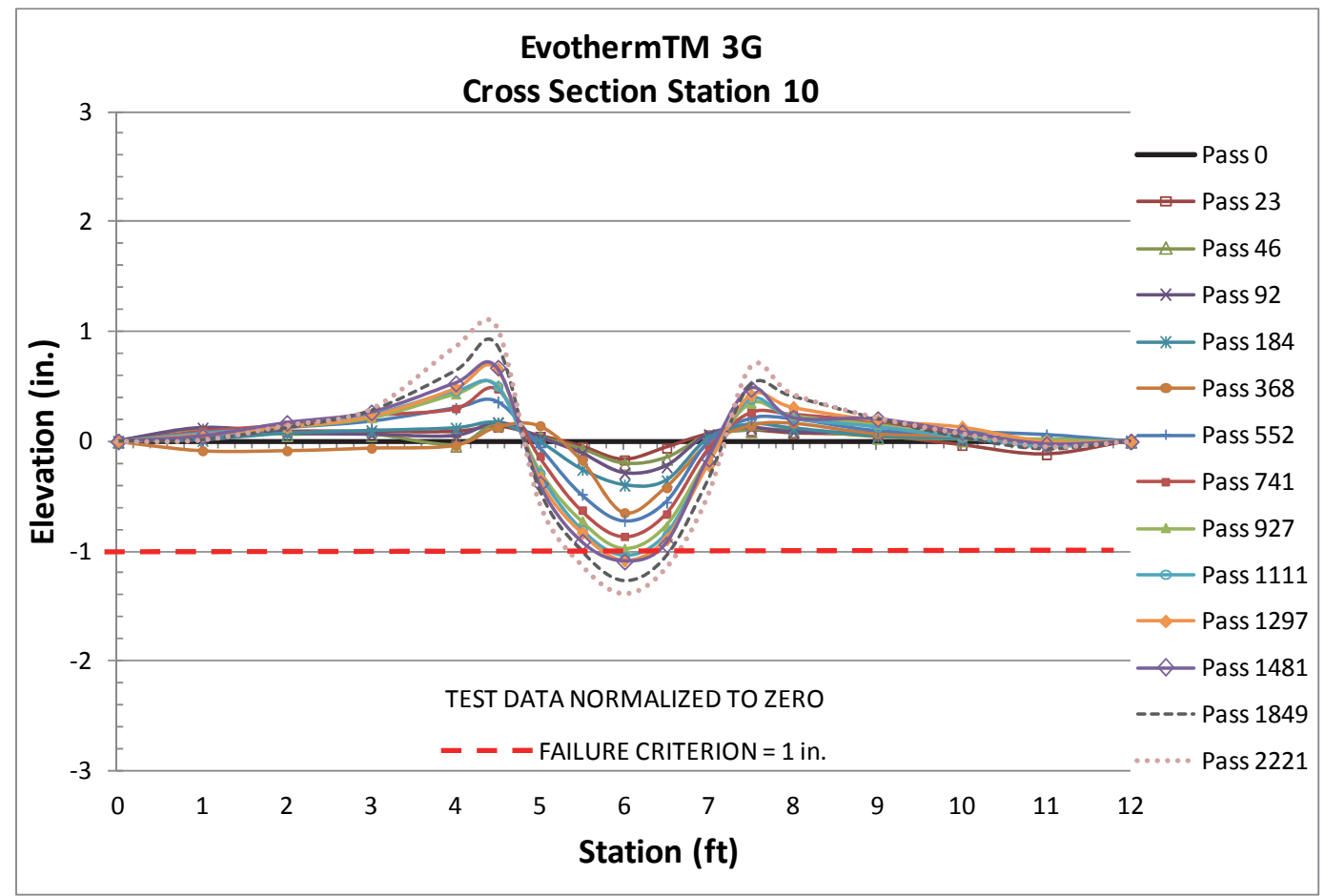


Figure B23. Evotherm ${ }^{\mathrm{TM}} 3 \mathrm{G}$ cross section permanent deformation at STA 0+15.

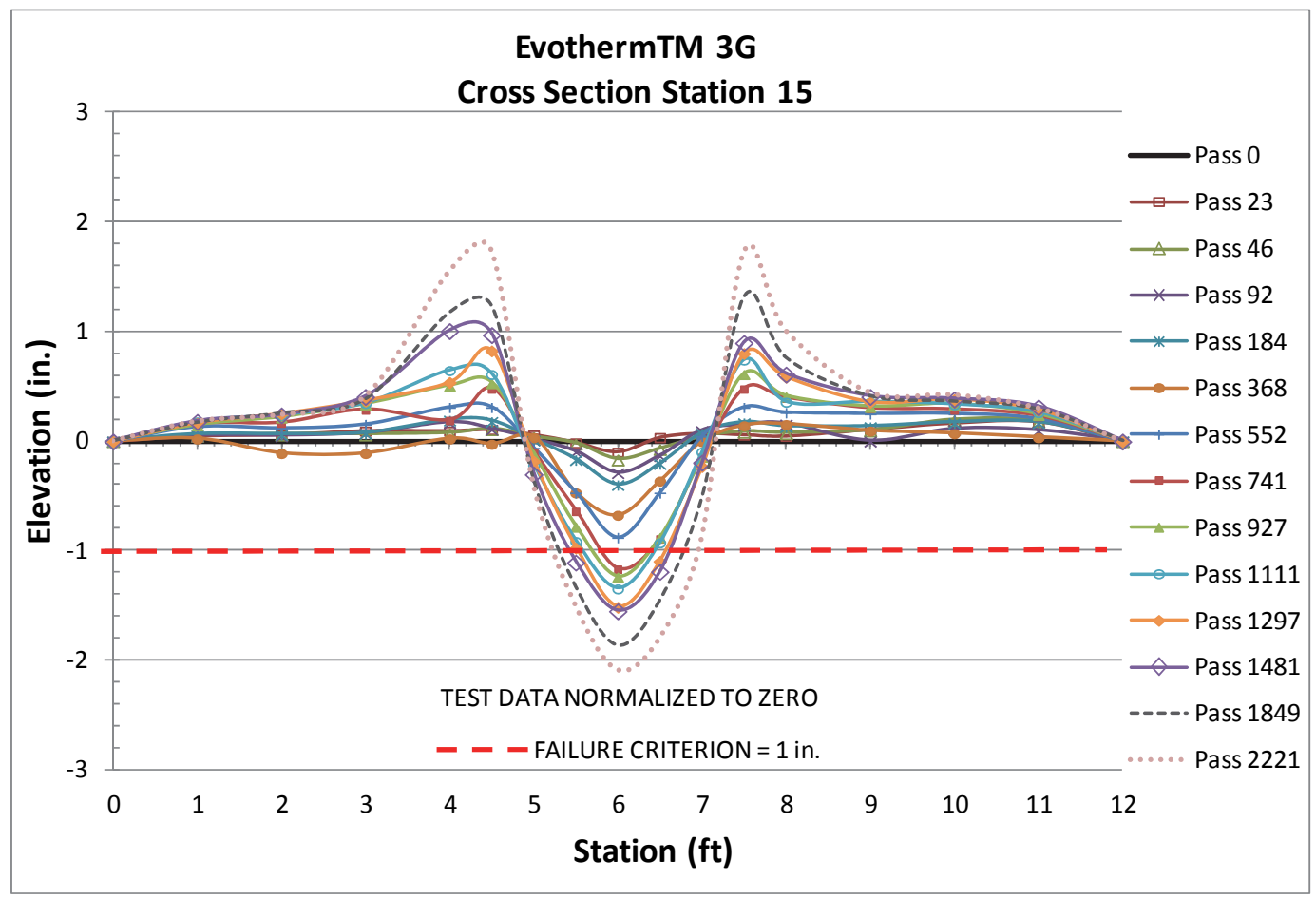

Figure B24. Evotherm ${ }^{\mathrm{TM}} 3 \mathrm{G}$ cross section permanent deformation at STA $0+20$.

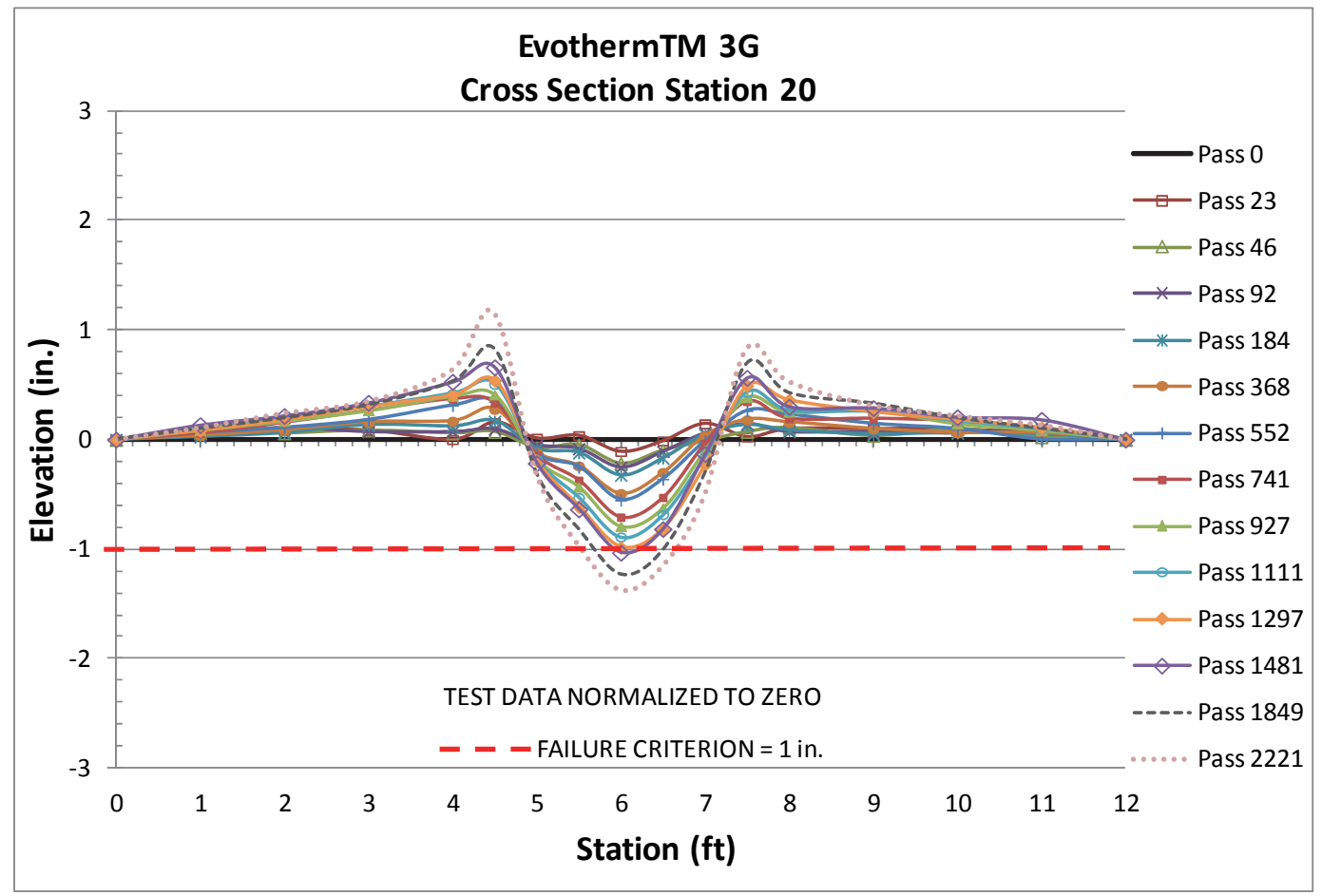


Figure B25. Evotherm ${ }^{\mathrm{TM}} 3 \mathrm{G}$ cross section permanent deformation at STA 0+25.

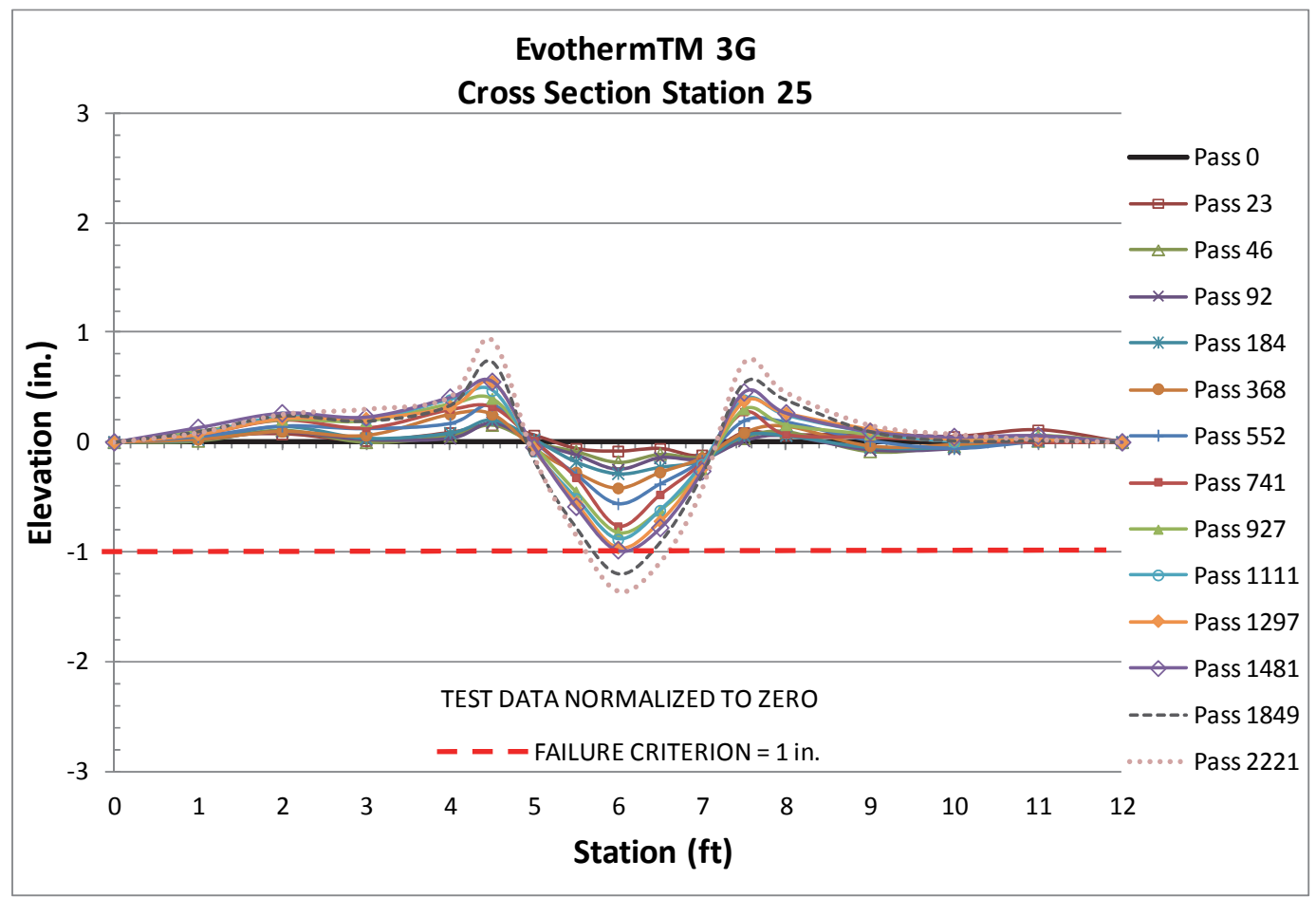

Figure B26. Evotherm ${ }^{\mathrm{TM}} 3 \mathrm{G}$ cross section permanent deformation at STA $0+30$.

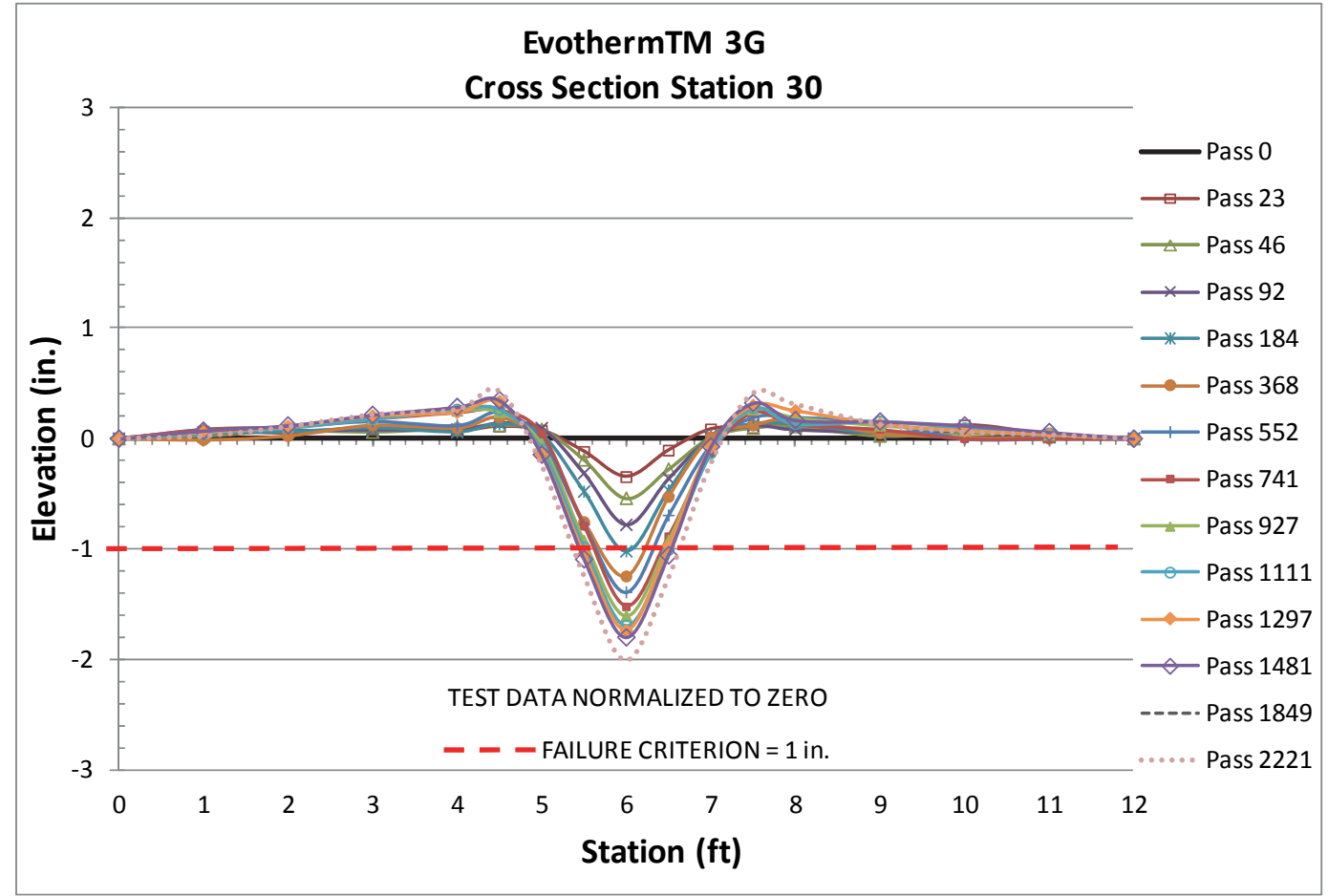


Figure B27. Evotherm ${ }^{\mathrm{TM}} 3 \mathrm{G}$ cross section permanent deformation at STA $0+35$.

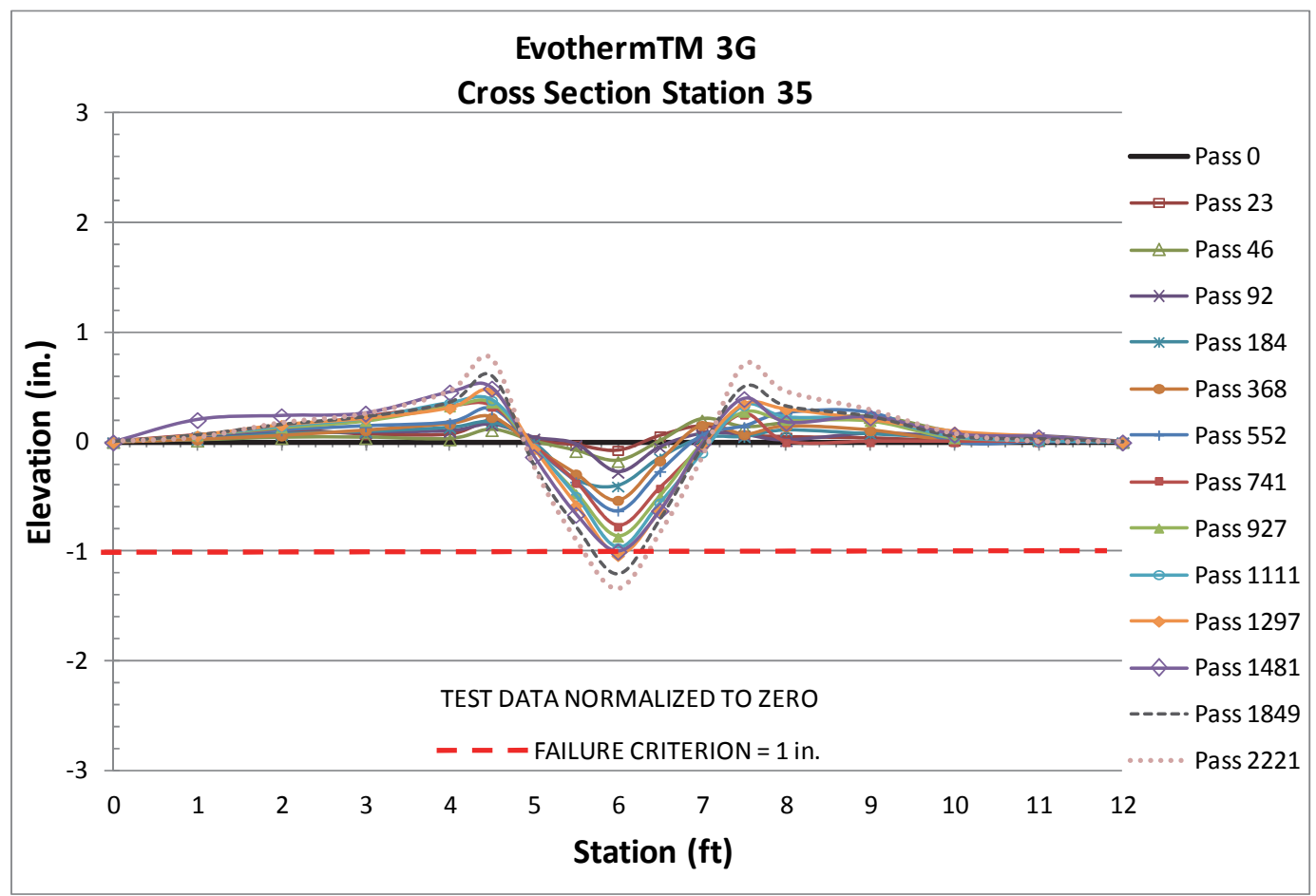

Figure B28. Evotherm ${ }^{\mathrm{TM}} 3 \mathrm{G}$ cross section permanent deformation at STA $0+40$.

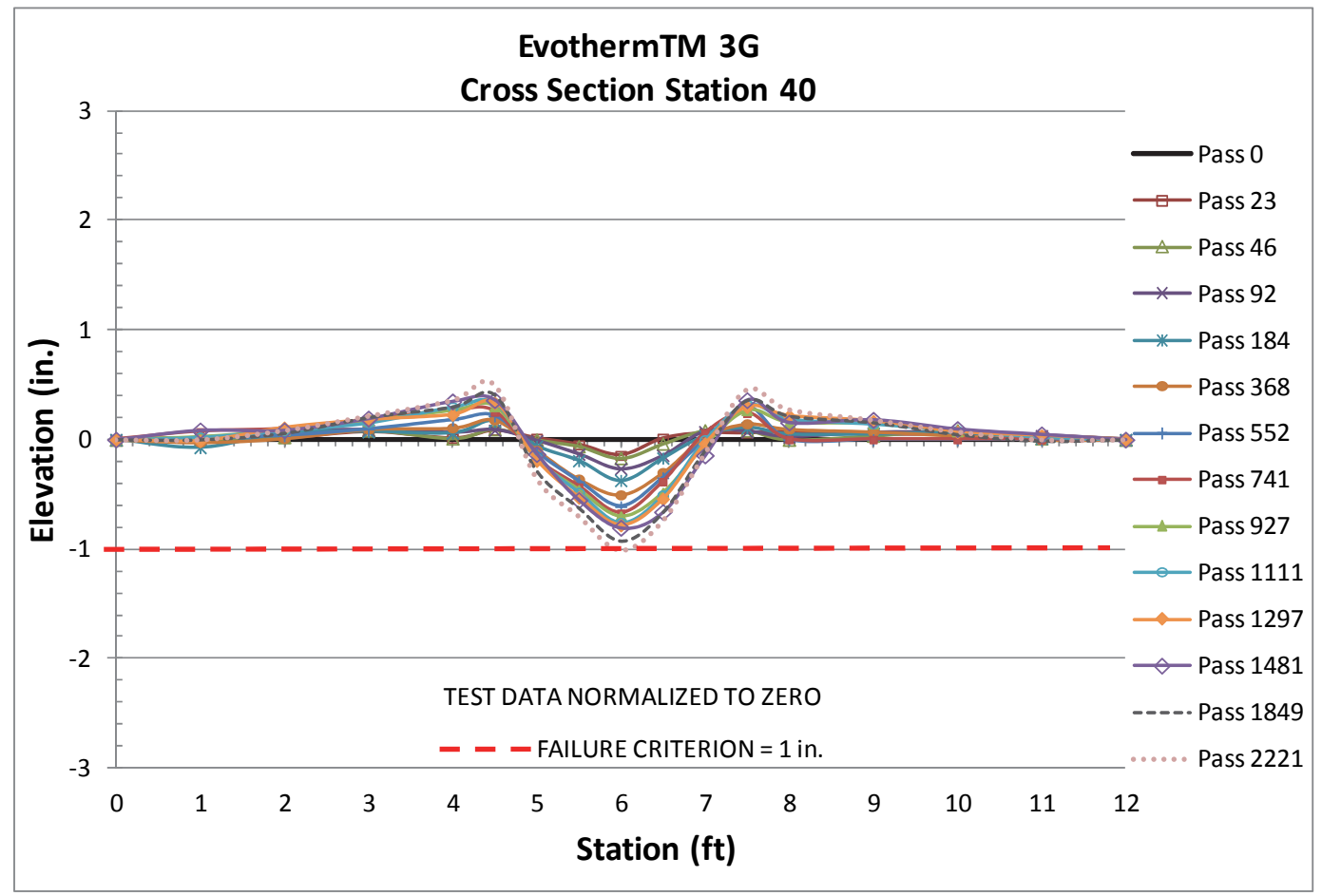




\section{Appendix C: FWD raw data}

Figure C1. FWD test raw data for HMA (pre-traffic at ambient temperature).

\begin{tabular}{|c|c|c|c|c|c|c|c|c|c|c|c|c|}
\hline \multirow[b]{2}{*}{ Station ID } & \multirow[b]{2}{*}{ Drop } & \multirow{2}{*}{\begin{tabular}{c|} 
Surface \\
Temperature $\left({ }^{\circ} \mathrm{F}\right)$ \\
\end{tabular}} & \multirow[b]{2}{*}{ Stress (psi) } & \multirow[b]{2}{*}{ Force (Ib) } & \multicolumn{7}{|c|}{ Deflection at distance from center of the load plate (in.) } & \multirow[b]{2}{*}{ ISM (kips/in.) } \\
\hline & & & & & $0 \mathrm{mil}$ & $12 \mathrm{mil}$ & $24 \mathrm{mil}$ & $36 \mathrm{mil}$ & $48 \mathrm{mil}$ & $60 \mathrm{mil}$ & $72 \mathrm{mil}$ & \\
\hline $0+10$ & 1 & 65 & 215.9 & 23608.0 & 21.1 & 14.6 & 8.9 & 6.1 & 4.8 & 3.7 & 3.1 & 1119.4 \\
\hline $0+10$ & 2 & 65 & 214.8 & 23486.0 & 19.6 & 13.6 & 8.5 & 5.9 & 4.8 & 3.7 & 3.1 & 1197.7 \\
\hline $0+10$ & 3 & 65 & 213.7 & 23375.0 & 19.6 & 13.4 & 8.4 & 5.9 & 4.8 & 3.7 & 3.1 & 1193.8 \\
\hline $0+10$ & 4 & 65 & 173.0 & 18914.0 & 15.8 & 10.9 & 6.9 & 4.8 & 3.9 & 3.0 & 2.5 & 1196.3 \\
\hline $0+10$ & 5 & 65 & 173.1 & 18930.0 & 15.7 & 10.9 & 6.8 & 4.8 & 3.9 & 3.0 & 2.5 & 1208.0 \\
\hline $0+10$ & 6 & 65 & 125.8 & 13759.0 & 11.4 & 7.8 & 4.9 & 3.4 & 2.8 & 2.2 & 1.9 & 1208.0 \\
\hline $0+10$ & 7 & 65 & 79.9 & 8736.0 & 7.2 & 4.9 & 3.0 & 2.1 & 1.8 & 1.3 & 1.2 & 1206.6 \\
\hline $0+15$ & 1 & 65 & 214.5 & 23462.0 & 25.8 & 13.9 & 8.5 & 5.8 & 4.5 & 3.4 & 3.0 & 910.8 \\
\hline $0+15$ & 2 & 65 & 216.2 & 23645.0 & 18.9 & 12.8 & 8.0 & 5.7 & 4.6 & 3.6 & 3.2 & 1249.7 \\
\hline $0+15$ & 3 & 65 & 215.2 & 23537.0 & 18.7 & 12.5 & 8.0 & 5.7 & 4.6 & 3.7 & 3.2 & 1262.0 \\
\hline $0+15$ & 4 & \begin{tabular}{l|}
65 \\
\end{tabular} & 173.2 & 18942.0 & 16.0 & 10.2 & 6.4 & 4.6 & 3.8 & 3.0 & 2.6 & 1186.8 \\
\hline $0+15$ & 5 & 65 & 173.2 & 18945.0 & 15.7 & 10.1 & 6.4 & 4.6 & 3.8 & 3.0 & 2.6 & 1203.6 \\
\hline $0+15$ & 6 & 65 & 125.9 & 13772.0 & 11.7 & 7.4 & 4.6 & 3.3 & 2.7 & 2.1 & 1.9 & 1178.1 \\
\hline $0+15$ & 7 & 65 & 79.5 & 8692.0 & 7.6 & 4.9 & 2.8 & 2.0 & 1.6 & 1.3 & 1.1 & 1145.2 \\
\hline $0+20$ & 1 & 65 & 207.2 & 22662.0 & 31.8 & 16.0 & 9.6 & 6.4 & 4.8 & 3.7 & 3.1 & 713.5 \\
\hline $0+20$ & 2 & 65 & 208.3 & 22784.0 & 32.9 & 14.6 & 9.1 & 6.3 & 5.0 & 3.9 & 3.3 & 691.7 \\
\hline $0+20$ & 3 & 65 & 208.5 & 22796.0 & 21.4 & 14.3 & 9.0 & 6.3 & 5.0 & 3.9 & 3.4 & 1067.2 \\
\hline $0+20$ & 4 & \begin{tabular}{l|}
65 \\
\end{tabular} & 172.1 & 18815.0 & 17.5 & 11.7 & 7.3 & 5.1 & 4.1 & 3.2 & 2.7 & 1075.1 \\
\hline $0+20$ & 5 & 65 & 172.3 & 18842.0 & 17.3 & 11.6 & 7.2 & 5.1 & 4.0 & 3.2 & 2.7 & 1089.1 \\
\hline $0+20$ & 6 & 65 & 125.4 & 13716.0 & 12.6 & 8.4 & 5.1 & 3.6 & 2.9 & 2.3 & 1.9 & 1091.2 \\
\hline $0+20$ & 7 & 65 & 79.6 & 8699.0 & 8.1 & 5.3 & 3.2 & 2.2 & 1.8 & 1.4 & 1.2 & 1074.0 \\
\hline $0+25$ & 1 & 65 & 212.9 & 23283.0 & 22.8 & 15.9 & 10.0 & 6.5 & 4.7 & 3.2 & 2.7 & 1020.7 \\
\hline $0+25$ & 2 & 65 & 213.6 & 23363.0 & 20.7 & 14.4 & 9.3 & 6.4 & 4.9 & 3.6 & 3.1 & 1129.7 \\
\hline $0+25$ & 3 & 65 & 213.0 & 23288.0 & 19.9 & 14.1 & 9.2 & 6.4 & 5.0 & 3.6 & 3.1 & 1173.2 \\
\hline $0+25$ & 4 & 65 & 173.3 & 18953.0 & 16.3 & 11.4 & 7.5 & 5.2 & 4.0 & 3.0 & 2.6 & 1164.2 \\
\hline $0+25$ & 5 & 65 & 174.0 & 19033.0 & 16.1 & 11.4 & 7.4 & 5.2 & 4.0 & 3.0 & 2.6 & 1180.7 \\
\hline $0+25$ & 6 & 65 & 125.1 & 13677.0 & 11.7 & 8.2 & 5.3 & 3.7 & 2.9 & 2.1 & 1.8 & 1170.0 \\
\hline $0+25$ & 7 & 65 & 79.3 & 8676.0 & 7.4 & 5.0 & 3.2 & 2.2 & 1.8 & 1.3 & 1.2 & 1172.4 \\
\hline $0+30$ & 1 & 65 & 208.3 & 22784.0 & 27.2 & 16.9 & 9.4 & 6.0 & 4.6 & 3.5 & 3.1 & 837.0 \\
\hline $0+30$ & 2 & 65 & 208.3 & 22784.0 & 23.0 & 15.3 & 8.7 & 5.9 & 4.7 & 3.8 & 3.3 & 992.8 \\
\hline $0+30$ & 3 & 65 & 208.1 & 22760.0 & 22.2 & 14.9 & 8.6 & 5.9 & 4.7 & 3.8 & 3.3 & 1027.1 \\
\hline $0+30$ & 4 & 65 & 171.3 & 18728.0 & 18.0 & 12.2 & 7.0 & 4.8 & 3.9 & 3.1 & 2.7 & 1038.1 \\
\hline $0+30$ & 5 & 65 & 171.1 & 18712.0 & 17.9 & 12.0 & 7.0 & 4.8 & 3.9 & 3.1 & 2.7 & 1047.1 \\
\hline $0+30$ & 6 & \begin{tabular}{l|}
65 \\
\end{tabular} & 124.8 & 13648.0 & 13.0 & 8.7 & 5.0 & 3.4 & 2.8 & 2.2 & 1.9 & 1047.4 \\
\hline $0+30$ & 7 & 65 & 79.2 & 8660.0 & 8.5 & 5.6 & 3.1 & 2.1 & 1.7 & 1.4 & 1.2 & 1022.4 \\
\hline $0+35$ & 1 & 65 & 212.3 & 23217.0 & 20.8 & 14.3 & 8.9 & 6.1 & 4.6 & 3.5 & 3.0 & 1116.7 \\
\hline $0+35$ & 2 & 65 & 212.2 & 23209.0 & 19.5 & 13.0 & 8.3 & 6.0 & 4.6 & 3.6 & 3.1 & 1190.2 \\
\hline $0+35$ & 3 & 65 & 211.4 & 23117.0 & 19.0 & 12.7 & 8.2 & 5.8 & 4.7 & 3.6 & 3.1 & 1214.8 \\
\hline $0+35$ & 4 & 65 & 172.1 & 18819.0 & 15.7 & 10.4 & 6.6 & 4.7 & 3.8 & 2.9 & 2.6 & 1197.1 \\
\hline $0+35$ & 5 & 65 & 172.9 & 18906.0 & 15.7 & 10.3 & 6.6 & 4.7 & 3.8 & 3.0 & 2.6 & 1208.1 \\
\hline $0+35$ & 6 & 65 & 124.7 & 13637.0 & 11.4 & 7.5 & 4.7 & 3.4 & 2.7 & 2.1 & 1.8 & 1197.3 \\
\hline $0+35$ & 7 & 65 & 78.2 & 8554.0 & 7.4 & 4.7 & 2.9 & 2.1 & 1.7 & 1.3 & 1.1 & 1155.9 \\
\hline $0+40$ & 1 & 65 & 208.6 & 22815.0 & 21.5 & 14.3 & 8.8 & 6.0 & 4.6 & 3.6 & 3.2 & 1061.2 \\
\hline $0+40$ & 2 & 65 & 209.5 & 22911.0 & 19.6 & 13.3 & 8.4 & 6.0 & 4.7 & 3.8 & 3.3 & 1168.9 \\
\hline $0+40$ & 3 & 65 & 210.4 & 23010.0 & 19.2 & 13.1 & 8.3 & 6.0 & 4.8 & 3.8 & 3.3 & 1199.7 \\
\hline $0+40$ & 4 & 65 & 170.3 & 18628.0 & 15.7 & 10.6 & 6.7 & 4.8 & 3.9 & 3.1 & 2.7 & 1190.3 \\
\hline $0+40$ & 5 & 65 & 170.5 & 18641.0 & 15.5 & 10.5 & 6.7 & 4.8 & 3.9 & 3.1 & 2.7 & 1199.5 \\
\hline $0+40$ & 6 & 65 & 124.2 & 13581.0 & 11.3 & 7.6 & 4.8 & 3.4 & 2.8 & 2.2 & 1.9 & 1201.9 \\
\hline $0+40$ & 7 & 65 & 78.6 & 8596.0 & 7.3 & 4.8 & 3.0 & 2.1 & 1.8 & 1.4 & 1.2 & 1172.7 \\
\hline
\end{tabular}


Figure C2. FWD test raw data for HMA (pre-traffic at high temperature).

\begin{tabular}{|c|c|c|c|c|c|c|c|c|c|c|c|c|}
\hline \multirow[b]{2}{*}{ Station ID } & \multirow[b]{2}{*}{ Drop } & \multirow{2}{*}{\begin{tabular}{c|} 
Surface \\
Temperature $\left({ }^{\circ} \mathrm{F}\right)$
\end{tabular}} & \multirow[b]{2}{*}{ Stress (ksi) } & \multirow[b]{2}{*}{ Force (Ib) } & \multicolumn{7}{|c|}{ Deflection at distance from center of the load plate (in.) } & \multirow[b]{2}{*}{ ISM (kips/in.) } \\
\hline & & & & & $0 \mathrm{mil}$ & $12 \mathrm{mil}$ & $24 \mathrm{mil}$ & $36 \mathrm{mil}$ & $48 \mathrm{mil}$ & $60 \mathrm{mil}$ & $72 \mathrm{mil}$ & \\
\hline $0+10$ & 1 & 105 & 222.70 & 24359.00 & 39.40 & 19.95 & 9.72 & 6.63 & 5.66 & 4.52 & 3.74 & 618.25 \\
\hline $0+10$ & 2 & 105 & 223.40 & 24433.00 & 30.81 & 17.08 & 9.30 & 6.68 & 5.62 & 4.47 & 3.70 & 793.02 \\
\hline $0+10$ & 3 & 105 & 222.50 & 24335.00 & 29.57 & 16.78 & 9.24 & 6.68 & 5.65 & 4.48 & 3.70 & 822.96 \\
\hline $0+10$ & 4 & 105 & 173.10 & 18934.00 & 24.59 & 13.68 & 7.50 & 5.48 & 4.63 & 3.68 & 3.01 & 769.99 \\
\hline $0+10$ & 5 & 105 & 173.40 & 18958.00 & 24.42 & 13.57 & 7.50 & 5.48 & 4.61 & 3.65 & 3.03 & 776.33 \\
\hline $0+10$ & 6 & 105 & 127.60 & 13957.00 & 18.40 & 9.90 & 5.33 & 3.92 & 3.31 & 2.62 & 2.17 & 758.53 \\
\hline $0+10$ & 7 & 105 & 82.50 & 9025.00 & 12.35 & 6.27 & 3.30 & 2.45 & 2.08 & 1.62 & 1.36 & 730.77 \\
\hline $0+15$ & 1 & 105 & 213.90 & 23394.00 & 43.30 & 18.70 & 9.75 & 6.80 & 5.25 & 3.68 & 3.11 & 540.28 \\
\hline $0+15$ & 2 & 105 & 215.20 & 23529.00 & 38.52 & 17.95 & 9.06 & 6.46 & 5.28 & 4.05 & 3.48 & 610.83 \\
\hline $0+15$ & 3 & 105 & 215.90 & 23605.00 & 32.49 & 17.77 & 8.92 & 6.40 & 5.30 & 4.13 & 3.58 & 726.53 \\
\hline $0+15$ & 4 & 105 & 170.90 & 18692.00 & 26.24 & 14.77 & 7.18 & 5.19 & 4.29 & 3.38 & 2.93 & 712.35 \\
\hline $0+15$ & 5 & 105 & 171.40 & 18747.00 & 25.93 & 14.72 & 7.19 & 5.23 & 4.34 & 3.44 & 3.00 & 722.98 \\
\hline $0+15$ & 6 & 105 & 125.30 & 13700.00 & 19.19 & 11.03 & 5.07 & 3.68 & 3.10 & 2.42 & 2.12 & 713.91 \\
\hline $0+15$ & \begin{tabular}{l|}
7 \\
\end{tabular} & 105 & 79.70 & 8715.00 & 12.55 & 7.00 & 3.08 & 2.24 & 1.94 & 1.48 & 1.31 & 694.42 \\
\hline $0+20$ & 1 & 105 & 209.00 & 22855.00 & 37.83 & 21.27 & 10.34 & 6.76 & 5.03 & 4.39 & 3.84 & 604.15 \\
\hline $0+20$ & 2 & 105 & 210.20 & 22987.00 & 34.41 & 19.28 & 9.83 & 6.96 & 5.58 & 4.67 & 3.94 & 668.03 \\
\hline $0+20$ & 3 & 105 & 210.30 & 23003.00 & 37.20 & 18.89 & 9.72 & 6.99 & 5.69 & 4.72 & 3.93 & 618.36 \\
\hline $0+20$ & 4 & 105 & 169.70 & 18557.00 & 36.94 & 15.49 & 7.85 & 5.71 & 4.71 & 3.86 & 3.19 & 502.36 \\
\hline $0+20$ & 5 & 105 & 169.70 & 18562.00 & 29.40 & 15.27 & 7.79 & 5.69 & 4.70 & 3.83 & 3.16 & 631.36 \\
\hline $0+20$ & 6 & 105 & 124.60 & 13629.00 & 21.46 & 11.13 & 5.51 & 4.00 & 3.33 & 2.68 & 2.26 & 635.09 \\
\hline $0+20$ & 7 & 105 & 78.90 & 8625.00 & 14.44 & 7.13 & 3.41 & 2.46 & 2.05 & 1.59 & 1.35 & 597.30 \\
\hline $0+25$ & 1 & 105 & 209.10 & 22868.00 & 36.25 & 18.05 & 10.63 & 7.35 & 5.49 & 3.53 & 2.74 & 630.84 \\
\hline $0+25$ & 2 & 105 & 211.30 & 23106.00 & 30.46 & 16.64 & 10.16 & 7.13 & 5.63 & 4.06 & 3.30 & 758.57 \\
\hline $0+25$ & 3 & 105 & 212.10 & 23193.00 & 29.19 & 16.57 & 10.06 & 7.08 & 5.63 & 4.11 & 3.39 & 794.55 \\
\hline $0+25$ & 4 & 105 & 169.90 & 18585.00 & 23.65 & 13.51 & 8.11 & 5.76 & 4.65 & 3.42 & 2.87 & 785.84 \\
\hline $0+25$ & 5 & 105 & 171.00 & 18704.00 & 23.35 & 13.39 & 8.08 & 5.76 & 4.66 & 3.46 & 2.93 & 801.03 \\
\hline $0+25$ & 6 & 105 & 124.10 & 13577.00 & 17.07 & 9.59 & 5.68 & 4.10 & 3.31 & 2.52 & 2.08 & 795.37 \\
\hline $0+25$ & 7 & 105 & 78.80 & 8617.00 & 11.10 & 5.93 & 3.45 & 2.52 & 2.12 & 1.55 & 1.32 & 776.31 \\
\hline $0+30$ & 1 & 105 & 202.40 & 22138.00 & 58.41 & 24.37 & 9.52 & 5.51 & 4.55 & 4.15 & 3.70 & 379.01 \\
\hline $0+30$ & 2 & 105 & 205.30 & 22455.00 & 47.40 & 20.48 & 8.86 & 5.98 & 5.07 & 4.36 & 3.81 & 473.73 \\
\hline $0+30$ & 3 & 105 & 205.80 & 22503.00 & 42.67 & 19.73 & 8.76 & 6.03 & 5.27 & 4.40 & 3.82 & 527.37 \\
\hline $0+30$ & 4 & 105 & 167.80 & 18347.00 & 34.39 & 16.36 & 7.17 & 4.97 & 4.34 & 3.59 & 3.13 & 533.50 \\
\hline $0+30$ & 5 & 105 & 167.80 & 18351.00 & 34.12 & 16.05 & 7.11 & 4.98 & 4.37 & 3.59 & 3.11 & 537.84 \\
\hline $0+30$ & 6 & 105 & 122.90 & 13442.00 & 25.52 & 12.09 & 5.09 & 3.51 & 3.09 & 2.52 & 2.22 & 526.72 \\
\hline $0+30$ & 7 & 105 & 78.20 & 8557.00 & 17.77 & 8.29 & 3.21 & 2.19 & 1.95 & 1.55 & 1.36 & 481.54 \\
\hline $0+35$ & 1 & 105 & 206.60 & 22598.00 & 43.20 & 17.56 & 9.35 & 6.59 & 5.20 & 3.88 & 3.31 & 523.10 \\
\hline $0+35$ & 2 & 105 & 209.10 & 22863.00 & 30.26 & 16.45 & 8.99 & 6.39 & 5.20 & 4.03 & 3.47 & 755.55 \\
\hline $0+35$ & 3 & 105 & 209.00 & 22860.00 & 24.08 & 16.30 & 8.90 & 6.33 & 5.19 & 4.03 & 3.50 & 949.34 \\
\hline $0+35$ & 4 & 105 & 171.30 & 18728.00 & 22.60 & 13.27 & 7.20 & 5.14 & 4.21 & 3.29 & 2.85 & 828.67 \\
\hline $0+35$ & 5 & 105 & 171.50 & 18760.00 & 22.53 & 13.09 & 7.01 & 5.11 & 4.25 & 3.25 & 2.83 & 832.67 \\
\hline $0+35$ & 6 & 105 & 123.50 & 13510.00 & 17.37 & 9.94 & 5.02 & 3.65 & 3.04 & 2.19 & 2.02 & 777.78 \\
\hline $0+35$ & 7 & 105 & 78.80 & 8620.00 & 11.51 & 7.20 & 3.07 & 2.24 & 1.90 & 1.43 & 1.26 & 748.91 \\
\hline $0+40$ & 1 & 105 & 208.60 & 22815.00 & 37.59 & 18.69 & 9.37 & 6.10 & 4.74 & 4.14 & 3.50 & 606.94 \\
\hline $0+40$ & 2 & 105 & 209.30 & 22891.00 & 31.16 & 17.28 & 9.06 & 6.31 & 5.15 & 4.25 & 3.64 & 734.63 \\
\hline $0+40$ & \begin{tabular}{l|l}
3 & \\
\end{tabular} & 105 & 208.80 & 22839.00 & 30.85 & 16.90 & 8.96 & 6.33 & 5.22 & 4.33 & 3.67 & 740.32 \\
\hline $0+40$ & 4 & 105 & 171.60 & 18763.00 & 25.32 & 13.81 & 7.26 & 5.16 & 4.29 & 3.53 & 2.99 & 741.03 \\
\hline $0+40$ & 5 & 105 & 171.70 & 18776.00 & 25.19 & 13.62 & 7.19 & 5.14 & 4.29 & 3.53 & 2.99 & 745.38 \\
\hline $0+40$ & \begin{tabular}{l|l}
6 & \\
\end{tabular} & 105 & 123.90 & 13550.00 & 18.74 & 10.04 & 5.18 & 3.68 & 3.07 & 2.48 & 2.11 & 723.05 \\
\hline $0+40$ & 7 & 105 & 77.60 & 8482.00 & 12.19 & 6.38 & 3.16 & 2.25 & 1.89 & 1.50 & 1.30 & 695.82 \\
\hline
\end{tabular}


Figure C3. FWD test raw data for HMA (post-traffic at high temperature).

\begin{tabular}{|c|c|c|c|c|c|c|c|c|c|c|c|c|}
\hline \multirow[b]{2}{*}{ Station ID } & \multirow[b]{2}{*}{ Drop } & \multirow{2}{*}{$\begin{array}{c}\text { Surface } \\
\text { Temperature }\left({ }^{\circ} \mathrm{F}\right)\end{array}$} & \multirow[b]{2}{*}{ Stress (ksi) } & \multirow[b]{2}{*}{ Force (lb) } & \multicolumn{7}{|c|}{ Deflection at distance from center of the load plate (in.) } & \multirow[b]{2}{*}{ ISM (kips/in.) } \\
\hline & & & & & $0 \mathrm{mil}$ & $12 \mathrm{mil}$ & $24 \mathrm{mil}$ & $36 \mathrm{mil}$ & $48 \mathrm{mil}$ & $60 \mathrm{mil}$ & $72 \mathrm{mil}$ & \\
\hline $0+10$ & 1 & 103 & 224.30 & 24533.00 & 31.87 & 16.50 & 9.22 & 6.96 & 5.96 & 4.70 & 3.96 & 769.78 \\
\hline $0+10$ & 2 & 103 & 223.30 & 24422.00 & 29.85 & 16.55 & 9.28 & 7.00 & 5.99 & 4.71 & 4.02 & 818.16 \\
\hline $0+10$ & 3 & 103 & 222.60 & 24338.00 & 29.61 & 16.52 & 9.26 & 6.98 & 6.01 & 4.69 & 3.99 & 821.95 \\
\hline $0+10$ & 4 & 103 & 173.30 & 18950.00 & 25.05 & 13.63 & 7.61 & 5.74 & 4.89 & 3.81 & 3.27 & 756.49 \\
\hline $0+10$ & 5 & 103 & 173.40 & 18966.00 & 24.12 & 13.59 & 7.61 & 5.73 & 4.90 & 3.83 & 3.27 & 786.32 \\
\hline $0+10$ & 6 & 103 & 128.10 & 14010.00 & 19.70 & 9.74 & 5.36 & 4.04 & 3.43 & 2.68 & 2.29 & 711.17 \\
\hline $0+10$ & 7 & 103 & 84.60 & 9247.00 & 13.33 & 5.94 & 3.28 & 2.46 & 2.11 & 1.62 & 1.42 & 693.70 \\
\hline $0+15$ & 1 & 103 & 213.50 & 23344.00 & 39.03 & 20.82 & 11.04 & 7.66 & 5.79 & 4.70 & 3.82 & 598.10 \\
\hline $0+15$ & 2 & 103 & 213.20 & 23315.00 & 36.35 & 19.76 & 10.74 & 7.50 & 6.30 & 4.74 & 4.16 & 641.40 \\
\hline $0+15$ & 3 & 103 & 212.70 & 23259.00 & 33.05 & 19.58 & 10.74 & 7.50 & 6.28 & 4.75 & 4.16 & 703.75 \\
\hline $0+15$ & 4 & 103 & 170.50 & 18644.00 & 29.04 & 15.93 & 8.63 & 6.04 & 5.06 & 3.87 & 3.35 & 642.01 \\
\hline $0+15$ & 5 & 103 & 170.60 & 18657.00 & 29.21 & 15.80 & 8.61 & 6.03 & 5.05 & 3.85 & 3.36 & 638.72 \\
\hline $0+15$ & 6 & 103 & 125.70 & 13748.00 & 23.15 & 11.39 & 6.06 & 4.25 & 3.57 & 2.73 & 2.36 & 593.87 \\
\hline $0+15$ & 7 & 103 & 79.80 & 8731.00 & 15.57 & 7.08 & 3.67 & 2.63 & 2.22 & 1.70 & 1.45 & 560.76 \\
\hline $0+20$ & 1 & 103 & 204.60 & 22379.00 & 28.94 & 19.70 & 11.18 & 8.00 & 6.20 & 4.17 & 3.79 & 773.29 \\
\hline $0+20$ & 2 & 103 & 211.40 & 23117.00 & 26.57 & 18.54 & 10.79 & 8.01 & 6.52 & 4.63 & 4.05 & 870.04 \\
\hline $0+20$ & 3 & 103 & 213.40 & 23336.00 & 27.20 & 18.40 & 10.74 & 8.13 & 6.52 & 4.72 & 4.09 & 857.94 \\
\hline $0+20$ & 4 & 103 & 170.50 & 18644.00 & 22.50 & 14.85 & 8.65 & 6.55 & 5.29 & 3.83 & 3.33 & 828.62 \\
\hline $0+20$ & 5 & 103 & 171.50 & 18760.00 & 22.53 & 14.76 & 8.61 & 6.46 & 5.26 & 3.95 & 3.37 & 832.67 \\
\hline $0+20$ & 6 & 103 & 127.00 & 13891.00 & 16.63 & 10.58 & 6.08 & 4.54 & 3.77 & 2.69 & 2.36 & 835.30 \\
\hline $0+20$ & 7 & 103 & 84.20 & 9212.00 & 11.40 & 6.56 & 3.65 & 2.80 & 2.22 & 1.74 & 1.47 & 808.07 \\
\hline $0+25$ & 1 & 103 & 193.70 & 21182.00 & 74.16 & 31.26 & 9.19 & 6.24 & 5.28 & 4.02 & 3.66 & 285.63 \\
\hline $0+25$ & 2 & 103 & 198.90 & 21753.00 & 61.95 & 25.53 & 8.83 & 6.42 & 5.55 & 4.39 & 3.92 & 351.14 \\
\hline $0+25$ & 3 & 103 & 200.30 & 21903.00 & 59.45 & 23.07 & 8.82 & 6.51 & 5.59 & 4.49 & 3.96 & 368.43 \\
\hline $0+25$ & 4 & 103 & 163.10 & 17835.00 & 49.50 & 19.59 & 7.27 & 5.26 & 4.59 & 3.66 & 3.24 & 360.30 \\
\hline $0+25$ & 5 & 103 & 163.00 & 17824.00 & 48.35 & 18.97 & 7.23 & 5.26 & 4.57 & 3.65 & 3.23 & 368.65 \\
\hline $0+25$ & 6 & 103 & 124.40 & 13605.00 & 37.63 & 14.92 & 5.22 & 3.70 & 3.21 & 2.63 & 2.26 & 361.55 \\
\hline $0+25$ & 7 & 103 & 79.50 & 8692.00 & 27.79 & 10.56 & 3.24 & 2.25 & 1.95 & 1.39 & 1.38 & 312.77 \\
\hline $0+30$ & 1 & 103 & 213.30 & 23331.00 & 26.49 & 15.76 & 9.43 & 7.00 & 5.68 & 4.66 & 4.07 & 880.75 \\
\hline $0+30$ & 2 & 103 & 214.80 & 23494.00 & 26.52 & 15.70 & 9.40 & 7.00 & 5.67 & 4.74 & 4.10 & 885.90 \\
\hline $0+30$ & 3 & 103 & 216.20 & 23648.00 & 26.52 & 15.67 & 9.41 & 7.00 & 5.70 & 4.76 & 4.10 & 891.70 \\
\hline $0+30$ & 4 & 103 & 171.90 & 18795.00 & 22.11 & 12.83 & 7.64 & 5.65 & 4.63 & 3.83 & 3.32 & 850.07 \\
\hline $0+30$ & 5 & 103 & 173.60 & 18990.00 & 22.03 & 12.81 & 7.64 & 5.68 & 4.55 & 3.85 & 3.34 & 862.01 \\
\hline $0+30$ & 6 & 103 & 127.20 & 13906.00 & 16.70 & 9.30 & 5.41 & 4.02 & 3.20 & 2.72 & 2.35 & 832.69 \\
\hline $0+30$ & 7 & 103 & 82.90 & 9064.00 & 11.17 & 5.84 & 3.33 & 2.48 & 2.06 & 1.68 & 1.44 & 811.46 \\
\hline $0+35$ & 1 & 103 & 211.80 & 23164.00 & 33.42 & 16.52 & 9.63 & 6.96 & 5.80 & 4.51 & 3.88 & 693.12 \\
\hline $0+35$ & 2 & 103 & 210.70 & 23042.00 & 28.35 & 16.42 & 9.62 & 6.96 & 5.79 & 4.50 & 3.85 & 812.77 \\
\hline $0+35$ & 3 & 103 & 210.60 & 23026.00 & 28.16 & 16.40 & 9.62 & 6.96 & 5.79 & 4.50 & 3.85 & 817.68 \\
\hline $0+35$ & 4 & 103 & 172.50 & 18863.00 & 25.97 & 13.41 & 7.76 & 5.62 & 4.69 & 3.63 & 3.15 & 726.34 \\
\hline $0+35$ & 5 & 103 & 172.70 & 18887.00 & 24.87 & 13.35 & 7.74 & 5.61 & 4.69 & 3.65 & 3.16 & 759.43 \\
\hline $0+35$ & 6 & 103 & 125.20 & 13696.00 & 19.64 & 9.70 & 5.47 & 3.98 & 3.32 & 2.56 & 2.24 & 697.35 \\
\hline $0+35$ & 7 & 103 & 80.40 & 8795.00 & 13.43 & 6.20 & 3.40 & 2.46 & 2.06 & 1.58 & 1.41 & 654.88 \\
\hline $0+40$ & 1 & 103 & 205.10 & 22432.00 & 31.31 & 17.76 & 8.91 & 6.56 & 5.37 & 4.23 & 3.70 & 716.45 \\
\hline $0+40$ & 2 & 103 & 209.30 & 22891.00 & 39.50 & 17.26 & 9.00 & 6.82 & 5.47 & 4.63 & 3.92 & 579.52 \\
\hline $0+40$ & 3 & 103 & 209.50 & 22915.00 & 34.21 & 17.13 & 8.86 & 6.81 & 5.50 & 4.65 & 3.91 & 669.83 \\
\hline $0+40$ & 4 & 103 & 171.30 & 18728.00 & 28.87 & 13.88 & 7.32 & 5.51 & 4.51 & 3.78 & 3.17 & 648.70 \\
\hline $0+40$ & 5 & 103 & 171.60 & 18771.00 & 28.98 & 13.65 & 7.30 & 5.42 & 4.59 & 3.75 & 3.12 & 647.72 \\
\hline $0+40$ & 6 & 103 & 124.20 & 13585.00 & 21.62 & 9.81 & 5.12 & 3.82 & 3.25 & 2.64 & 2.25 & 628.35 \\
\hline $0+40$ & 7 & 103 & 79.20 & 8660.00 & 14.29 & 6.27 & 3.19 & 2.45 & 1.92 & 1.70 & 1.42 & 606.02 \\
\hline
\end{tabular}


Figure C4. FWD test raw data for Foamed Asphalt (pre-traffic at ambient temperature).

\begin{tabular}{|c|c|c|c|c|c|c|c|c|c|c|c|c|}
\hline \multirow[b]{2}{*}{ Station ID } & \multirow[b]{2}{*}{ Drop } & \multirow{2}{*}{$\begin{array}{c}\text { Surface } \\
\text { Temperature }\left({ }^{\circ} \mathrm{F}\right)\end{array}$} & \multirow[b]{2}{*}{ Stress (ksi) } & \multirow[b]{2}{*}{ Force (Ib) } & \multicolumn{7}{|c|}{ Deflection at distance from center of the load plate (in.) } & \multirow[b]{2}{*}{ ISM (kips/in.) } \\
\hline & & & & & 0 in. & 12 in. & 24 in. & 36 in & 48 in. & $60 \mathrm{in.}$ & 72 in. & \\
\hline $0+10$ & 1 & 55 & 218.50 & 23891.00 & 19.14 & 12.65 & 8.00 & 5.73 & 4.61 & 3.39 & 2.80 & 1248.22 \\
\hline $0+10$ & 2 & 55 & 217.30 & 23767.00 & 18.65 & 12.32 & 7.83 & 5.67 & 4.48 & 3.50 & 2.92 & 1274.37 \\
\hline $0+10$ & 3 & 55 & 216.90 & 23719.00 & 18.55 & 12.18 & 7.84 & 5.68 & 4.52 & 3.52 & 2.93 & 1278.65 \\
\hline $0+10$ & 4 & 55 & 173.00 & 18922.00 & 15.11 & 9.83 & 6.33 & 4.59 & 3.70 & 2.83 & 2.38 & 1252.28 \\
\hline $0+10$ & 5 & 55 & 173.10 & 18926.00 & 14.98 & 9.95 & 6.31 & 4.57 & 3.64 & 2.86 & 2.41 & 1263.42 \\
\hline $0+10$ & 6 & 55 & 123.30 & 13481.00 & 10.83 & 7.12 & 4.46 & 3.24 & 2.61 & 2.06 & 1.74 & 1244.78 \\
\hline $0+10$ & 7 & 55 & 81.20 & 8882.00 & 6.86 & 4.41 & 2.72 & 1.98 & 1.59 & 1.34 & 1.14 & 1294.75 \\
\hline $0+15$ & 1 & 55 & 219.90 & 24045.00 & 17.90 & 12.48 & 7.84 & 5.41 & 4.16 & 3.03 & 2.65 & 1343.30 \\
\hline $0+15$ & 2 & 55 & 221.20 & 24195.00 & 17.18 & 11.92 & 7.59 & 5.42 & 4.33 & 3.29 & 2.84 & 1408.32 \\
\hline $0+15$ & 3 & 55 & 221.60 & 24235.00 & 17.06 & 11.87 & 7.57 & 5.43 & 4.35 & 3.33 & 2.84 & 1420.57 \\
\hline $0+15$ & 4 & 55 & 172.50 & 18866.00 & 13.78 & 9.58 & 6.13 & 4.41 & 3.56 & 2.74 & 2.35 & 1369.09 \\
\hline $0+15$ & 5 & 55 & 172.70 & 18882.00 & 13.69 & 9.57 & 6.15 & 4.41 & 3.56 & 2.73 & 2.35 & 1379.25 \\
\hline $0+15$ & 6 & 55 & 121.30 & 13264.00 & 9.70 & 6.77 & 4.33 & 3.13 & 2.55 & 2.00 & 1.70 & 1367.42 \\
\hline $0+15$ & 7 & 55 & 77.40 & 8470.00 & 6.15 & 4.16 & 2.63 & 1.91 & 1.57 & 1.22 & 1.04 & 1377.24 \\
\hline $0+20$ & 1 & 55 & 213.20 & 23320.00 & 21.62 & 13.81 & 8.23 & 5.57 & 4.31 & 3.11 & 2.69 & 1078.63 \\
\hline $0+20$ & 2 & 55 & 213.20 & 23315.00 & 20.19 & 13.04 & 7.91 & 5.56 & 4.44 & 3.37 & 2.89 & 1154.78 \\
\hline $0+20$ & 3 & 55 & 213.20 & 23312.00 & 19.90 & 12.93 & 7.91 & 5.59 & 4.50 & 3.42 & 2.93 & 1171.46 \\
\hline $0+20$ & 4 & 55 & 169.50 & 18538.00 & 16.33 & 10.55 & 6.43 & 4.56 & 3.67 & 2.80 & 2.41 & 1135.21 \\
\hline $0+20$ & 5 & 55 & 169.90 & 18577.00 & 16.22 & 10.47 & 6.42 & 4.56 & 3.67 & 2.82 & 2.43 & 1145.31 \\
\hline $0+20$ & 6 & 55 & 121.90 & 13331.00 & 11.73 & 7.62 & 4.59 & 3.27 & 2.64 & 2.03 & 1.77 & 1136.49 \\
\hline $0+20$ & 7 & 55 & 78.60 & 8593.00 & 7.55 & 4.76 & 2.83 & 2.03 & 1.66 & 1.30 & 1.11 & 1138.15 \\
\hline $0+25$ & 1 & 55 & 215.20 & 23537.00 & 20.56 & 13.57 & 8.60 & 5.97 & 4.55 & 3.27 & 2.77 & 1144.80 \\
\hline $0+25$ & 2 & 55 & 216.60 & 23692.00 & 19.34 & 12.80 & 8.26 & 5.93 & 4.70 & 3.56 & 3.02 & 1225.03 \\
\hline $0+25$ & 3 & 55 & 217.00 & 23727.00 & 19.04 & 12.72 & 8.24 & 5.94 & 4.73 & 3.61 & 3.06 & 1246.17 \\
\hline $0+25$ & 4 & 55 & 168.30 & 18406.00 & 15.46 & 10.31 & 6.71 & 4.84 & 3.88 & 2.95 & 2.51 & 1190.56 \\
\hline $0+25$ & 5 & 55 & 168.60 & 18443.00 & 15.34 & 10.26 & 6.68 & 4.83 & 3.87 & 2.95 & 2.51 & 1202.28 \\
\hline $0+25$ & 6 & 55 & 123.70 & 13529.00 & 11.04 & 7.43 & 4.74 & 3.44 & 2.74 & 2.17 & 1.80 & 1225.45 \\
\hline $0+25$ & 7 & 55 & 79.50 & 8696.00 & 7.04 & 4.47 & 2.91 & 2.13 & 1.74 & 1.37 & 1.13 & 1235.23 \\
\hline $0+30$ & 1 & 55 & 211.20 & 23098.00 & 22.51 & 14.06 & 8.33 & 5.72 & 4.50 & 3.33 & 2.85 & 1026.12 \\
\hline $0+30$ & 2 & 55 & 211.10 & 23082.00 & 21.74 & 13.38 & 8.01 & 5.69 & 4.61 & 3.59 & 3.09 & 1061.73 \\
\hline $0+30$ & 3 & 55 & 210.40 & 23006.00 & 21.59 & 13.27 & 7.98 & 5.70 & 4.63 & 3.62 & 3.12 & 1065.59 \\
\hline $0+30$ & 4 & 55 & 168.20 & 18398.00 & 17.50 & 10.75 & 6.46 & 4.63 & 3.81 & 2.97 & 2.55 & 1051.31 \\
\hline $0+30$ & 5 & 55 & 169.30 & 18517.00 & 17.44 & 10.69 & 6.44 & 4.61 & 3.77 & 2.96 & 2.55 & 1061.75 \\
\hline $0+30$ & 6 & 55 & 121.80 & 13315.00 & 12.61 & 7.73 & 4.59 & 3.29 & 2.73 & 2.13 & 1.83 & 1055.91 \\
\hline $0+30$ & 7 & 55 & 77.90 & 8514.00 & 8.02 & 4.88 & 2.84 & 2.04 & 1.66 & 1.33 & 1.17 & 1061.60 \\
\hline $0+35$ & 1 & 55 & 211.70 & 23148.00 & 18.83 & 11.75 & 7.50 & 5.27 & 4.26 & 3.06 & 2.78 & 1229.31 \\
\hline $0+35$ & 2 & 55 & 214.00 & 23402.00 & 18.18 & 11.09 & 7.22 & 5.26 & 4.29 & 3.33 & 2.91 & 1287.24 \\
\hline $0+35$ & 3 & 55 & 214.00 & 23407.00 & 17.87 & 11.01 & 7.19 & 5.25 & 4.30 & 3.32 & 2.94 & 1309.85 \\
\hline $0+35$ & 4 & 55 & 165.60 & 18105.00 & 16.78 & 8.93 & 5.85 & 4.28 & 3.50 & 2.71 & 2.37 & 1078.96 \\
\hline $0+35$ & 5 & 55 & 166.10 & 18160.00 & 14.61 & 8.90 & 5.83 & 4.28 & 3.51 & 2.72 & 2.39 & 1242.98 \\
\hline $0+35$ & $\begin{array}{ll}6 \\
\end{array}$ & 55 & 123.50 & 13502.00 & 10.57 & 6.41 & 4.20 & 3.06 & 2.54 & 1.96 & 1.74 & 1277.39 \\
\hline $0+35$ & 7 & 55 & 79.20 & 8660.00 & 7.14 & 3.97 & 2.57 & 1.89 & 1.54 & 1.28 & 1.06 & 1212.89 \\
\hline $0+40$ & 1 & 55 & 208.90 & 22847.00 & 19.49 & 11.85 & 7.31 & 5.19 & 4.15 & 3.30 & 2.80 & 1172.24 \\
\hline $0+40$ & 2 & 55 & 209.00 & 22855.00 & 18.58 & 11.30 & 7.15 & 5.24 & 4.31 & 3.48 & 2.93 & 1230.09 \\
\hline $0+40$ & 3 & 55 & 209.00 & 22860.00 & 18.33 & 11.24 & 7.15 & 5.25 & 4.34 & 3.52 & 2.96 & 1247.14 \\
\hline $0+40$ & 4 & 55 & 169.30 & 18509.00 & 14.85 & 9.10 & 5.80 & 4.27 & 3.55 & 2.81 & 2.42 & 1246.40 \\
\hline $0+40$ & 5 & 55 & 169.50 & 18533.00 & 14.70 & 9.08 & 5.79 & 4.26 & 3.54 & 2.82 & 2.43 & 1260.75 \\
\hline $0+40$ & 6 & 55 & 121.90 & 13336.00 & 10.65 & 6.52 & 4.13 & 3.04 & 2.53 & 1.98 & 1.74 & 1252.21 \\
\hline $0+40$ & 7 & 55 & 77.30 & 8454.00 & 6.76 & 4.07 & 2.56 & 1.89 & 1.59 & 1.28 & 1.10 & 1250.59 \\
\hline
\end{tabular}


Figure C5. FWD test raw data for Foamed Asphalt (pre-traffic at high temperature).

\begin{tabular}{|c|c|c|c|c|c|c|c|c|c|c|c|c|}
\hline \multirow[b]{2}{*}{ Station ID } & \multirow[b]{2}{*}{ Drop } & \multirow{2}{*}{\begin{tabular}{|c|} 
Surface \\
Temperature $\left({ }^{\circ} \mathrm{F}\right)$
\end{tabular}} & \multirow[b]{2}{*}{ Stress (ksi) } & \multirow[b]{2}{*}{ Force $(\mathrm{Ib})$} & \multicolumn{7}{|c|}{ Deflection at distance from center of the load plate (in.) } & \multirow[b]{2}{*}{ ISM (kips/in.) } \\
\hline & & & & & 0 in. & 12 in. & 24 in. & 36 in & 48 in. & $60 \mathrm{in.}$ & 72 in. & \\
\hline $0+10$ & 1 & 104 & 230.70 & 25234.00 & 38.06 & 16.79 & 9.35 & 6.76 & 5.54 & 4.26 & 2.52 & 663.01 \\
\hline $0+10$ & 2 & 104 & 230.60 & 25223.00 & 35.26 & 16.97 & 9.44 & 6.81 & 5.59 & 4.32 & 2.55 & 715.34 \\
\hline $0+10$ & 3 & 104 & 230.10 & 25167.00 & 35.16 & 17.04 & 9.47 & 6.84 & 5.59 & 4.33 & 2.55 & 715.78 \\
\hline $0+10$ & 4 & 104 & 178.10 & 19474.00 & 29.20 & 14.25 & 7.77 & 5.66 & 4.65 & 3.57 & 2.16 & 666.92 \\
\hline $0+10$ & 5 & 104 & 177.40 & 19397.00 & 25.04 & 14.16 & 7.72 & 5.65 & 4.60 & 3.56 & 2.15 & 774.64 \\
\hline $0+10$ & 6 & 104 & 129.40 & 14152.00 & 21.63 & 10.49 & 5.51 & 4.04 & 3.33 & 2.62 & 1.57 & 654.28 \\
\hline $0+10$ & 7 & 104 & 83.70 & 9148.00 & 15.05 & 6.78 & 3.39 & 2.55 & 2.03 & 1.59 & 1.00 & 607.84 \\
\hline $0+15$ & 1 & 106 & 226.60 & 24779.00 & 42.92 & 18.63 & 9.44 & 6.40 & 4.87 & 3.56 & 2.49 & 577.33 \\
\hline $0+15$ & 2 & 106 & 229.40 & 25088.00 & 37.33 & 16.93 & 9.14 & 6.43 & 5.13 & 3.89 & 2.61 & 672.06 \\
\hline $0+15$ & 3 & 106 & 228.90 & 25036.00 & 36.33 & 16.61 & 9.07 & 6.43 & 5.17 & 3.98 & 2.64 & 689.13 \\
\hline $0+15$ & 4 & 106 & 177.00 & 19355.00 & 29.87 & 13.70 & 7.42 & 5.30 & 4.31 & 3.31 & 2.20 & 647.97 \\
\hline $0+15$ & 5 & 106 & 175.40 & 19183.00 & 29.48 & 13.53 & 7.36 & 5.27 & 4.31 & 3.33 & 2.20 & 650.71 \\
\hline $0+15$ & 6 & 106 & 134.30 & 14687.00 & 21.44 & 9.94 & 5.27 & 3.81 & 3.10 & 2.37 & 1.56 & 685.03 \\
\hline $0+15$ & 7 & 106 & 88.40 & 9672.00 & 14.22 & 6.30 & 3.24 & 2.39 & 1.92 & 1.46 & 0.96 & 680.17 \\
\hline $0+20$ & 1 & 105 & 216.20 & 23640.00 & 45.09 & 20.83 & 9.94 & 6.66 & 5.17 & 3.72 & 2.45 & 524.28 \\
\hline $0+20$ & 2 & 105 & 217.50 & 23783.00 & 39.15 & 18.72 & 9.54 & 6.68 & 5.43 & 4.15 & 2.62 & 607.48 \\
\hline $0+20$ & 3 & 105 & 218.30 & 23875.00 & 37.62 & 18.52 & 9.52 & 6.69 & 5.44 & 4.28 & 2.66 & 634.64 \\
\hline $0+20$ & 4 & 105 & 170.40 & 18636.00 & 30.62 & 15.38 & 7.75 & 5.51 & 4.54 & 3.57 & 2.19 & 608.62 \\
\hline $0+20$ & 5 & 105 & 170.40 & 18636.00 & 26.24 & 15.24 & 7.72 & 5.48 & 4.52 & 3.62 & 2.20 & 710.21 \\
\hline $0+20$ & 6 & 105 & 126.30 & 13807.00 & 22.74 & 11.43 & 5.52 & 3.93 & 3.23 & 2.58 & 1.57 & 607.17 \\
\hline $0+20$ & 7 & 105 & 81.40 & 8903.00 & 16.13 & 7.59 & 3.48 & 2.51 & 2.07 & 1.61 & 1.00 & 551.95 \\
\hline $0+25$ & 1 & 97 & 228.40 & 24972.00 & 30.94 & 17.35 & 9.84 & 6.98 & 5.56 & 4.48 & 2.81 & 807.11 \\
\hline $0+25$ & 2 & 97 & 224.90 & 24596.00 & 35.24 & 17.19 & 9.82 & 6.96 & 5.62 & 4.48 & 2.81 & 697.96 \\
\hline $0+25$ & 3 & 97 & 226.30 & 24750.00 & 32.22 & 17.21 & 9.88 & 7.01 & 5.65 & 4.56 & 2.84 & 768.16 \\
\hline $0+25$ & 4 & 97 & 177.70 & 19434.00 & 26.59 & 14.28 & 8.07 & 5.74 & 4.59 & 3.71 & 2.27 & 730.88 \\
\hline $0+25$ & 5 & 97 & 176.80 & 19339.00 & 26.85 & 14.26 & 8.08 & 5.76 & 4.63 & 3.73 & 2.30 & 720.26 \\
\hline $0+25$ & 6 & 97 & 136.10 & 14882.00 & 19.86 & 10.44 & 5.74 & 4.11 & 3.28 & 2.65 & 1.61 & 749.35 \\
\hline $0+25$ & 7 & 97 & 85.40 & 9339.00 & 13.14 & 6.58 & 3.53 & 2.55 & 2.09 & 1.61 & 1.02 & 710.73 \\
\hline $0+30$ & 1 & 97 & 210.40 & 23006.00 & 57.50 & 21.97 & 9.60 & 6.51 & 5.08 & 3.63 & 2.59 & 400.10 \\
\hline $0+30$ & 2 & 97 & 211.70 & 23153.00 & 51.88 & 20.14 & 9.31 & 6.57 & 5.34 & 4.07 & 2.81 & 446.28 \\
\hline $0+30$ & 3 & 97 & 211.50 & 23129.00 & 50.43 & 20.08 & 9.31 & 6.57 & 5.38 & 4.17 & 2.83 & 458.64 \\
\hline $0+30$ & 4 & 97 & 167.80 & 18347.00 & 42.30 & 17.03 & 7.60 & 5.35 & 4.43 & 3.45 & 2.33 & 433.74 \\
\hline $0+30$ & 5 & 97 & 168.20 & 18398.00 & 38.01 & 17.01 & 7.57 & 5.32 & 4.42 & 3.48 & 2.33 & 484.03 \\
\hline $0+30$ & 6 & 97 & 124.30 & 13589.00 & 30.26 & 13.19 & 5.44 & 3.81 & 3.18 & 2.50 & 1.68 & 449.07 \\
\hline $0+30$ & 7 & 97 & 79.40 & 8680.00 & 22.59 & 9.15 & 3.41 & 2.39 & 2.03 & 1.52 & 1.06 & 384.24 \\
\hline $0+35$ & 1 & 97 & 218.20 & 23862.00 & 30.98 & 16.10 & 9.15 & 6.27 & 4.98 & 3.91 & 2.63 & 770.24 \\
\hline $0+35$ & 2 & 97 & 220.60 & 24124.00 & 27.39 & 14.99 & 8.83 & 6.29 & 5.08 & 4.07 & 2.69 & 880.76 \\
\hline $0+35$ & 3 & 97 & 219.50 & 24002.00 & 26.54 & 14.74 & 8.74 & 6.24 & 5.11 & 4.11 & 2.70 & 904.37 \\
\hline $0+35$ & 4 & 97 & 171.00 & 18700.00 & 21.94 & 12.20 & 7.14 & 5.10 & 4.17 & 3.35 & 2.17 & 852.32 \\
\hline $0+35$ & 5 & 97 & 172.10 & 18819.00 & 21.80 & 12.13 & 7.12 & 5.10 & 4.20 & 3.37 & 2.20 & 863.26 \\
\hline $0+35$ & 6 & 97 & 125.70 & 13748.00 & 16.17 & 8.87 & 5.07 & 3.64 & 2.98 & 2.39 & 1.56 & 850.22 \\
\hline $0+35$ & 7 & 97 & 81.10 & 8866.00 & 10.89 & 5.68 & 3.17 & 2.29 & 1.88 & 1.51 & 0.97 & 814.14 \\
\hline $0+40$ & 1 & 100 & 212.00 & 23185.00 & 36.53 & 18.63 & 9.38 & 6.57 & 5.38 & 4.84 & 3.39 & 634.68 \\
\hline $0+40$ & 2 & 100 & 210.80 & 23050.00 & 34.91 & 17.17 & 9.27 & 6.69 & 5.58 & 5.00 & 3.61 & 660.27 \\
\hline $0+40$ & 3 & 100 & 210.00 & 22971.00 & 33.59 & 16.87 & 9.25 & 6.70 & 5.61 & 4.46 & 3.64 & 683.86 \\
\hline $0+40$ & 4 & 100 & 170.00 & 18593.00 & 27.41 & 13.79 & 7.48 & 5.41 & 4.54 & 3.52 & 2.96 & 678.33 \\
\hline $0+40$ & 5 & 100 & 170.60 & 18660.00 & 25.76 & 13.73 & 7.51 & 5.42 & 4.52 & 3.48 & 2.92 & 724.38 \\
\hline $0+40$ & 6 & 100 & 124.40 & 13605.00 & 20.62 & 10.05 & 5.28 & 3.79 & 3.17 & 2.46 & 2.07 & 659.80 \\
\hline $0+40$ & 7 & 100 & 80.00 & 8744.00 & 14.31 & 6.56 & 3.30 & 2.36 & 1.98 & 1.56 & 1.31 & 611.04 \\
\hline
\end{tabular}


Figure C6. FWD test raw data for Foamed Asphalt (post-traffic at high temperature).

\begin{tabular}{|c|c|c|c|c|c|c|c|c|c|c|c|c|}
\hline \multirow[b]{2}{*}{ Station ID } & \multirow[b]{2}{*}{ Drop } & \multirow{2}{*}{$\begin{array}{c}\text { Surface } \\
\text { Temperature }\left({ }^{\circ} \mathrm{F}\right)\end{array}$} & \multirow[b]{2}{*}{ Stress (ksi) } & \multirow[b]{2}{*}{ Force (Ib) } & \multicolumn{7}{|c|}{ Deflection at distance from center of the load plate (in.) } & \multirow[b]{2}{*}{ ISM (kips/in.) } \\
\hline & & & & & 0 in. & 12 in. & 24 in. & 36 in & $48 \mathrm{in}$. & $60 \mathrm{in.}$ & 72 in. & \\
\hline $0+10$ & 1 & 106 & 224.10 & 24512.00 & 39.85 & 17.55 & 9.43 & 6.68 & 5.49 & 4.47 & 3.68 & 615.11 \\
\hline $0+10$ & 2 & 106 & 224.60 & 24560.00 & 36.04 & 17.24 & 9.64 & 6.95 & 5.57 & 4.48 & 3.82 & 681.47 \\
\hline $0+10$ & 3 & 106 & 224.70 & 24568.00 & 32.61 & 17.24 & 9.60 & 6.97 & 5.68 & 4.52 & 3.84 & 753.39 \\
\hline $0+10$ & 4 & 106 & 173.80 & 19006.00 & 27.82 & 14.35 & 7.87 & 5.70 & 4.59 & 3.65 & 3.15 & 683.18 \\
\hline $0+10$ & 5 & 106 & 173.80 & 19006.00 & 28.00 & 14.32 & 7.92 & 5.74 & 4.63 & 3.68 & 3.16 & 678.79 \\
\hline $0+10$ & 6 & 106 & 129.00 & 14113.00 & 21.41 & 10.48 & 5.38 & 3.96 & 3.50 & 2.58 & 2.20 & 659.18 \\
\hline $0+10$ & 7 & 106 & 84.60 & 9247.00 & 14.70 & 6.98 & 3.71 & 2.63 & 1.86 & 1.63 & 1.41 & 629.05 \\
\hline $0+15$ & 1 & 106 & 199.90 & 21856.00 & 31.20 & 16.21 & 8.62 & 6.60 & 5.26 & 3.68 & 3.17 & 700.51 \\
\hline $0+15$ & 2 & 106 & 204.00 & 22308.00 & 27.31 & 15.33 & 8.62 & 6.61 & 5.42 & 3.98 & 3.37 & 816.84 \\
\hline $0+15$ & 3 & 106 & 204.80 & 22395.00 & 26.53 & 15.24 & 8.59 & 6.56 & 5.42 & 4.05 & 3.41 & 844.14 \\
\hline $0+15$ & 4 & 106 & 164.30 & 17967.00 & 22.72 & 12.52 & 7.02 & 5.30 & 4.43 & 3.34 & 2.78 & 790.80 \\
\hline $0+15$ & 5 & 106 & 164.50 & 17986.00 & 26.69 & 12.37 & 6.97 & 5.27 & 4.39 & 3.32 & 2.71 & 673.89 \\
\hline $0+15$ & 6 & 106 & 121.90 & 13336.00 & 17.48 & 8.87 & 4.89 & 3.67 & 3.09 & 2.29 & 1.90 & 762.93 \\
\hline $0+15$ & 7 & 106 & 76.10 & 8327.00 & 11.42 & 5.33 & 2.88 & 2.19 & 1.79 & 1.37 & 1.09 & 729.16 \\
\hline $0+20$ & 1 & 104 & 218.20 & 23859.00 & 46.72 & 21.72 & 9.79 & 6.87 & 5.56 & 4.00 & 3.59 & 510.68 \\
\hline $0+20$ & 2 & 104 & 217.30 & 23759.00 & 39.01 & 19.02 & 9.71 & 7.06 & 5.85 & 4.38 & 3.75 & 609.05 \\
\hline $0+20$ & 3 & 104 & 215.50 & 23569.00 & 35.33 & 18.52 & 9.70 & 7.12 & 5.94 & 4.51 & 3.78 & 667.11 \\
\hline $0+20$ & 4 & 104 & 170.20 & 18609.00 & 29.47 & 15.26 & 7.93 & 5.78 & 4.81 & 3.65 & 3.04 & 631.46 \\
\hline $0+20$ & 5 & 104 & 170.60 & 18652.00 & 30.23 & 15.07 & 7.92 & 5.79 & 4.81 & 3.67 & 3.07 & 617.00 \\
\hline $0+20$ & 6 & 104 & 126.60 & 13846.00 & 22.30 & 11.05 & 5.58 & 4.06 & 3.37 & 2.56 & 2.13 & 620.90 \\
\hline $0+20$ & 7 & 104 & 82.50 & 9021.00 & 15.00 & 7.20 & 3.50 & 2.54 & 2.12 & 1.58 & 1.39 & 601.40 \\
\hline $0+25$ & 1 & 101 & 217.10 & 23743.00 & 41.31 & 21.56 & 10.70 & 7.46 & 6.02 & 4.22 & 3.60 & 574.75 \\
\hline $0+25$ & 2 & 101 & 220.20 & 24084.00 & 33.12 & 19.01 & 10.53 & 7.61 & 6.28 & 4.69 & 3.84 & 727.17 \\
\hline $0+25$ & 3 & 101 & 221.00 & 24168.00 & 32.66 & 18.67 & 10.55 & 7.59 & 6.33 & 4.78 & 3.86 & 739.99 \\
\hline $0+25$ & 4 & 101 & 170.10 & 18601.00 & 26.95 & 15.19 & 8.70 & 6.09 & 5.31 & 3.89 & 3.21 & 690.20 \\
\hline $0+25$ & 5 & 101 & 169.60 & 18549.00 & 26.63 & 14.99 & 8.57 & 6.12 & 5.26 & 3.91 & 3.19 & 696.55 \\
\hline $0+25$ & 6 & 101 & 124.10 & 13569.00 & 19.83 & 10.69 & 5.87 & 4.22 & 3.70 & 2.66 & 2.35 & 684.27 \\
\hline $0+25$ & 7 & 101 & 82.60 & 9029.00 & 13.18 & 6.77 & 3.68 & 2.66 & 2.20 & 1.75 & 1.30 & 685.05 \\
\hline $0+30$ & 1 & 100 & 204.80 & 22400.00 & 49.17 & 30.57 & 9.52 & 6.39 & 5.53 & 4.38 & 3.40 & 455.56 \\
\hline $0+30$ & 2 & 100 & 207.50 & 22693.00 & 46.73 & 28.76 & 9.28 & 6.48 & 5.51 & 4.56 & 3.97 & 485.62 \\
\hline $0+30$ & 3 & 100 & 208.70 & 22823.00 & 45.77 & 27.83 & 9.36 & 6.53 & 5.61 & 4.56 & 3.51 & 498.65 \\
\hline $0+30$ & 4 & 100 & 164.00 & 17930.00 & 39.05 & 23.42 & 7.78 & 5.32 & 4.63 & 3.70 & 3.06 & 459.15 \\
\hline $0+30$ & 5 & 100 & 164.20 & 17959.00 & 35.78 & 22.90 & 7.76 & 5.37 & 4.67 & 3.70 & 3.16 & 501.93 \\
\hline $0+30$ & 6 & 100 & 126.70 & 13851.00 & 27.99 & 17.42 & 5.61 & 3.73 & 3.26 & 2.55 & 2.24 & 494.86 \\
\hline $0+30$ & 7 & 100 & 81.70 & 8929.00 & 18.95 & 11.97 & 3.50 & 2.23 & 1.97 & 1.52 & 1.33 & 471.19 \\
\hline $0+35$ & 1 & 100 & 220.30 & 24092.00 & 25.42 & 16.45 & 9.54 & 7.03 & 5.91 & 4.76 & 3.91 & 947.76 \\
\hline $0+35$ & 2 & 100 & 222.60 & 24346.00 & 26.98 & 16.31 & 9.60 & 7.05 & 5.94 & 4.89 & 3.91 & 902.37 \\
\hline $0+35$ & 3 & 100 & 222.20 & 24298.00 & 26.92 & 16.25 & 9.56 & 7.04 & 5.93 & 4.80 & 3.91 & 902.60 \\
\hline $0+35$ & 4 & 100 & 174.10 & 19037.00 & 23.18 & 13.41 & 7.79 & 5.67 & 4.81 & 3.85 & 3.17 & 821.27 \\
\hline $0+35$ & 5 & 100 & 174.40 & 19069.00 & 23.24 & 13.35 & 7.80 & 5.69 & 4.82 & 3.89 & 3.18 & 820.52 \\
\hline $0+35$ & 6 & 100 & 130.90 & 14311.00 & 17.35 & 9.74 & 5.50 & 4.00 & 3.37 & 2.81 & 2.21 & 824.84 \\
\hline $0+35$ & 7 & 100 & 86.10 & 9418.00 & 11.66 & 6.20 & 3.38 & 2.45 & 2.07 & 1.74 & 1.35 & 807.72 \\
\hline $0+40$ & 1 & 100 & 221.10 & 24176.00 & 29.26 & 16.67 & 9.58 & 7.06 & 5.96 & 4.82 & 3.94 & 826.25 \\
\hline $0+40$ & 2 & 100 & 221.50 & 24224.00 & 26.60 & 16.60 & 9.63 & 7.11 & 6.01 & 5.00 & 3.98 & 910.68 \\
\hline $0+40$ & 3 & 100 & 220.80 & 24148.00 & 25.85 & 16.48 & 9.63 & 7.11 & 6.02 & 4.94 & 3.96 & 934.16 \\
\hline $0+40$ & 4 & 100 & 174.50 & 19085.00 & 22.97 & 13.48 & 7.78 & 5.72 & 4.84 & 3.89 & 3.20 & 830.87 \\
\hline $0+40$ & 5 & 100 & 174.90 & 19128.00 & 22.99 & 13.45 & 7.78 & 5.72 & 4.85 & 3.92 & 3.20 & 832.01 \\
\hline $0+40$ & 6 & 100 & 125.30 & 13703.00 & 17.91 & 9.78 & 5.46 & 3.99 & 3.38 & 2.77 & 2.24 & 765.10 \\
\hline $0+40$ & 7 & 100 & 81.90 & 8961.00 & 12.22 & 6.20 & 3.32 & 2.41 & 2.05 & 1.67 & 1.35 & 733.31 \\
\hline
\end{tabular}


Figure C7. FWD test raw data for Sasobit $\circledast$ (pre-traffic at ambient temperature).

\begin{tabular}{|c|c|c|c|c|c|c|c|c|c|c|c|c|}
\hline \multirow[b]{2}{*}{ Station ID } & \multirow[b]{2}{*}{ Drop } & \multirow{2}{*}{$\begin{array}{c}\text { Surface } \\
\text { Temperature }\left({ }^{\circ} \mathrm{F}\right)\end{array}$} & \multirow[b]{2}{*}{ Stress (ksi) } & \multirow[b]{2}{*}{ Force $(\mathrm{Ib})$} & \multicolumn{7}{|c|}{ Deflection at distance from center of the load plate (in.) } & \multirow[b]{2}{*}{ ISM (kips/in.) } \\
\hline & & & & & 0 in. & 12 in. & $24 \mathrm{in.}$ & 36 in & $48 \mathrm{in.}$ & $60 \mathrm{in.}$ & 72 in. & \\
\hline $0+10$ & 1 & 63 & 234.70 & 25670.00 & 19.55 & 12.43 & 7.97 & 5.82 & 4.60 & 3.34 & 2.85 & 1313.04 \\
\hline $0+10$ & 2 & 63 & 221.70 & 24248.00 & 18.19 & 11.88 & 7.77 & 5.80 & 4.65 & 3.41 & 2.92 & 1333.04 \\
\hline $0+10$ & 3 & 63 & 220.60 & 24124.00 & 17.91 & 11.80 & 7.78 & 5.81 & 4.65 & 3.44 & 2.94 & 1346.96 \\
\hline $0+10$ & 4 & 63 & 183.10 & 20029.00 & 14.67 & 9.66 & 6.34 & 4.74 & 3.81 & 2.82 & 2.41 & 1365.30 \\
\hline $0+10$ & 5 & 63 & 181.30 & 19826.00 & 14.56 & 9.61 & 6.34 & 4.65 & 3.79 & 2.86 & 2.43 & 1361.68 \\
\hline $0+10$ & 6 & 63 & 133.70 & 14623.00 & 10.44 & 6.89 & 4.50 & 3.29 & 2.67 & 2.02 & 1.74 & 1400.67 \\
\hline $0+10$ & 7 & 63 & 82.80 & 9053.00 & 6.65 & 4.29 & 2.78 & 2.02 & 1.66 & 1.26 & 1.12 & 1361.35 \\
\hline $0+15$ & 1 & 63 & 232.30 & 25405.00 & 19.35 & 12.65 & 7.87 & 5.56 & 4.41 & 3.31 & 2.91 & 1312.92 \\
\hline $0+15$ & 2 & 63 & 231.50 & 25313.00 & 18.01 & 11.88 & 7.64 & 5.54 & 4.51 & 3.49 & 3.01 & 1405.50 \\
\hline $0+15$ & 3 & 63 & 231.40 & 25310.00 & 17.66 & 11.79 & 7.61 & 5.54 & 4.52 & 3.52 & 3.03 & 1433.18 \\
\hline $0+15$ & 4 & 63 & 195.50 & 21385.00 & 14.56 & 9.67 & 6.23 & 4.52 & 3.69 & 2.87 & 2.47 & 1468.75 \\
\hline $0+15$ & 5 & 63 & 194.70 & 21297.00 & 14.43 & 9.61 & 6.21 & 4.53 & 3.69 & 2.88 & 2.49 & 1475.88 \\
\hline $0+15$ & 6 & 63 & 144.70 & 15821.00 & 10.36 & 6.90 & 4.45 & 3.22 & 2.63 & 2.04 & 1.80 & 1527.12 \\
\hline $0+15$ & 7 & 63 & 90.20 & 9865.00 & 6.81 & 4.32 & 2.75 & 1.99 & 1.65 & 1.30 & 1.13 & 1448.60 \\
\hline $0+20$ & 1 & 63 & 222.70 & 24351.00 & 20.93 & 13.00 & 7.77 & 5.35 & 4.14 & 3.30 & 2.87 & 1163.45 \\
\hline $0+20$ & 2 & 63 & 220.30 & 24092.00 & 19.39 & 12.07 & 7.48 & 5.34 & 4.26 & 3.50 & 3.00 & 1242.50 \\
\hline $0+20$ & 3 & 63 & 219.70 & 24029.00 & 19.09 & 11.88 & 7.38 & 5.30 & 4.33 & 3.52 & 3.02 & 1258.72 \\
\hline $0+20$ & 4 & 63 & 175.50 & 19188.00 & 15.52 & 9.70 & 6.04 & 4.36 & 3.52 & 2.84 & 2.47 & 1236.34 \\
\hline $0+20$ & 5 & 63 & 175.20 & 19156.00 & 15.39 & 9.65 & 6.01 & 4.35 & 3.52 & 2.85 & 2.48 & 1244.70 \\
\hline $0+20$ & 6 & 63 & 125.50 & 13719.00 & 11.06 & 7.01 & 4.29 & 3.09 & 2.50 & 2.02 & 1.77 & 1240.42 \\
\hline $0+20$ & 7 & 63 & 79.10 & 8649.00 & 7.08 & 4.44 & 2.65 & 1.89 & 1.59 & 1.30 & 1.13 & 1221.61 \\
\hline $0+25$ & 1 & 63 & 243.30 & 26611.00 & 20.03 & 12.08 & 7.30 & 5.09 & 3.98 & 2.96 & 2.69 & 1328.56 \\
\hline $0+25$ & 2 & 63 & 239.90 & 26233.00 & 17.48 & 11.22 & 7.02 & 5.02 & 4.04 & 3.12 & 2.85 & 1500.74 \\
\hline $0+25$ & 3 & 63 & 235.70 & 25778.00 & 17.21 & 11.15 & 6.99 & 5.01 & 4.04 & 3.17 & 2.84 & 1497.85 \\
\hline $0+25$ & 4 & 63 & 184.20 & 20143.00 & 13.99 & 9.07 & 5.70 & 4.10 & 3.30 & 2.63 & 2.33 & 1439.81 \\
\hline $0+25$ & 5 & 63 & 183.50 & 20071.00 & 13.92 & 9.04 & 5.69 & 4.12 & 3.30 & 2.62 & 2.38 & 1441.88 \\
\hline $0+25$ & 6 & 63 & 136.90 & 14969.00 & 10.15 & 6.55 & 4.08 & 2.96 & 2.37 & 1.87 & 1.71 & 1474.78 \\
\hline $0+25$ & 7 & 63 & 87.00 & 9513.00 & 6.45 & 4.14 & 2.54 & 1.87 & 1.52 & 1.17 & 1.20 & 1474.88 \\
\hline $0+30$ & 1 & 63 & 228.40 & 24977.00 & 23.02 & \begin{tabular}{l|}
14.07 \\
\end{tabular} & 7.80 & 5.25 & 3.98 & 3.01 & 2.63 & 1085.01 \\
\hline $0+30$ & 2 & 63 & 223.80 & 24470.00 & 21.59 & 12.91 & 7.45 & 5.20 & 4.11 & 3.24 & 2.76 & 1133.40 \\
\hline $0+30$ & 3 & 63 & 224.20 & 24517.00 & 21.03 & 12.74 & 7.44 & 5.20 & 4.14 & 3.24 & 2.79 & 1165.81 \\
\hline $0+30$ & 4 & 63 & 173.90 & 19022.00 & 17.15 & 10.35 & 6.04 & 4.23 & 3.38 & 2.59 & 2.28 & 1109.15 \\
\hline $0+30$ & 5 & 63 & 173.40 & 18961.00 & 16.90 & 10.25 & 6.02 & 4.21 & 3.37 & 2.56 & 2.28 & 1121.95 \\
\hline $0+30$ & 6 & 63 & 123.10 & 13458.00 & 12.19 & 7.44 & 4.28 & 3.00 & 2.41 & 1.81 & 1.64 & 1104.02 \\
\hline $0+35$ & 2 & 63 & 217.80 & 23822.00 & 19.61 & \begin{tabular}{|l|}
12.47 \\
\end{tabular} & 7.72 & 5.44 & 4.34 & 3.28 & 2.87 & 1214.79 \\
\hline $0+35$ & 3 & 63 & 217.50 & 23791.00 & 19.28 & 12.30 & 7.69 & 5.44 & 4.32 & 3.25 & 2.87 & 1233.97 \\
\hline $0+35$ & 4 & 63 & 172.30 & 18842.00 & 15.73 & 10.00 & 6.22 & 4.49 & 3.52 & 2.67 & 2.37 & 1197.84 \\
\hline $0+35$ & 5 & 63 & 173.30 & 18953.00 & 15.54 & 9.96 & 6.18 & 4.46 & 3.48 & 2.65 & 2.33 & 1219.63 \\
\hline $0+35$ & 6 & 63 & 125.90 & 13767.00 & 11.33 & 7.21 & 4.45 & 3.23 & 2.50 & 1.91 & 1.71 & 1215.09 \\
\hline $0+35$ & 7 & 63 & 81.50 & 8914.00 & 7.37 & 4.59 & 2.76 & 1.97 & 1.61 & 1.24 & 1.10 & 1209.50 \\
\hline $0+40$ & 1 & 63 & 213.20 & 23315.00 & 22.57 & 13.72 & 8.04 & 5.62 & 4.48 & 3.46 & 2.91 & 1033.01 \\
\hline $0+40$ & 2 & 63 & 212.40 & 23225.00 & 21.45 & 13.03 & 7.80 & 5.59 & 4.56 & 3.55 & 3.02 & 1082.75 \\
\hline $0+40$ & 3 & 63 & 211.50 & 23129.00 & 21.17 & 12.89 & 7.79 & 5.59 & 4.56 & 3.54 & 3.03 & 1092.54 \\
\hline $0+40$ & 4 & 63 & 170.80 & 18684.00 & 17.21 & 10.56 & 6.39 & 4.56 & 3.71 & 2.84 & 2.50 & 1085.65 \\
\hline $0+40$ & 5 & 63 & 170.10 & 18596.00 & 17.03 & 10.47 & 6.35 & 4.55 & 3.72 & 2.73 & 2.51 & 1091.96 \\
\hline $0+40$ & 6 & 63 & 125.10 & 13677.00 & 12.41 & 7.60 & 4.57 & 3.26 & 2.67 & 1.92 & 1.81 & 1102.10 \\
\hline $0+40$ & $7 \mid$ & 63 & 79.50 & 8692.00 & 8.03 & 4.85 & 2.86 & 2.04 & 1.69 & 1.80 & 1.17 & 1082.44 \\
\hline
\end{tabular}


Figure C8. FWD test raw data for Sasobit $\AA$ (pre-traffic at high temperature).

\begin{tabular}{|c|c|c|c|c|c|c|c|c|c|c|c|c|}
\hline \multirow[b]{2}{*}{ Station ID } & \multirow[b]{2}{*}{ Drop } & \multirow{2}{*}{$\begin{array}{c}\text { Surface } \\
\text { Temperature }\left({ }^{\circ} \mathrm{F}\right)\end{array}$} & \multirow[b]{2}{*}{ Stress (ksi) } & \multirow[b]{2}{*}{ Force (Ib) } & \multicolumn{7}{|c|}{ Deflection at distance from center of the load plate (in.) } & \multirow[b]{2}{*}{ ISM (kips/in.) } \\
\hline & & & & & 0 in. & 12 in. & 24 in. & 36 in & 48 in. & 60 in. & 72 in. & \\
\hline $0+10$ & 1 & 102 & 202.40 & 22130.00 & 27.36 & 13.98 & 8.31 & 6.17 & 5.09 & 3.99 & 3.34 & 808.85 \\
\hline $0+10$ & 2 & 102 & 204.00 & 22308.00 & 26.79 & 13.98 & 8.54 & 6.30 & 5.09 & 3.97 & 3.34 & 832.70 \\
\hline $0+10$ & 3 & 102 & 204.50 & 22360.00 & 26.58 & 13.94 & 8.24 & 6.15 & 5.09 & 3.98 & 3.34 & 841.23 \\
\hline $0+10$ & 4 & 102 & 163.30 & 17864.00 & 22.24 & 11.53 & 6.69 & 4.99 & 4.12 & 3.23 & 2.71 & 803.24 \\
\hline $0+10$ & 5 & 102 & 163.80 & 17914.00 & 22.17 & 11.48 & 6.71 & 5.00 & 4.13 & 3.21 & 2.69 & 808.03 \\
\hline $0+10$ & 6 & 102 & 113.40 & 12400.00 & 16.62 & 8.41 & 4.76 & 3.55 & 2.95 & 2.29 & 1.91 & 746.09 \\
\hline $0+10$ & 7 & 102 & 73.00 & 7986.00 & 10.85 & 5.44 & 2.83 & 2.14 & 1.85 & 1.43 & 1.22 & 736.04 \\
\hline $0+15$ & 1 & 102 & 199.00 & 21765.00 & 32.45 & 15.12 & 8.67 & 6.28 & 4.99 & 3.61 & 3.16 & 670.72 \\
\hline $0+15$ & 2 & 102 & 203.60 & 22260.00 & 28.11 & 13.52 & 8.43 & 6.11 & 5.02 & 3.75 & 3.32 & 791.89 \\
\hline $0+15$ & 3 & 102 & 205.20 & 22443.00 & 27.94 & 13.53 & 8.35 & 6.07 & 4.99 & 3.79 & 3.24 & 803.26 \\
\hline $0+15$ & 4 & 102 & 165.30 & 18081.00 & 23.13 & 11.11 & 6.69 & 4.95 & 4.01 & 3.09 & 2.59 & 781.71 \\
\hline $0+15$ & 5 & 102 & 165.60 & 18105.00 & 22.92 & 10.77 & 6.70 & 4.94 & 4.02 & 3.10 & 2.63 & 789.92 \\
\hline $0+15$ & 6 & 102 & 112.30 & 12284.00 & 16.81 & 7.82 & 4.77 & 3.53 & 2.82 & 2.19 & 1.86 & 730.76 \\
\hline $0+15$ & 7 & 102 & 73.20 & 8010.00 & 10.96 & 4.81 & 3.27 & 2.24 & 1.66 & 1.39 & 1.49 & 730.84 \\
\hline $0+20$ & 1 & 102 & 196.50 & 21488.00 & 34.77 & 16.32 & 8.19 & 5.65 & 4.54 & 3.38 & 3.18 & 618.00 \\
\hline $0+20$ & 2 & 102 & 199.60 & 21824.00 & 29.70 & 14.63 & 7.87 & 5.62 & 4.78 & 3.63 & 3.24 & 734.81 \\
\hline $0+20$ & 3 & 102 & 199.20 & 21784.00 & 28.88 & 14.35 & 7.77 & 5.66 & 4.75 & 3.76 & 3.27 & 754.29 \\
\hline $0+20$ & 4 & 102 & 160.60 & 17566.00 & 24.48 & 11.91 & 6.33 & 4.60 & 3.90 & 3.06 & 2.62 & 717.57 \\
\hline $0+20$ & 5 & 102 & 161.90 & 17705.00 & 24.29 & 11.86 & 6.36 & 4.64 & 3.94 & 3.09 & 2.68 & 728.90 \\
\hline $0+20$ & 6 & 102 & 115.00 & 12574.00 & 18.50 & 8.74 & 4.49 & 3.26 & 2.78 & 2.15 & 1.83 & 679.68 \\
\hline $0+20$ & 7 & 102 & 71.40 & 7803.00 & 12.16 & 5.53 & 2.69 & 2.01 & 1.72 & 1.31 & 1.24 & 641.69 \\
\hline $0+25$ & 1 & 102 & 201.90 & 22083.00 & 28.32 & 14.57 & 7.99 & 5.56 & 4.41 & 3.22 & 2.98 & 779.77 \\
\hline $0+25$ & 2 & 102 & 205.60 & 22482.00 & 22.95 & 13.05 & 7.47 & 5.43 & 4.47 & 3.47 & 3.12 & 979.61 \\
\hline $0+25$ & 3 & 102 & 206.10 & 22543.00 & 19.68 & 12.78 & 7.32 & 5.36 & 4.54 & 3.44 & 3.12 & 1145.48 \\
\hline $0+25$ & 4 & 102 & 166.50 & 18205.00 & 20.51 & 10.43 & 5.90 & 4.35 & 3.62 & 2.86 & 2.52 & 887.62 \\
\hline $0+25$ & 5 & 102 & 166.50 & 18205.00 & 20.28 & 10.33 & 5.85 & 4.33 & 3.61 & 2.84 & 2.51 & 897.68 \\
\hline $0+25$ & 6 & 102 & 113.00 & 12352.00 & 14.88 & 7.51 & 4.17 & 3.10 & 2.57 & 2.03 & 1.78 & 830.11 \\
\hline $0+25$ & 7 & 102 & 73.20 & 8006.00 & 9.52 & 4.77 & 2.56 & 1.94 & 1.63 & 1.29 & 1.11 & 840.97 \\
\hline $0+30$ & 1 & 102 & 193.50 & 21158.00 & 48.69 & 18.79 & 8.16 & 5.53 & 4.34 & 3.12 & 2.89 & 434.55 \\
\hline $0+30$ & 2 & 102 & 197.40 & 21583.00 & 42.54 & 16.43 & 7.73 & 5.47 & 4.47 & 3.33 & 2.93 & 507.36 \\
\hline $0+30$ & 3 & 102 & 199.00 & 21761.00 & 42.37 & 16.23 & 7.69 & 5.47 & 4.47 & 3.38 & 2.98 & 513.59 \\
\hline $0+30$ & 4 & 102 & 161.20 & 17626.00 & 36.04 & 13.68 & 6.20 & 4.42 & 3.61 & 2.75 & 2.41 & 489.07 \\
\hline $0+30$ & 5 & 102 & 161.40 & 17650.00 & 35.37 & 13.59 & 6.18 & 4.40 & 3.60 & 2.74 & 2.39 & 499.01 \\
\hline $0+30$ & 6 & 102 & 115.50 & 12633.00 & 27.49 & 10.40 & 4.43 & 3.13 & 2.57 & 1.98 & 1.74 & 459.55 \\
\hline $0+35$ & 2 & 102 & 197.40 & 21583.00 & 42.54 & 16.43 & 7.73 & 5.47 & 4.47 & 3.33 & 2.93 & 507.36 \\
\hline $0+35$ & 3 & 102 & 199.00 & 21761.00 & 42.37 & 16.23 & 7.69 & 5.47 & 4.47 & 3.38 & 2.98 & 513.59 \\
\hline $0+35$ & 4 & 102 & 161.20 & 17626.00 & 36.04 & 13.68 & 6.20 & 4.42 & 3.61 & 2.75 & 2.41 & 489.07 \\
\hline $0+35$ & 5 & 102 & 161.40 & 17650.00 & 35.37 & 13.59 & 6.18 & 4.40 & 3.60 & 2.74 & 2.39 & 499.01 \\
\hline $0+35$ & 6 & 102 & 115.50 & 12633.00 & 27.49 & 10.40 & 4.43 & 3.13 & 2.57 & 1.98 & 1.74 & 459.55 \\
\hline $0+35$ & 7 & 102 & 72.20 & 7895.00 & 18.98 & 6.99 & 2.71 & 1.93 & 1.61 & 1.23 & 1.08 & 415.96 \\
\hline $0+40$ & 1 & 102 & 197.60 & 21610.00 & 33.69 & 15.90 & 8.22 & 5.84 & 4.98 & 3.80 & 3.46 & 641.44 \\
\hline $0+40$ & 2 & 102 & 198.50 & 21705.00 & 31.93 & 15.74 & 8.26 & 5.80 & 5.02 & 3.70 & 3.41 & 679.77 \\
\hline $0+40$ & 3 & 102 & 199.50 & 21816.00 & 31.76 & 15.76 & 8.30 & 5.83 & 4.98 & 3.74 & 3.35 & 686.90 \\
\hline $0+40$ & 4 & 102 & 161.10 & 17613.00 & 25.59 & 12.99 & 6.65 & 4.72 & 3.94 & 3.10 & 2.66 & 688.28 \\
\hline $0+40$ & 5 & 102 & 160.90 & 17597.00 & 26.15 & 12.97 & 6.63 & 4.71 & 3.93 & 3.09 & 2.65 & 672.93 \\
\hline $0+40$ & 6 & 102 & 114.50 & 12519.00 & 20.31 & 9.58 & 4.71 & 3.36 & 2.81 & 2.18 & 1.88 & 616.40 \\
\hline $0+40$ & 7 & 102 & 71.70 & 7843.00 & 13.84 & 6.22 & 2.88 & 2.04 & 1.70 & 1.33 & 1.15 & 566.69 \\
\hline
\end{tabular}


Figure C9. FWD test raw data for Sasobit ${ }^{\circledR}$ (post-traffic at high temperature).

\begin{tabular}{|c|c|c|c|c|c|c|c|c|c|c|c|c|}
\hline \multirow[b]{2}{*}{ Station ID } & \multirow[b]{2}{*}{ Drop } & \multirow{2}{*}{$\begin{array}{c}\text { Surface } \\
\text { Temperature }\left({ }^{\circ} \mathrm{F}\right)\end{array}$} & \multirow[b]{2}{*}{ Stress (ksi) } & \multirow[b]{2}{*}{ Force (Ib) } & \multicolumn{7}{|c|}{ Deflection at distance from center of the load plate (in.) } & \multirow[b]{2}{*}{ ISM (kips/in.) } \\
\hline & & & & & 0 in. & 12 in. & $24 \mathrm{in.}$ & 36 in & $48 \mathrm{in.}$ & 60 in. & 72 in. & \\
\hline $0+10$ & 1 & 95 & 218.60 & 23907.00 & 43.72 & 16.93 & 9.09 & 6.74 & 5.81 & 4.15 & 3.79 & 546.82 \\
\hline $0+10$ & 2 & 95 & 218.70 & 23918.00 & 42.11 & 16.13 & 9.09 & 6.83 & 5.83 & 4.27 & 4.10 & 567.99 \\
\hline $0+10$ & 3 & 95 & 218.20 & 23862.00 & 38.04 & 15.96 & 9.10 & 6.89 & 5.83 & 4.48 & 3.87 & 627.29 \\
\hline $0+10$ & 4 & 95 & 171.60 & 18768.00 & 31.00 & 13.17 & 7.41 & 5.66 & 4.76 & 3.68 & 3.09 & 605.42 \\
\hline $0+10$ & 5 & 95 & 171.80 & 18787.00 & 29.41 & 13.06 & 7.39 & 5.65 & 4.77 & 3.68 & 3.09 & 638.80 \\
\hline $0+10$ & 6 & 95 & 121.50 & 13291.00 & 23.24 & 9.57 & 5.25 & 4.02 & 3.37 & 2.61 & 2.20 & 571.90 \\
\hline $0+10$ & 7 & 95 & 79.50 & 8692.00 & 16.02 & 6.09 & 3.22 & 2.45 & 2.07 & 1.59 & 1.35 & 542.57 \\
\hline $0+15$ & 1 & 97 & 222.90 & 24374.00 & 31.41 & 17.92 & 9.41 & 7.47 & 5.90 & 4.49 & 3.64 & 775.99 \\
\hline $0+15$ & 2 & 97 & 227.60 & 24893.00 & 32.20 & 16.11 & 9.10 & 7.22 & 5.89 & 4.66 & 3.81 & 773.07 \\
\hline $0+15$ & 3 & 97 & 228.00 & 24930.00 & 34.36 & 15.84 & 9.09 & 7.21 & 5.89 & 4.72 & 3.86 & 725.55 \\
\hline $0+15$ & 4 & 97 & 179.90 & 19672.00 & 29.95 & 12.91 & 7.38 & 5.87 & 4.76 & 3.81 & 3.15 & 656.83 \\
\hline $0+15$ & 5 & 97 & 180.10 & 19691.00 & 30.81 & 12.78 & 7.33 & 5.86 & 4.67 & 3.84 & 3.15 & 639.11 \\
\hline $0+15$ & 6 & 97 & 126.40 & 13819.00 & 23.30 & 9.34 & 5.27 & 4.19 & 3.35 & 2.74 & 2.24 & 593.09 \\
\hline $0+15$ & 7 & 97 & 83.90 & 9180.00 & 15.65 & 5.85 & 3.23 & 2.61 & 1.85 & 1.70 & 1.44 & 586.58 \\
\hline $0+20$ & 1 & 97 & 220.10 & 24065.00 & 41.13 & 18.02 & 9.43 & 7.06 & 5.77 & 4.16 & 3.83 & 585.10 \\
\hline $0+20$ & 2 & 97 & 223.80 & 24473.00 & 36.38 & 16.02 & 9.04 & 7.06 & 5.78 & 4.41 & 3.96 & 672.70 \\
\hline $0+20$ & 3 & 97 & 224.40 & 24544.00 & 36.31 & 15.76 & 9.02 & 6.94 & 5.76 & 4.46 & 3.86 & 675.96 \\
\hline $0+20$ & 4 & 97 & 176.80 & 19334.00 & 30.99 & 13.09 & 7.37 & 5.64 & 4.70 & 3.68 & 3.15 & 623.88 \\
\hline $0+20$ & 5 & 97 & 176.60 & 19318.00 & 30.93 & 13.03 & 7.35 & 5.65 & 4.70 & 3.70 & 3.15 & 624.57 \\
\hline $0+20$ & 6 & 97 & 123.90 & 13550.00 & 23.12 & 9.72 & 5.27 & 4.00 & 3.34 & 2.62 & 2.24 & 586.07 \\
\hline $0+20$ & 7 & 97 & 81.80 & 8950.00 & 15.75 & 6.34 & 3.24 & 2.46 & 2.06 & 1.62 & 1.39 & 568.25 \\
\hline $0+25$ & 1 & 95 & 224.40 & 24536.00 & 31.77 & 18.53 & 9.65 & 7.02 & 5.23 & 3.64 & 3.52 & 772.30 \\
\hline $0+25$ & 2 & 95 & 228.30 & 24961.00 & 29.24 & 16.31 & 9.66 & 7.27 & 5.29 & 3.87 & 3.68 & 853.66 \\
\hline $0+25$ & 3 & 95 & 229.10 & 25052.00 & 27.44 & 16.12 & 9.37 & 7.35 & 5.29 & 3.92 & 3.73 & 912.97 \\
\hline $0+25$ & 4 & 95 & 179.70 & 19648.00 & 22.93 & 13.19 & 7.81 & 5.97 & 4.30 & 3.21 & 3.08 & 856.87 \\
\hline $0+25$ & 5 & 95 & 179.10 & 19585.00 & 22.91 & 13.10 & 10.02 & 5.77 & 4.30 & 3.29 & 3.03 & 854.87 \\
\hline $0+25$ & 6 & 95 & 126.90 & 13875.00 & 16.94 & 9.52 & 5.61 & 4.05 & 2.99 & 2.35 & 2.13 & 819.07 \\
\hline $0+25$ & 7 & 95 & 82.90 & 9064.00 & 11.40 & 6.07 & 3.39 & 2.43 & 1.86 & 1.48 & 1.32 & 795.09 \\
\hline $0+30$ & 1 & 93 & 206.10 & 22535.00 & 69.41 & 23.51 & 8.91 & 6.70 & 5.25 & 3.67 & 3.05 & 324.67 \\
\hline $0+30$ & 2 & 93 & 214.10 & 23418.00 & 47.89 & 19.01 & 8.76 & 6.64 & 5.25 & 3.85 & 3.21 & 489.00 \\
\hline $0+30$ & 3 & 93 & 217.00 & 23732.00 & 45.37 & 18.67 & 8.89 & 6.65 & 5.26 & 3.80 & 3.14 & 523.08 \\
\hline $0+30$ & 4 & 93 & 175.20 & 19156.00 & 39.77 & 15.83 & 7.31 & 5.30 & 4.28 & 3.13 & 2.61 & 481.67 \\
\hline $0+30$ & 5 & 93 & 174.80 & 19112.00 & 41.71 & 15.76 & 7.35 & 5.31 & 4.30 & 3.17 & 2.68 & 458.21 \\
\hline $0+30$ & 6 & 93 & 133.20 & 14568.00 & 31.74 & 11.96 & 5.21 & 3.71 & 3.01 & 2.19 & 1.87 & 458.98 \\
\hline $0+35$ & 2 & 91 & 227.20 & 24845.00 & 31.68 & 17.21 & 9.71 & 7.35 & 5.35 & 4.18 & 3.59 & 784.25 \\
\hline $0+35$ & 3 & 91 & 225.80 & 24695.00 & 37.54 & 16.75 & 9.64 & 7.22 & 5.42 & 4.15 & 3.61 & 657.83 \\
\hline $0+35$ & 4 & 91 & 176.90 & 19342.00 & 24.67 & 13.69 & 7.87 & 5.82 & 4.55 & 3.49 & 2.89 & 784.03 \\
\hline $0+35$ & 5 & 91 & 176.80 & 19334.00 & 24.37 & 13.69 & 7.80 & 5.91 & 4.40 & 3.46 & 2.93 & 793.35 \\
\hline $0+35$ & 6 & 91 & 122.80 & 13431.00 & 18.04 & 9.74 & 5.51 & 4.11 & 3.16 & 2.39 & 2.07 & 744.51 \\
\hline $0+35$ & 7 & 91 & 80.20 & 8771.00 & 12.06 & 6.53 & 3.39 & 2.67 & 1.74 & 1.63 & 1.27 & 727.28 \\
\hline $0+40$ & 1 & 93 & 220.50 & 24116.00 & 38.46 & 20.24 & 10.57 & 7.39 & 5.95 & 4.22 & 3.63 & 627.04 \\
\hline $0+40$ & 2 & 93 & 222.70 & 24354.00 & 33.56 & 18.24 & 10.21 & 7.36 & 5.98 & 4.32 & 3.72 & 725.69 \\
\hline $0+40$ & 3 & 93 & 222.10 & 24290.00 & 33.12 & 17.93 & 10.14 & 7.35 & 5.94 & 4.34 & 3.63 & 733.39 \\
\hline $0+40$ & 4 & 93 & 174.40 & 19077.00 & 27.91 & 14.71 & 8.19 & 5.82 & 4.74 & 3.58 & 2.99 & 683.52 \\
\hline $0+40$ & 5 & 93 & 173.80 & 19006.00 & 27.62 & 14.56 & 8.12 & 5.78 & 4.75 & 3.58 & 3.00 & 688.12 \\
\hline $0+40$ & 6 & 93 & 121.80 & 13323.00 & 20.85 & 10.61 & 5.73 & 4.07 & 3.36 & 2.52 & 2.12 & 638.99 \\
\hline $0+40$ & 7 & 93 & 80.00 & 8752.00 & 14.63 & 6.89 & 3.56 & 2.53 & 2.04 & 1.58 & 1.32 & 598.22 \\
\hline
\end{tabular}


Figure C10. FWD test raw data for Evotherm ${ }^{\mathrm{TM}} 3 \mathrm{G}$ (pre-traffic at ambient temperature).

\begin{tabular}{|c|c|c|c|c|c|c|c|c|c|c|c|c|}
\hline \multirow[b]{2}{*}{ Station ID } & \multirow[b]{2}{*}{ Drop } & \multirow{2}{*}{$\begin{array}{c}\text { Surface } \\
\text { Temperature }\left({ }^{\circ} \mathrm{F}\right)\end{array}$} & \multirow[b]{2}{*}{ Stress (ksi) } & \multirow[b]{2}{*}{ Force $(\mathrm{Ib})$} & \multicolumn{7}{|c|}{ Deflection at distance from center of the load plate (in.) } & \multirow[b]{2}{*}{ ISM (kips/in.) } \\
\hline & & & & & 0 in. & 12 in. & $24 \mathrm{in.}$ & 36 in & 48 in. & 60 in. & 72 in. & \\
\hline $0+10$ & 1 & 58 & 225.10 & 24612.00 & 17.72 & 11.24 & 6.69 & 4.43 & 3.47 & 2.64 & 2.33 & 1388.94 \\
\hline $0+10$ & 2 & 58 & 223.80 & 24473.00 & 16.85 & 10.59 & 6.44 & 4.44 & 3.58 & 2.79 & 2.39 & 1452.40 \\
\hline $0+10$ & 3 & 58 & 222.90 & 24374.00 & 16.52 & 10.50 & 6.44 & 4.47 & 3.62 & 2.82 & 2.41 & 1475.42 \\
\hline $0+10$ & 4 & 58 & 175.10 & 19148.00 & 13.14 & 8.48 & 5.21 & 3.63 & 2.95 & 2.30 & 1.97 & 1457.23 \\
\hline $0+10$ & 5 & 58 & 175.00 & 19136.00 & 13.00 & 8.43 & 5.20 & 3.62 & 2.94 & 2.29 & 2.00 & 1472.00 \\
\hline $0+10$ & 6 & 58 & 129.80 & 14192.00 & 9.55 & 6.17 & 3.76 & 2.62 & 2.12 & 1.69 & 1.45 & 1486.07 \\
\hline $0+10$ & 7 & 58 & 83.50 & 9128.00 & 6.20 & 3.96 & 2.38 & 1.66 & 1.40 & 1.08 & 0.96 & 1472.26 \\
\hline $0+15$ & 1 & 58 & 225.70 & 24687.00 & 16.46 & 10.71 & 6.45 & 4.45 & 3.52 & 2.67 & 2.38 & 1499.82 \\
\hline $0+15$ & 2 & 58 & 228.00 & 24930.00 & \begin{tabular}{|l|}
15.57 \\
\end{tabular} & 10.16 & 6.24 & 4.43 & 3.57 & 2.85 & 2.49 & 1601.16 \\
\hline $0+15$ & 3 & 58 & 228.80 & 25020.00 & \begin{tabular}{|l|}
15.47 \\
\end{tabular} & 10.12 & 6.26 & 4.46 & 3.63 & 2.89 & 2.54 & 1617.32 \\
\hline $0+15$ & 4 & 58 & 175.00 & 19136.00 & 12.50 & 8.20 & 5.09 & 3.62 & 2.99 & 2.33 & 2.10 & 1530.88 \\
\hline $0+15$ & 5 & 58 & 175.70 & 19212.00 & 12.41 & 8.19 & 5.09 & 3.63 & 2.98 & 2.33 & 2.12 & 1548.11 \\
\hline $0+15$ & 6 & 58 & 126.80 & 13862.00 & 8.98 & 5.90 & 3.65 & 2.59 & 2.14 & 1.67 & 1.52 & 1543.65 \\
\hline $0+15$ & 7 & 58 & 80.90 & 8842.00 & 5.62 & 3.66 & 2.24 & 1.58 & \begin{tabular}{l|l|}
1.33 \\
\end{tabular} & 1.02 & 0.95 & 1573.31 \\
\hline $0+20$ & 1 & 58 & 220.80 & 24144.00 & 18.19 & 11.35 & 6.69 & 4.49 & 3.48 & 2.57 & 2.29 & 1327.32 \\
\hline $0+20$ & 2 & 58 & 221.80 & 24255.00 & 22.61 & 10.58 & 6.36 & 4.41 & 3.56 & 2.79 & 2.42 & 1072.76 \\
\hline $0+20$ & 3 & 58 & 221.90 & 24271.00 & 16.79 & 10.46 & 6.34 & 4.41 & 3.58 & 2.81 & 2.44 & 1445.56 \\
\hline $0+20$ & 4 & 58 & 170.30 & 18628.00 & 13.60 & 8.49 & 5.16 & 3.61 & 2.93 & 2.26 & 2.00 & 1369.71 \\
\hline $0+20$ & 5 & 58 & 170.10 & 18604.00 & 13.42 & 8.40 & 5.13 & 3.60 & 2.92 & 2.29 & 1.99 & 1386.29 \\
\hline $0+20$ & 6 & 58 & 125.20 & 13696.00 & 9.80 & 6.08 & 3.69 & 2.57 & 2.09 & 1.65 & 1.43 & 1397.55 \\
\hline $0+20$ & 7 & 58 & 78.90 & 8633.00 & 6.17 & 3.85 & 2.29 & 1.67 & \begin{tabular}{l|l|}
1.32 \\
\end{tabular} & 1.11 & 0.89 & 1399.19 \\
\hline $0+25$ & 1 & 59 & 227.40 & 24869.00 & 16.84 & 10.77 & 6.47 & 4.29 & 3.30 & 2.44 & 2.20 & 1476.78 \\
\hline $0+25$ & 2 & 59 & 228.10 & 24941.00 & 15.57 & 10.06 & 6.18 & 4.28 & \begin{tabular}{l|l}
3.45 \\
\end{tabular} & 2.69 & 2.35 & 1601.86 \\
\hline $0+25$ & 3 & 59 & 227.70 & 24901.00 & 15.29 & 10.00 & 6.17 & 4.30 & 3.48 & 2.73 & 2.38 & 1628.58 \\
\hline $0+25$ & 4 & 59 & 172.80 & 18903.00 & 12.38 & 8.15 & 5.04 & 3.54 & 2.87 & 2.23 & 1.95 & 1526.90 \\
\hline $0+25$ & 5 & 59 & 173.30 & 18950.00 & 12.30 & 8.13 & 5.04 & 3.54 & 2.87 & 2.24 & 1.96 & 1540.65 \\
\hline $0+25$ & 6 & 59 & 130.00 & 14219.00 & 8.79 & 5.84 & 3.59 & 2.52 & 2.04 & 1.57 & 1.39 & 1617.63 \\
\hline $0+25$ & 7 & 59 & 82.30 & 8998.00 & 5.58 & 3.58 & 2.19 & 1.56 & 1.30 & 0.97 & 0.88 & 1612.54 \\
\hline $0+30$ & 1 & 60 & 215.40 & 23553.00 & 22.46 & 12.26 & 6.54 & 4.15 & 3.18 & 2.41 & 2.11 & 1048.66 \\
\hline $0+30$ & 2 & 60 & 215.60 & 23573.00 & 21.32 & 11.46 & 6.23 & 4.11 & 3.33 & 2.60 & 2.26 & 1105.68 \\
\hline $0+30$ & 3 & 60 & 215.60 & 23577.00 & 20.87 & 11.31 & 6.21 & 4.14 & 3.33 & 2.64 & 2.29 & 1129.71 \\
\hline $0+30$ & 4 & 60 & 169.20 & 18501.00 & 16.88 & 9.10 & 5.03 & 3.35 & 2.73 & 2.13 & 1.89 & 1096.03 \\
\hline $0+30$ & 5 & 60 & 170.00 & 18589.00 & 16.78 & 9.04 & 5.05 & 3.33 & 2.65 & 2.35 & 1.84 & 1107.81 \\
\hline $0+30$ & 6 & 60 & 125.20 & 13696.00 & 12.23 & 6.63 & 3.64 & 2.43 & 1.98 & 1.54 & 1.39 & 1119.87 \\
\hline $0+30$ & 7 & 60 & 78.80 & 8612.00 & 7.65 & 4.11 & 2.23 & 1.49 & 1.23 & 0.96 & 0.87 & 1125.75 \\
\hline $0+35$ & 1 & 60 & 223.60 & 24454.00 & 16.96 & 11.22 & 6.66 & 4.47 & 3.44 & 2.53 & 2.17 & 1441.86 \\
\hline $0+35$ & 2 & 60 & 224.50 & 24552.00 & 15.86 & 10.54 & 6.39 & 4.46 & 3.50 & 2.67 & 2.34 & 1548.05 \\
\hline $0+35$ & 3 & 60 & 224.30 & 24528.00 & 15.62 & 10.43 & 6.39 & 4.43 & 3.52 & 2.69 & 2.31 & 1570.29 \\
\hline $0+35$ & 4 & 60 & 172.30 & 18839.00 & 12.69 & 8.46 & 5.23 & 3.63 & 2.88 & 2.19 & 1.89 & 1484.55 \\
\hline $0+35$ & 5 & 60 & 172.70 & 18887.00 & 12.63 & 8.43 & 5.19 & 3.63 & 2.87 & 2.19 & 1.89 & 1495.41 \\
\hline $0+35$ & 6 & 60 & 125.40 & 13711.00 & 9.18 & 6.10 & 3.69 & 2.60 & 2.04 & 1.54 & 1.34 & 1493.57 \\
\hline $0+35$ & 7 & 60 & 79.60 & 8707.00 & 5.85 & 3.76 & 2.30 & 1.54 & 1.27 & 0.98 & 0.89 & 1488.38 \\
\hline $0+40$ & 1 & 60 & 214.70 & 23481.00 & 18.52 & 11.96 & 7.07 & 4.60 & 3.48 & 2.56 & 2.27 & 1267.87 \\
\hline $0+40$ & 2 & 60 & 214.00 & 23402.00 & 17.32 & 11.18 & 6.76 & 4.59 & 3.61 & 2.75 & 2.41 & 1351.15 \\
\hline $0+40$ & 3 & 60 & 213.20 & 23312.00 & 17.10 & 11.06 & 6.72 & 4.59 & 3.63 & 2.78 & 2.43 & 1363.27 \\
\hline $0+40$ & 4 & 60 & 172.70 & 18890.00 & 13.93 & 8.94 & 5.43 & 3.72 & 2.95 & 2.25 & 1.98 & 1356.07 \\
\hline $0+40$ & 5 & 60 & 173.40 & 18958.00 & 13.83 & 8.91 & 5.44 & 3.72 & 2.96 & 2.26 & 1.98 & 1370.79 \\
\hline $0+40$ & 6 & 60 & 126.70 & 13851.00 & 9.93 & 6.39 & 3.85 & 2.63 & 2.09 & 1.59 & 1.42 & 1394.86 \\
\hline $0+40$ & 7 & 60 & 80.60 & 8818.00 & 6.45 & \begin{tabular}{ll|}
4.07 \\
\end{tabular} & 2.43 & 1.65 & 1.32 & 1.03 & 0.90 & 1367.13 \\
\hline
\end{tabular}


Figure C11. FWD test raw data for Evotherm ${ }^{\mathrm{TM}} 3 \mathrm{G}$ (pre-traffic at high temperature).

\begin{tabular}{|c|c|c|c|c|c|c|c|c|c|c|c|c|}
\hline \multirow[b]{2}{*}{ Station ID } & \multirow[b]{2}{*}{ Drop } & \multirow{2}{*}{$\begin{array}{c}\text { Surface } \\
\text { Temperature }\left({ }^{\circ} \mathrm{F}\right)\end{array}$} & \multirow[b]{2}{*}{ Stress (ksi) } & \multirow[b]{2}{*}{ Force (lb) } & \multicolumn{7}{|c|}{ Deflection at distance from center of the load plate (in.) } & \multirow[b]{2}{*}{ ISM (kips/in.) } \\
\hline & & & & & 0 in. & $12 \mathrm{in.}$ & $24 \mathrm{in.}$ & 36 in & 48 in. & $60 \mathrm{in.}$ & 72 in. & \\
\hline $0+10$ & 1 & 109 & 211.50 & 23125.00 & 36.01 & 15.07 & 7.34 & 5.13 & 4.15 & 3.34 & 2.82 & 642.18 \\
\hline $0+10$ & 2 & 109 & 213.70 & 23375.00 & 30.38 & 13.70 & 7.18 & 5.15 & 4.25 & 3.39 & 2.88 & 769.42 \\
\hline $0+10$ & 3 & 109 & 213.50 & 23344.00 & 29.43 & 13.58 & 7.17 & 5.15 & 4.27 & 3.39 & 2.87 & 793.20 \\
\hline $0+10$ & 4 & 109 & 168.20 & 18398.00 & 24.35 & 11.20 & 5.86 & 4.25 & 3.52 & 2.78 & 2.37 & 755.56 \\
\hline $0+10$ & 5 & 109 & 168.40 & 18411.00 & 24.07 & 11.15 & 5.89 & 4.26 & 3.54 & 2.80 & 2.38 & 764.89 \\
\hline $0+10$ & 6 & 109 & 122.30 & 13370.00 & 18.25 & 8.20 & 4.21 & 3.06 & 2.56 & 2.02 & 1.70 & 732.60 \\
\hline $0+10$ & 7 & 109 & 77.80 & 8509.00 & 12.32 & 5.26 & 2.19 & 1.52 & 1.54 & 1.27 & 1.04 & 690.67 \\
\hline $0+15$ & 1 & 109 & 215.20 & 23529.00 & 36.02 & 13.82 & 7.30 & 5.15 & 4.11 & 2.78 & 2.84 & 653.22 \\
\hline $0+15$ & 2 & 109 & 216.20 & 23640.00 & 33.67 & 12.86 & 7.05 & 5.24 & 4.12 & 3.24 & 3.01 & 702.11 \\
\hline $0+15$ & 3 & 109 & 216.60 & 23692.00 & 28.56 & 11.97 & 7.03 & 5.23 & 4.15 & 3.26 & 3.05 & 829.55 \\
\hline $0+15$ & 4 & 109 & 167.40 & 18308.00 & 24.17 & 9.58 & 5.74 & 4.28 & 3.40 & 2.69 & 2.50 & 757.47 \\
\hline $0+15$ & 5 & 109 & 167.40 & 18303.00 & 24.23 & 10.26 & 5.31 & 4.27 & 3.41 & 2.66 & 2.52 & 755.39 \\
\hline $0+15$ & 6 & 109 & 121.50 & 13288.00 & 19.13 & 7.61 & 4.06 & 3.04 & 2.51 & 1.88 & 1.80 & 694.62 \\
\hline $0+15$ & 7 & 109 & 78.60 & 8593.00 & 12.70 & 4.87 & 2.48 & 1.88 & 1.59 & 1.11 & 1.26 & 676.61 \\
\hline $0+20$ & 1 & 109 & 208.90 & 22844.00 & 36.91 & 16.09 & 7.80 & 5.19 & 4.03 & 2.66 & 2.73 & 618.91 \\
\hline $0+20$ & 2 & 109 & 212.30 & 23217.00 & 28.65 & 14.44 & 7.43 & 5.20 & 4.26 & 3.18 & 2.92 & 810.37 \\
\hline $0+20$ & 3 & 109 & 213.10 & 23299.00 & 29.56 & 14.23 & 7.42 & 5.22 & 4.35 & 3.24 & 2.98 & 788.19 \\
\hline $0+20$ & 4 & 109 & 165.30 & 18078.00 & 24.99 & 11.90 & 6.07 & 4.29 & 3.56 & 2.74 & 2.43 & 723.41 \\
\hline $0+20$ & 5 & 109 & 166.10 & 18165.00 & 24.72 & 11.85 & 6.07 & 4.30 & 3.55 & 2.75 & 2.44 & 734.83 \\
\hline $0+20$ & 6 & 109 & 121.20 & 13251.00 & 18.78 & 8.71 & 4.26 & 3.02 & 2.55 & 1.96 & 1.73 & 705.59 \\
\hline $0+20$ & 7 & 109 & 77.10 & 8427.00 & 12.89 & 5.63 & 2.60 & 1.84 & 1.56 & 1.19 & 1.07 & 653.76 \\
\hline $0+25$ & 1 & 109 & 213.10 & 23307.00 & 31.99 & 14.67 & 7.53 & 4.83 & 3.62 & 2.52 & 2.50 & 728.57 \\
\hline $0+25$ & 2 & 109 & 216.10 & 23632.00 & 28.18 & 13.17 & 7.14 & 4.94 & 4.00 & 3.02 & 2.76 & 838.61 \\
\hline $0+25$ & 3 & 109 & 215.10 & 23518.00 & 27.17 & 12.87 & 7.07 & 4.94 & 4.04 & 3.10 & 2.79 & 865.59 \\
\hline $0+25$ & 4 & 109 & 167.10 & 18271.00 & 22.93 & 10.63 & 5.80 & 4.07 & 3.33 & 2.60 & 2.29 & 796.82 \\
\hline $0+25$ & 5 & 109 & 167.50 & 18316.00 & 22.57 & 10.52 & 5.78 & 4.07 & 3.34 & 2.61 & 2.29 & 811.52 \\
\hline $0+25$ & 6 & 109 & 125.90 & 13764.00 & 17.70 & 7.69 & 4.13 & 2.92 & 2.40 & 1.85 & 1.63 & 777.63 \\
\hline $0+25$ & 7 & 109 & 80.40 & 8795.00 & 12.28 & 4.83 & 2.53 & 1.81 & 1.50 & 1.15 & 1.01 & 716.21 \\
\hline $0+30$ & 1 & 109 & 200.80 & 21959.00 & 69.10 & 17.63 & 6.87 & 4.11 & 3.15 & 2.48 & 2.34 & 317.79 \\
\hline $0+30$ & 2 & 109 & 202.40 & 22130.00 & 58.58 & 16.26 & 6.80 & 4.50 & 3.51 & 3.05 & 2.57 & 377.77 \\
\hline $0+30$ & 3 & 109 & 202.70 & 22170.00 & 58.07 & 16.43 & 6.76 & 4.47 & 3.56 & 3.19 & 2.61 & 381.78 \\
\hline $0+30$ & 4 & 109 & 162.40 & 17756.00 & 46.29 & 14.05 & 5.47 & 3.70 & 2.95 & 2.70 & 2.16 & 383.58 \\
\hline $0+30$ & 5 & 109 & 162.60 & 17780.00 & 48.09 & 14.02 & 5.38 & 3.74 & 2.98 & 2.68 & 2.16 & 369.72 \\
\hline $0+30$ & 6 & 109 & 119.00 & 13018.00 & 36.70 & 10.90 & 3.77 & 2.79 & 2.19 & 1.96 & 1.54 & 354.71 \\
\hline $0+30$ & 7 & 109 & 74.60 & 8160.00 & 26.12 & 7.63 & 2.08 & 1.70 & 1.39 & 1.38 & 0.96 & 312.40 \\
\hline $0+35$ & 1 & 109 & 209.70 & 22934.00 & 31.35 & 14.92 & 7.67 & 5.00 & 3.85 & 3.00 & 2.63 & 731.55 \\
\hline $0+35$ & 2 & 109 & 213.60 & 23363.00 & 27.74 & 13.68 & 7.38 & 5.04 & 4.05 & 3.19 & 2.74 & 842.21 \\
\hline $0+35$ & 3 & 109 & 213.20 & 23315.00 & 27.07 & 13.48 & 7.33 & 5.02 & 4.06 & 3.18 & 2.75 & 861.29 \\
\hline $0+35$ & 4 & 109 & 167.50 & 18319.00 & 22.69 & 11.16 & 6.00 & 4.13 & 3.34 & 2.56 & 2.24 & 807.36 \\
\hline $0+35$ & 5 & 109 & 167.70 & 18340.00 & 22.56 & 11.12 & 6.00 & 4.17 & 3.34 & 2.59 & 2.22 & 812.94 \\
\hline $0+35$ & 6 & 109 & 122.20 & 13362.00 & 16.06 & 8.03 & 4.24 & 2.93 & 2.39 & 1.85 & 1.65 & 832.00 \\
\hline $0+35$ & 7 & 109 & 79.00 & 8641.00 & 10.79 & 5.38 & 2.67 & 1.93 & 1.48 & 1.21 & 1.11 & 800.83 \\
\hline $0+40$ & 1 & 109 & 202.70 & 22170.00 & 37.26 & 16.29 & 8.13 & 5.28 & 3.96 & 2.71 & 2.59 & 595.01 \\
\hline $0+40$ & 2 & 109 & 204.10 & 22316.00 & 32.39 & 14.96 & 7.76 & 5.28 & 4.17 & 3.07 & 2.77 & 688.98 \\
\hline $0+40$ & 3 & 109 & 204.20 & 22336.00 & 31.51 & 14.80 & 7.72 & 5.29 & 4.19 & 3.13 & 2.81 & 708.85 \\
\hline $0+40$ & 4 & 109 & 165.20 & 18062.00 & 25.80 & 12.10 & 6.20 & 4.28 & 3.41 & 2.56 & 2.28 & 700.08 \\
\hline $0+40$ & 5 & 109 & 165.00 & 18049.00 & 25.44 & 12.02 & 6.19 & 4.29 & 3.41 & 2.59 & 2.29 & 709.47 \\
\hline $0+40$ & 6 & 109 & 121.30 & 13267.00 & 19.25 & 8.89 & 4.40 & 3.08 & 2.45 & 1.81 & 1.60 & 689.19 \\
\hline $0+40$ & 7 & 109 & 76.80 & 8395.00 & 13.13 & 5.78 & 2.72 & 1.90 & 1.55 & 1.15 & 1.05 & 639.38 \\
\hline
\end{tabular}


Figure C12. FWD test raw data for Evotherm ${ }^{\mathrm{TM}} 3 \mathrm{G}$ (post-traffic at high temperature).

\begin{tabular}{|c|c|c|c|c|c|c|c|c|c|c|c|c|}
\hline \multirow[b]{2}{*}{ Station ID } & \multirow[b]{2}{*}{ Drop } & \multirow{2}{*}{$\begin{array}{c}\text { Surface } \\
\text { Temperature }\left({ }^{\circ} \mathrm{F}\right)\end{array}$} & \multirow[b]{2}{*}{ Stress (ksi) } & \multirow[b]{2}{*}{ Force (lb) } & \multicolumn{7}{|c|}{ Deflection at distance from center of the load plate (in.) } & \multirow[b]{2}{*}{ ISM (kips/in.) } \\
\hline & & & & & 0 in. & $12 \mathrm{in.}$ & 24 in. & 36 in & $48 \mathrm{in.}$. & $60 \mathrm{in.}$ & $72 \mathrm{in.}$ & \\
\hline $0+10$ & 1 & 101 & 237.90 & 26016.00 & 37.96 & 15.39 & 8.13 & 5.90 & 4.94 & 5.21 & 3.29 & 685.35 \\
\hline $0+10$ & 2 & 101 & 235.40 & 25742.00 & 37.25 & 15.48 & 8.22 & 5.92 & 4.95 & 5.10 & 3.29 & 691.06 \\
\hline $0+10$ & 3 & 101 & 236.10 & 25818.00 & 35.87 & 15.49 & 8.19 & 5.94 & 5.02 & 4.95 & 3.33 & 719.77 \\
\hline $0+10$ & 4 & 101 & 184.00 & 20119.00 & 28.93 & 12.96 & 6.70 & 4.85 & 4.10 & 3.41 & 2.70 & 695.44 \\
\hline $0+10$ & 5 & 101 & 183.90 & 20111.00 & 28.63 & 12.88 & 6.68 & 4.86 & 4.14 & 3.62 & 2.71 & 702.44 \\
\hline $0+10$ & 6 & 101 & 126.70 & 13851.00 & 21.26 & 9.60 & 4.81 & 3.52 & 2.94 & 2.58 & 1.93 & 651.51 \\
\hline $0+10$ & 7 & 101 & 82.70 & 9048.00 & 14.74 & 6.47 & 3.12 & 2.26 & 1.72 & 2.54 & 1.15 & 613.84 \\
\hline $0+15$ & 1 & 101 & 231.40 & 25305.00 & 34.16 & 16.18 & 7.83 & 5.84 & 4.87 & 3.44 & 3.00 & 740.78 \\
\hline $0+15$ & 2 & 101 & 237.70 & 25995.00 & 28.72 & 14.82 & 7.84 & 6.00 & 5.02 & 3.74 & 3.12 & 905.12 \\
\hline $0+15$ & 3 & 101 & 239.70 & 26210.00 & 30.28 & 14.82 & 7.89 & 6.00 & 5.02 & 3.09 & 2.53 & 865.59 \\
\hline $0+15$ & 4 & 101 & 183.10 & 20029.00 & 26.56 & 12.06 & 6.48 & 4.92 & 4.11 & 3.17 & 2.29 & 754.10 \\
\hline $0+15$ & 5 & 101 & 181.80 & 19881.00 & 25.44 & 11.99 & 6.47 & 4.91 & 4.14 & 3.18 & 2.46 & 781.49 \\
\hline $0+15$ & 6 & 101 & 138.80 & 15183.00 & 18.81 & 8.82 & 4.66 & 3.47 & 2.84 & 2.24 & 1.78 & 807.18 \\
\hline $0+15$ & 7 & 101 & 90.20 & 9865.00 & 12.91 & 5.48 & 2.81 & 2.05 & 2.17 & 1.35 & 1.56 & 764.14 \\
\hline $0+20$ & 1 & 101 & 226.20 & 24734.00 & 43.36 & 17.72 & 7.89 & 5.65 & 4.72 & 3.24 & 3.02 & 570.43 \\
\hline $0+20$ & 2 & 101 & 231.10 & 25274.00 & 38.31 & 16.80 & 8.02 & 5.77 & 4.86 & 3.64 & 3.22 & 659.72 \\
\hline $0+20$ & 3 & 101 & 230.80 & 25239.00 & 36.83 & 16.63 & 8.00 & 5.69 & 4.89 & 3.72 & 3.24 & 685.28 \\
\hline $0+20$ & 4 & 101 & 177.10 & 19370.00 & 30.53 & 14.11 & 6.70 & 4.76 & 4.00 & 3.12 & 2.66 & 634.46 \\
\hline $0+20$ & 5 & 101 & 176.30 & 19275.00 & 30.14 & 13.93 & 6.67 & 4.68 & 4.00 & 3.09 & 2.64 & 639.52 \\
\hline $0+20$ & 6 & 101 & 129.90 & 14203.00 & 23.20 & 10.56 & 4.77 & 3.39 & 2.85 & 2.25 & 1.91 & 612.20 \\
\hline $0+20$ & 7 & 101 & 84.20 & 9207.00 & 16.38 & 7.02 & 2.95 & 2.08 & 1.78 & 1.37 & 1.17 & 562.09 \\
\hline $0+25$ & 1 & 101 & 230.60 & 25223.00 & 32.47 & 16.51 & 8.24 & 5.81 & 4.56 & 3.09 & 2.93 & 776.81 \\
\hline $0+25$ & 2 & 101 & 235.70 & 25778.00 & 30.29 & 15.80 & 8.14 & 5.79 & 4.81 & 3.53 & 3.18 & 851.04 \\
\hline $0+25$ & 3 & 101 & 237.00 & 25913.00 & 30.18 & \begin{tabular}{l|}
15.77 \\
\end{tabular} & 8.15 & 5.77 & 4.83 & 3.63 & 3.22 & 858.61 \\
\hline $0+25$ & 4 & 101 & 177.20 & 19382.00 & 24.46 & 12.89 & 6.58 & 4.65 & 3.96 & 3.03 & 2.61 & 792.40 \\
\hline $0+25$ & 5 & 101 & 177.30 & 19386.00 & 24.57 & 12.77 & 6.61 & 4.70 & 3.98 & 3.04 & 2.62 & 789.01 \\
\hline $0+25$ & 6 & 101 & 134.90 & 14747.00 & 18.12 & 9.44 & 4.72 & 3.40 & 2.78 & 2.11 & 1.83 & 813.85 \\
\hline $0+25$ & 7 & 101 & 88.90 & 9722.00 & 12.05 & 5.85 & 2.85 & 2.09 & 1.64 & 1.31 & 1.14 & 806.80 \\
\hline $0+30$ & 1 & 101 & 210.50 & 23022.00 & 65.50 & 30.17 & 7.88 & 4.40 & 3.78 & 2.80 & 2.71 & 351.48 \\
\hline $0+30$ & 2 & 101 & 215.90 & 23605.00 & 55.00 & 25.91 & 7.77 & 4.90 & 4.27 & 3.17 & 2.90 & 429.18 \\
\hline $0+30$ & 3 & 101 & 217.20 & 23748.00 & 52.72 & 25.13 & 7.83 & 4.98 & 4.30 & 3.29 & 2.91 & 450.46 \\
\hline $0+30$ & 4 & 101 & 167.70 & 18343.00 & 45.23 & 21.48 & 6.58 & 4.12 & 3.54 & 2.76 & 2.37 & 405.55 \\
\hline $0+30$ & 5 & 101 & 167.10 & 18279.00 & 43.70 & 20.96 & 6.54 & 4.10 & 3.53 & 2.76 & 2.39 & 418.28 \\
\hline $0+30$ & 6 & 101 & 127.60 & 13954.00 & 34.27 & 16.44 & 4.81 & 2.91 & 2.48 & 1.95 & 1.66 & 407.18 \\
\hline $0+30$ & 7 & 101 & 81.10 & 8871.00 & 23.31 & 11.78 & 3.12 & 1.81 & 1.51 & 1.20 & 1.05 & 380.57 \\
\hline $0+35$ & 1 & 101 & 216.00 & 23624.00 & 62.07 & 15.73 & 8.27 & 6.02 & 4.36 & 3.30 & 2.77 & 380.60 \\
\hline $0+35$ & 2 & 101 & 221.50 & 24219.00 & 25.84 & 14.57 & 8.27 & 6.10 & 4.49 & 0.83 & 2.82 & 937.27 \\
\hline $0+35$ & 3 & 101 & 224.40 & 24544.00 & 25.81 & 14.62 & 8.31 & 6.02 & 4.63 & 3.68 & 2.93 & 950.95 \\
\hline $0+35$ & 4 & 101 & 181.30 & 19822.00 & 21.88 & 12.33 & 6.88 & 4.83 & 3.83 & 2.97 & 2.41 & 905.94 \\
\hline $0+35$ & 5 & 101 & 180.40 & 19727.00 & 22.18 & 12.35 & 6.95 & 4.97 & 3.81 & 2.65 & 2.44 & 889.40 \\
\hline $0+35$ & 6 & 101 & 139.20 & 15223.00 & 16.81 & 9.03 & 4.88 & 3.45 & 2.70 & 1.86 & 1.68 & 905.59 \\
\hline $0+35$ & 7 & 101 & 89.70 & 9814.00 & 11.53 & 5.72 & 2.96 & 2.07 & 1.70 & 1.37 & 1.06 & 851.17 \\
\hline $0+40$ & 1 & 101 & 226.10 & 24727.00 & 39.26 & 18.24 & 9.43 & 6.37 & 5.01 & 3.43 & 3.00 & 629.83 \\
\hline $0+40$ & 2 & 101 & 226.70 & 24790.00 & 38.80 & 17.50 & $\begin{array}{ll}9.37 \\
\end{array}$ & 6.42 & 5.10 & 3.64 & 3.15 & 638.92 \\
\hline $0+40$ & 3 & 101 & 225.40 & 24652.00 & 32.35 & 17.31 & 9.34 & 6.35 & 5.20 & 3.62 & 3.09 & 762.04 \\
\hline $0+40$ & 4 & 101 & 172.10 & 18823.00 & 33.47 & 14.08 & 7.46 & 5.07 & 4.14 & 2.91 & 2.53 & 562.38 \\
\hline $0+40$ & 5 & 101 & 172.70 & 18882.00 & 33.51 & 13.99 & 7.41 & 5.07 & 4.11 & 2.96 & 2.55 & 563.47 \\
\hline $0+40$ & 6 & 101 & 125.20 & 13692.00 & 24.19 & 10.30 & 5.20 & 3.57 & 2.88 & 2.09 & 1.78 & 566.02 \\
\hline $0+40$ & 7 & 101 & 80.40 & 8795.00 & 16.09 & 6.63 & 3.20 & 2.17 & 1.76 & 1.27 & 1.09 & 546.61 \\
\hline
\end{tabular}




\section{Appendix D: Pavement Response Data}

Figure D1. Typical of EPC raw data from dynamic slow roll test.

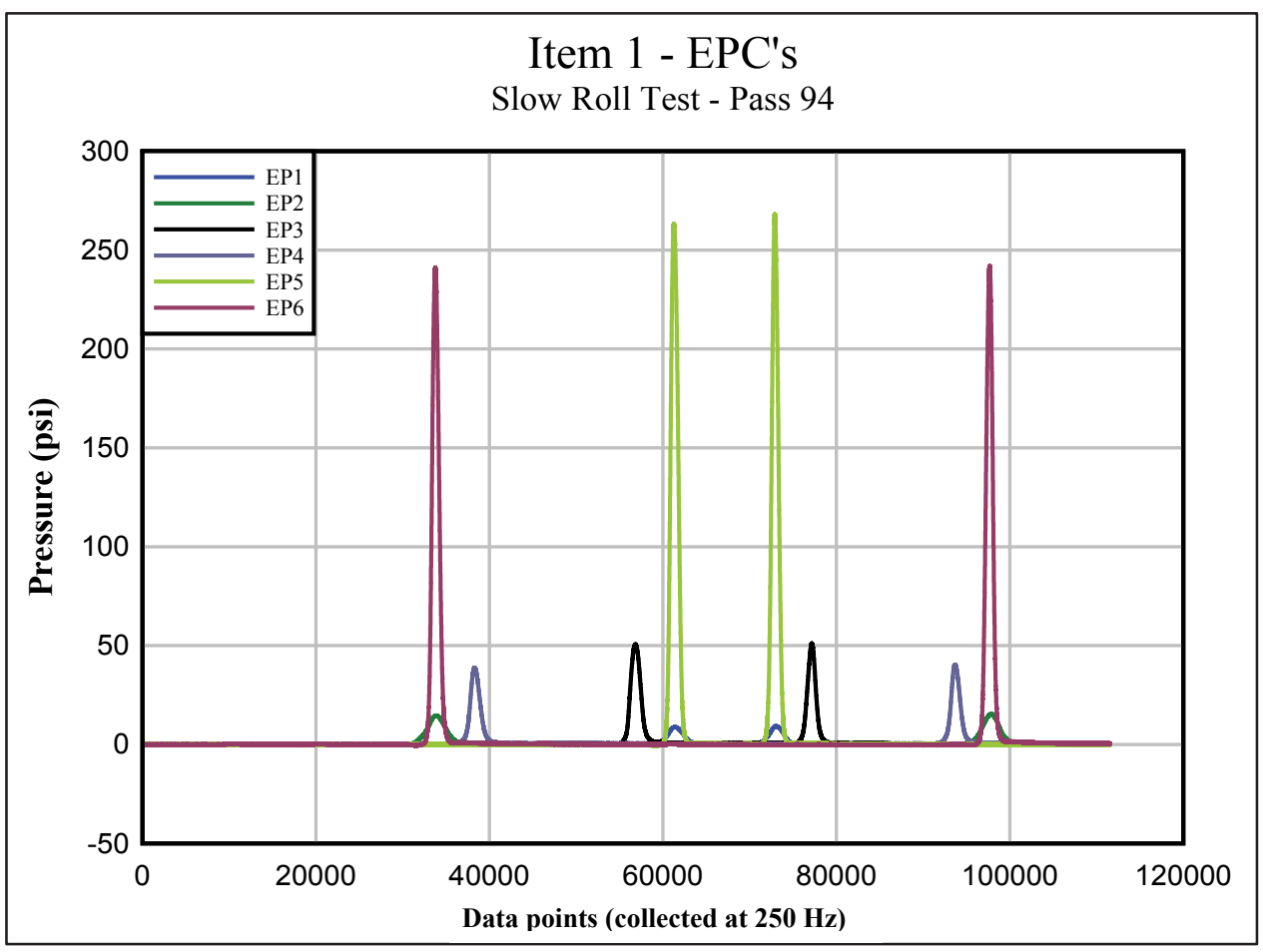

Figure D2. Typical of SSD raw data from dynamic slow roll test.

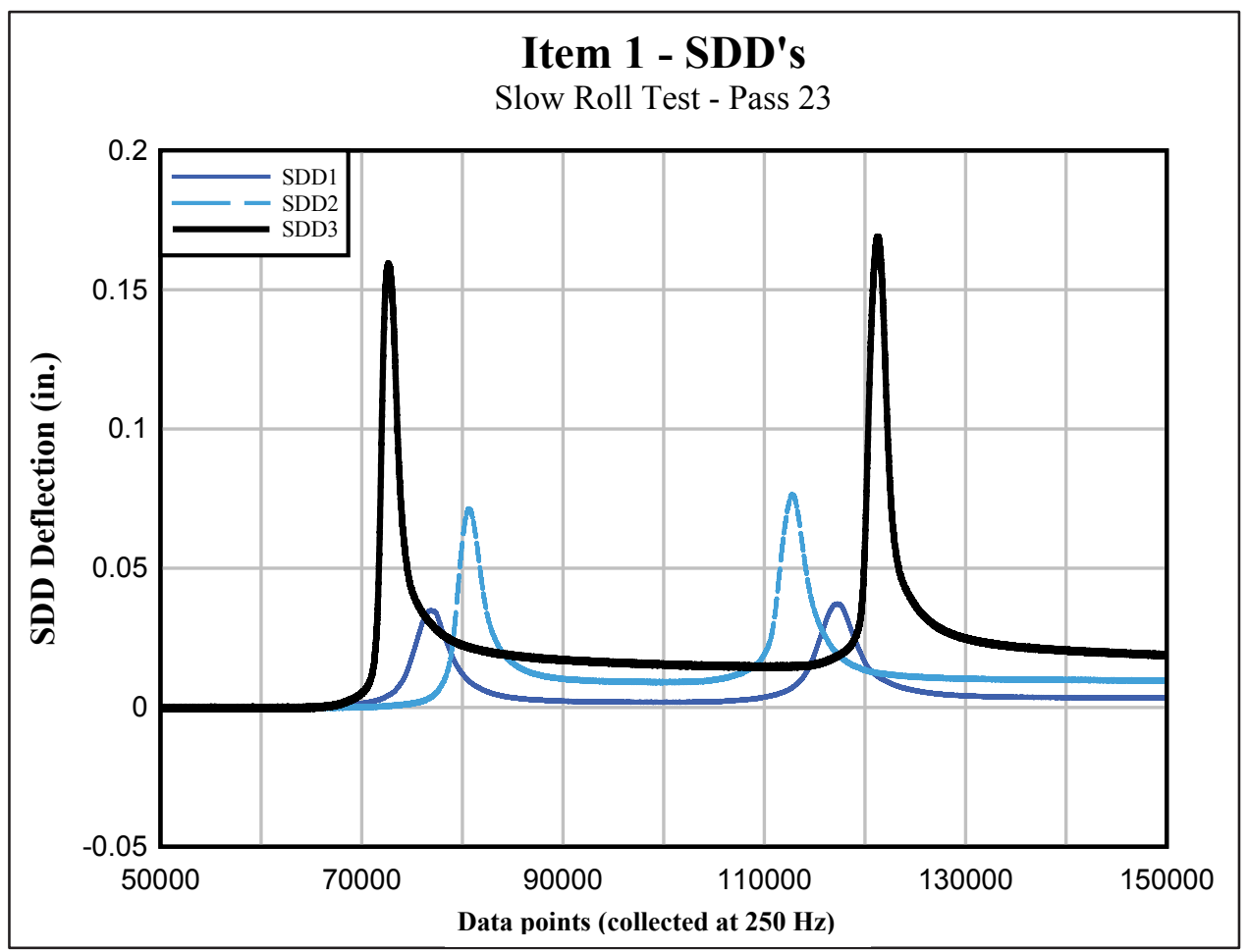


Figure D3. Typical of SSG raw data from dynamic slow roll test.

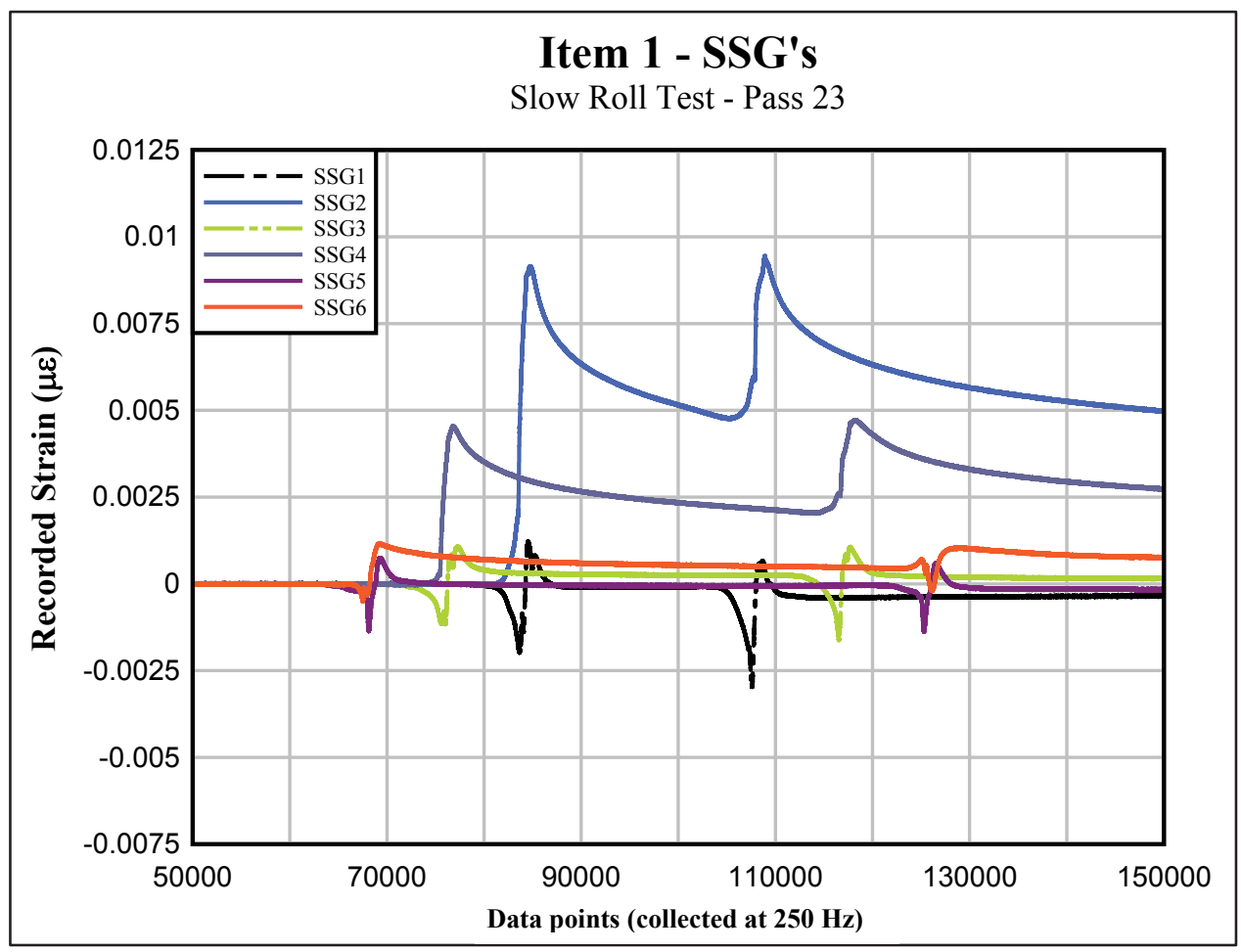

Figure D4. Typical of ASG raw data from dynamic slow roll test.

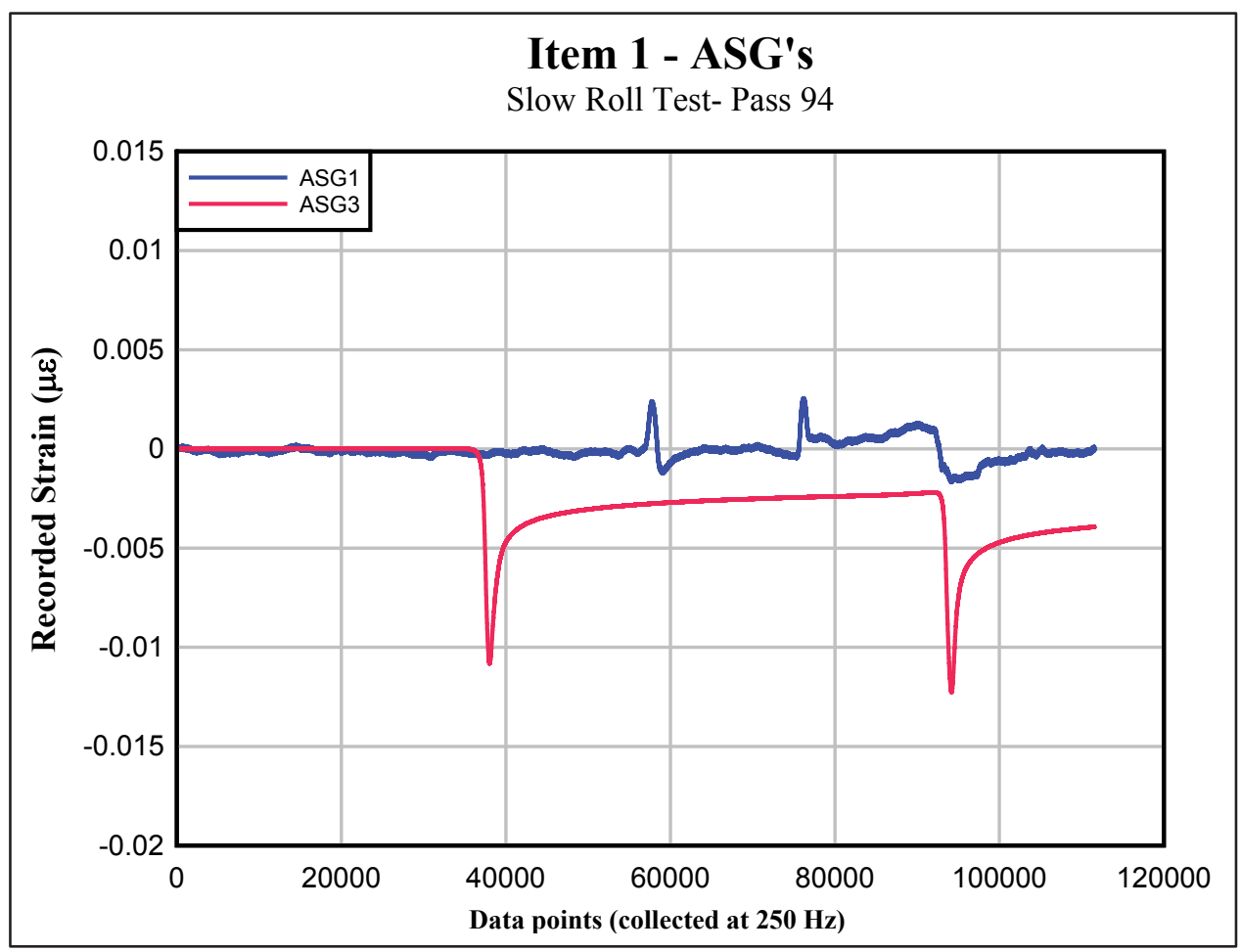


Figure D5. Typical of EPC raw data from dynamic sweep test.

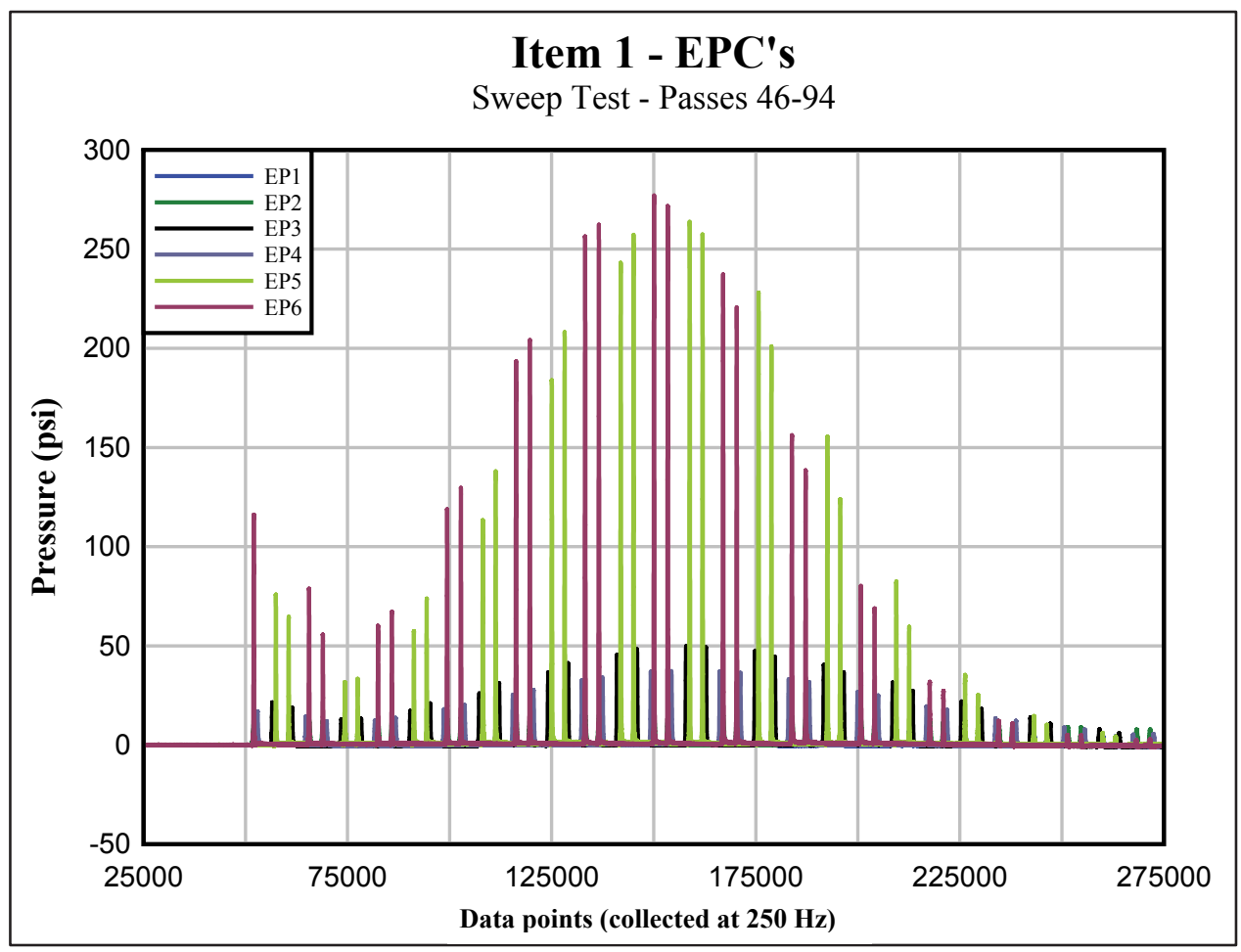

Figure D6. Typical of SSD raw data from dynamic sweep test.

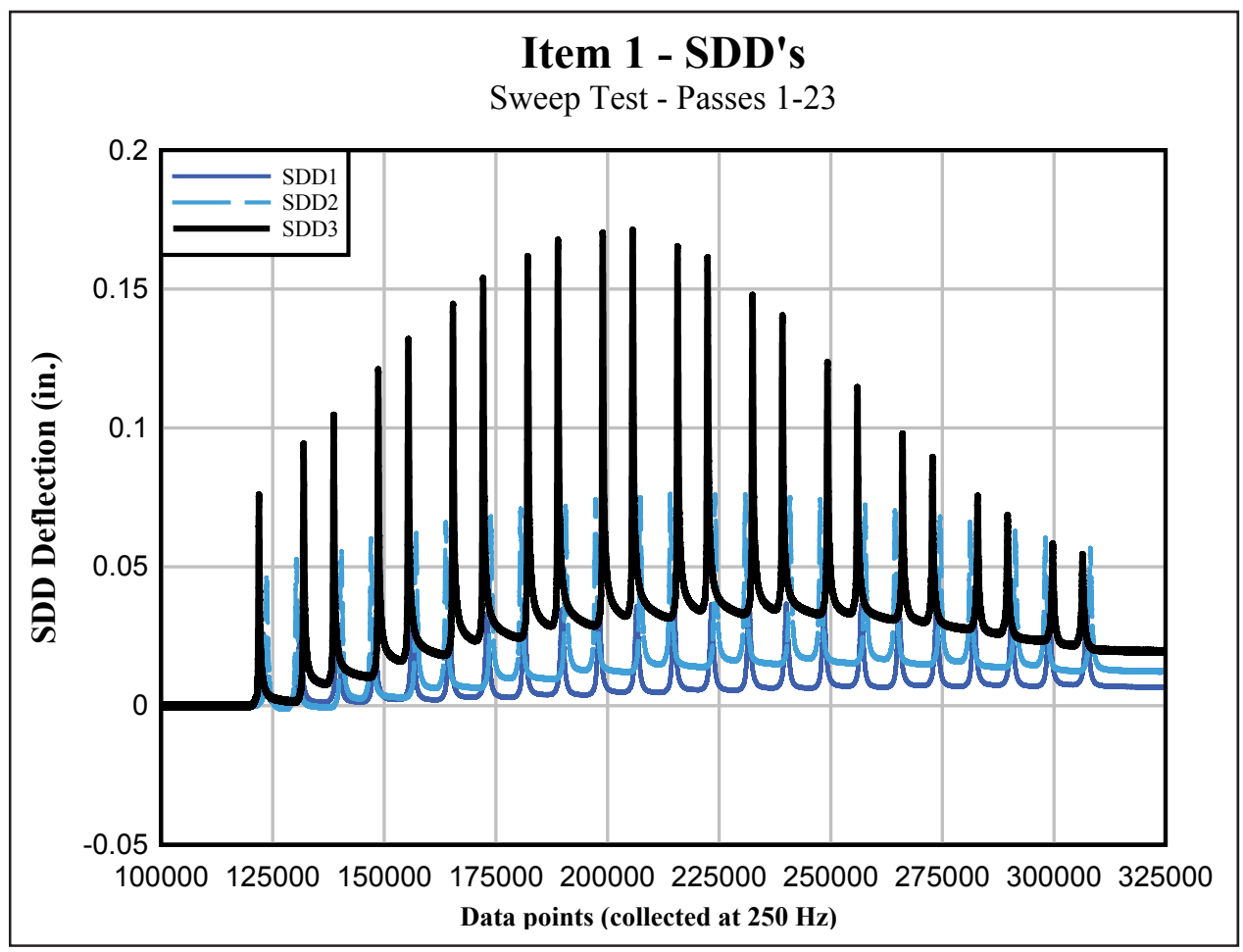


Figure D7. Typical of SSG raw data from dynamic sweep test.

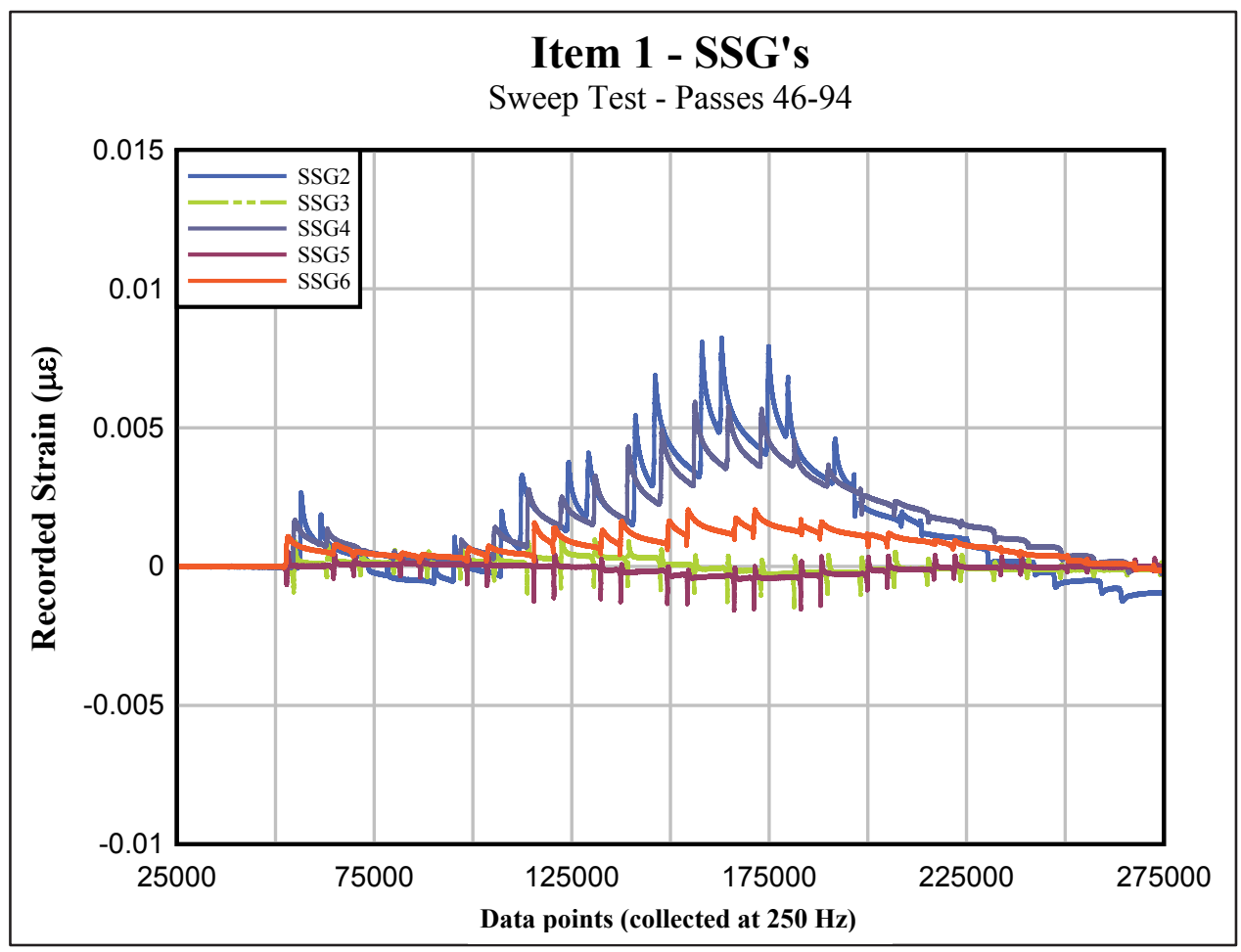

Figure D8. Typical of ASG raw data from dynamic sweep test.

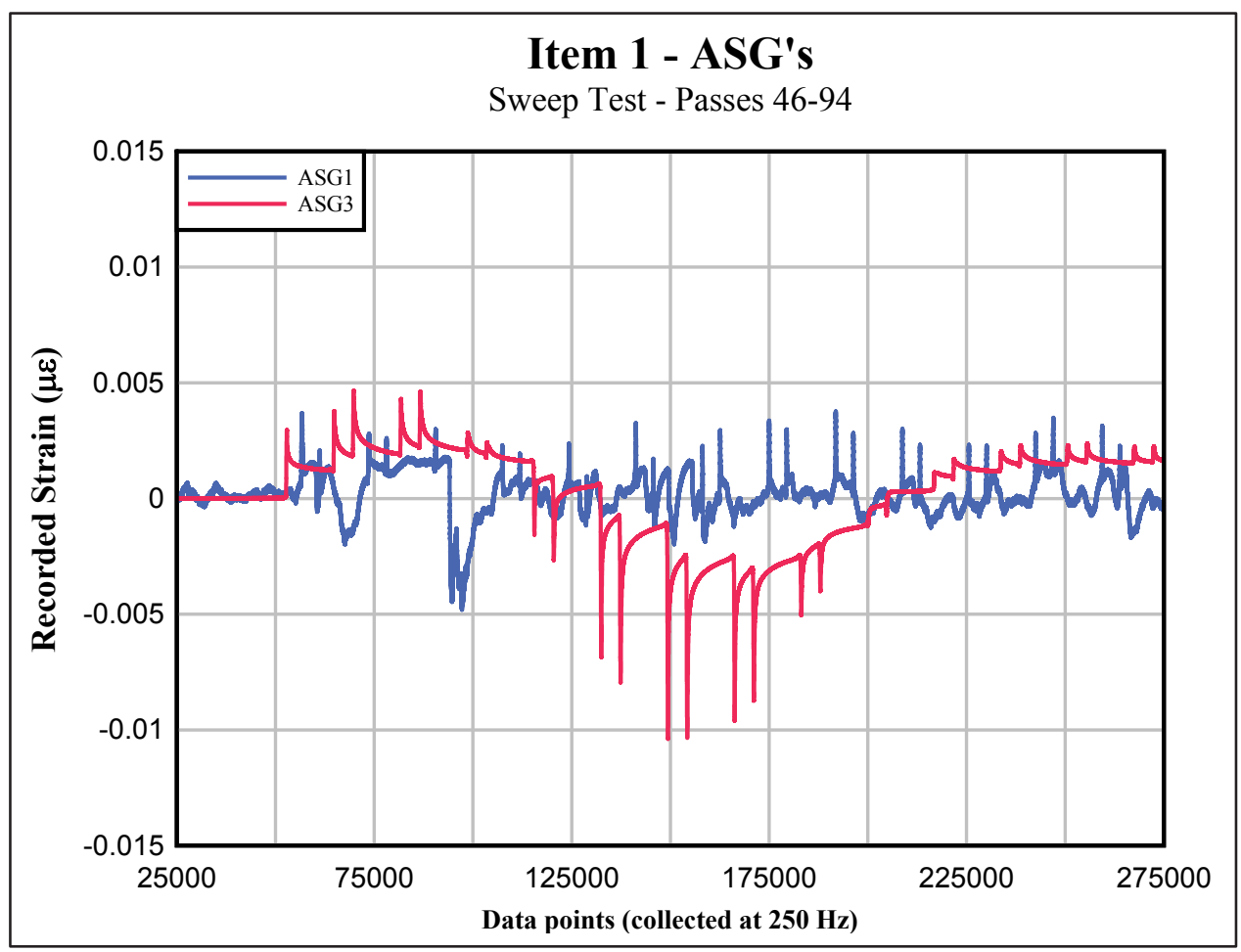




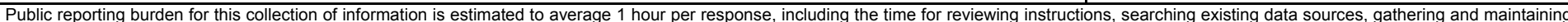

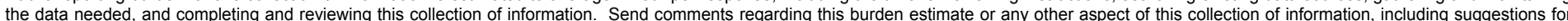

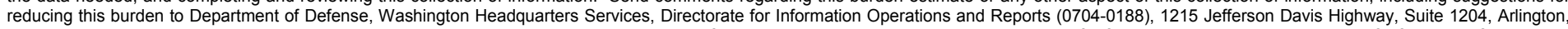

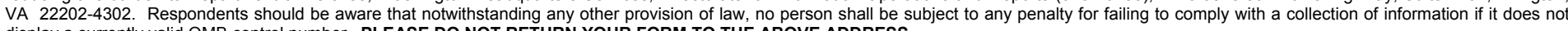
display a currently valid OMB control number. PLEASE DO NOT RETURN YOUR FORM TO THE ABOVE ADDRESS.
1. REPORT DATE (DD-MM-YYYY) 2. REPORT TYPE

\section{DATES COVERED (From - To)}

January 2014 Final

\section{TITLE AND SUBTITLE}

Full-Scale Accelerated Pavement Testing of Warm-Mix Asphalt (WMA) for Airfield Pavements

5a. CONTRACT NUMBER

5b. GRANT NUMBER

5c. PROGRAM ELEMENT NUMBER

\section{AUTHOR(S)}

5d. PROJECT NUMBER

Mariely Mejias-Santiago, Jesse D. Doyle, and John F. Rushing

5e. TASK NUMBER

5f. WORK UNIT NUMBER

\section{PERFORMING ORGANIZATION NAME(S) AND ADDRESS(ES)}

8. PERFORMING ORGANIZATION REPORT

Geotechnical and Structures Laboratory

US Army Engineer Research and Development Center NUMBER

3909 Halls Ferry Road

ERDC/GSL TR-14-3

Vicksburg, MS 39180-6199

\section{SPONSORING / MONITORING AGENCY NAME(S) AND ADDRESS(ES)}

US Air Force Civil Engineer Center

139 Barnes Drive, Suite 1

Tyndall AFB, FL 32403-5319

10. SPONSOR/MONITOR'S ACRONYM(S)

AFCEC

11. SPONSOR/MONITOR'S REPORT NUMBER(S)

\section{DISTRIBUTION / AVAILABILITY STATEMENT}

Approved for public release; distribution is unlimited.

\section{SUPPLEMENTARY NOTES}

\section{ABSTRACT}

This report presents results from full-scale accelerated pavement testing of warm-mix asphalt (WMA) mixtures designed for airfield pavements. Three WMA mixtures were evaluated and compared to a control hot-mix asphalt (HMA) mixture. Data are presented from instrumented pavement test sections of WMA and HMA trafficked using a heavy-vehicle simulator (HVS-A) configured with an F-15E military jet aircraft wheel with a high load, high tire pressure and at high pavement temperatures. Surface permanent deformation is presented as a function of number of traffic cycles for the different pavement sections. Pavement instrumentation data are presented to show that rutting performance was not influenced by any differences in the structural capacity of the supporting layers. Additional testing was conducted on areas of the test sections not trafficked by the HVS-A to assess any potential problems associated with grooving the surface of WMA airfield pavements and to compare the performance of grooved WMA to that of grooved HMA. The results from this research demonstrated that WMA is a viable alternative to HMA for use on heavily trafficked airfield pavements.

\begin{tabular}{|c|c|c|c|c|c|}
\hline $\begin{array}{l}\text { 15. SUBJECT TER } \\
\text { Warm-mix aspha } \\
\text { Accelerated pave }\end{array}$ & testing & $\begin{array}{l}\text { Heavy-vehicle } \\
\text { Asphalt rutting } \\
\text { Full-scale pave }\end{array}$ & $\begin{array}{l}\text { lator } \\
\text { test section }\end{array}$ & & \\
\hline \multicolumn{3}{|c|}{ 16. SECURITY CLASSIFICATION OF: } & 17. LIMITATION & 18. NUMBER & $\begin{array}{l}\text { 19a. NAME OF RESPONSIBLE } \\
\text { PERSON }\end{array}$ \\
\hline $\begin{array}{l}\text { a. REPORT } \\
\text { Unclassified }\end{array}$ & $\begin{array}{l}\text { b. ABSTRACT } \\
\text { Unclassified }\end{array}$ & $\begin{array}{l}\text { c. THIS PAGE } \\
\text { Unclassified }\end{array}$ & & 125 & $\begin{array}{l}\text { 19b. TELEPHONE NUMBER (include } \\
\text { area code) }\end{array}$ \\
\hline
\end{tabular}

